Mariana Afonso Abade Couceiro

\title{
Dinâmica de sedimentos coesivos em um estuário altamente estratificado: rio Araranguá, SC
}

Tese apresentada ao Instituto Oceanográfico da Universidade de São Paulo, como parte dos requisitos para obtenção do título de Doutor em Ciências, Programa de Oceanografia, área de Oceanografia Geológica.

Orientador: Prof. Dr. Eduardo Siegle Coorientador: Prof. Dr. Carlos A. F. Schettini 
Universidade de São Paulo

Instituto Oceanográfico

Dinâmica de sedimentos coesivos em um estuário altamente estratificado: rio Araranguá, SC

Mariana Afonso Abade Couceiro

Tese apresentada ao Instituto Oceanográfico da Universidade de São Paulo, como parte dos requisitos para obtenção do título de Doutor em Ciências, área de Oceanografia (Biológica, Física ou Química e Geológica)

VERSÃO CORRIGIDA

Julgada em 24/04/2015

Prof. Dr. Eduardo Siegle

Conceito

Prof. Dr. Joseph Harari

Conceito

Prof. Dr. Mauricio Almeida Noernberg

Conceito

Prof. Dr. Nils Edvin Asp Neto

Conceito

Prof. Dr. Rubens Cesar Lopes Figueira

Conceito 


\section{Sumário}

Agradecimentos $\quad$ V

Resumo vi

Abstract vii

Lista de figuras viii

Lista de tabelas xiii

Lista de símbolos $\quad$ xiv

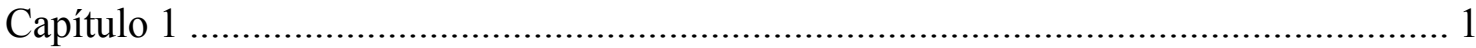

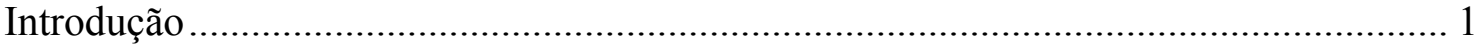

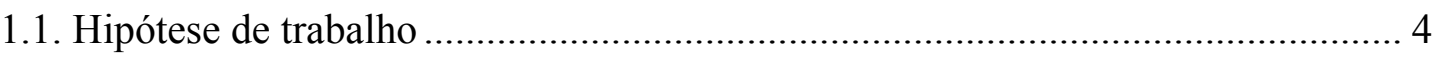

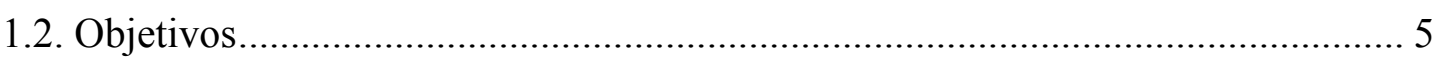

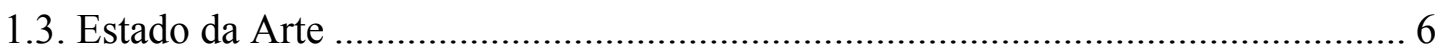

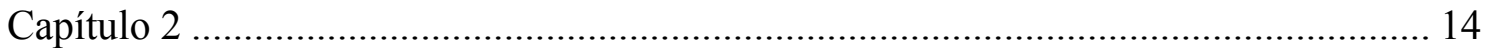

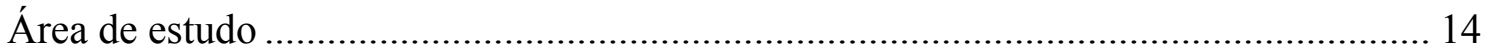

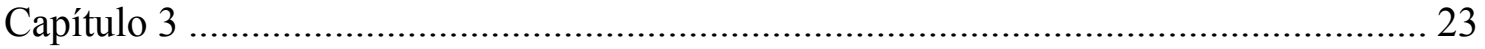

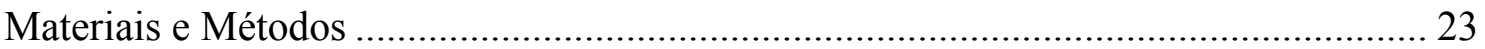

3.1. Calibração e validação do modelo numérico...................................................... 24

3.1.1. Dados para calibração e validação do modelo.............................................. 25

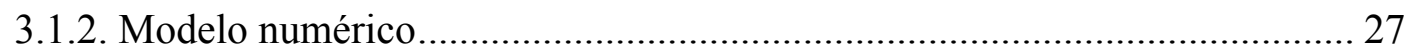

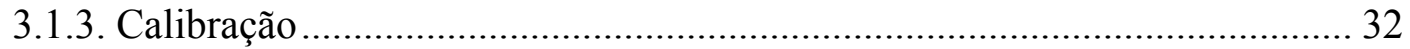

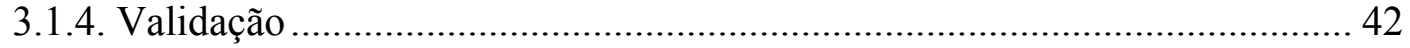

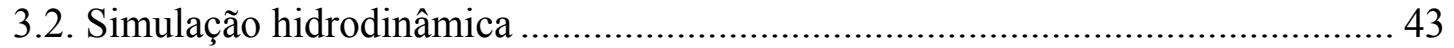

3.3. Modelo de trajetórias das partículas .................................................................. 48

3.3.1. Campo de velocidade longitudinal do modelo Delft3D ............................. 49

3.3.2. Velocidade de decantação das partículas.................................................... 52

3.3.3. Programando no Matlab ........................................................................... 58

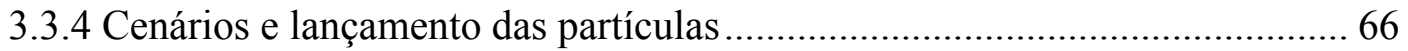

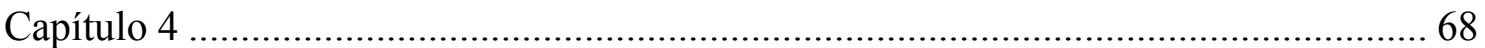

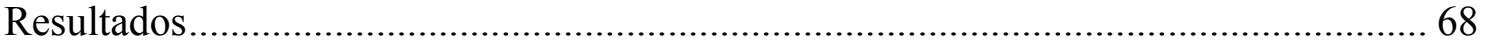

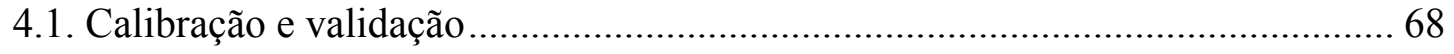

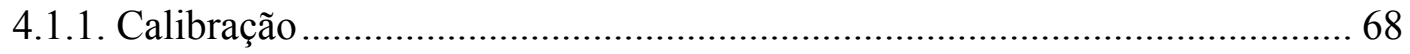

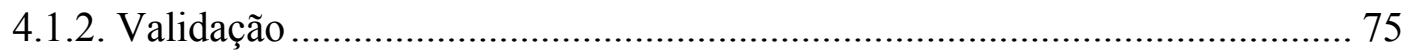

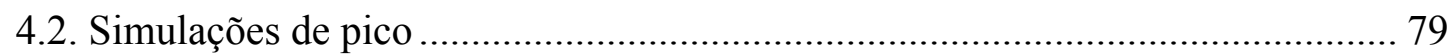

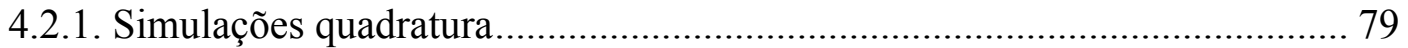




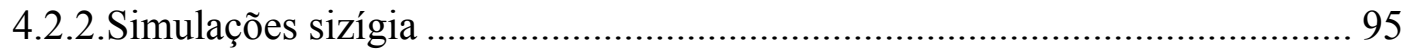

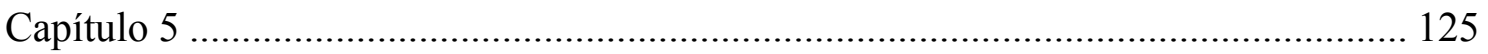

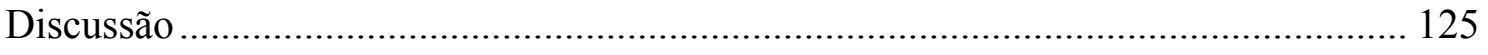

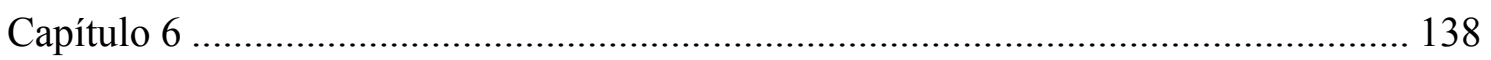

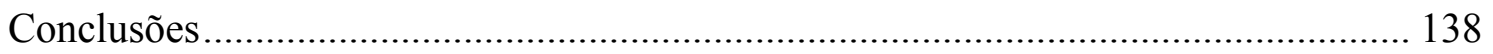

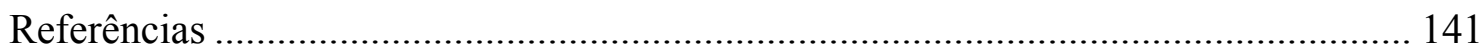

Anexo I - Descrição do modelo numérico ................................................................... 150

Anexo II - Batimetria do modelo numérico .............................................................. 168 


\section{AGRADECIMENTOS}

Ao meu orientador, Prof. Dr. Eduardo Siegle, pela oportunidade de realização do trabalho, pela confiança e pelos ensinamentos, ao qual sou muito grata à sua atenção. Ao meu coorientador, Prof. Dr. Carlos Augusto França Schettini, pelo incentivo, atenção e paciência. E por ter disponibilizado os dados disponíveis dos campos realizados no estuário do rio Araranguá.

À todos os professores que contribuíram para o meu aprendizado, através das disciplinas.

À Profa. Dra. Carla D’Aquino (UFSC) por me receber em sua casa e pela colaboração nos campos.

Aos bombeiros: Sargento Célio, Soldado João Ricardo e Soldado Eli, à Defesa Civil e ao pessoal do Iate Clube de Araranguá, pelo apoio logístico para a realização das atividades no campo.

Aos colegas do Laboratório de Dinâmica Costeira (LDC-USP) e do IO: Mirella, Lilian, Bruna, Talitha, Cássia, Ana Amélia, Juliana Damasceno, Juliana Ribeiro, Júlia, Diana, Carol, Lara, Bárbara, Débora, Paulo, Hélio, Tito, Felipe, Caio, Dalton, Pedro, Leonardo, Mário e Giba, pelo apoio ao longo desses anos e pelas boas e produtivas conversas.

Aos colegas do Laboratório de Hidrodinâmica Costeira (LaHiCo-UFPE): Nane, Babi, Felipe e José, pela boa companhia durante minha estadia em Recife.

Ao Éder e ao Ricardo, pela atenção e grande ajuda com os computadores.

À Maria de Lourdes por sua atenção ao longo desses anos.

Às meninas da secretaria de pós-graduação: Ana Paula, Silvana, Letícia e Fátima. E ao Daniel.

Aos funcionários da biblioteca do $\mathrm{IO}$, em especial ao Wagner e à Cida.

À turma da Didi, por toda atenção durante os intervalos do café.

A todos os funcionários do Instituto Oceanográfico pela atenção.

Aos meus familiares, Ana, Nilton, Gabriel, Flávia, Sonia Brejão, José, Ataul, Sonia Maria, Alcina e Raquel, por estarem sempre presentes.

Ao meu marido Fernando, principal incentivador deste projeto de vida e pelo apoio incondicional em todos os momentos de minha vida. 


\section{RESUMO}

O objetivo deste estudo é compreender a dinâmica das partículas no estuário do rio Araranguá (SC) em termos de transporte em suspensão, deposição e exportação, em diferentes condições físico-químicas da água, com pH baixo $(<4,5)$ e normal $(>=7)$, e sob condições de regime transiente da descarga fluvial. O estuário do rio Araranguá é classificado como altamente estratificado e dominado pela descarga fluvial. Um aspecto fundamental nos processos que controlam a dinâmica de materiais em suspensão no estuário é a atividade de lavra e beneficiamento do carvão, que gera uma drenagem ácida no rio Mãe Luzia. O seu $\mathrm{pH}$ baixo $(\sim 3)$ indica que o processo de floculação é intensificado no interior do estuário. Com o objetivo de melhor entender a hidrodinâmica do estuário, um modelo tridimensional foi implementado para a região. O modelo foi calibrado e validado com dados observados. Simulações com diferentes picos de descarga fluvial $\left(100,400,700\right.$ e $\left.1000 \mathrm{~m}^{3} \cdot \mathrm{s}^{-1}\right)$ e baixa descarga $\left(30 \mathrm{~m}^{3} \cdot \mathrm{s}^{-1}\right)$ foram realizadas. Para calcular o transporte do material particulado em suspensão foi desenvolvido um modelo Lagrangeano da trajetória da partícula. O modelo da trajetória utiliza os resultados do modelo hidrodinâmico e a velocidade de decantação das partículas. $\mathrm{O}$ estuário respondeu rapidamente às variações da descarga fluvial. A cunha salina foi transportada para fora do estuário durante os picos de $700 \mathrm{e} 1000 \mathrm{~m}^{3} . \mathrm{s}^{-1}$. A descarga fluvial é o fator dominante no controle da intrusão da salinidade no estuário e, em condições de baixa descarga, o transporte advectivo de sal é dominado pelo termo dispersivo da circulação gravitacional. O tempo de residência médio das partículas no estuário foi menor em condições de $\mathrm{pH}$ baixo. A exportação das partículas aumentou com o aumento da descarga fluvial (pico de $1000 \mathrm{~m}^{3} \cdot \mathrm{s}^{-1}$ ), sendo que $27 \%$ e $30 \%$ foram exportadas para a plataforma interna durante os experimentos com $\mathrm{pH}$ baixo e $\mathrm{pH}$ normal, respectivamente. A região de deposição das partículas indica que com a diminuição do $\mathrm{pH}$, as partículas passam a depositar mais à jusante no estuário. O evento de descarga de $1000 \mathrm{~m}^{3} . \mathrm{s}^{-1}$ não foi capaz de remover a grande maioria das partículas do estuário, mas foi responsável por redistribuir as partículas ao longo do médio estuário, onde se depositaram em condições favoráveis com baixas velocidades e ausência de salinidade. O trabalho demonstra que apesar da alta estratificação do estuário, a acidez de suas águas, seu padrão de circulação, com baixas velocidades e a presença da cunha salina, possuem um papel fundamental no transporte das partículas, resultando em maior potencial de retenção do material em suspensão no estuário do rio Araranguá.

Palavras-chave: estuário estratificado, regime transiente, drenagem ácida, trajetória da partícula, rio Araranguá 


\begin{abstract}
The present study assessed the dynamics of particles of the Araranguá (SC) river estuary in terns of suspended transport, deposition and exportation in different conditions of physical-chemical of water, with low $(<4,5)$ and normal $\mathrm{pH}(>=7)$, and transient of river discharge conditions. The Araranguá river estuary is a highly stratified flash-flood dominated. The river basin of the Mãe Luzia river, one of the main tributaries of the Araranguá river, is performed the activity of mining and coal processing, wich generates an acidic drainage. Its low $\mathrm{pH}$ indicates that flocculation process is intensified in estuary inner. With the objective of better understanding the estuarine processes, a three-dimensional hydrodynamics model was implemented. The model was calibrated and verified using observational data. Simulations were conducted with freshet peak ranged over 100, 400, 700 and $1000 \mathrm{~m}^{3} \cdot \mathrm{s}^{-1}$. Lagrangian particle tracking algorithms was developed to represent the suspended particle transport at estuary. The particle tracking used the montion resulting from hydrodynamics model and the particle settling velocity. The estuary responded quickly the river discharge variations. During the pulse event the velocities at water column were unidirectional down-estuary is shown the barotropic dominates over baroclinic component. During the highest flash flood event (700 and $1000 \mathrm{~m}^{3} . \mathrm{s}^{-1}$ ) the salt water was pushed out of the estuary. The river discharge is a dominating factor affecting the salinity intrusion in the estuarine system and under low discharge conditions the advective salt transport is dominated by dispersive term of gravitational circulation. The mean residence time of the particles was lowest in $\mathrm{pH}$ low conditions. The particles export is great as the river discharge is rising $\left(1000 \mathrm{~m}^{3} \cdot \mathrm{s}^{-1}\right)$ with $27 \%$ and $30 \%$ exported to inner shelf during the experiments with low and normal $\mathrm{pH}$, respectively. The particles deposition local indicates that with the $\mathrm{pH}$ decrease the particles become to be deposited further downstream. The discharge event of $1000 \mathrm{~m}^{3} \cdot \mathrm{s}^{-1}$ was not able to remove all particles out, but was response to redistribute the particles along of the meddle estuary, where settling in favorable conditions at low velocities and absence of salinity. The study shows that although high stratification of estuary, the acidity of water, the pattern of circulation, at low velocities, and the salt wedge presence play a fundamental role in the transport of particle matter resulting in increased the potential retention of suspended matter in the Araranguá river estuary.
\end{abstract}

Key-words: stratified estuary, transient flow, acid drainage, particle tracking, Araranguá river 


\section{LISTA DE FIGURAS}

Figura 1.1. Classificação dos estuários de acordo com a estratificação da salinidade. (Adaptado de Valle-Levinson, 2010).

Figura 2.1. (A) Localização da bacia hidrográfica do rio Araranguá em Santa Catarina, (B) os principais rios com a localização de unidade de mineração ou processamento de carvão, e (C) uma imagem obtida a partir do Google Earth da confluência dos rios Itoupava e Mãe Luzia ilustrando o gradiente de coloração indicativo da concentração de sedimentos em suspensão.

Figura 2.2. Descarga média diária dos rios Itoupava (A), Mãe Luzia (B) e Araranguá (C), entre os anos de 1943 e 2004.

Figura 2.3. Descarga fluvial média mensal e desvio padrão para o rio Araranguá baseado em dados médios diários dos anos de 1943 até 2004.

Figura 2.4. (A) Histograma da frequência média diária de descarga fluvial e (B) histograma de frequência de intervalo de dias entre pulsos de alta descarga fluvial. Ambos os resultados foram obtidos com a série de dados de descarga fluvial entre o período de 1943 a 2004.

Figura 3.1. Imagem do Google com a representação dos percursos realizados durante os levantamentos batimétricos para o ano de 2006 (azul) e 2014 (rosa).

Figura 3.2. Localização da área de estudo com a indicação das estações de coleta de dados \#1 ( $7 \mathrm{~km}$ da desembocadura) e \#2 ( $31 \mathrm{~km}$ da desembocadura).

Figura 3.3. Domínio do modelo, com a representação da grade numérica e contornos abertos.

Figura 3.4. Exemplos das grades verticais sigma (esquerda) e Z (direita).

Figura 3.5. Esquema das etapas do processo de calibração do modelo bidimensional e tridimensional.

Figura 3.6. Variação da concordância entre os dados de velocidade de correntes observados e modelados com diferentes valores do número de Chézy. Na estação \#1 (esquerda) e na estação \#2 (direita).

Figura 3.7. Comparação da distribuição longitudinal da salinidade no primeiro dia de simulação para os perfis observados (A) e modelado (B).

Figura 3.8. Histogramas de ocorrência das direções da velocidade das correntes: (A) observado, \#1; (B) observado, \#2; (C) modelado, \#1 e (D) modelado, \#2.

Figure 3.9. Esquema da variação da descarga fluvial para todas as simulações. A variação da descarga ocorres rapidamente, em um curto período de tempo depois diminui até o valor de $30 \mathrm{~m}^{3} \cdot \mathrm{s}^{-1}$.

Figura 3.10. Tempo de retorno em meses dos eventos de descarga fluvial extrapolados para o rio Araranguá.

Figura 3.11. Representação geral da estrutura do modelo da trajetória da partícula.

Figura 3.12. (A) Representação do trecho selecionado (em roxo) do domínio. (B) Representação do subdomínio.

Figura 3.13. Representação do angulo entre a orientação principal do canal e o norte.

Figura 3.14. (A) Perspectiva isométrica do tanque anular e sua instrumentação; (B) fotografia do tanque durante um experimento; e (C) seção transversal do tanque.

Figura 3.15. Representação da variação da velocidade do fluxo ao longo do tempo. Adaptado de Couceiro \& Schettini (2010). 
Figura 3.16. Séries temporais da variação da concentração de MPS para os experimentos SA1(linha rosa), SA3 (linha amarela), SB1 (linha laranja) e SB3 (linha verde). Adaptado de Couceiro \& Schettini (2010).

Figura 3.17. Fluxograma da sequência lógica dos passos realizados pelo terceiro ciclo do MTP. Para o cálculo da trajetória da partícula.

Figura 3.18. Representação de uma célula da grade para os cálculos do MTP. P representa a partícula e $\mathrm{V}$ a velocidade em cada vértice da célula.

Figura 3.19. Perfis verticais de material particulado em suspensão (MPS) nas estações \#1 e \#2, nos dias 02 de agosto (A), com descarga fluvial $\sim 25 \mathrm{~m}^{3} . \mathrm{s}^{-1} \mathrm{e} 30$ de setembro de 2008, após um evento de alta descarga $\left(\sim 400 \mathrm{~m}^{3} \cdot \mathrm{s}^{-1}\right)$.

Figura 4.1. Descarga fluvial média diária utilizada no processo de calibração.

Figura 4.2. Comparação da série temporal do nível da água observada (----) e modelada (-) nas estações \#1 (A) e \#2 (B) para o período de calibração (10/06 09/07).

Figura 4.3. Comparação da série temporal da velocidade média da corrente observada (----) e modelada (-) nas estações \#1 (A) e \#2 (B) para o período de calibração (10/06 - 09/07).

Figura 4.4. Comparação entre a salinidade do fundo observada (----) e modelada (一) na estação \#1, para o período de calibração.

Figura 4.5. Comparação da distribuição longitudinal da salinidade em relação ao perfil realizado em 01 de agosto de 2008 para (A) observado e (B) modelado.

Figura 4.6. Comparação da distribuição longitudinal da salinidade em relação ao perfil realizado em 30 de setembro de 2008 para (A) observado e (B) modelado.

Figura 4.7. Descarga fluvial média diária utilizada no processo de validação.

Figura 4.8. Comparação da série temporal observada (----) e modelada (-) do nível da água (A-\#1 e B-\#2) e corrente longitudinal média (C-\#1 e D-\#2) para o período de validação $(01 / 08-31 / 08)$.

Figura 4.9. Comparação entre a salinidade do fundo modelada $(-)$ e observada (----) na estação \#1, para o período de validação.

Figura 4.10. Resultados do modelo. Séries temporais da variação do nível da água (B), da velocidade das correntes (C) e da salinidade (diferença entre a salinidade do fundo e da superfície) (D), das simulações de descarga fluvial, Q30 (linha preta), Q100 (linha azul), Q400 (linha vermelha), Q700 (linha verde) e Q1000 (linha magenta) em condição de maré de quadratura para a Estação \#1. As velocidades positivas indicam as correntes de vazante e as negativas as correntes de enchente.

Figura 4.11. Resultados do modelo. Variação temporal dos termos de descarga fluvial (linhas sólidas) e circulação gravitacional (linhas descontinuas) da equação do transporte advectivo de sal, em $\mathrm{kg} \cdot \mathrm{m}^{-1} \cdot \mathrm{s}^{-1}$. Os valores estão em módulo. Para todas as simulações realizadas na quadratura na posição que corresponde a estação \#1.

Figura 4.12. Representação dos instantes, $\mathrm{t} 1, \mathrm{t} 2, \mathrm{t} 3, \mathrm{t} 4, \mathrm{t} 5$ e $\mathrm{t} 6$, escolhidos para representar graficamente a distribuição da salinidade.

Figura 4.13. Resultados do modelo. Distribuição vertical da salinidade ao longo do perfil longitudinal e ao longo do tempo ( $\mathrm{t} 1, \mathrm{t} 2, \mathrm{t} 3$, $\mathrm{t} 4$, $\mathrm{t} 5$ e t6), no estuário do rio Araranguá, em condições de descarga fluvial de $30 \mathrm{~m}^{3} \cdot \mathrm{s}^{-1}(\mathrm{Q} 30)$, com início na quadratura.

Figura 4.14. Resultados do modelo. Distribuição vertical da salinidade ao longo do perfil longitudinal e ao longo do tempo ( $\mathrm{t} 1, \mathrm{t} 2, \mathrm{t} 3, \mathrm{t} 4$, $\mathrm{t} 5$ e t6), no estuário do rio Araranguá, para a simulação Q100, com pico na quadratura. 
Figura 4.15. Resultados do modelo. Distribuição vertical da salinidade ao longo do perfil longitudinal e ao longo do tempo ( $\mathrm{t} 1, \mathrm{t} 2, \mathrm{t} 3, \mathrm{t} 4$, $\mathrm{t} 5$ e $\mathrm{t} 6)$, no estuário do rio Araranguá para a simulação Q400, com pico na quadratura.

Figura 4.16. Resultados do modelo. Distribuição vertical da salinidade ao longo do perfil longitudinal e ao longo do tempo ( $\mathrm{t} 1, \mathrm{t} 2, \mathrm{t} 3, \mathrm{t} 4, \mathrm{t} 5$ e t6), no estuário do rio Araranguá para a simulação Q700, com pico na quadratura.

Figura 4.17. Resultados do modelo. Distribuição vertical da salinidade ao longo do perfil longitudinal e ao longo do tempo ( $\mathrm{t} 1, \mathrm{t} 2, \mathrm{t} 3, \mathrm{t} 4$, $\mathrm{t} 5 \mathrm{e} \mathrm{t} 6)$, no estuário do rio Araranguá para a simulação Q1000, com pico na quadratura.

Figura 4.18. Resultados do modelo. Perfis médios de velocidade (A) e salinidade (B) para o período entre $t 1$ e t6. Para todas as simulações com pico na quadratura, Q30 (linha preta), Q100 (linha azul), Q400 (linha vermelha), Q700 (linha verde) e Q1000 (linha magenta), na estação \#1 $(\sim 7 \mathrm{~km}$ da desembocadura).

Figura 4.19. Resultado do modelo. Salinidade do fundo nos primeiros $29 \mathrm{~km}$ do estuário do rio Araranguá ao longo do tempo para as simulações Q30 (A), Q100 (B), Q400 (C), Q700 (D) e Q1000 (F), com inicio em condições de quadratura.

Figura 4.20. Resultados do modelo. Séries temporais da variação do nível da água (B), da velocidade das correntes (C) e da salinidade (diferença entre a salinidade do fundo e da superfície) (D), das simulações de descarga fluvial, Q30 (linha preta), Q100 (linha azul), Q400 (linha vermelha), Q700 (linha verde) e Q1000 (linha magenta), em condição de maré de sizígia para a estação \#1.

Figura 4.21. Resultados do modelo. Variação temporal dos termos de descarga fluvial (linhas sólidas) e circulação gravitacional (linhas descontinuas) da equação do transporte advectivo de sal, em $\mathrm{kg} \cdot \mathrm{m}^{-1} \cdot \mathrm{s}^{-1}$. Os valores estão em módulo. Para todas as simulações realizadas na quadratura na posição que corresponde a estação \#1.

Figura 4.22. Resultados do modelo. Distribuição vertical da salinidade ao longo do perfil longitudinal e ao longo do tempo ( $\mathrm{t} 1, \mathrm{t} 2, \mathrm{t} 3, \mathrm{t} 4, \mathrm{t} 5 \mathrm{e} \mathrm{t} 6)$, no estuário do rio Araranguá, em condições de descarga fluvial de $30 \mathrm{~m}^{3} \cdot \mathrm{s}^{-1}$ ( Q30), com início na sizígia.

Figura 4.23. Resultados do modelo. Distribuição vertical da salinidade ao longo do perfil longitudinal e ao longo do tempo ( $\mathrm{t} 1, \mathrm{t} 2, \mathrm{t} 3, \mathrm{t} 4$, $\mathrm{t} 5$ e $\mathrm{t} 6)$, no estuário do rio Araranguá, da simulação Q100, com pico na sizígia.

Figura 4.24. Resultados do modelo. Distribuição vertical da salinidade ao longo do perfil longitudinal e ao longo do tempo ( $\mathrm{t} 1, \mathrm{t} 2, \mathrm{t} 3$, $\mathrm{t} 4$, $\mathrm{t} 5$ e t6), no estuário do rio Araranguá, da simulação Q400, com pico na sizígia.

Figura 4.25. Resultados do modelo. Distribuição vertical da salinidade ao longo do perfil longitudinal e ao longo do tempo ( $\mathrm{t} 1, \mathrm{t} 2, \mathrm{t} 3, \mathrm{t} 4$, $\mathrm{t} 5$ e $\mathrm{t} 6)$, no estuário do rio Araranguá, da simulação Q700, com pico na sizígia.

Figura 4.26. Resultados do modelo. Distribuição vertical da salinidade ao longo do perfil longitudinal e ao longo do tempo ( $\mathrm{t} 1, \mathrm{t} 2, \mathrm{t} 3, \mathrm{t} 4$, $\mathrm{t} 5 \mathrm{e} \mathrm{t} 6)$, no estuário do rio Araranguá, da simulação Q1000, com pico na sizígia.

Figura 4.27. Resultados do modelo. Perfis médios de velocidade (A) e salinidade (B) para o período entre t1 e t6. Para todas as simulações com pico na sizígia, Q30 (linha preta), Q100 (linha azul), Q400 (linha vermelha), Q700 (linha verde) e Q1000 (linha magenta), na estação \#1 ( $7 \mathrm{~km}$ da desembocadura).

Figura 4.28. Resultado do modelo. Salinidade do fundo nos primeiros $29 \mathrm{~km}$ do estuário do rio Araranguá ao longo do tempo para as simulações Q30 (A), Q100 (B), Q400 (C), Q700 (D) e Q1000 (F), com inicio em condições de sizígia. 
Figura 4.29. (A) Representação do domínio longitudinal do modelo do transporte das partículas. $\mathrm{O}$ esquema mostra os limites à montante (rio Itoupava) e à jusante (desembocadura do rio Araranguá), e a divisão do domínio em setores, utilizada para as representações dos locais de deposição das partículas. (B) Localização dos setores de deposição em uma imagem do Google. Os limites dos setores estão definidos pelo pontos laranja. No total são 17 setores.

Figura 4.30. Série temporal (A) da descarga fluvial, (B) do nível da água, (C) da velocidade da corrente na superficie (linha azul) e no fundo (linha vermelha), (D) da variação da salinidade (diferença entre a salinidade do fundo pela superfície), (E) das partículas em suspensão (linha azul), exportadas (linha verde) e depositadas (linha vermelha) durante o experimento com $\mathrm{pH}$ baixo (Caso 1), (F) das partículas em suspensão (linha azul), exportadas (linha verde) e depositadas (linha vermelha) durante o experimento com pH normal (Caso 2). A linha preta em $\mathrm{E}$ e $\mathrm{F}$ representa a variação de baixa frequência dos valores das partículas depositadas. Os resultados em E e F correspondem ao lançamento das partículas durante o pico de descarga de $400 \mathrm{~m}^{3} \cdot \mathrm{s}^{-1}$. Os resultados do modelo hidrodiâmico em B, C e D são de um ponto localizado na confluência entre os rio Itoupava e Mãe Luzia. Em C, as velocidade positivas indicam as corentes de vazante e as negativas as correntes de enchente.

Figura 4.31. Gráficos indicando a posição das partículas no domínio do modelo da trajetória das partículas para alguns instantes da simulação com descarga de $400 \mathrm{~m}^{3} \cdot \mathrm{s}^{-1}$. O gráfico superior mostra a variação a descarga fluvial $\left(\mathrm{m}^{3} \cdot \mathrm{s}^{-1}\right)$ e a variação do nível da água $(\mathrm{m})$, abaixo estão os gráficos da partícula para o experimento com $\mathrm{pH}$ baixo (gráficos da esquerda) e para o experimento com $\mathrm{pH}$ normal (gráficos da direita). A cor das partículas representa os instantes que estão destacados (círculo preenchido) nos gráficos de descarga e nível na parte superior. A cor desses círculos corresponde a cor das partículas. Os pontos em preto nos gráficos representam a região de lançamento das partículas (confluência).

Figura 4.32. Gráfico da anomalia temporal da deposição das partículas ao longo do domínio. Lançamento das partículas no pico de descarga de $400 \mathrm{~m}^{3} . \mathrm{s}^{-1}$. Os valores negativos, em azul, indicam os setores de decantação das partículas do experimento com $\mathrm{pH}$ baixo (Caso 1) e os valores positivos, indicam os setores de decantação das partículas do experimento com pH normal (Caso 2). A linha tracejada indica a região da confluência. Acima da linha é o rio Itoupava e abaixo o rio Araranguá. O número de partículas, representa ao longo do tempo, a quantidade de partículas acumuladas em cada trecho do estuário.

Figura 4.33. Série temporal (A) da descarga fluvial, (B) do nível da água, (C) da velocidade da corrente na superficie (linha azul) e no fundo (linha vermelha), (D) da variação da salinidade (diferença entre a salinidade do fundo pela superfície), (E) das partículas em suspensão (linha azul), exportadas (linha verde) e depositadas (linha vermelha) durante o experimento com $\mathrm{pH}$ baixo (Caso 3), (F) das partículas em suspensão (linha azul), exportadas (linha verde) e depositadas (linha vermelha) durante o experimento com pH normal (Caso 4). A linha preta em E e F representa a variação de baixa frequência dos valores das partículas depositadas. Os resultados em E e F correspondem ao lançamento das partículas durante o pico de descarga de $1000 \mathrm{~m}^{3} \cdot \mathrm{s}^{-1}$. Os resultados do modelo hidrodiâmico em B, C e D são de um ponto localizado na confluência entre os rio Itoupava e Mãe Luzia. Em C, as velocidade positivas indicam as corentes de vazante e as negativas as correntes de enchente. 
Figura 4.34. Gráficos indicando a posição das partículas no domínio do modelo da trajetória das partículas para alguns instantes da simulação com descarga de $1000 \mathrm{~m}^{3} \cdot \mathrm{s}^{-1}$. O gráfico superior mostra a variação a descarga fluvial $\left(\mathrm{m}^{3} \cdot \mathrm{s}^{-1}\right)$ e a variação do nível da água $(\mathrm{m})$, abaixo estão os gráficos da partícula para o experimento com $\mathrm{pH}$ baixo (gráficos da esquerda) e para o experimento com $\mathrm{pH}$ normal (gráficos da direita). A cor das partículas representa os instantes que estão destacados (círculo preenchido) nos gráficos de descarga e nível na parte superior. A cor desses círculos corresponde a cor das partículas. Os pontos em preto nos gráficos representam a região de lançamento das partículas (confluência).

Figura 4.35. Gráfico da anomalia temporal da deposição das partículas ao longo do domínio. Lançamento das partículas no pico de descarga de $1000 \mathrm{~m}^{3} . \mathrm{s}^{-1}$. Os valores negativos, em azul, indicam os setores de decantação das partículas do experimento com $\mathrm{pH}$ baixo (Caso 3 ) e os valores positivos, indicam os setores de decantação das partículas do experimento com pH normal (Caso 4). A linha tracejada indica a região da confluência. Acima da linha é o rio Itoupava e abaixo o rio Araranguá. $\mathrm{O}$ número de partículas, representa ao longo do tempo, a quantidade de partículas acumuladas em cada trecho do estuário.

Figura 5.1. Representação do modelo conceitual do transporte das partículas no estuário do rio Araranguá em condições de pH normal e pH baixo. 
Tabela 2.1. Descarga fluvial média mensal, desvio padrão e razão desvio:média para o rio Araranguá, entre os anos de 1943 e 2004.

Tabela 3.1. Amplitude e fase das componentes da maré extraídas do FES2004 (Finite Element Solution - AVISO) na posição: $29^{\circ}$ 05' 09,085'S e $49^{\circ} 05^{\prime}$ ' $06,085 "$ ".

Tabela 3.2. Parâmetros do modelo definidos pelo processo de calibração do modelo tridimensional.

Tabela 3.3. Resumo das séries experimentais. Em destaque (azul), os experimentos cujo os resultados foram utilizados para estimar a velocidade de decantação das partículas. Adaptado de Couceiro \& Schettini (2010).

Tabela 3.4. Valores estimados da velocidade de decantação $\left(\mathrm{cm} . \mathrm{s}^{-1}\right)$ calculados pela Equação (3.21) em diferentes condições de velocidade de fluxo para os experimentos dinâmicos com o tanque anular.

Tabela 3.5. Esquema dos cenários configurados para as simulações com o MTP.

Tabela 4.1. Comparação estatística entre os dados do modelo e os dados observados para variação do nível da água $(\mathrm{m})$, velocidade de corrente $\left(\mathrm{m} . \mathrm{s}^{-1}\right)$ e salinidade do fundo, para o período da calibração.

Tabela 4.2. Comparação estatística entre os dados do modelo e os dados observados para variação do nível da água $(\mathrm{m})$ e velocidade de corrente $\left(\mathrm{m} \cdot \mathrm{s}^{-1}\right)$ para a validação.

Tabela 4.3: Termos do transporte advectivo de sal, calculados como os resultados do modelo, para o período de passagem do pico de descarga (25 horas), em todas as simulações (Q30, Q100, Q400, Q700 e Q1000), realizadas em condições de maré de quadratura. Valores em kg. $\mathrm{m}^{-1} \cdot \mathrm{s}^{-1}$.

Tabela 4.4. Termos do transporte advectivo de sal, calculados com os resultados do modelo, para o período de passagem do pico de descarga (25 horas), em todas as simulações (Q30, Q100, Q400, Q700 e Q1000), realizadas em condições de maré de sizígia. Valores em $\mathrm{kg} \cdot \mathrm{m}^{-1} \cdot \mathrm{s}^{-1}$.

Tabela 4.5. Porcentagem das partícula que foram exportadas e que depositaram, contabilizadas no final de cada experimento, com lançamento das partículas durante os eventos de descarga fluvial (400 e $\left.1000 \mathrm{~m}^{3} \cdot \mathrm{s}^{-1}\right)$.

Tabela 4.6. Tempo médio de residências das partículas em suspensão no estuário durante todo os experimentos com pH baixo (Caso 1 e 3) e pH normal (Caso 2 e 4). 


\section{LISTA DE SÍMBOLOS}

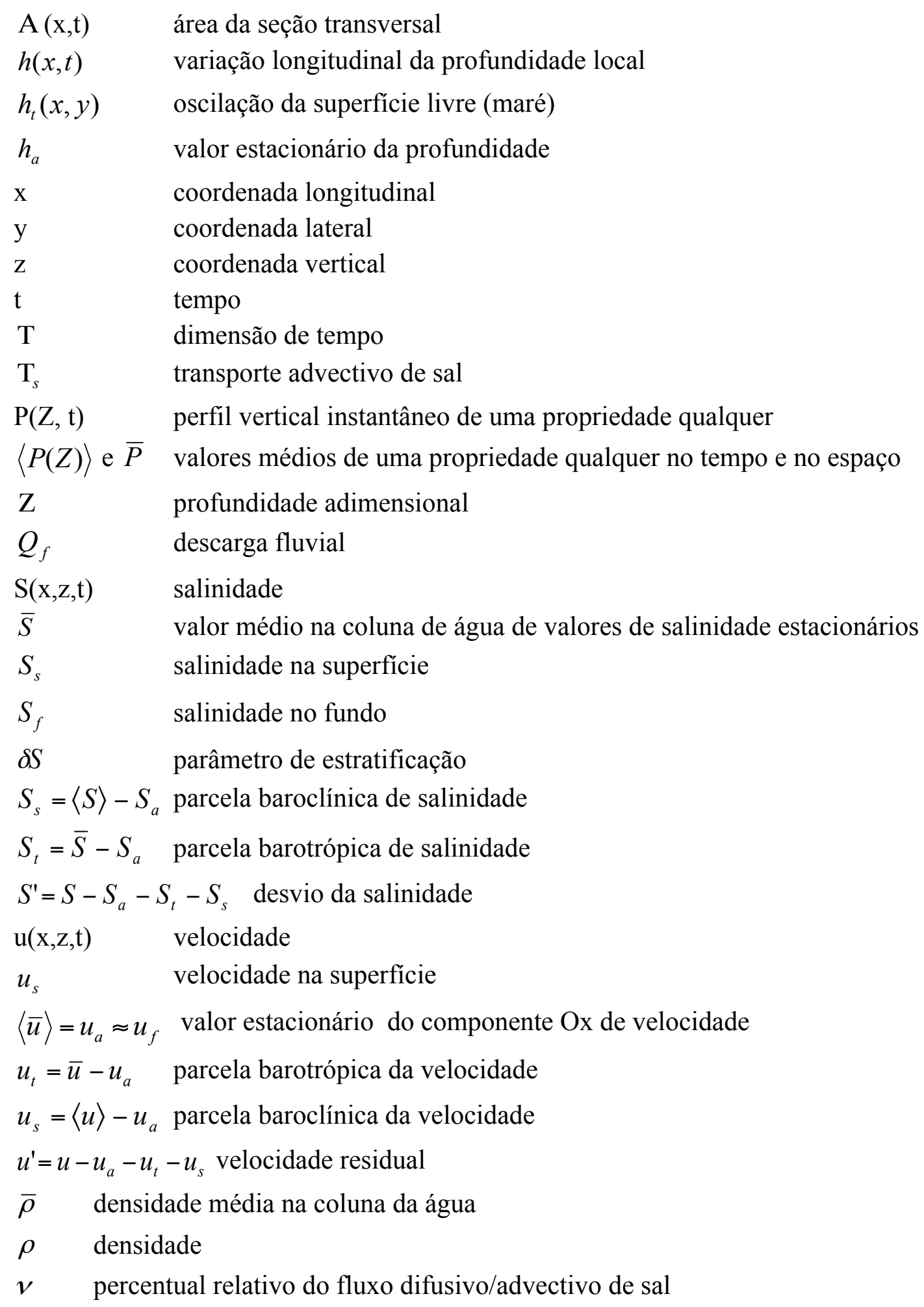




\section{Capítulo 1}

\section{Introdução}

Os estuários são as principais vias de transferência de água, sedimento, nutrientes e poluentes dos continentes para os oceanos. Grande parte do material sedimentar estuarino é proveniente da erosão da bacia de drenagem, cujos principais constituintes são silte e argila, que constituem partículas inferiores a $60 \mu \mathrm{m}$ (Mehta \& Partheniades, 1975; Krone, 1978). O transporte dos sedimentos através do estuário até que alcancem a região costeira é controlado pelo aporte fluvial de sedimentos e pelo padrão de circulação estuarino. Essa circulação é gerada pelas variações do nível do mar, pela descarga de água doce, pelo gradiente de densidade, pela circulação da plataforma continental e pela ação do vento na superfície livre (Miranda et al., 2002). Embora a circulação desempenhe um papel primordial na dinâmica sedimentar, as características dos sedimentos podem desempenhar um papel igualmente importante.

O entendimento do comportamento dos sedimentos finos, quando em suspensão e quando depositados, é de essencial importância para os estudos de contaminantes no ambiente aquático (Milligan \& Loring, 1997). O estudo do transporte de material floculado em suspensão, descritos pela análise de distribuição de sedimento de fundo, pode informar quais regiões podem ser impactadas por contaminantes, uma vez que estão associados ao material floculado.

Para definir as características hidrodinâmicas de um estuário é necessário um grande conjunto de observações, devido à grande variabilidade temporal e espacial da densidade e do campo advectivo. A descarga fluvial e os gradientes longitudinais de salinidade (densidade) gerados pela diluição da água do mar são fundamentais para dinâmica do estuário e, em consequência, para os processos de transporte e mistura que ocorrem em seu interior (Miranda et al., 2012). A influência combinada da circulação e estratificação nos estuários determina os fluxos de sal e água doce em seu interior (Geyer, 2010). Os processos de troca de massas de água entre os estuários e o oceano 
adjacente são relevantes para o transporte e a dispersão de materiais dissolvidos e em suspensão, incluindo poluentes e larvas de peixes.

O estuário do rio Araranguá, área de estudo desta tese, está localizado no extremo sul do litoral de Santa Catarina. O rio Araranguá é formado pela confluência dos rios Itoupava e Mãe Luzia. O primeiro drena áreas com atividades agropecuárias enquanto o segundo drena também áreas de atividades de mineração e processamento de carvão. Um dos impactos ambientais decorrentes desta última é a formação de drenagem ácida, onde o $\mathrm{pH}$ dos cursos de água podem ficar abaixo de 4 . O baixo $\mathrm{pH}$ da água tem efeito floculante sobre os sedimentos em suspensão, e as águas provenientes do rio Mãe Luzia são desprovidas de sedimentos em suspensão, ao contrário do rio Itoupava. A confluência das águas de ambos, produz a floculação dos sedimentos em suspensão do rio Itoupava, acelerando a decantação ao longo do estuário do rio Araranguá.

O objetivo desta tese é compreender a dinâmica das partículas em suspensão, em termos de transporte em suspensão, exportação e deposição, no estuário do rio Araranguá. Este, um estuário altamente estratificado, dominado pela descarga fluvial e influenciado pelo $\mathrm{pH}$ baixo $(\sim 3)$. O entendimento do processo de transporte é dependente de uma descrição apropriada da hidrodinâmica do sistema estuarino. Para caracterizar a hidrodinâmica do estuário, foi aplicado um modelo hidrodinâmico tridimensional (Delft3D). Para avaliar a transporte das partículas, foi aplicado um modelo Lagrangeano da trajetória das partículas que considera as variáveis dependentes em função do tempo e de sua posição inicial. O deslocamento das partículas foi controlado pela hidrodinâmica do estuário, obtida pelos resultados do Delft3D, e pela velocidade de decantação das partículas, obtidas pela parametrização de uma serie temporal de variação da concentração do material particulado em suspensão, em experimentos com um tanque anular (Couceiro \& Schettini, 2010).

Uma série de simulações foi realizada com o modelo hidrodinâmico com o objetivo de determinar as principais alterações do padrão de circulação e distribuição da salinidade no estuário. O modelo foi forçado pela descarga fluvial e pela circulação gravitacional. O modelo da trajetória das partículas foi aplicado para avaliar as principais diferenças da dinâmica das partículas em diferentes condições de $\mathrm{pH}$, baixo e 
normal, e diferentes condições transientes de descarga fluvial, com descarga média e alta. Neste trabalho, foram utilizados os termos $\mathrm{pH}$ baixo, para valor de $\mathrm{pH}$ da água menor ou igual a 4,5, e pH normal, para valor de $\mathrm{pH}$ da água maior ou igual a 7.

O entendimento do movimento das partículas é importante para compreender, de modo geral:

1. o transporte de poluentes e contaminantes, uma vez que podem estar (ou estão) adsorvidos na camada superficial dos sedimentos finos;

2. o assoreamento devido à deposição de sedimentos finos, o qual é um problema especialmente importante em estuários e canais estuarinos, onde a presença de alta salinidade e baixa velocidade de fluxo resulta no assentamento de sedimentos floculados transportados pelo fluxo;

3. alta concentração de sedimento em suspensão dificulta a penetração de luz na coluna da água (Dyer, 1995), afetando o crescimento de certas espécies de algas, diminuindo a disponibilidade de alimento para outras espécies e limitando a produção primária;

4. sedimentos coesivos adsorvem poluentes tais como metais pesados, pesticidas e nutrientes, e são transportados no ambiente aquático. A sua presença está relacionada com a qualidade da água. As substâncias toxicas antes dissolvidas na água, quando absorvidas nos sedimentos coesivos podem ser depositadas no fundo do rio;

5. compreender a influência da descarga fluvial no transporte de sedimento é decisivo para gestão do material dragado; 


\subsection{Hipótese de trabalho}

A hipótese do trabalho é que o processo de floculação, intensificado pelo baixo $\mathrm{pH}$ da água, retém os sedimentos finos no estuário no do rio Araranguá, aumentando sua eficiência filtradora. Em condições controladas, em laboratório, foi possível verificar que o rio Mãe Luzia induz o processo de floculação dos sedimentos em suspensão do rio Itoupava, com eficiência floculante similar a presença de eletrólitos da água do mar com salinidade de 1 (Couceiro \& Schettini, 2010). Essas características sugerem que o rio Mãe Luzia intensifica o efeito filtrante do estuário, retendo grande quantidade de sedimentos finos no estuário, através do processo de floculação. Por outro lado, ainda não se sabe como esse material floculado é transportado no estuário, e como a hidrodinâmica do sistema contribui para a retenção ou exportação dos sedimentos. 


\subsection{Objetivos}

O objetivo geral desta tese é compreender a dinâmica dos sedimentos em suspensão em termos de transporte em suspensão, deposição e exportação, em um estuário altamente estratificado, dominado pelo rio, tendo como peculiaridade o efeito da drenagem ácida causada pela atividade de mineração. Os objetivos específicos são:

- Entender a hidrodinâmica e distribuição de salinidade em diferentes condições de descarga fluvial no estuário, através da aplicação de um modelo numérico.

- Melhor compreender a dinâmica de partículas em suspensão, através do desenvolvimento e aplicação de um modelo da trajetória de partículas pelo método Lagrangeano.

- Caracterizar a dinâmica das partículas em suspensão em condições de pH baixo e normal, e em condições de regime transientes (descarga fluvial).

- Avaliar o que muda no estuário em termos de exportação e deposição em condições de pH baixo e normal. 


\subsection{Estado da Arte}

\section{Estuários}

A maior parte das grandes cidades costeiras do mundo estão situadas às margens de estuários. Essa ocupação e desenvolvimento se deram a partir das condições favoráveis ao acesso para o interior do continente, facilitando a instalação de portos e áreas comerciais ligadas à pesca e à construção naval, e pela capacidade de renovação periódica de suas águas sob a influência das marés. Os estuários são considerados como ambientes de extrema importância na produtividade primária, devido às altas concentrações de nutrientes, além de constituírem o hábitat natural de aves, mamíferos e peixes, sendo ambientes de desova de muitas espécies de peixes de valor comercial e rota de aves migratórias. A ocupação desordenada, a utilização do estuário como corpo receptor de efluentes naturais, industriais e de substâncias patogênicas e a falta de gerenciamento colocam em risco o desenvolvimento sustentável desses ambientes.

Estuários são definidos como corpos de água restritos no qual a água do mar é mensuravelmente diluída pela água doce proveniente da drenagem continental, possuindo uma livre ligação com o mar aberto (Cameron \& Pritchard, 1963). Em toda a sua extensão o estuário sofre influência da maré, sendo dividido em três setores: 1) estuário inferior ou marinho, com livre conexão com o oceano adjacente; 2) estuário médio, sujeito à forte mistura da água marinha com a água fluvial; 3) estuário superior ou fluvial, caracterizado por água doce sujeito à influência da maré. Uma definição mais completa pode ser compreendida na adaptação da clássica definição de Pritchard (Dyer, 1997): “estuário é um corpo de água costeiro semifechado com ligação livre com o oceano aberto, estendendo-se rio acima até o limite da influência da maré, sendo que em seu interior a água do mar é mensuravelmente diluída pela água doce oriunda da drenagem continental".

A circulação da água e os processos de mistura nesses ambientes são controlados pela diferença de densidade e a interação entre a água doce e a água marinha. Embora exista somente uma diferença de $2 \%$ entre a densidade da água doce e da água marinha, esta diferença já é suficiente para criar um gradiente de pressão horizontal que afeta a 
dinâmica do estuário (Dyer, 1997). A densidade da água do mar depende tanto da salinidade quanto da temperatura, mas em estuários a variação da salinidade é maior em comparação a variação da temperatura (Dyer, 1997).

A forçante que impulsiona correntes de maré estuário acima (enchente) e estuário abaixo (vazante), representando o gradiente de pressão gerado pela inclinação periódica do nível do mar devido à oscilação da maré, possui natureza barotrópica e seu efeito é independente da profundidade (Miranda et al., 2002). O gradiente longitudinal da salinidade integrado entre a superfície livre e a profundidade do fundo inclui ao efeito dinâmico movimento estuário acima de natureza baroclínica. Essas forçantes atuam simultaneamente no corpo de água estuarino em função do espaço e do tempo (Miranda et al., 2002).

Com a supressão do movimento barotrópico, o movimento resultante impulsionado pelo gradiente longitudinal de salinidade (estuário acima) e pela descarga de água doce (estuário abaixo) é bidirecional, denominado de circulação gravitacional. Ainda nessas condições, o movimento estuário abaixo arrasta elementos da água do mar para a camada superficial (intrusionamento de massa), causando um aumento da salinidade na camada superficial. A retirada desse volume de água por arrasto é compensada pela advecção horizontal na camada de água do mar situada abaixo do gradiente de salinidade (Miranda et al., 2002). A oscilação periódica da maré implementa nesse processo a mistura de águas através da associação da difusão turbulenta com o movimento de arrasto. A turbulência é um mecanismo de dissipação de energia gerada pelo cisalhamento de velocidade, promovida pelo atrito das correntes com os limites do corpo estuarino e pelo atrito interno (Dyer, 1997).

No contexto que envolve a escala de maré, os estuários podem ser classificados pela altura da maré de acordo com a classificação de Hayes (1975) como: (1) micromaré, com a variação da altura menor que $2 \mathrm{~m}$; (2) mesomaré, com variação da altura superior a $2 \mathrm{~m}$ e inferior a $4 \mathrm{~m}$; (3) macromaré, com variação da altura superior a $4 \mathrm{~m}$ e inferior a $6 \mathrm{~m}$. A classificação em hipermaré é uma adição recente e compreende alturas de maré acima de $6 \mathrm{~m}$. 
O grau de estratificação de salinidade em um sistema estuarino é determinado pela importância relativa entre as forças que promovem os processos de mistura e estabilização da coluna de água, onde fatores como a razão entre a largura e profundidade, a descarga fluvial, maré e o vento desempenham papeis importantes. De acordo com a estratificação da coluna da água os estuários podem ser classificados com cunha salina, fortemente estratificado, fracamente estratificado e bem misturado (Fig. 1.1) (Pritchard, 1955; Cameron \& Pritchard, 1963; Valle-Levinson, 2010).
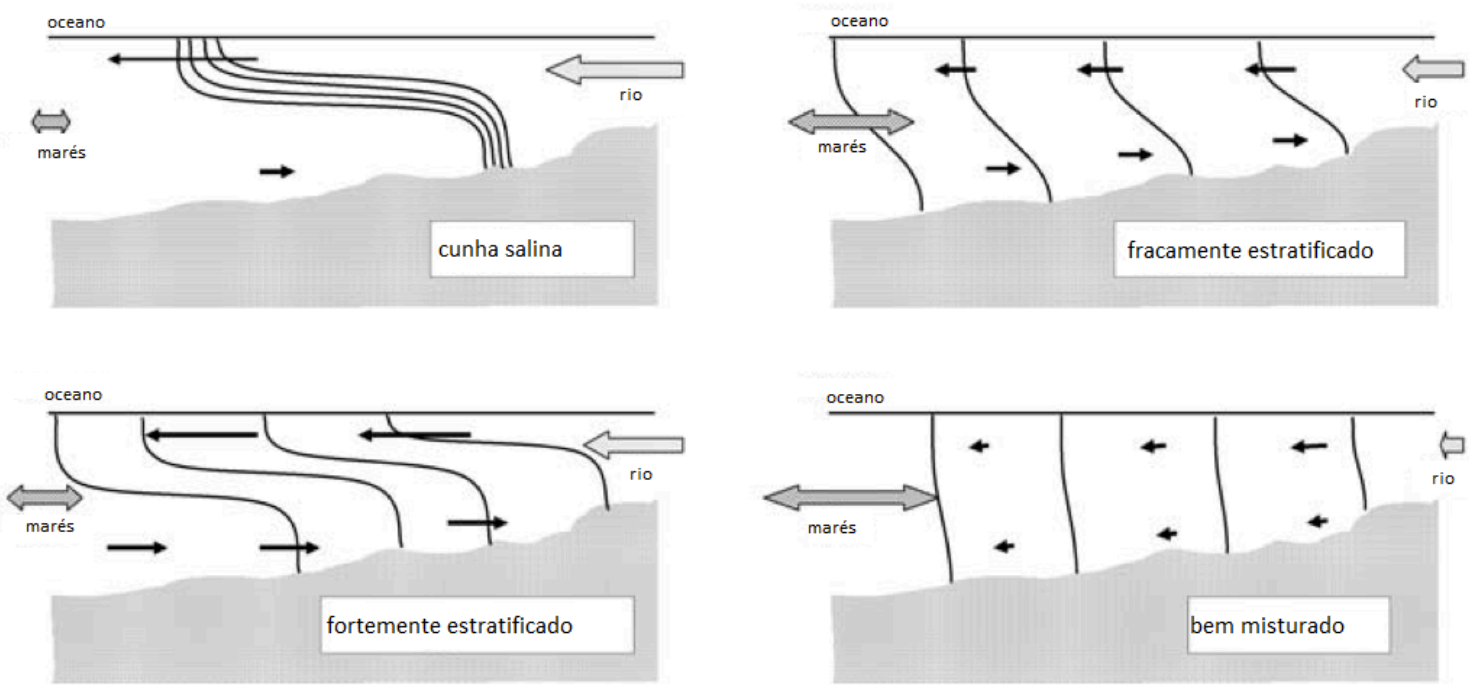

Figura 1.1. Classificação dos estuários de acordo com a estratificação da salinidade. (Adaptado de Valle-Levinson, 2010).

Estuários classificados como cunha salina possuem elevada descarga e regime de micromaré. São sistemas fortemente estratificados durante as marés de enchente, quando a cunha salina entra no sistema (Valle-Levinson, 2010). A presença de uma acentuada estratificação vertical, com grande diferença dos valores da salinidade superficial e do fundo é representativa de estuário classificado como altamente estratificado. Esses estuários possuem como característica a presença de uma interface distinta entre a água da descarga fluvial e a água do mar, tendo o intrusionamento de massa como processo predominante e responsável pelo aumento da salinidade na camada superficial (Miranda et al., 2002). Estuário parcialmente misturado possui estratificação vertical moderada com poucas unidades de diferença entre a salinidade 
superficial e do fundo. Estuários que não apresentam diferença significante entre a salinidade da superfície e do fundo, distinguindo-se pela ausência da haloclina, são classificados como bem misturados.

Em estuários altamente estratificados, a água menos densa de origem fluvial flui estuário abaixo nas camadas superficiais, enquanto que as águas mais profundas, e mais densas, de origem marinha, fluem estuário acima. A espessura e as velocidades da camada superficial diminuem em direção à desembocadura conforme o estuário se torna mais largo (Dyer, 1997). A interface entre a água doce e a água salina, conhecida como haloclina, deve ser horizontal e deve estender-se estuário acima como o nível da água (Dyer, 1997).

\section{Sedimentos coesivos}

Os sedimentos em estuários refletem a dinâmica complexa desse ambiente. $\mathrm{Na}$ região costeira, os sedimentos dominantes são os arenosos e no interior do estuário há sedimentos finos, incluindo muitas vezes os sedimentos argilosos, com grande concentração de matéria orgânica. Os sedimentos são fragmentos formados pelo intemperismo físico e químico das rochas da crosta terrestre (Van Rijn, 1993). Sedimentos coesivos são fragmentos formados a partir da decomposição química das rochas. Em ambientes marinhos, os sedimentos coesivos consistem de uma mistura de argila, silte, areia fina, matéria orgânica, água e alguns gases. O que determina o comportamento coesivo do sedimento no ambiente aquoso é a relação entre as partículas de argila, os argilominerais, e a matéria orgânica com as propriedades químicas do fluido (Winterwerp \& Kesteren, 2004).

O processo de floculação em estuários está principalmente associado com a presença de água marinha, ocorrendo a partir de salinidade de 0,5 (Postma, 1967; Winterwerp, 2002). Uma vez formados, os flocos permanecem em suspensão se as flutuações das forças da velocidade vertical (difusão turbulenta) forem maiores que a velocidade de decantação. Contudo, os flocos são normalmente frágeis e rompem-se sob condições turbulentas. Desta forma, flocos maiores somente serão formados em 
menores velocidades de corrente, o que maximiza a sua deposição no fundo (Döbereiner, 1982). Contrariamente, condições turbulentas impedem a formação de flocos grandes, e mantém as partículas em suspensão permitindo que estas sejam carregadas e possivelmente exportadas para a região costeira. O processo de floculação dos sedimentos finos (e.g., Eisma, 1986) aumenta potencialmente a sua velocidade de decantação, e por consequência a sua retenção no estuário, o que torna estes ambientes filtros de materiais na transição continente-oceano (Schubel \& Carter, 1984).

A estrutura do grupo dos argilo-minerais compreende de lâminas de $\mathrm{SiO}_{4}$ tetraédrica unidas de diferentes maneiras, geralmente envolvendo uma camada de alumínio ou hidróxido de alumínio e substituições de um elemento por outro, proporcionando uma grande variedade (Dyer, 1986). Os quatro principais argilominerais são a caolinita, ilita, montmorilonita e clorita. A característica de sua estrutura pode variar, particularmente quando são introduzidos na água do mar, onde a concentração de íons dissolvidos é elevada (Dyer, 1986).

As forças de atração eletrostáticas são basicamente dependentes das propriedades físicas e mineralógicas das argilas. A concentração total de íons circundantes na água, a temperatura e o $\mathrm{pH}$, podem determinar a espessura da dupla camada. Caso o potencial eletrolítico diminui, abaixo de um valor crítico, ocorre floculação. Duas partículas, quando possuem a dupla camada, aproximam-se uma da outra por movimento Brownian e afastam-se por terem a mesma carga. A suspensão é estável quando uma pequena quantidade de eletrólitos está presente na água, quando é adicionado mais eletrólitos, o potencial da dupla camada diminui e a possibilidade de duas partículas se unirem aumenta (Postma, 1967).

Sedimentos coesivos e partículas floculadas formam grandes agregados. Seu tamanho aumenta e sua densidade diminui mas sua velocidade de decantação aumenta (Dyer, 1997). A velocidade de deposição é uma função do tamanho e da densidade da partícula. Em ambientes estuarinos isso se torna complicado devido à floculação do material particulado em suspensão, formando agregados ou flocos, os quais são grandes, mas menos densos do que partículas inicialmente individuais (Manning \& Dyer, 1999). A deposição clássica de sedimentos coesivos ocorre quando a tensão do fundo diminui abaixo da tensão crítica. A erosão de partículas de sedimentos finos do fundo 
normalmente acontece quando a tensão aumenta acima de um valor crítico. $\mathrm{O}$ valor crítico da erosão é maior ou igual ao da deposição (Manning et al., 2011).

A transferência de substâncias entre os rios e o oceano está intimamente relacionada com o processo de floculação na zona de turbidez máxima, que por sua vez aumenta a eficiência da filtração nos estuários. A floculação em estuários é promovida pelo aumento da salinidade, elevada concentração de sedimentos, alta proporção de matéria orgânica e baixa corrente turbulenta (Krank, 1984). A turbidez máxima, por si só, não é, portanto, um fenômeno estático: move se pelo estuário com as marés e a estação do ano, empurrando para dentro pela enchente e para forra pela vazante; algumas vezes é empurrada totalmente para fora do estuário durante um período de descarga muito elevada do rio, ou movimentos afastados em direção do interior quando a descarga do rio é baixa (Eisma, 1986).

O sedimento na região estuarina de turbidez máxima é normalmente floculado e consequentemente tem uma alta velocidade de decantação, o que pode levar para um fluxo significante de sedimento para o fundo quando as correntes de velocidade diminuem. Durante períodos de alta descarga fluvial, materiais compostos por grãos finos podem ser aprisionados em frentes salinas alcançando concentração suficientemente alta de modo que consolidam, podendo ocorrer no sedimento um aumento do tamanho, seu fortalecimento e, consequentemente o aumento da velocidade de decantação de flocos ressuspendidos do fundo durante alto estresse (Milligan et al., 2001). Material em suspensão em estuários e águas costeiras geralmente decanta em velocidades de fluxo de 10 a $15 \mathrm{~cm} \cdot \mathrm{s}^{-1}$ (Eisma, 1986).

Os sedimentos transportados pelos rios são geralmente uma mistura heterogênea que reflete a variedade da fonte de grãos disponível na bacia. Quando a descarga do rio aumenta, a advecção estuário abaixo aumenta, trazendo um conjunto de sedimentos. As correntes mais fortes nas camadas superficiais carrega os sedimentos para plataforma e o retorno das correntes de fundo é fraco. Depois dessa perturbação, ocorre o estágio durante o qual o fluxo diminui e permite que a cunha salina flua estuário acima. O fluxo residual estuário acima é reforçado e a turbidez máxima é restabelecida. A circulação residual eventualmente carrega a maioria dos sedimentos de volta para cabeceira do estuário (Dyer, 1997). 


\section{Modelagem de estuários}

Um número recente de estudos consideram os modelos tridimensionais como ferramenta de estudo dos estuários. Esses estudos investigaram: as variações da maré na mistura turbulenta e estratificação, no estuário Johor, Singapura (Hasan et al., 2013); a intrusão salina e a circulação residual, no estuário Danshuei, Taiwan (Liu et al., 2011); distribuição da salinidade e trocas verticais do fluxo, ao longo do estuário Hudson (Ralston et al., 2008); as variações da circulação, da intrusão salina e da estratificação vertical, sobre diferentes condições de descarga fluvial e vento, no estuário Pamlico, Estados Unidos (Xu et al., 2008); os processos hidrodinâmicos, estuário de ST. Lucie, Estados Unidos (Ji et al., 2007); estimar a distribuição da salinidade e as frações de água doce para estimar o tempo de residência no estuário North Bay, Estados Unidos (Huang, 2007); a influência da descarga do rio na intrusão salina e na circulação residual, no estuário Danshuei, Taiwan (Liu et al., 2007); a hidrodinâmica e os processos do transporte de sal no estuário Alafia, Estados Unidos (Chen, 2004); a dinâmica da circulação lateral de um estuário idealizado retilíneo sobre variações da estratificação (Lerczak \& Geyer, 2004); as distribuições temporais e espaciais da circulação e salinidade em resposta aos efeitos da mudança da descarga fluvial, no estuário Apalachicola, Estados Unidos (2003);

A modelagem numérica dos sedimentos coesivos pode ser realizada em modelos tridimensionais, os quais possibilitam resolver processos nas três dimensões, em modelos bidimensionais, onde são considerados os processos médios na coluna da água ou unidirecionais, onde os processos são resolvidos em uma única direção. $\mathrm{O}$ movimento do fluido, responsável pelo movimento das partículas em suspensão, pode ser medido de dois modos: Euleriano e Lagrangeano. No primeiro, a velocidade e a direção são registradas no tempo em um ponto fixo em relação às coordenadas externas. No segundo caso, a trajetória da partícula é seguida, sua velocidade e direção, em qualquer tempo, podem ser reconstruídas, mais se referem para diferentes posições com relação a referencias externas (Dyer, 1986). 
O modelo de trajetória de partícula é aquele no qual a massa é transportada como partículas discretas. Algumas razões para utilizar o modelo de trajetória da partículas foram apontadas por Dimou \& Adans (1993): (a) as fontes são mais fáceis de serem representadas com o modelo da trajetória da partícula; (b) esses modelos são mais naturais onde os processos de transporte e destino são melhores descritos pelos atributos de partículas individuais (padrões de comportamento de larvas de peixes, decantação de partículas de diferentes tamanhos) mais do que agregados (concentrações); (c) pode ser uma escolha mais direta quando estamos interessados em propriedades integradas da distribuição da concentração (tempo de residência) mais do que a concentração em si. Além dessas razões, os modelos da trajetória permitem um maior controle dos processos estudados.

Modelar sedimentos coesivos é um processo difícil considerando a complexidade das suas propriedades químicas e físicas. Por essa razão, não existem muitos trabalhos com aplicação de modelos de transporte de sedimentos coesivos. Alguns trabalhos estão sendo realizados para ajustar os modelos (e.g. Lumborg \& Windelin, 2003). Modelos de trajetória da partícula têm sido utilizados frequentemente acoplados aos modelos hidrodinâmicos, em estudos de ambientes aquáticos, para: estudar os processos de dispersão e o tempo de residência nas Rias da Galícia, Espanha (Gesteira et al., 1998); compreender os processos de interação entre a maré, a circulação residual e a descarga de água doce, na Inglaterra (Sentchev \& Korotenko, 2005); predizer o transporte e a dispersão de microalgas tóxicas, na Ria de Aveiro, Portugal (Cerejo \& Dias, 2007); entender o comportamento do deslocamento de organismos pelágicos, na Baia de Chesapeake (North et al., 2008); entender a conexão entre os nutrientes, os poluentes e as larvas de peixes, no Golfo do Califórnia, México (Marinone et al., 2008); simular a emissão de poluentes em áreas portuárias no estuário de Lima, Portugal (Vale \& Dias, 2011); determinar a trajetória do material dragado na Baia de Liverpool, Inglaterra (Brown et al., 2015). 


\section{Capítulo 2}

\section{Área de estudo}

A bacia hidrográfica do rio Araranguá está localizada no litoral sul do estado de Santa Catarina (Fig. 2.1), pertencente à vertente atlântica com uma área de drenagem de $3.020 \mathrm{~km}^{2}$. Os dois principais rios formadores da bacia formam a mesobacia do rio Mãe Luzia e Itoupava, com uma área da drenagem de $1.501 \mathrm{e} 1.181 \mathrm{~km}^{2}$, respectivamente (SANTA CATARINA, 1997). O rio Araranguá recebe esta denominação após a junção dos rios Itoupava e Mãe Luzia, com extensão aproximada de $35 \mathrm{~km}$ e orientação geral de leste-oeste. Seu curso é formado por meandros, sendo que na proximidade de sua desembocadura, o rio se desloca para nordeste paralelamente a linha de costa, desaguando no oceano Atlântico. A profundidade média do canal, entre sua desembocadura e a cidade de Araranguá, é $8 \mathrm{~m}$. Próximo da desembocadura, a profundidade máxima é de $4 \mathrm{~m}$ e ao longo do estuário, em sua porção intermediária, chega aos $18 \mathrm{~m}$.

A área de drenagem do rio Mãe Luzia é caracterizada pela atividade de lavra e beneficiamento do carvão, gerando uma drenagem ácida que impede ou limita a utilização da água devido a sua acidez e a presença de contaminantes (Gothe, 1989). De 30 a $60 \%$ do material minerado, durante o processo do beneficiamento do carvão, é refugado, gerando um grande volume de rejeito (Bidone et al., 2000). O rejeito oriundo dessa atividade é constituído basicamente por materiais carbonosos e minerais (pirita e argilominerais) e está disposto no solo e nos recursos hídricos (Bidone et al., 2000). 

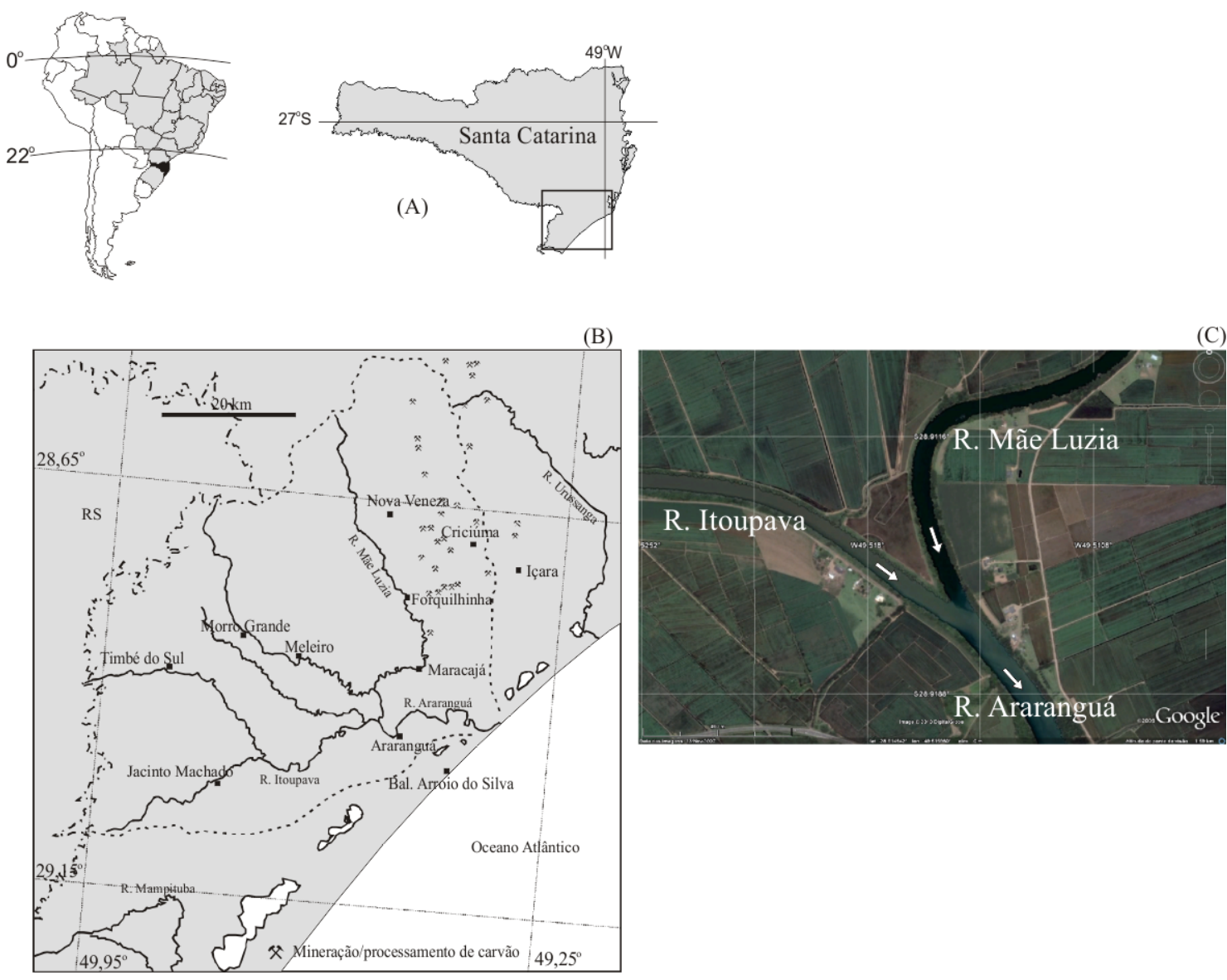

Figura 2.1. (A) Localização da bacia hidrográfica do rio Araranguá em Santa Catarina, (B) os principais rios com a localização de unidade de mineração ou processamento de carvão, e (C) uma imagem obtida a partir do Google Earth da confluência dos rios Itoupava e Mãe Luzia ilustrando o gradiente de coloração indicativo da concentração de sedimentos em suspensão. 
Os rejeitos ricos em pirita, quando oxidam em contato com o ar, a água e sob a ação de bactérias (Thiobacillus ferroxidans), promovem a acidificação da água, caracterizada pela cor vermelho alaranjada (White et al., 1997; Braungardt et al., 2003; Fungaro \& Izidoro, 2006). As reações químicas que explicam a oxidação da pirita e a produção de ácido no ambiente são compreendidas pelas seguintes equações:

$$
\begin{aligned}
& \mathrm{FeS}_{2}(\mathrm{~s})+7 / 2 \mathrm{O}_{2}(\mathrm{~g})+\mathrm{H}_{2} \mathrm{O}(\mathrm{l}) \longleftrightarrow \mathrm{Fe}^{2+}(\mathrm{aq})+2 \mathrm{SO}_{4}{ }^{2-}(\mathrm{aq})+2 \mathrm{H}^{+}(\mathrm{aq}) \\
& \mathrm{Fe}^{2+}(\mathrm{aq})+1 / 4 \mathrm{O}_{2}(\mathrm{~g})+2 \mathrm{H}^{+}(\mathrm{aq}) \\
& \mathrm{Fe}^{3+}(\mathrm{aq})+3 \mathrm{H}_{2} \mathrm{O}(\mathrm{l}) \\
& 4 \mathrm{FeS}_{2}(\mathrm{~s})+15 \mathrm{O}_{2}(\mathrm{~g})+14 \mathrm{H}_{2} \mathrm{O}(\mathrm{l})+\mathrm{H}_{2} \mathrm{O} \\
&
\end{aligned}
$$

A acidez é gerada quando o íon ferroso gerado na Equação (2.1) é oxidado ao estado férrico na Equação (2.2) que se hidrolisa na Equação (2.3), gerando mais acidez (Fugaro \& Izidoro, 2006). Com baixos valore de $\mathrm{pH}$, altos índices de acidez e presença de sulfatos e metais pesados, as águas desse sistema tornam-se impróprias para a agricultura, para o abastecimento humano e industrial.

Devido ao modo de exploração e descarte do carvão, unidades produtoras de coque intensificam a degradação do ambiente na região, comprometendo as águas dos rios, lagos e do lençol freático (Pompêo et al., 2004). As bacias hidrográficas do estado de Santa Catarina, consideradas impactadas pela atividade mineradora de carvão são três: a bacia do rio Araranguá, do rio Tubarão e do rio Urussanga (Fugaro \& Izidoro, 2006). Grande parte das bacias hidrográficas de região carbonífera da Santa Catarina está comprometida qualitativamente, apresentando valores de sulfatos que chegam até $7.000 \mathrm{mg} .1^{-1}$, ferro até $2.000 \mathrm{mg} . \mathrm{l}^{-1}$ e $\mathrm{pH}$ com valores entre 1,5 e 3 (Santa Catarina, 2004). 
O sistema de drenagem do rio Itoupava apresenta uma área de grande importância no cultivo de arroz, aproximadamente 2.860 hectares. Na época do preparo das quadras de arroz, ocorre considerável aumento da disponibilidade de sedimentos para os cursos de água. Além de comprometer a qualidade do sistema hídrico, a rizicultura gera conflitos no que concerne a utilização da água, pois necessita de grandes volumes para o cultivo (Santa Catarina, 1997).

A bacia do rio Araranguá está inserida em uma região de clima subtropical úmido, segundo a classificação climática proposta por Koeppen, com verões quentes e temperatura média anual de $19^{\circ} \mathrm{C}$ (Santa Catarina, 1997). A pluviosidade total anual varia de 1.400 a $1.600 \mathrm{~mm}$, com maiores precipitações, em média, nos meses de janeiro e fevereiro e mínima no inverno (Santa Catarina, 1997). Nos anos de El Niño, as chances de chuvas acima do normal são maiores nas regiões sul e sudeste do Brasil (http://www.cptec.inpe.br/noticias/noticia/8530).

As estações fluviométricas da Agência Nacional de Águas (ANA) mais próximas do rio Araranguá estão localizadas nos rios Itoupava, estação de Taquaruçu (84950000), e Mãe Luzia, estação de Forquilhinha (84820000), com área de drenagem de 898 e $523 \mathrm{~km}^{2}$, respectivamente. A análise dos dados de descarga diária entre os anos de 1943 e 2004 (Fig. 2.2, A e B), fornece uma descarga média de $35 \pm 63,5$ e $18 \pm 36,8$ $\mathrm{m}^{3} . \mathrm{s}^{-1}$, com máxima de $1.147 \mathrm{e} 1.103 \mathrm{~m}^{3} \cdot \mathrm{s}^{-1}$, para o rios Itoupava e Mãe Luzia, respectivamente.

Extrapolando, linearmente, os dados de descarga fluvial do rio Itoupava para a área total da bacia do rio Araranguá é possível determinar a descarga média mensal para bacia. A extrapolação é possível devido a baixa declividade dos rios que formam a bacia e da homogeneidade espacial das chuvas na região (Santa Catarina, 1997). Ao longo do ano, a descarga média mensal é máxima nos meses de fevereiro $\left(152 \pm 232 \mathrm{~m}^{3} \cdot \mathrm{s}^{-1}\right)$, janeiro $\left(131 \pm 213 \mathrm{~m}^{3} \cdot \mathrm{s}^{-1}\right)$ e setembro $\left(105 \pm 193 \mathrm{~m}^{3} \cdot \mathrm{s}^{-1}\right)$, e mínima nos meses de maio $\left(57 \pm 142 \mathrm{~m}^{3} \cdot \mathrm{s}^{-1}\right)$, junho $\left(53 \pm 116 \mathrm{~m}^{3} \cdot \mathrm{s}^{-1}\right)$ e julho $\left(57 \pm 114 \mathrm{~m}^{3} \cdot \mathrm{s}^{-1}\right)$ (Tabela 2.1; Fig. 2.3). A razão entre o desvio padrão e os dados médios mensais (Tab. 2.1), mostra que existe uma alta variabilidade durante todo o ano, com máxima nos meses de maio, junho, julho e agosto. 


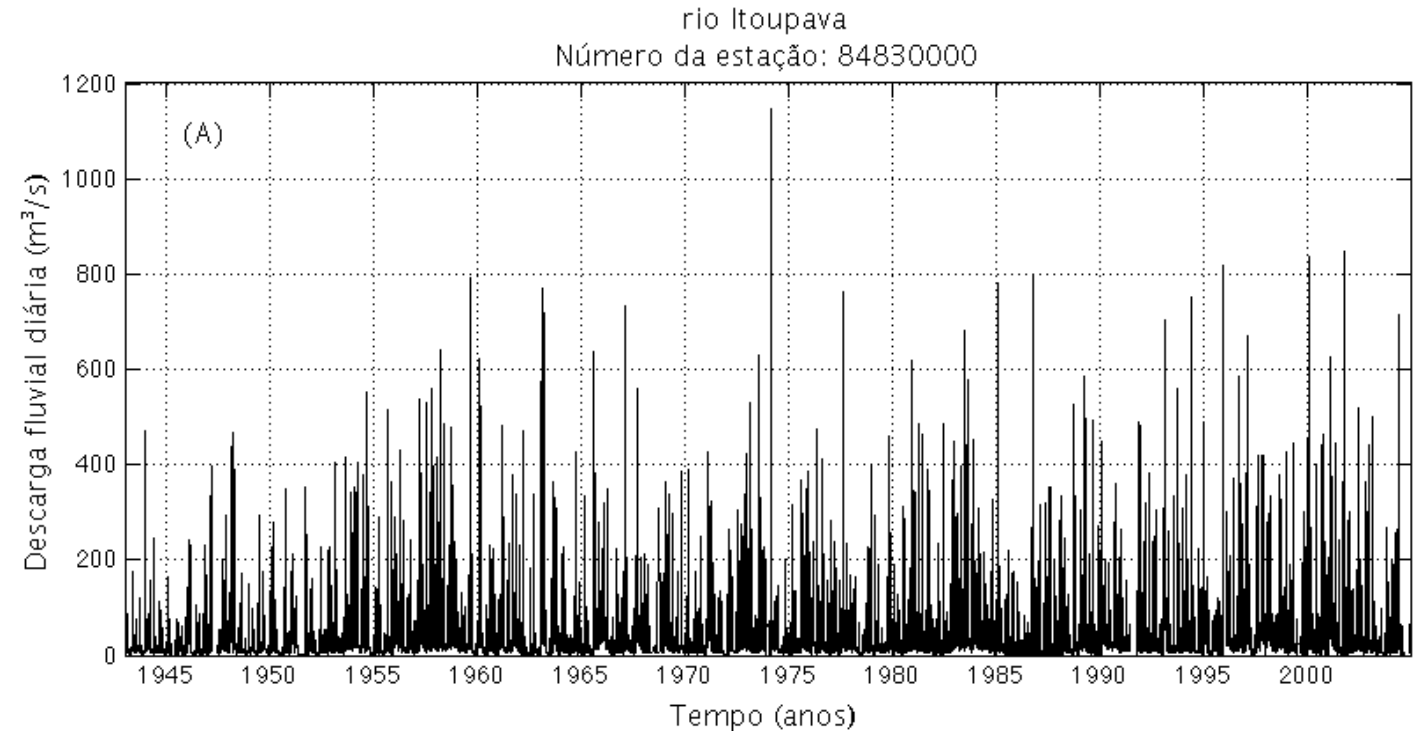

rio Mãe Luzia
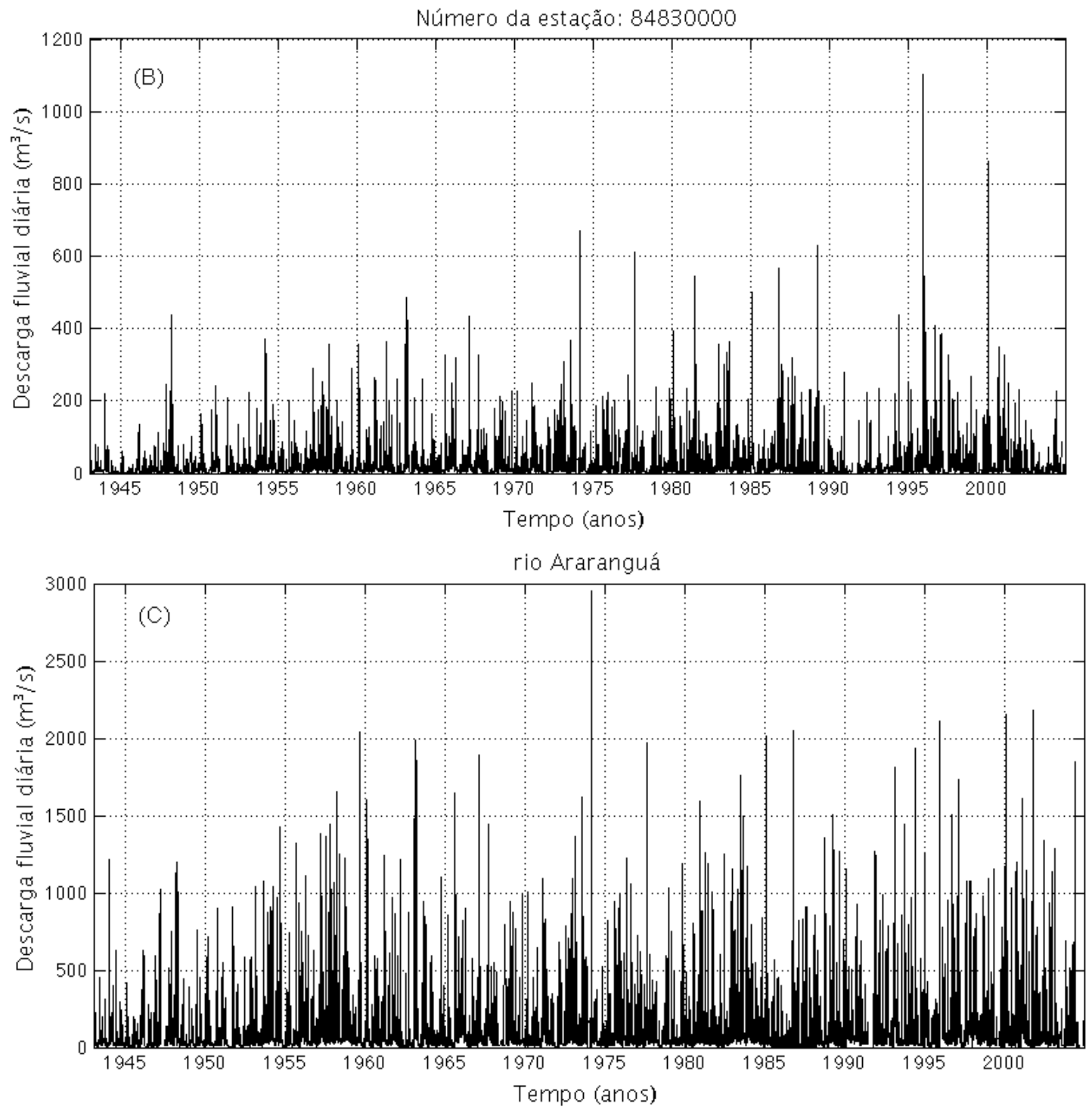

Figura 2.2. Descarga média diária dos rios Itoupava (A), Mãe Luzia (B) e Araranguá (C) entre os anos de 1943 e 2004. 
Tabela 2.1. Descarga fluvial média mensal, desvio padrão e razão desvio:média para o rio Araranguá, entre os anos de 1943 e 2004.

\begin{tabular}{lll}
\hline Mês & $\begin{array}{l}\text { Média e desvio padrão } \\
\left(\mathrm{m}^{3} \cdot \mathrm{s}^{-1}\right)\end{array}$ & Desvio padrão/média \\
\hline Janeiro & $92 \pm 135$ & 1,46 \\
Fevereiro & $152 \pm 232$ & 1,52 \\
Março & $131 \pm 213$ & 1,62 \\
Abril & $77 \pm 129$ & 1,67 \\
Maio & $57 \pm 142$ & 2,46 \\
Junho & $53 \pm 116$ & 2,18 \\
Julho & $57 \pm 114$ & 2 \\
Agosto & $69 \pm 150$ & 2,14 \\
Setembro & $105 \pm 193$ & 1.84 \\
Outubro & $98 \pm 164$ & 1,67 \\
Novembro & $86 \pm 144$ & 1,66 \\
Dezembro & $77 \pm 151$ & 1,95 \\
\hline
\end{tabular}

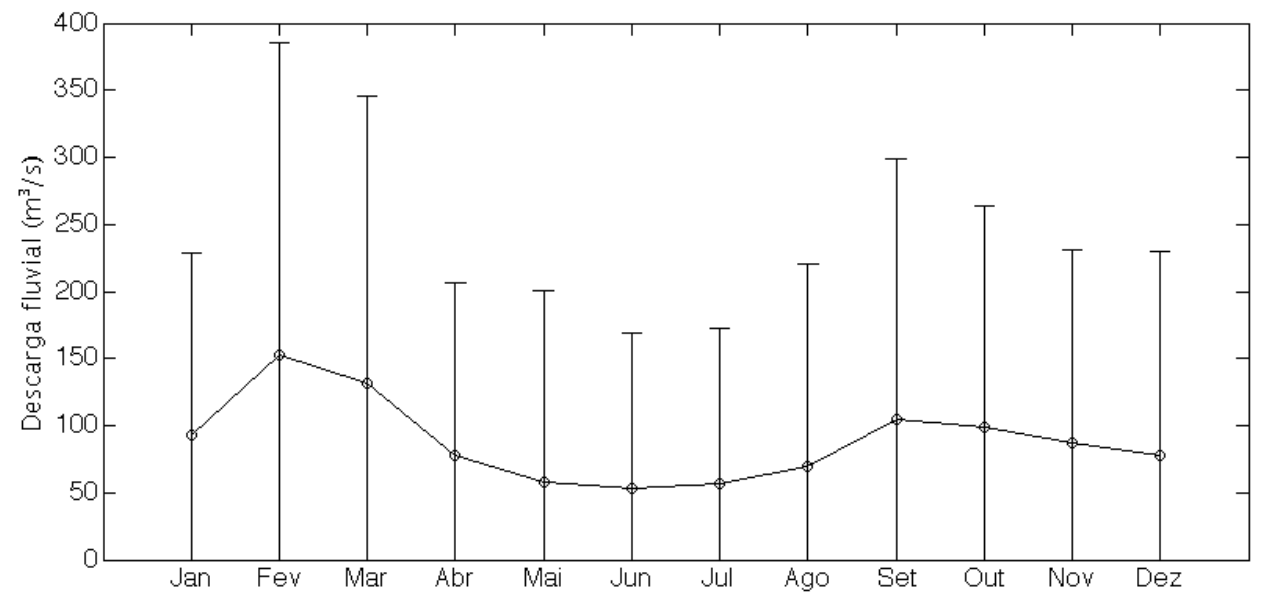

Figura 2.3. Descarga fluvial média mensal e desvio padrão para o rio Araranguá baseado em dados médios diários dos anos de 1943 até 2004. 
O aporte fluvial no estado de Santa Catarina é caracterizado por bacias de drenagem de dimensões pequenas. Os rios são fortemente influenciados por eventos de pequena escala temporal. Os principais rios são: o rio Itajaí, com vazão média de 247 $\mathrm{m}^{3} . \mathrm{s}^{-1}$; o rio Itapocu, com vazão média de $77 \mathrm{~m}^{3} . \mathrm{s}^{-1}$; o rio Tijucas, com vazão de 58 $\mathrm{m}^{3} \cdot \mathrm{s}^{-1}$; o rio Tubarão, com vazão média de $130 \mathrm{~m}^{3} \cdot \mathrm{s}^{-1}$; o rio Araranguá, com vazão média de $88 \mathrm{~m}^{3} . \mathrm{s}^{-1}$ e o rio Mampituba, com vazão média de $19 \mathrm{~m}^{3} . \mathrm{s}^{-1}$. Assim como o estuário do rio Itajaí-Açu, o estuário do rio Araranguá pode ser caracterizado como um sistema dominado por eventos de alta descarga de curta duração (Barreto \& Schettini, 2014; Schettini, 2002). A distribuição da frequência das médias diária (Fig. 2.4-A) mostra que durante a maior parte do tempo, cerca de 60\% do período analisado (19432004), a descarga fluvial é inferior ao valor médio total $\left(88 \mathrm{~m}^{3} . \mathrm{s}^{-1}\right)$, para o mesmo período, em torno de $30 \mathrm{~m}^{3} \cdot \mathrm{s}^{-1}$. Na região, os pulsos de descarga ocorrem esporadicamente devido a precipitação na bacia hidrográfica (Schettini, 2002). O período de baixa descarga, entre os pulsos de alta descarga, dura em média 10 dias (Fig. 2.4-B), podendo durar até 160 dias.

A

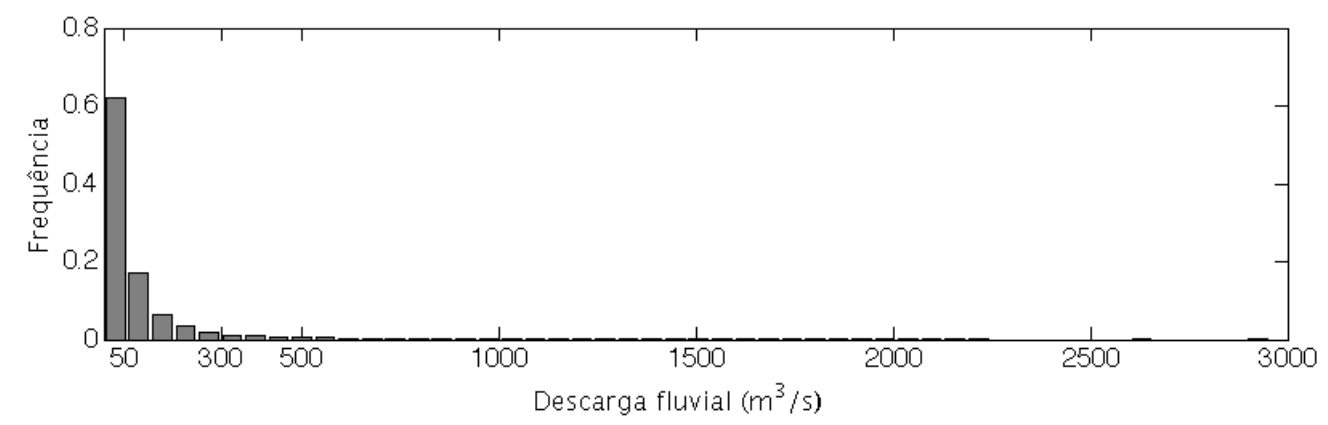

B

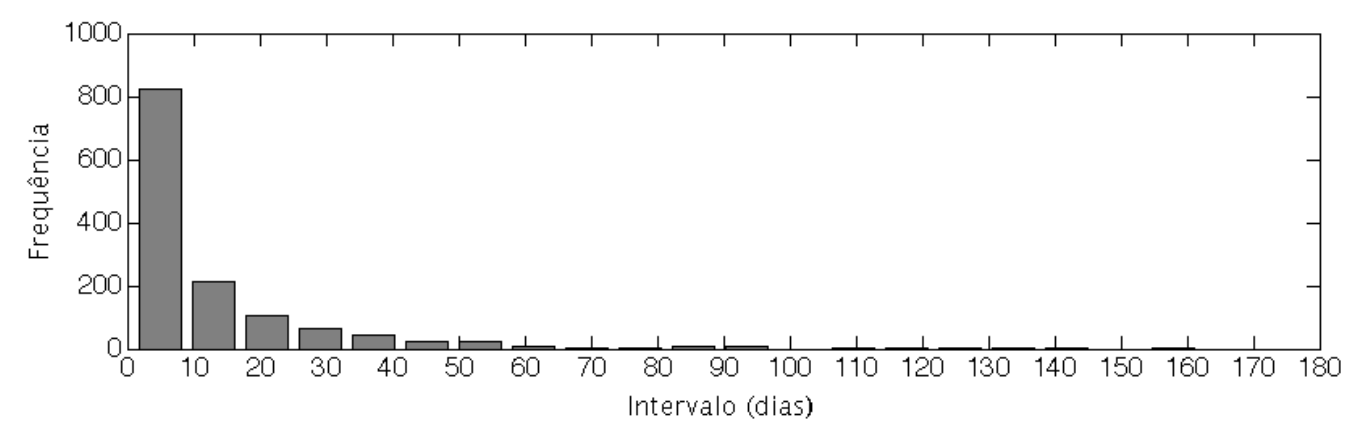

Figura 2.4. (A) Histograma da frequência média diária de descarga fluvial e (B) histograma de frequência de intervalo de dias entre pulsos de alta descarga fluvial. Ambos os resultados foram obtidos com a série de dados de descarga fluvial entre o período de 1943 a 2004. 
De acordo com a classificação de Hayes (1975), o estuário do rio Araranguá pode ser classificado como de micromaré, com predomínio de semidiurno e altura de $\sim$ 0,9 m (INPH, 1993). A relação entre as componentes diurnas e semidiurnas da maré, obtida pelo número de forma $\left(\mathrm{N}_{\mathrm{f}}=\mathrm{K}_{1}+\mathrm{O}_{1} / \mathrm{M}_{2}+\mathrm{S}_{2}\right)$ é $\sim 0,8$ e classifica a maré da região como sendo mista com predominância semidiurna $\left(0,25<\mathrm{N}_{\mathrm{f}}<1,5\right)$. Caracterizada por apresentar duas preamares e duas baixa-mares no dia.

D’Aquino et al (2010) apresentaram uma primeira caracterização da hidrodinâmica do estuário do rio Araranguá, após um evento de elevada descarga fluvial. Os autores definiram o padrão de circulação como do tipo altamente estratificado e dominado pela descarga fluvial. Em seus resultados, as correntes de maré, tanto de enchente quanto de vazante, atingem cerca de $0,3 \mathrm{~m} \mathrm{~s}^{-1}$, porém sob influência da descarga fluvial podem elevar-se acima de $0,5 \mathrm{~m} \mathrm{~s}^{-1}$. A intrusão salina é grandemente afetada pela descarga fluvial, e em períodos de baixa descarga pode chegar até a confluência dos rios Itoupava e Mãe Luzia (D’Aquino et al., 2010).

Na mesma campanha de 2006, foi realizada uma avaliação da hidrodinâmica e do transporte de sedimento em suspensão no estuário do rio Araranguá por Manique et al. (2011). Os autores observaram que com a diminuição da descarga fluvial, o efeito da circulação gravitacional passou a ser mais notável, resultando na exportação pela camada superficial e importação na camada de fundo. Nessa condição, o estuário passa de exportador para importador de sedimento em suspensão (Manique et al., 2011).

D’Aquino et al. (2010) sugere que a exportação de sedimentos finos para a plataforma ocorre através de pulsos de descarga fluvial. Sendo que os autores comparam o regime de transporte de sedimento finos do estuário do Araranguá com o transporte no estuário do rio Itajaí-Açu, o qual possui dois modos principais de transporte: um marinho e um fluvial. O modo fluvial opera quando a descarga fluvial é acima da média ocorrendo a exportação de grande quantidade de sedimento. $\mathrm{O}$ modo marinho ocorre em períodos de baixa descarga fluvial e a hidrodinâmica é controlada parcialmente pelas marés. Nesse acaso, a carga em suspensão de origem fluvial é reduzida e grande parte do material fica retido no estuário. 
Em uma campanha realizada em 2008 por Barreto \& Schettini (2014), foi possível observar o ajuste da hidrodinâmica do estuário do rio Araranguá em diferentes condições de pulsos de descarga fluvial. Em seus resultados, durante um período de baixa descarga, a hidrodinâmica é regida pelo ajuste baroclínico, com camada superior dominada pelo processo advectivo e a camada do fundo semi-estática com baixa velocidade para montante. Durante pulsos fortes de descarga a hidrodinâmica passa a ser controlada pelo regime barotrópico fluvial.

Os sedimentos de fundo ao longo do estuário são arenosos próximo à desembocadura e lamosos na porção mais a montante. Não há medições de concentração de material particulado em suspensão (MPS), contudo observações empíricas mostram que a concentração de MPS no rio Itoupava é muito maior que a do Mãe Luzia. A deriva litorânea é de sudoeste para noroeste, com migração da foz do estuário do rio Araranguá para o norte (Siegle \& Asp, 2007). Na barra do estuário, junto ao Morro dos Conventos, a feição morfológica presente são ilhas barreiras, características do trecho sul catarinense (Krebs, 2004). 


\section{Capítulo 3}

\section{Materiais e Métodos}

De forma a cumprir os objetivos propostos, o projeto teve como plano utilizar: (A) resultados de experimentos realizados em laboratório (Couceiro \& Schettini, 2010), (B) dados hidrológicos coletados em campo (Barreto \& Schettini, 2014), (C) resultados de um modelo numérico hidrodinâmico (Delft3D), e (D) de um modelo de trajetória da partícula, para compreender a complexidade dos processos dinâmicos e o transporte de sedimentos finos em um estuário altamente estratificado, dominado pela descarga fluvial e com $\mathrm{pH}$ baixo.

A metodologia de desenvolvimento desse trabalho é dividida em três partes principais. A primeira parte (Parte 1) trata dos procedimentos utilizados para calibrar e validar um modelo hidrodinâmico tridimensional com dados de variação do nível, velocidade de correntes e salinidade, coletados no campo. Desta forma, os dados obtidos em campo foram utilizados para calibrar e validar o modelo.

A segunda parte (Parte 2) consiste na aplicação do modelo hidrodinâmico, previamente calibrado (Parte 1), para compreender como os pulsos de descarga fluvial influenciam na hidrodinâmica e na distribuição da salinidade. Isso porque o estuário do rio Araranguá é classificado como altamente estratificado e dominado pelo rio (D’Aquino et al., 2010). Eventos, de curta duração, de elevação da descarga fluvial são esporádicos e característicos da bacia de drenagem do rio Araranguá.

A terceira parte (Parte 3) consiste na aplicação de um modelo da trajetória de partículas, para compreender a dinâmica do material floculado no estuário. O modelo de trajetória de partículas foi desenvolvido por meio de programação no Matlab® (MathWorks, Inc.). O modelo simula a trajetória das partículas a partir dos resultados do modelo hidrodinâmico e das velocidades de decantação obtidas pelos experimentos de laboratório. A partícula aqui refere-se ao material floculado ou não, que foi 
observado nos experimentos de laboratório, com o tanque anular. Os resultados dos experimentos do tanque são utilizados para estimar a velocidade de decantação das partículas. Definido o campo de velocidade, salinidade e a velocidade de decantação da partícula, é possível definir a trajetória da partícula no estuário.

\subsection{Calibração e validação do modelo numérico}

A calibração e validação do modelo são processos necessários para considerar o modelo uma ferramenta de estudo confiável. Uma vez calibrado e validado, o modelo pode ser utilizados com propósitos mais relevantes para o estudo de processos e fenômenos que ocorrem na natureza. Nesse estudo, tanto o processo de calibração quando o de validação consiste na comparação entre dados observados e dados modelados. A calibração é o ajuste de alguns parâmetros do modelo até que a diferença entre os dados observados e modelados esteja dentro de uma variação aceitável, comparados através de parâmetros estatísticos. Os ajustes, normalmente, consistem na variação de parâmetros como a rugosidade do fundo e os coeficientes de viscosidade e difusividade horizontal (2D) e vertical (3D). Na validação, o modelo ajustado passa por um teste com um conjunto de dados, diferente do conjunto de dados utilizados na calibração, para verificar a capacidade do modelo em reproduzir tais fenômenos.

Como na literatura não existe um procedimento padrão para calibrar e validar modelos (Cheng et al., 1991), normalmente, são realizadas comparações qualitativas entre séries temporais de curta duração do nível da água ou das velocidades de correntes, produzidas pelo modelo numérico com os dados medidos, na mesma localização e no mesmo período de tempo (Cheng et al., 1993). Uma análise quantitativa do erro também faz parte do método de calibração. Cheng et al. (1993) recomenda que o modelo seja calibrado inicialmente pelo nível da água e pelas correntes. 


\subsubsection{Dados para calibração e validação do modelo}

\section{Batimetria}

A batimetria do sistema estuarino do rio Araranguá foi realizada em duas campanhas de coleta. A primeira em maio de 2006 e a segunda em junho de 2014. Em 2006, o levantamento batimétrico compreendeu de boa parte do canal do estuário do rio Araranguá, desde sua desembocadura até aproximadamente $27 \mathrm{~km}$ a montante. Os dados batimétricos foram registrados com uma ecossonda da marca Furuno modelo L4100 e a posição geográfica com um receptor GPS da marca Garmin, modelo XL12. As medições foram reduzidas com base nos registros de variação do nível da água registrado por um perfilador acústico de correntes por efeito Doppler (PACD), fundeado a cerca de $7,5 \mathrm{~km}$ da desembocadura.

Em 2014, de forma a complementar o levantamento realizado anteriormente (2006), foi realizado um novo levantamento. Este abrangeu o trecho final do levantamento de 2006 até a confluência dos rios Itoupava e Mãe Luzia, cerca de 6 km a montante, e rio acima, cerca de $8 \mathrm{~km}$ e $6 \mathrm{~km}$ a partir da confluência, nos rios Itoupava e Mãe Luzia, respectivamente. Detalhando melhor, as regiões da confluência dos rios, Itoupava e Mãe Luzia, como também parte da extensão dos principais tributários. No segundo levantamento foi utilizada uma sonda da Garmin, modelo GPSMAP 526s. As medições foram corrigidas com base nos registros de variação do nível da água medidos pela leitura de uma régua fixa na margem do estuário, na proximidade do ponto inicial dos registros. A leitura da régua foi realizada no intervalo de meia hora entre o início e o término dos levantamentos. Os percursos realizados nos dois levantamentos estão representados na Figura 3.1. Adicionalmente, para a parte da plataforma continental, foram extraídas informações da batimetria da região costeira adjacente com base de dados do ETOPO (Global Gridded Elevations Data) obtidas em http://www.ngdc.noaa.gov/mgg/global/global.html. 


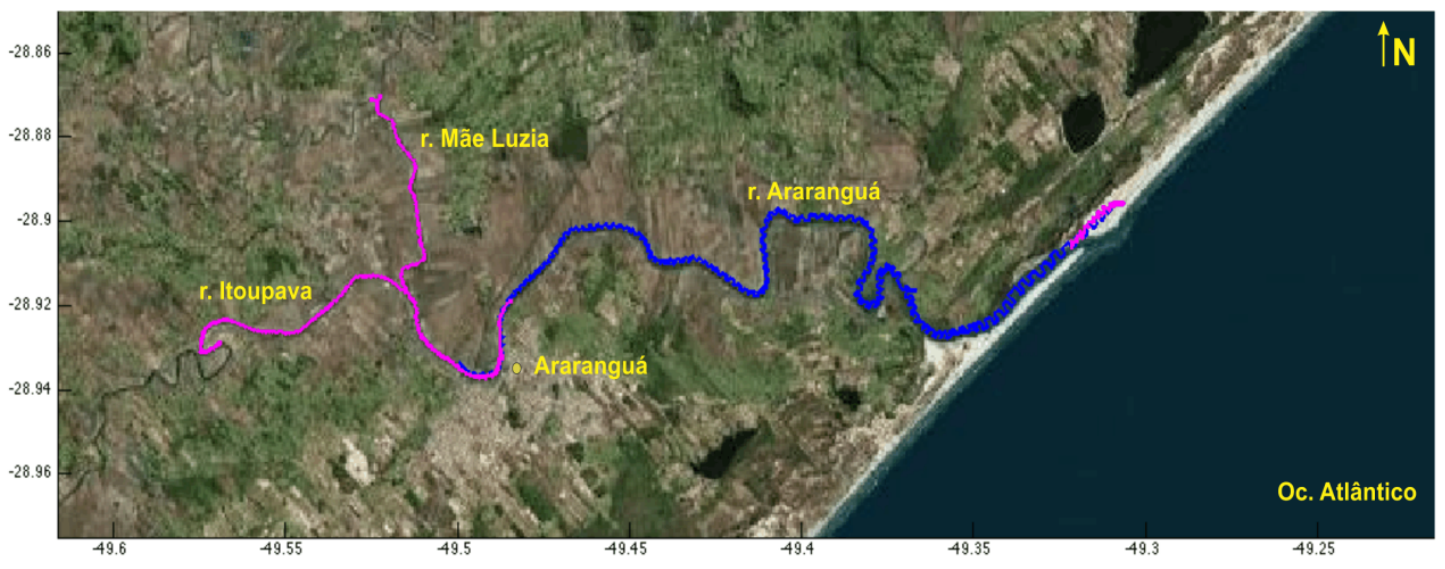

Figura 3.1. Imagem do Google com a representação dos percursos realizados durante os levantamentos batimétricos para o ano de 2006 (azul) e 2014 (rosa).

\section{Dados hidrológicos}

Séries temporais de variação do nível da água, velocidade das correntes e salinidade foram utilizadas no procedimento de calibração e validação do modelo numérico. As séries de dados foram coletadas em uma campanha oceanográfica realizada entre os meses de junho e setembro de 2008 no estuário do rio Araranguá, Santa Catarina. Durante esse período, os dados foram registrados em duas estações sinóticas ao longo do canal do estuário do rio Araranguá. Uma, a cerca de 7,5 km de distância da desembocadura (\#1) e a segunda, a cerca de $31 \mathrm{~km}$ de distância da desembocadura (\#2), conforme ilustrado na Figura 3.2. Na estação \#1, foi fundeado um perfilador acústico de correntes por efeito Doppler (PACD) da marca Nortek, modelo Aquadopp Profiler de $1000 \mathrm{kHz}$. Na estação \#2, foi fundeado um PACD da marca Sontek, modelo Argonaut de $1500 \mathrm{kHz}$. Juntamente com os PACD's, foram instalados registradores de condutividade e temperatura da marca JFE-Alec, modelo Compact-CT. Nos dias 10 de junho, 01 de agosto e 30 de setembro, foram realizados perfilagens longitudinais com um CTD desde a desembocadura até a confluência dos rios Itoupava e Mãe Luzia.

Os dados foram coletados através do projeto "Processos de transporte e retenção de sedimentos finos em estuários dominados por rios - TRANSEST" (CNPq: 306217/2007-4), coordenado pelo Prof. Dr. Carlos A.F. Schettini. 

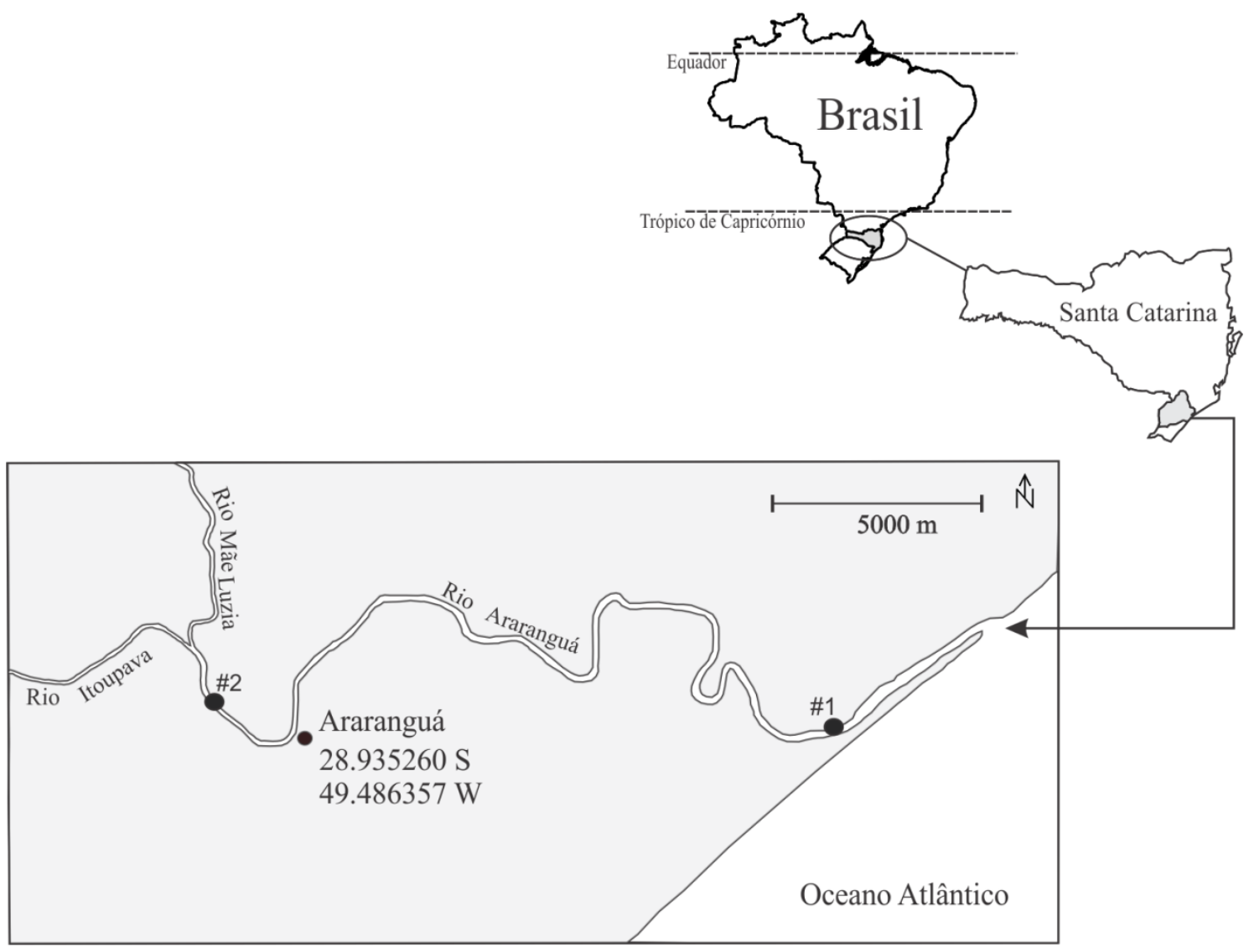

Figura 3.2. Localização da área de estudo com a indicação das estações de coleta de dados \#1 ( $7 \mathrm{~km}$ da desembocadura) e \#2 ( $31 \mathrm{~km}$ da desembocadura).

\subsubsection{Modelo numérico}

O modelo numérico hidrodinâmico utilizado no estuário do rio Araranguá foi o Delft3D, desenvolvido pela Deltares (Delft, Holanda). O Delft3D simula os processos hidrodinâmicos resolvendo as equações de Navier-Stokes integradas verticalmente na coluna da água, incluindo os efeitos de Coriolis, fricção do vento, atrito com o fundo e viscosidade turbulenta. O método numérico é baseado em diferenças finitas e as discretizações são resolvidas em grades curvilíneas ou retilíneas do tipo Arakawa "C". O Delft3D-FLOW é o módulo hidrodinâmico do programa, no qual um sistema de equações de águas rasas são resolvidas em modo bidimensional e tridimensional. Pode ser utilizado em estudos de mares rasos, áreas costeiras, estuários, rios, lagos e lagoas. Mais informações sobre o módulo hidrodinâmico e formulações hidrodinâmicas utilizadas pelo modelo são apresentadas no Anexo I. 


\section{Configuração do modelo numérico}

\section{Grade numérica}

A modelagem hidrodinâmica pode ser realizada em diferentes tipos de grades numéricas. Em geral, são consideradas grades com eixos x e y, nas direções Leste-Oeste e Norte-Sul. No Delft, a construção da grade numérica é feita no módulo Delft3DRGFGRID. Para representar melhor o estuário do rio Araranguá, foi utilizada uma grade curvilínea ortogonal, que permite definir áreas do domínio com maior resolução, na região de interesse e áreas com menor resolução. Além de representar as feições em forma de meandros do estuário. Desta forma, o número de células reduz, assim com o tempo de computação simulações. O domínio do modelo (Fig. 3.3), representado pela grade numérica, inclui o estuário do rio Araranguá, parte da extensão dos rios Itoupava $(\sim 8 \mathrm{~km})$ e Mãe Luzia $(\sim 6 \mathrm{~km})$ e uma área da região costeira adjacente $\left(\sim 560 \mathrm{~km}^{2}\right)$. O domínio horizontal é representado por 119 células na direção M (longitudinais) e 646 células na direção $\mathrm{N}$ (transversais). O tamanho das células da grade na região dos canais estuarinos variam entre 20 e 200 m, e na região costeira entre 50 e $1200 \mathrm{~m}$. 


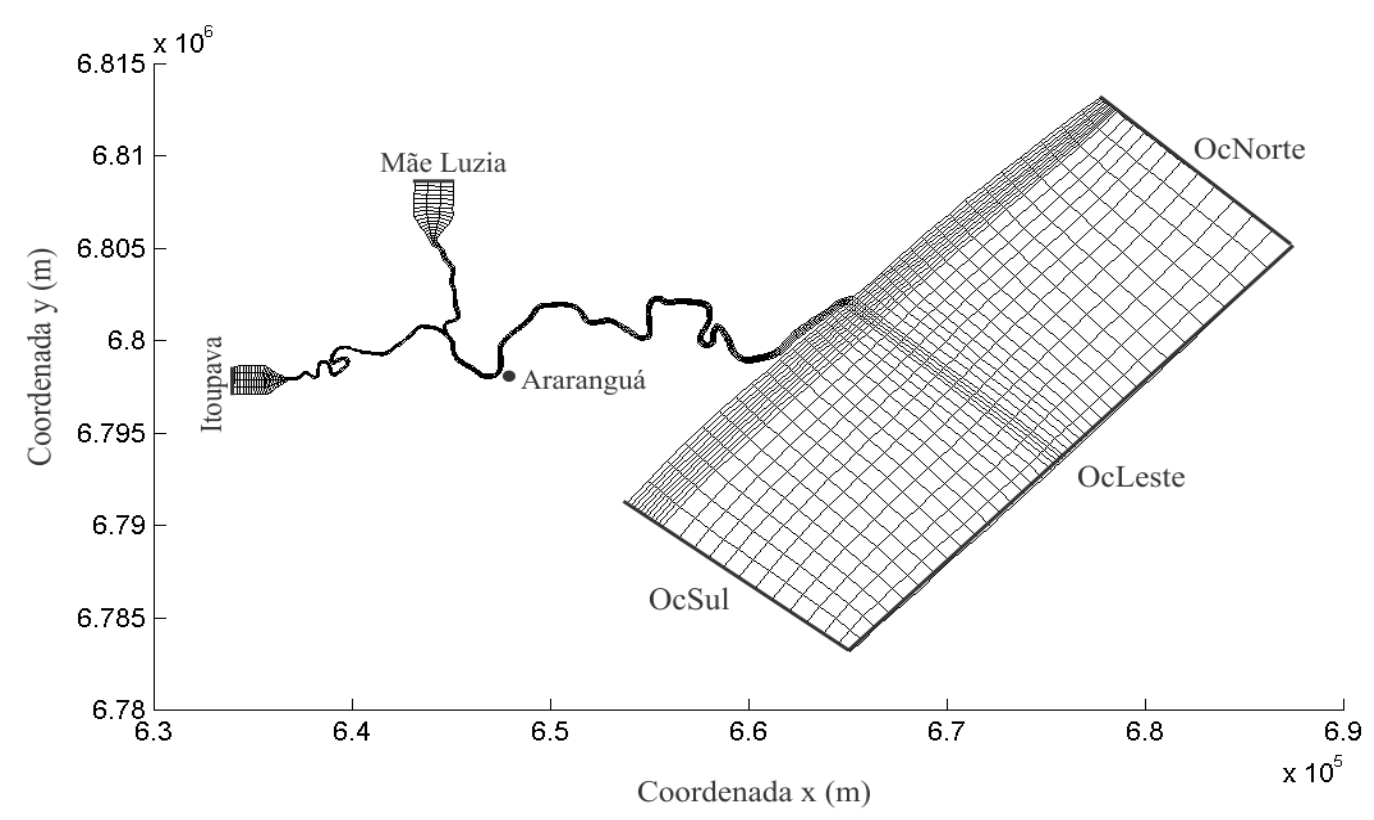

Figura 3.3. Domínio do modelo, com a representação da grade numérica e contornos abertos.

No Delft, o domínio computacional vertical pode ser estruturado de acordo com dois sistemas: coordenada-Z e coordenada- $\sigma$ (Fig. 3.4). A coordenada-Z possui linhas paralelas na horizontal, as quais representam bem a região das isopicnais. Já o fundo, não é representado por uma linha e sim por linhas que formam degraus. Isso pode implicar em uma imprecisão na aproximação da tensão de fundo e advecção horizontal na região mais próxima do fundo. As linhas da coordenada- $\sigma$ são quase horizontais. A primeira e última linha seguem a superfície e o fundo, respectivamente, sendo que a distribuição entre as linhas pode ser definida pelo usuário. As linhas seguem a topografia do fundo e a superfície, mas geralmente, não seguem a isopicnal. A coordenada-Z é indicada para estudos de ambientes estratificados e com variações abruptas da topografia do fundo, pois reduz a mistura artificial das propriedades escalares como a temperatura e a salinidade (Deltares, 2011). 


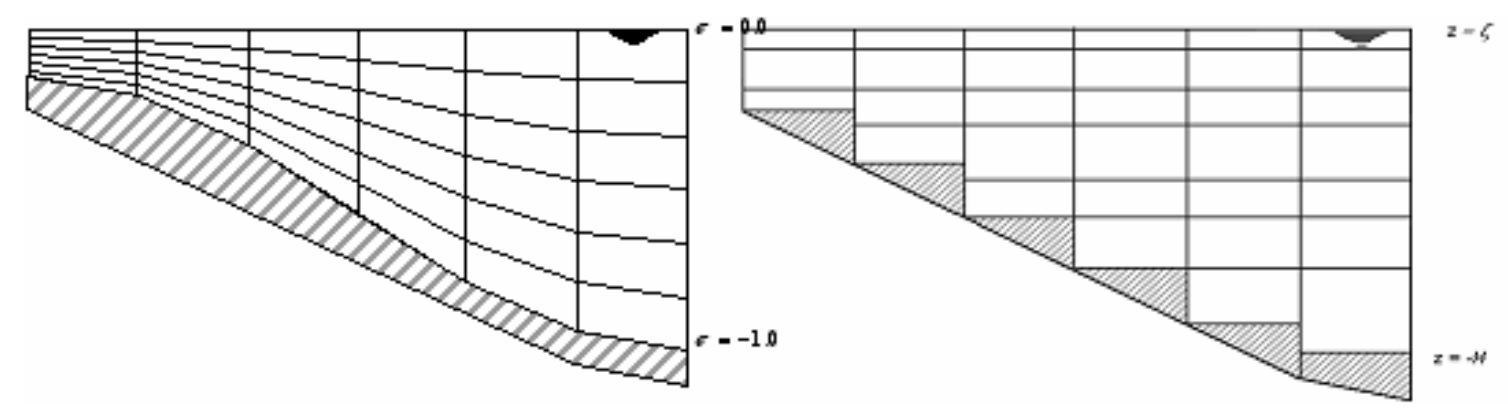

Figura 3.4. Exemplos das grades verticais sigma (esquerda) e Z (direita).

\section{Condições de contorno}

O domínio do modelo possui cinco contornos, sendo três externos e dois internos. Os contornos externos representam a região costeira adjacente, nomeados de OcSul, OcLeste e OcNorte, e dois nos limites a montante dos rios (Fig. 3.3). Os contornos internos representam os rios Itoupava e Mãe Luzia, os quais são representados por uma "caixa", em suas extremidades, buscando representar o volume do estuário. As caixas foram criadas para equalizar o prisma de maré durante a simulação. Os contornos, além de delimitarem o domínio do modelo, representam os limites onde as forçantes do sistema são impostas. No caso, a variação da maré na região costeira e a descarga fluvial nos limites dos rios. Com o domínio definido e os dados batimétricos conhecidos, foi possível gerar a batimetria para todo o domínio através da interpolação triangular. Esta é considerada a interpolação mais adequada para conjuntos de dados que possuem uma resolução próxima da resolução da grade. A interpolação foi realizada no módulo Delft3D-QUICKIN. A representação gráfica da batimetria do domínio está no Anexo II.

\section{Pré-configuração do modelo}

Nos procedimentos de calibração, o modelo foi forçado pela descarga fluvial, nível da água e salinidade. As condições de contorno nos limites dos rios foram impostas pela descarga fluvial, valor da média diária, correspondente ao período das 
medições em campo, e salinidade zero. Os dados de descarga fluvial foram obtidos pelo site da Agência Nacional de Águas (ANA) em http://hidroweb.ana.gov.br. No modelo, os valores de descarga fluvial entraram como dados de velocidade média na coluna da água. A velocidade $\left(\mathrm{m} \cdot \mathrm{s}^{-1}\right)$ foi igualada a divisão da descarga fluvial $\left(\mathrm{m}^{3} \cdot \mathrm{s}^{-1}\right)$ pela área da seção transversal $\left(\mathrm{m}^{2}\right)$ dos rios na proximidade das "caixas". Nos três contornos externos, da região costeira, a variação horária do nível da água foi imposta pela série temporal de variação do nível registrado pelo equipamento (PACD) fundeado na estação \#1, mais próxima da desembocadura, e salinidade de 31. Este valor de salinidade, 31, corresponde ao valor de salinidade observado na região da desembocadura do estuário do rio Araranguá. As condições de contorno entre a superfície livre da água e o ar, foi considerada nula, sem a tensão de cisalhamento do vento. Como o estuário é estreito e meandrante, o efeito do vento na circulação e distribuição da salinidade é pequeno.

Os parâmetros físicos constantes para todo o domínio foram: a gravidade, 9,81 $\mathrm{m} . \mathrm{s}^{-2}$, a densidade da água, $1.024 \mathrm{~kg} \cdot \mathrm{m}^{-3}$ e a temperatura, $18^{\circ} \mathrm{C}$. Nas condições de contorno do fundo, o valor do coeficiente de rugosidade foi definido, em ambas as direções (x e y), para a formulação de Chézy. As tensões tangenciais das bordas laterais não foram consideradas. Os valores aplicados para a viscosidade e difusividade (horizontal e vertical) foram definidos na calibração do modelo. O coeficiente de rugosidade do fundo juntamente com a viscosidade e a difusividade horizontal e vertical são os principais fatores na calibração do modelo, os valores utilizados são descritos da seção 3.1.3 (Calibração).

O modelo de fechamento turbulento vertical utilizado em todas as simulações foi o K-Epsilon. Esse modelo calcula apenas dois parâmetros físicos, o componente vertical de viscosidade, responsável pela difusão vertical de momentum, e a difusividade vertical, responsável pela difusão vertical de uma concentração. Esse modelo de fechamento turbulento é o recomendado para estudos de modelagem em ambientes estratificados (Deltares, 2011).

O tamanho das células da grade e o passo de tempo determinam a estabilidade e precisão do modelo. Essas dimensões, de espaço e tempo, seguem uma determinada condição de estabilidade, que no Delft3D depende do número de Courant. O número de 
Courant é uma relação entre a velocidade de propagação, o passo de tempo e o tamanho da célula da grade:

$c=\frac{\Delta \mathrm{t} \sqrt{\mathrm{gh}}}{\Delta \mathrm{x}}$

onde $c$ é a celeridade, $\Delta t$ o passo de tempo (em segundos), $\Delta x$ o espaçamento da célula em $x, g$ a aceleração gravitacional e $h$ a profundidade da coluna da água. O espaçamento em $x$ deve ser o mínimo de toda grade. Geralmente, o número de Courant não deve exceder o valor de 10, mas devido a problemas com pequenas variações no espaço e tempo, o número de Courant pode ser substancialmente maior (Deltares, 2011). O passo de tempo utilizado em todas as simulações foi de 12 segundos, resultando em um número de Courant de 6,5.

\subsubsection{Calibração}

A calibração consistiu no processo de ajuste do modelo com o objetivo de melhor reproduzir os dados observados. O processo teve como base a comparação entre os dados medidos em campo e os dados de saída do modelo, para o mesmo período e os mesmos pontos de coleta. As séries temporais observadas utilizadas na calibração correspondem ao período entre os dias 10 de junho e 09 de julho de 2008, abrangendo as marés de sizígia e quadratura. Durante esse período, ocorreu um evento de pico de descarga fluvial de aproximadamente $125 \mathrm{~m}^{3} . \mathrm{s}^{-1}$. As variáveis utilizadas na comparação foram a variação do nível da água, a velocidade das correntes e a salinidade de fundo, coletadas em duas estações (\#1 e \#2) ao longo do estuário (Fig. 3.2).

Com o objetivo de quantificar a concordância entre os resultados observados e modelados na calibração e na validação, foram calculados, para cada variável, o erro médio absoluto (EMA) (Equação 3.2), a raiz do erro quadrático médio (REQM) (Equação 3.3) e método sugerido por Willmott (1981), baseado no parâmetro de Skill definido por Warner et al. (2005) (Equação 3.4). 
$\mathrm{EAM}=\frac{\sum_{\mathrm{l}=1}^{\mathrm{n}}\left|\mathrm{X}_{\text {modelo }}-\mathrm{X}_{\mathrm{obs}}\right|}{\mathrm{N}}$

$\mathrm{REQM}=\sqrt{\frac{\sum_{\mathrm{l}=1}^{\mathrm{n}}\left|\mathrm{X}_{\text {modelo }}-\mathrm{X}_{\mathrm{obs}}\right|^{2}}{\mathrm{~N}}}$

Skill $=1-\frac{\sum\left|\mathrm{X}_{\text {modelo }}-\mathrm{X}_{\text {obs }}\right|^{2}}{\sum\left(\left|\mathrm{X}_{\text {modelo }}-\overline{\mathrm{X}}_{\mathrm{obs}}\right|+\left|\mathrm{X}_{\mathrm{obs}}-\overline{\mathrm{X}}_{\mathrm{obs}}\right|\right)^{2}}$

onde $X$ é a variável de interesse e $\overline{\mathrm{X}}$ a média temporal. $N$ é o número total de dados. $\mathrm{O}$ parâmetro de Skill varia no intervalo entre zero (0) e um (1), indicando total discordância ou completa concordância, respectivamente, entre os resultados do modelo e as observações de campo. Como referência, Allen et al. (2007) classificou os valores de Skill $>$ 0,65 como excelente, 0,5-0,65 como muito bom, 0,2-0,5 como bom e $<0,2$ como pobre.

Por se tratar de um estuário estratificado, algumas etapas foram necessárias para que o modelo pudesse ser ajustado de forma a reproduzir, consistentemente, a estratificação da salinidade. O esquema apresentado na Figura 3.5 descreve a sequência e o objetivo de cada etapa do processo de calibração. 
$A$ - Modelo 2D

$B$ - Domínio vertical

$C$ - Aquecimento do campo de salinidade

D - Modelo 3D
Objetivo: calibrar o modelo hidrodinâmico bidimensional (2D).

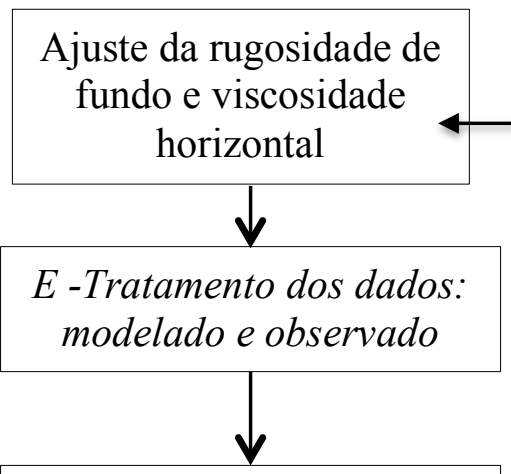

Comparação quantitativa: Parâmetro de SKILL

Simulações teste do modelo 3D com coordenada sigma e

$\mathrm{Z}$. tipo de coordenada vertical, sigma ou $\mathrm{Z}$.
Ajuste do número de camadas $\mathrm{Z}$.
Objetivo: preparar a condição inicial do campo de salinidade para as simulações de calibração da salinidade
Objetivo: calibrar o modelo 3D para o nível, as corrente e a salinidade de fundo

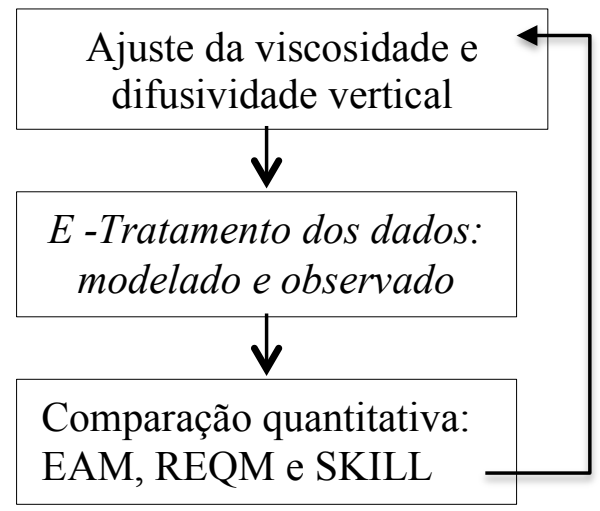

Figura 3.5. Esquema das etapas do processo de calibração do modelo bidimensional e tridimensional. 
A - Modelo 2D: Primeiramente, foi utilizado o modelo hidrodinâmico bidimensional (2D) com o objetivo de calibrar o modelo, utilizando os dados de variação do nível da água e velocidade de correntes para o período observado. A configuração do modelo segue como descrito na seção 3.1.2 (Configuração do modelo numérico). Os principais parâmetros utilizados na calibração são os coeficientes de rugosidade de fundo (número de Chézy $\left.-\mathrm{m}^{1 / 2} \cdot \mathrm{s}^{-1}\right)$ e de viscosidade horizontal $\left(\mathrm{m}^{2} \cdot \mathrm{s}^{-1}\right)$. Diferentes combinações dos coeficientes de rugosidade do fundo e viscosidade horizontal foram utilizadas. Cada coeficiente foi ajustado separadamente, enquanto o coeficiente de rugosidade do fundo era testado, o coeficiente de viscosidade permanecia constante e vice-versa, até alcançar a melhor concordância entre os dados observados e modelados. A concordância entre o observado e o modelado foi quantificada através do parâmetro estatístico de Skill (Equação 3.4) nas duas estações (\#1 e \#2).

Um teste de sensibilidade foi realizado para avaliar a concordância, através do parâmetro de Skill, entre os dados de velocidade de correntes observados e modelados com diferentes valores de Chézy. O teste de sensibilidade (Fig. 3.6.) mostra que com os valores de Chézy de 38 e 36 a concordância foi melhor quantificada nas estações \#1 e \#2, respectivamente. Os valores de Skill correspondente foram de 0,75 (\#1) e 0,78 (\#2). Com esses valores de Chézy (38 e 36), em ambas as estações, a concordância entre os resultados do modelo e os dados observado para o nível da água foi de 0,99 . Como na estação \#1 a diferença entre os valores de Skill com valores de Chézy de 36 e 38 é pequena, ficou definido para todo o domínio e de forma uniforme, o valor de Chézy de 38. Na calibração, a variação do coeficiente de viscosidade não alterou de forma significativa as variações do nível da água e das correntes. Os valores de viscosidade horizontal foram definido em $1 \mathrm{~m}^{2} \cdot \mathrm{s}^{-1}$ para toda área do domínio. 

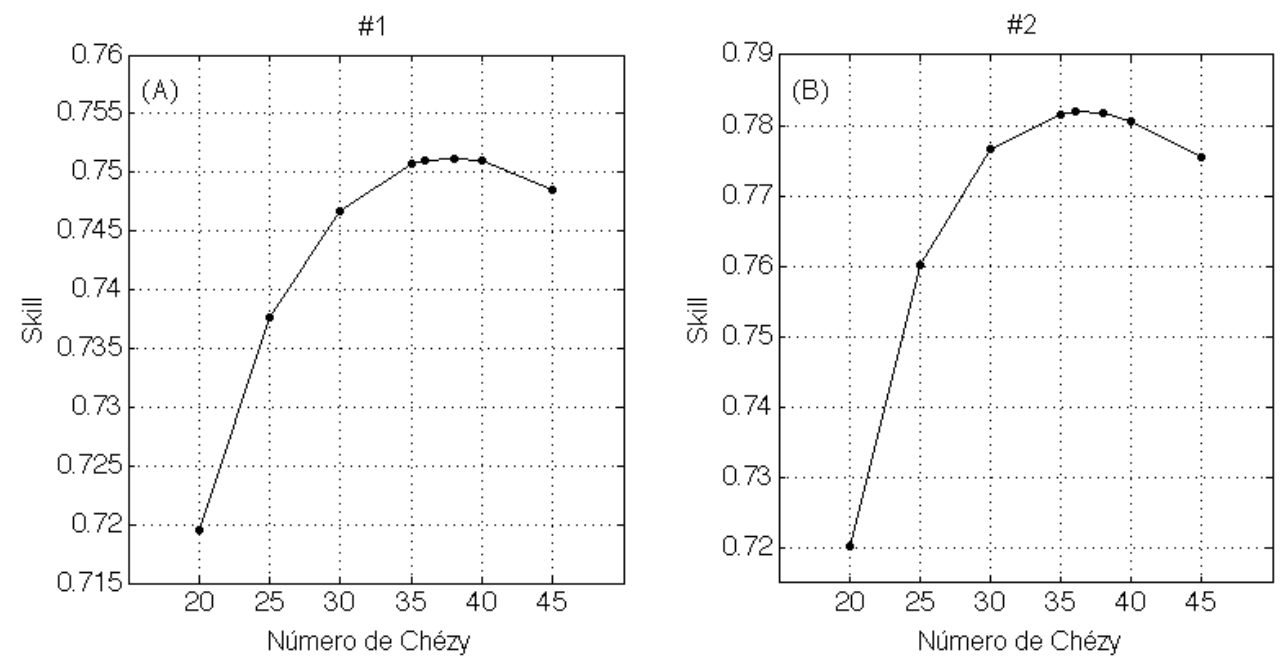

Figura 3.6. Variação da concordância entre os dados de velocidade de correntes observados e modelados com diferentes valores do número de Chézy. Na estação \#1 (esquerda) e na estação \#2 (direita).

B - Domínio vertical: Antes de começar a calibração do modelo tridimensional, uma série de testes foram realizados para determinar a configuração do modelo quanto ao domínio vertical. A configuração do domínio vertical pode ser estruturado de acordo com dois sistemas de coordenadas, $\mathrm{Z}$ e sigma. $\mathrm{O}$ objetivo desses testes foi identificar a configuração vertical da grade que melhor representa a estratificação vertical da salinidade.

Os testes consistiram em simulações simples, com descarga fluvial constante de $20 \mathrm{~m}^{3} \cdot \mathrm{s}^{-1}$ e série de elevação do nível geradas pelas quatro constantes harmônicas principais $\left(\mathrm{M}_{2}, \mathrm{~S}_{2}, \mathrm{O}_{1}\right.$ e $\left.\mathrm{K}_{1}\right)$. Os valores de fase e amplitude componentes da maré astronômica foram extraídas do FES2004 (Global tide - AVISO), para um ponto situado no limite externo do domínio (Tab. 3.1). A salinidade inicial em todo o domínio foi de 31. Com salinidade constante de 31 nos contornos abertos correspondentes a região costeira e 0 nos contornos dos rios. A temperatura da água inicial em todo o domínio foi de $17^{\circ} \mathrm{C}$. A tensão do vento na superfície da água não foi considerada. Nas simulações, o número de camadas variou entre o mínimo de 5 e o máximo de 50.

Quando se utiliza a maré como forçante do modelo é preciso calibrar a intensidade das velocidades das correntes geradas no interior do estuário. A magnitude das velocidades modeladas devem ser próximas das velocidades observadas. Em 
condições de baixa descarga fluvial, as velocidade das correntes medidas em campo foram em torno $0,2 \mathrm{~m}^{2} \cdot \mathrm{s}^{-1}$. Um teste foi realizado para observar as velocidades das correntes nos dois pontos do estuário, estação \#1 e \#2, com as quatro constantes harmônicas principais: $\mathrm{M}_{2}, \mathrm{~S}_{2}, \mathrm{O}_{1}$ e $\mathrm{K}_{1}$ (Tab. 3.1). Somente com os valores da amplitude e fase, sem correções destes valores, e com correções da amplitude das constante. Sem as correções, as velocidades foram maiores que as observadas em campo. E com a correção em 0,4 no valor da amplitude, as velocidades foram reproduzidas de forma mais parecida com os dados observados.

Tabela 3.1. Amplitude e fase das componentes da maré extraídas do FES2004 (Finite Element Solution - AVISO) na posição: $29^{\circ} 05^{\prime}$ 09,085”S e $49^{\circ} 05^{\prime}$ 06,085”.

\begin{tabular}{ccc}
\hline Componente da maré & Amplitude $(\mathrm{cm})$ & Fase (graus) \\
\hline $\mathrm{O}_{1}$ & 0,1115 & 108,3 \\
$\mathrm{~K}_{1}$ & 0,0674 & 179,2 \\
$\mathrm{M}_{2}$ & 0,1188 & 164,5 \\
$\mathrm{~S}_{2}$ & 0,0965 & 150,2 \\
\hline
\end{tabular}

Com o resultado desses testes, foi possível verificar que com as camadas sigma o modelo produz mistura vertical, independente do número de camadas e da resolução entra elas. Em todos os testes com camadas sigma o modelo reproduziu mistura, mesmo utilizando o recurso do modelo que barra a difusão vertical artificial (anti-creep). Isso porque as coordenadas sigma possui uma grande desvantagem em casos de variações abruptas da profundidade. Embora a coordenada sigma seja ajustada ao contorno do fundo (na vertical), não possui resolução suficiente em torno da picnoclina. Já com as camadas Z, o modelo reproduziu estratificação vertical de salinidade.

A configuração do domínio foi definido em coordenadas-Z com 20 camadas na vertical. O número de células na vertical varia ao longo do domínio horizontal de acordo com a profundidade, sendo que os primeiros $4 \mathrm{~m}$ de profundidade são representados por 9 camadas em todo domínio, com espaçamento de 0,5 m entre elas. 
Os resultados desses testes mostraram que o domínio vertical configurado com as coordenas-Z foi eficiente na reprodução da estratificação da salinidade no estuário.

C - Aquecimento do campo de salinidade: Para definir as condições iniciais da distribuição da salinidade, no plano horizontal e vertical do domínio, foi realizada uma pré-simulação. O objetivo da pré-simulação foi alcançar, com o próprio modelo, através de uma simulação, a condição inicial de distribuição da salinidade do primeiro dia da campanha, que é o primeiro dia da série temporal utilizada no processo de calibração 3D. Desta forma, a simulação de calibração já começa com informações da distribuição de sal no domínio. A distribuição longitudinal e vertical da salinidade foi registrada no primeiro dia da campanha (2008) com um CTD. Os perfis verticais foram realizados, a cada quilômetro, desde da desembocadura até a confluência dos rios.

Na pré-simulação, o modelo partiu de condições iniciais constantes em todo domínio para: os valores de salinidade (31), velocidade $\left(0 \mathrm{~m} . \mathrm{s}^{-1}\right)$ e variação da superfície livre $(0 \mathrm{~m})$. O modelo foi forçado pela descarga fluvial (contornos dos rios) e pela maré (contornos costeiros). A descarga fluvial foi constate e equivalente ao valor médio diário de $18 \mathrm{~m}^{3} . \mathrm{s}^{-1}$, correspondente ao dia 10 de junho de 2008 , primeiro da campanha de campo. E a maré, pelas quatro constantes harmônicas principais $\left(\mathrm{M}_{2}, \mathrm{~S}_{2}\right.$, $\mathrm{O}_{1}$ e $\mathrm{K}_{1}$ ), já ajustadas pela correção das amplitudes.

Para alcançar, de forma aproximada, a condição de distribuição da salinidade observada, foram escolhidos cinco pontos de monitoramento dos perfis verticais de salinidade ao longo do estuário, desde a desembocadura até a região da confluência dos rios Itoupava e Mãe Luzia. Os pontos de extração do perfil vertical de sal no domínio do modelo possuem, aproximadamente, a mesma posição dos pontos perfilados com CTD, no dia 10 de junho de 2008. Dos perfis verticais, observados e modelados, foram calculados os parâmetros de estratificação (diferença entre a salinidade do fundo e da superfície). E a cada dez minutos de simulação, o parâmetro de estratificação foi calculado e comparado com o observado nos cinco pontos. No instante em que os valores coincidiram de forma aproximada, a simulação foi interrompida. Além do parâmetro de estratificação, foram comparados os dados de salinidade do fundo e da superfície para cada ponto. Dessa forma, foi possível verificar que após 17 dias de simulação, nas condições descritas acima, a distribuição da salinidade alcançou uma boa 
aproximação em relação aos dados medidos (Fig. 3.7). O perfil do fundo modelado não é exatamente o mesmo do observado, pois os pontos escolhido do modelo não são os mesmos pontos dos perfis observados.
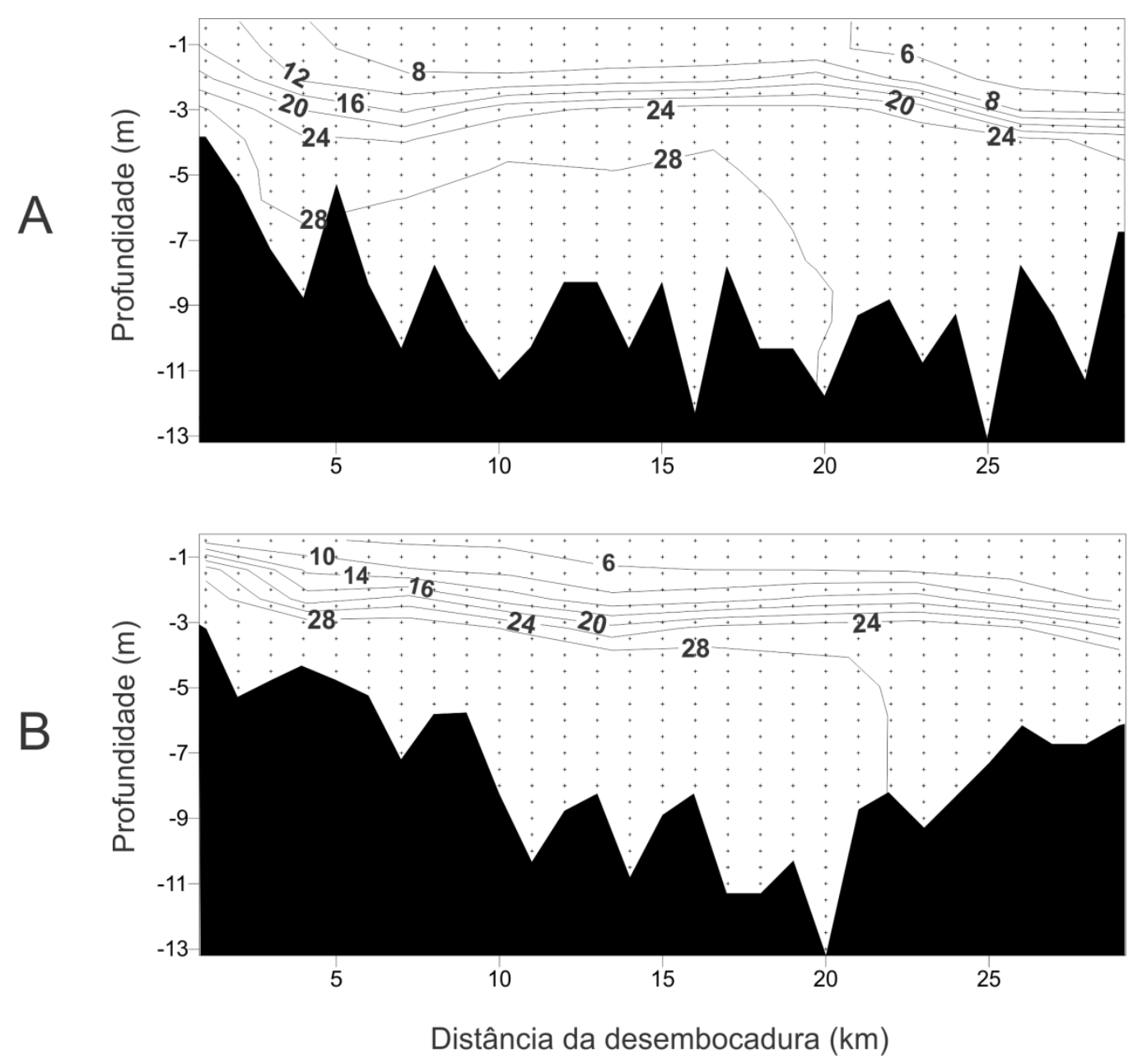

Figura 3.7. Comparação da distribuição longitudinal da salinidade no primeiro dia de simulação para os perfis observados (A) e modelados (B).

D - Modelo 3D: Na modelagem tridimensional, mais parâmetros devem ser ajustados para calibrar o modelo. Além do coeficiente de rugosidade do fundo e do coeficiente de viscosidade horizontal, entram no processo os coeficientes de difusividade horizontal, viscosidade vertical, difusividade vertical e o modelo de fechamento da turbulência. $\mathrm{O}$ modelo de fechamento de turbulência utilizado foi o k-Epsilon, recomendado para fluxos estratificados (Deltares, 2011). Esse modelo de fechamento da turbulência utiliza os coeficientes verticais de viscosidade e difusividade na equação de transporte. 
Como nessa etapa o objetivo é calibrar o modelo tridimensional, o procedimento realizado assemelha-se com o processo da primeira etapa (A - Modelo 2D). Em adição aos dados de nível da água e velocidade das correntes, a salinidade também foi comparada com os dados observados. Os perfis longitudinais de salinidade realizados nos dias 10 de junho, 01 de agosto e 30 de setembro, foram utilizados para calibrar o gradiente longitudinal de salinidade no estuário, desde a desembocadura até a confluência dos rios. Os perfis do modelo foram extraídos de uma simulação que compreendeu todo o período em que os equipamentos ficaram fundeados, desde 10 de junho a 30 de setembro. Nessa simulação, o modelo foi forçado pela descarga fluvial e variação do nível da água, e a configuração, definida de acordo com o resultado das etapas anteriores da calibração.

A calibração do modelo tridimensional consistiu no ajuste dos coeficientes verticais de viscosidade e difusividade. Em fluxos fortemente estratificados, os valores de viscosidade vertical devem ser suficientes para conter pequenas oscilações geradas pelas forçantes dos contornos, principalmente em condições de elevada descarga fluvial. Nas simulações, os valores dos coeficientes verticais variaram entre $10^{-2}$ e $10^{-7} \mathrm{~m}^{2} \cdot \mathrm{s}^{-1}$. Com valores menores dos coeficientes verticais de viscosidade e difusividade, mais estratificado permanecia o fluxo. As variações desses parâmetros não alteraram a magnitude das correntes. A configuração final do modelo ficou definida de acordo com a Tabela 3.2. A validação e as demais simulações realizadas com o modelo foram definidas segundo os valores apresentados na nesta tabela. 
Tabela 3.2. Parâmetros do modelo definidos pelo processo de calibração do modelo tridimensional.

\begin{tabular}{lc}
\hline Parâmetro & Valor \\
\hline Passo de tempo & $12 \mathrm{~s}$ \\
Número de camadas-Z verticais & 20 \\
Viscosidade horizontal & $1,0 \mathrm{~m}^{2} \cdot \mathrm{s}^{-1}$ \\
Difusividade horizontal & $1,0 \mathrm{~m}^{2} \cdot \mathrm{s}^{-1}$ \\
Viscosidade vertical & $1,0 \times 10^{-7} \mathrm{~m}^{2} \cdot \mathrm{s}^{-1}$ \\
Difusividade vertical & $1,0 \times 10^{-7} \mathrm{~m}^{2} \cdot \mathrm{s}^{-1}$ \\
Número de Chézy & $38 \mathrm{~m}^{1 / 2} \mathrm{~s}^{-1}$ \\
Modelo de fechamento de turbulência & $\mathrm{K}-E p s i l o n$ \\
\hline
\end{tabular}

E - Tratamento dos dados observados e modelados: Tanto os dados de velocidade de correntes observados na campanha oceanográfica quanto os dados de saída do modelo foram tratados antes da comparação quantitativa. Os dados das componentes da velocidade, observada e modelada, foram convertidos de sistema cartesiano (norte-sul, leste-oeste) para sistema polar. A velocidade absoluta foi obtida por:

$$
\mathrm{V}_{\mathrm{a}}=\sqrt{\text { componenteU }^{2}+\text { componenteV }^{2}}
$$

A direção da corrente foi calculada pelo quadrante do vetor velocidade e pelo arco tangente da orientação trigonométrica. Para definir as correntes de vazante (valores positivos) e de enchente (valores negativos), utilizaram-se os dados de direção da velocidade para a construção de um histograma (Fig. 3.8). Na estação \#1, as velocidades de vazante, observadas e modeladas, foram definidas pelo setor do histograma de menor ocorrência, e as velocidades de enchente pelo setor de maior ocorrência. E na estação \#2, as velocidades, observadas e modeladas, foram definidas de forma inversa, sendo que o setor do histograma de maior ocorrência definiu as correntes de vazante e o setor de menor ocorrência as de enchente. A formação dessa relação pode ser explicada pela localização das estações, mais a jusante (\#1) e mais a montante (\#2). 

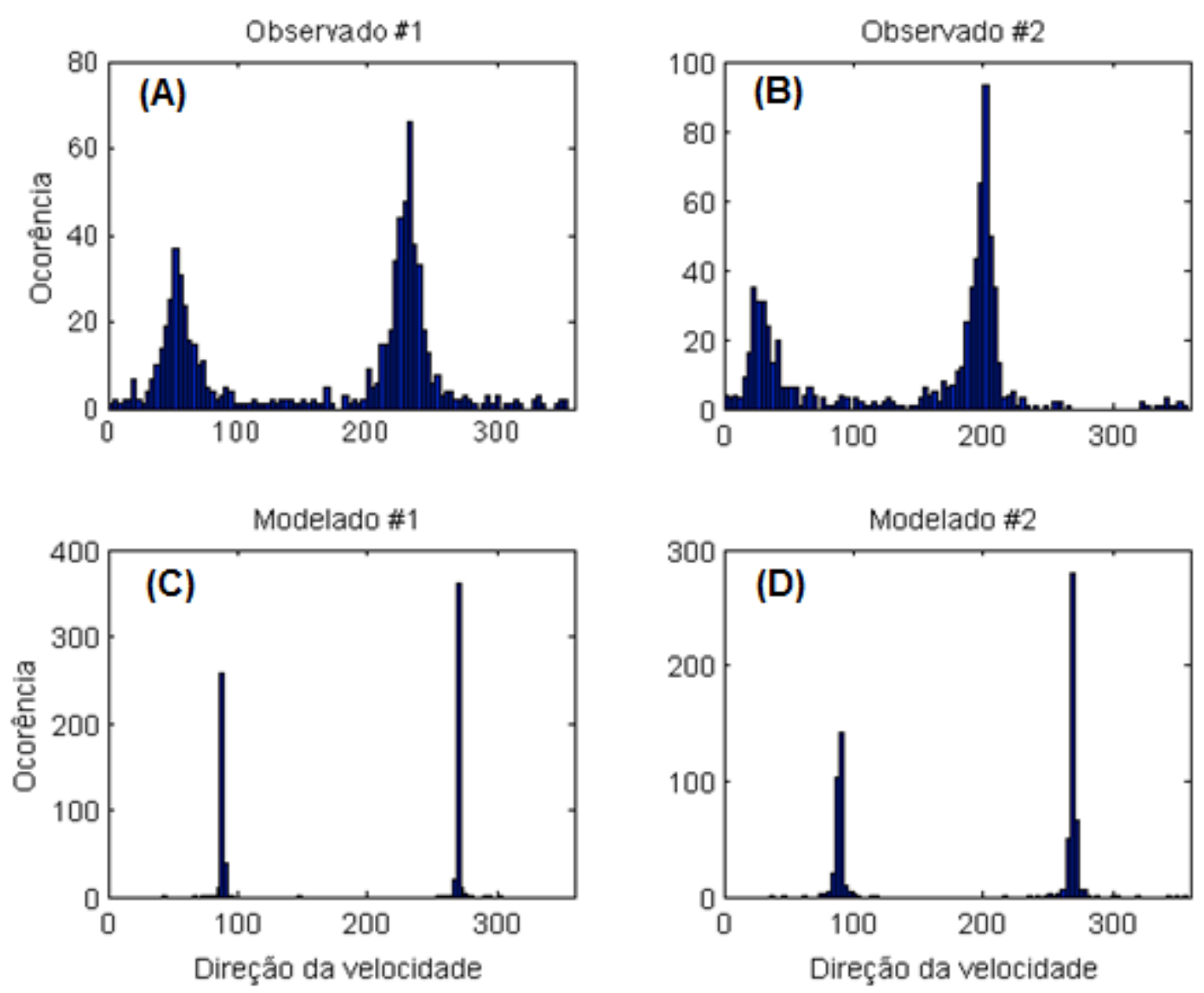

Figura 3.8. Histogramas de ocorrência das direções da velocidade das correntes: (A) observado, \#1; (B) observado, \#2; (C) modelado, \#1 e (D) modelado, \#2.

\subsubsection{Validação}

Para avaliar a qualidade dos resultados do modelo, foi realizada uma nova simulação tridimensional, para um período diferente, utilizando os mesmo parâmetros definidos na calibração. A validação do modelo foi realizada com dados observados durante o mês de agosto de 2008. Todos os parâmetros e coeficientes determinados nas etapas da calibração foram mantidos na validação. Series temporais de dados de descarga fluvial (média diária) e dados horários de nível da água foram inseridas nos contornos do modelo. Como na calibração, os resultados de nível da água, correntes e salinidade do fundo (apenas para estação \#1) do modelo, foram comparados com os dados observados, e avaliados quantitativamente pelas equações de 3.1 a 3.3. 


\subsection{Simulação hidrodinâmica}

O modelo calibrado e validado foi utilizado em simulações com eventos de elevação da descarga fluvial, para investigar as variações na estrutura da salinidade, na circulação e nos mecanismos de transporte de sal no estuário do rio Araranguá. Todos os valores constantes que fazem parte da configuração do modelo foram mantidos nas simulações hidrodinâmicas, sem nenhuma alteração, conforme a Tabela 3.2. A grade numérica e a extensão do domínio também permaneceram inalteradas. O domínio do modelo é limitado nos contornos abertos da região costeira em três segmentos, nomeados de OcNorte, OcLeste e OcSul (Fig. 3.3). Na região interna do domínio, os limites são representados nas “caixas” de cada rio, Itoupava e Mãe Luzia.

A ideia com as simulações é avaliar o que acontece com a hidrodinâmica do estuário durante e após um evento de alta descarga fluvial. Visto que na maior parte do tempo as descargas são baixas e os eventos de alta descarga são esporádicos, associados aos eventos de precipitação na bacia de drenagem. As simulações procederam da seguinte forma: nos dias que precedem o evento de alta descarga, a vazão permaneceu constante em $30 \mathrm{~m}^{3} \cdot \mathrm{s}^{-1}$; o pico ocorre, com duração de dois dias, entre o aumento da descarga e sua diminuição; e após o pico, o modelo continua rodando com descarga de $30 \mathrm{~m}^{3} \cdot \mathrm{s}^{-1}$ por mais 33 dias (Fig. 3.9). A descarga de $30 \mathrm{~m}^{3} \cdot \mathrm{s}^{-1}$ foi escolhida pois representa a condição de descarga que ocorre com maior frequência no estuário do rio Araranguá, entre os anos de 1943 e 2004 . Duas séries de experimentos foram realizadas, uma com os picos ocorrendo em condições de maré de quadratura e outra em condições de maré de sizígia. 
Para os cenários de pulsos de descarga fluvial, foram selecionados os picos de $100,400,700$ e $1000 \mathrm{~m}^{3} \cdot \mathrm{s}^{-1}\left(\mathrm{dQ}=300 \mathrm{~m}^{3} \cdot \mathrm{s}^{-1}\right)$. Esses picos foram escolhidos com base no gráfico de tempo de retorno dos eventos de descarga fluvial para o rio Araranguá (Fig. 3.10). O tempo de retorno de um evento é o intervalo médio de tempo, em anos, que decorre entre duas ocorrências subsequentes de uma vazão maior ou igual. Além das simulações com o pico de descarga, foi realizada uma simulação com descarga fluvial constante de $30 \mathrm{~m}^{3} \cdot \mathrm{s}^{-1}$ para servir de base de comparação, entre os experimentos de picos de descarga, e para avaliar o que acontece em uma condição de baixa descarga por um período prolongado.

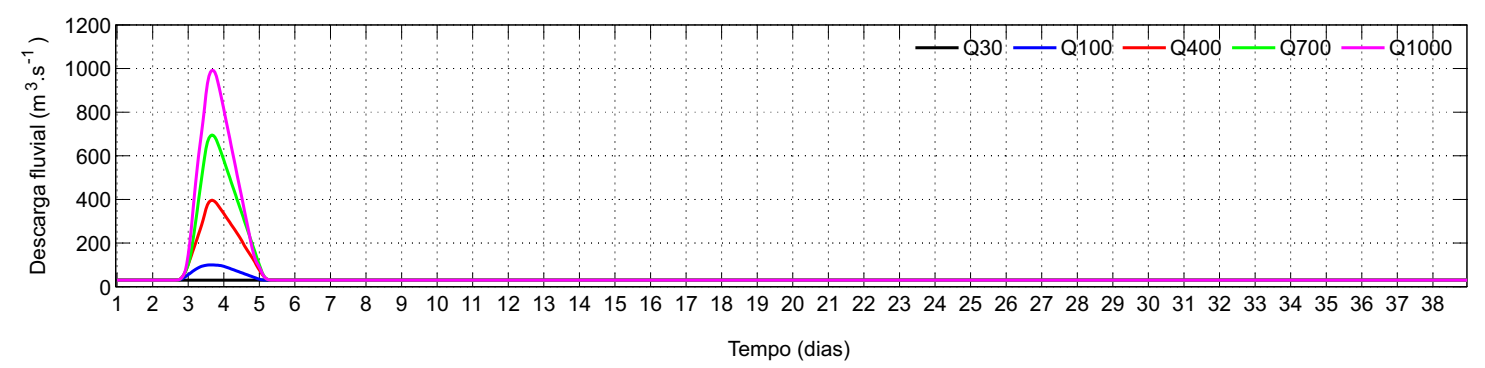

Figure 3.9. Esquema da variação da descarga fluvial para todas as simulações. A variação da descarga ocorres rapidamente, em um curto período de tempo depois diminui até o valor de $30 \mathrm{~m}^{3} \cdot \mathrm{s}^{-1}$.

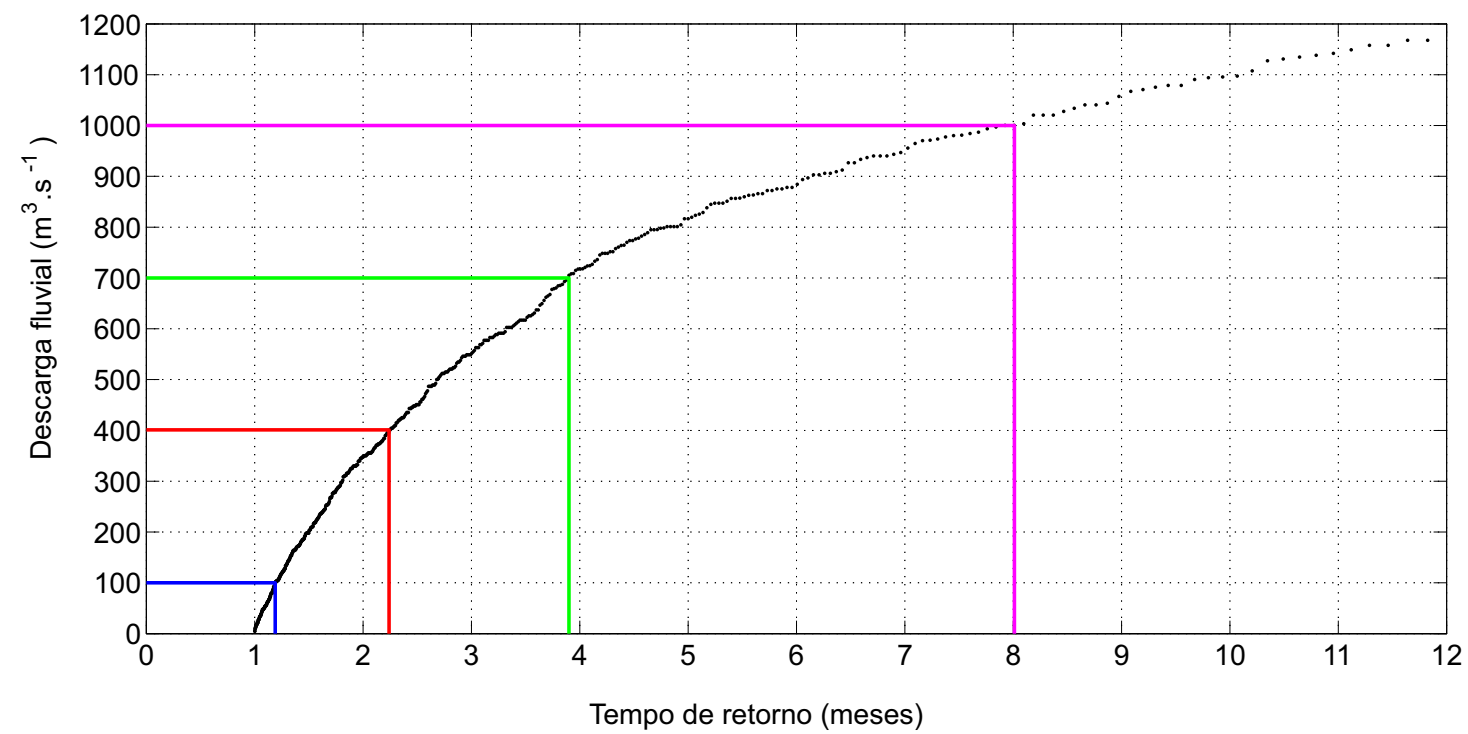

Figura 3.10. Tempo de retorno, em meses, dos eventos de descarga fluvial extrapolados para o rio Araranguá (série temporal de 1943 a 2004). 
Nas simulações, as quatro constituintes harmônicas $\mathrm{M}_{2}, \mathrm{~S}_{2}, \mathrm{O}_{1}$ e $\mathrm{K}_{1}$ foram utilizadas para gerar a série temporal de elevação do nível da água nos contornos da região costeira adjacente, com salinidade constante de 31. A amplitude e a fase das harmônicas estão apresentadas na Tabela 3.1. Dos valores de descarga fluvial inseridos nos contornos dos rios, $60 \%$ corresponde ao rio Itoupava e $40 \%$ ao rio Mãe Luzia. Assim, por exemplo, em condições de vazão de $30 \mathrm{~m}^{3} \cdot \mathrm{s}^{-1}, 18 \mathrm{~m}^{3} \cdot \mathrm{s}^{-1}$ é pelo Itoupava e 12 $\mathrm{m}^{3} \cdot \mathrm{s}^{-1}$ pelo Mãe Luzia. Embora a bacia de drenagem do rio Mãe Luzia seja um pouco maior que a do rio Itoupava, as vazões médias são maiores no rio Itoupava. Em ambos os contornos representados pelos rios a salinidade foi de zero.

A temperatura nos contornos dos rios e da região costeira foi configurada com valores constantes de $17{ }^{\circ} \mathrm{C}$ e $20{ }^{\circ} \mathrm{C}$, respectivamente. As condições iniciais de distribuição de salinidade, para todo o domínio, foram alcançadas em uma simulação de aquecimento, conforme foi realizada nos experimentos de calibração $(\mathrm{C}$ - Aquecimento do campo de salinidade), mas com descarga de $30 \mathrm{~m}^{3} \cdot \mathrm{s}^{-1}$. Desta forma, o modelo já começa com o campo de salinidade aquecido. Nos experimentos não foram consideradas as tensões na superfície livre devido ao vento.

\section{Transporte advectivo de sal}

Com o objetivo de avaliar a importância relativa do pulso de descarga fluvial na hidrodinâmica do estuário, foi aplicada a decomposição do transporte advectivo de sal. Com base em princípios físicos e considerando um estuário lateralmente homogêneo, o transporte de sal médio durante um ou mais ciclos de maré é dado por meio da seguinte equação:

$$
\mathrm{T}_{s}=\frac{1}{T} \int_{0}^{T} \int_{0}^{h} \rho u S d z d t
$$

onde $\rho$ é a densidade da água, $u$ a componente da velocidade, $S$ a salinidade e $T$ o intervalo de tempo. 
Com a Equação 3.6 pretende-se separar as parcelas do transporte de sal, geradas pelos componentes de influência periódica da maré (barotrópico) e circulação gravitacional (baroclínico). Para indicar os processos físicos responsáveis pelo movimento estuário acima (dispersivo) e estuário abaixo (advectivo), os componentes de velocidade longitudinal, salinidade e a espessura da coluna de água devem ser decompostos.

Descrito por Miranda et al. (2002), fundamentado em trabalhos de Bowden (1963), Fischer (1976), Hunkins (1981), Dyer (1974) e Kjerfve (1986), a decomposição para um canal estuarino lateralmente homogêneo é dado por:

$u(x, z, t)=u_{a}(x)+u_{t}(x, t)+u_{s}(x, z)+u^{\prime}(x, z, t)$,

e

$S(x, z, t)=S_{a}(x)+S_{t}(x, t)+S_{s}(x, z)+S^{\prime}(x, z, t)$,

onde $\mathrm{u}_{\mathrm{a}}$ é o valor médio no tempo e no espaço, dado por $<\bar{u}>$ e $\mathrm{S}_{\mathrm{a}}$ calculado por $<\bar{S}>$. Os primeiros termos das Equações (3.7) e (3.8) representam a redistribuição advectiva da salinidade pelo efeito da descarga fluvial. Os segundos termos representam os efeitos cíclicos da corrente da maré e os terceiros termos os efeitos da circulação gravitacional. Podendo ser definidos por:

$u_{t}=\bar{u}-u_{a}$

$$
S_{t}=\bar{S}-S_{a}
$$

$u_{s}=\langle u\rangle-u_{a}$,

e

$$
S_{s}=\langle S\rangle-S_{a}
$$

Os termos $\mathrm{u}^{\prime}$ e $\mathrm{S}^{\prime}$ compõem a parcela residual resultantes de processos físicos de pequena escala, dados por: 
$u^{\prime}=u-u_{a}-u_{t}-u_{s}$

e

$S^{\prime}=S-S_{a}-S_{t}-S_{s}$

A variação da coluna de água com a maré é composta pelos seguintes componentes:

$$
h(x, t)=h_{a}+h_{t}(x, t)
$$

sendo $h_{a}$ a média no tempo da profundidade local, obtida por $\langle h\rangle$ e $h_{t}$ a variação do nível da água ao longo do ciclo de maré.

Substituindo as equações (3.7), (3.8) e (3.15) na equação (3.6), resultando em 32 parcelas, das quais somente sete possuem significância no processo do transporte total médio de sal durante um ou mais ciclos de maré. Podendo assim, ser descrito por:

$$
T_{s}=\bar{\rho}\left(u_{a} h_{a} S_{a}+\left\langle h_{t} u_{t}\right\rangle S_{a}+h_{a}\left\langle u_{t} S_{t}\right\rangle+h_{a} \overline{u_{s} s_{s}}+h_{a}\left\langle\overline{u^{\prime} s^{\prime}}\right\rangle+\left\langle u_{t} S_{t} h_{t}\right\rangle+u_{a}\left\langle S_{t} h_{t}\right\rangle\right)
$$

podendo ser representada como $\mathrm{T}_{\mathrm{s}}=1+2+3+4+5+6+7$. Onde o termo 1 representa o transporte gerado pela descarga fluvial, com seu valor sempre estuário abaixo, de natureza advectiva. O termo 2 representa o transporte de massa gerado pela propagação da onda de maré no estuário (deriva de Stokes), geralmente transportando sal estuário abaixo. O termo 3 é a correlação de maré dos valores médios de velocidade e salinidade na coluna de água, normalmente gerencia o transporte de sal estuário acima. O termo 4 é o transporte da circulação estacionária (definida como a diferença entre a corrente de gravidade pelo componente gerado pela descarga fluvial ou residual). $\mathrm{O}$ resultado do cisalhamento oscilatório e o movimento gerado pelo vento e flutuações turbulentas de velocidade, com escala de tempo inferior ao período de maré, está representado no termo 5. O termo 6 é a dispersão da maré. E por último, o termo 7 
que corresponde a média temporal da correlação entre salinidade e a maré ponderada pela velocidade residual.

\subsection{Modelo de trajetórias das partículas}

O modelo de trajetórias das partículas (MTP) foi desenvolvido para calcular o deslocamento de partículas individuais no tempo e no espaço, as quais funcionam como indicadores do comportamento do material particulado em suspensão no estuário do rio Araranguá. Utilizando o campo das correntes, extraídas do modelo hidrodinâmico (Delft3D), e as velocidades de decantação das partículas, calculadas com os resultados dos experimentos de floculação realizados no tanque anular. O MTP calcula o deslocamento das partículas pelo método Lagrangeano, através de um algoritmo desenvolvido em ambiente Matlab® (MathWorks, Inc.).

A descrição dos movimentos e das características de um estuário pode ser obtida por dois métodos diferentes, utilizando as formulações básica de Euler e Lagrange (Miranda et al., 2012). No método Euleriano, as propriedades são medidas em pontos fixos no estuário ao longo do tempo, e no Lagrangeano essas medidas são feitas em um elemento de volume ao longo de sua trajetória ao longo do tempo (Miranda et al., 2012). Uma das vantagens desse método é a possibilidade de acompanhar o movimento de cada partícula com detalhes e precisão, em comparação com o método baseado no ponto de vista Euleriano.

No módulo hidrodinâmico do Delft3D o campo de correntes é calculado pelo método Euleriano. No MTP a trajetória da partícula é calculada pelo método Lagrangeano, sendo que as partículas são movimentadas pelo campo de correntes gerado no modelo hidrodinâmico. O método Lagrangeano foi escolhido, pois fornece informações precisas sobre a posição das partículas ao longo do domínio do modelo, e o modelo da trajetória da partícula por oferecer uma metodologia prática para a avaliação do transporte de sedimentos em escala temporal e espacial. Nesse estudo, o modelo está direcionado para representar a dinâmica do material particulado no estuário do rio 
Araranguá, mas o método pode ser adaptado para simular uma variedade de partículas tipo Lagrangeana tais como larvas de peixe, microalgas e outros organismos.

A base de dados necessária para rodar o MTP consiste nos dados gerados pelo modelo hidrodinâmico e pelos dados gerados nos experimentos com o tanque anular. Nesse estudo, o modelo hidrodinâmico foi implementado para o estuário do rio Araranguá com o objetivo de caracterizar a circulação do sistema. Os experimentos realizados no tanque anular foram realizados em um estudo anterior, com o objetivo de estudar o processo de floculação no estuário do rio Araranguá. A partir dos resultados desses estudos, foi possível desenvolver um modelo de trajetória da partícula (MTP) (Fig. 3.11).

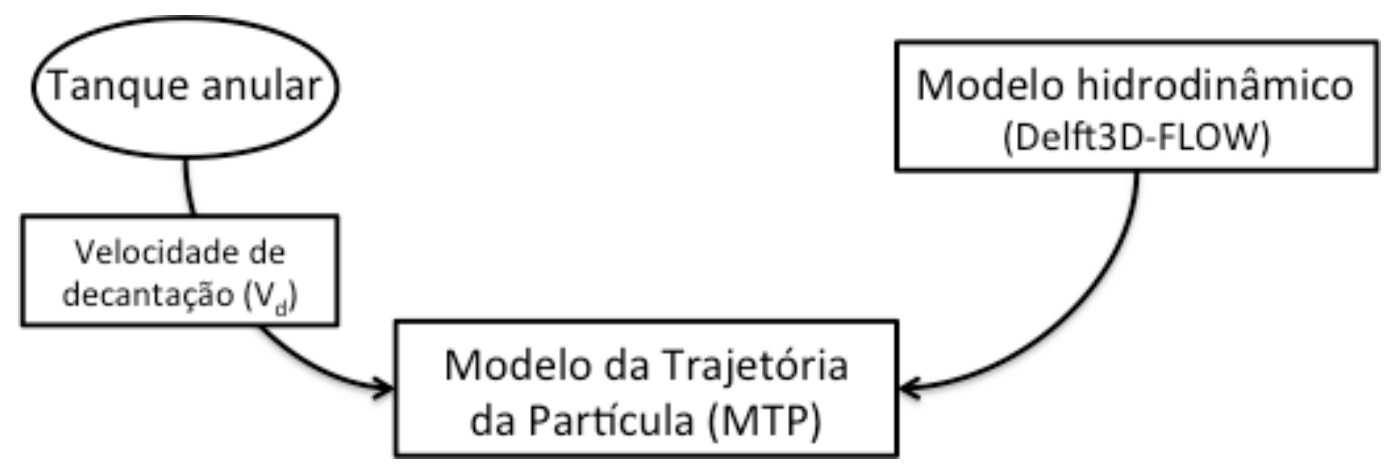

Figura 3.11. Representação geral da estrutura do modelo da trajetória da partícula

\subsubsection{Campo de velocidade longitudinal do modelo Delft3D}

As simulações realizadas com o Delft-FLOW geram dois tipos principais de arquivos de resultados. Um arquivo com séries temporais em pontos fixos no domínio, selecionado pelo usuário (trih-file.dat), e um arquivo com resultados em todos os pontos do domínio, de todas as seções longitudinais e transversais da grade numérica (trimfile.dat). Para o modelo da trajetória da partícula foi selecionado apenas um perfil longitudinal de todo o domínio. O perfil corresponde a uma seção longitudinal do canal que representa uma linha central do domínio no estuário do rio Araranguá, começando 
no contorno aberto do rio Itoupava até o limite do contorno aberto na região costeira adjacente (Fig. 3.12 - A), com extensão aproximada de $44 \mathrm{~km}$, e todas as células no plano vertical (Fig. 3.12 - B). Essa seção longitudinal passa a ser o subdomínio, no qual foram feitas as simulações de trajetória da partícula.

(A)

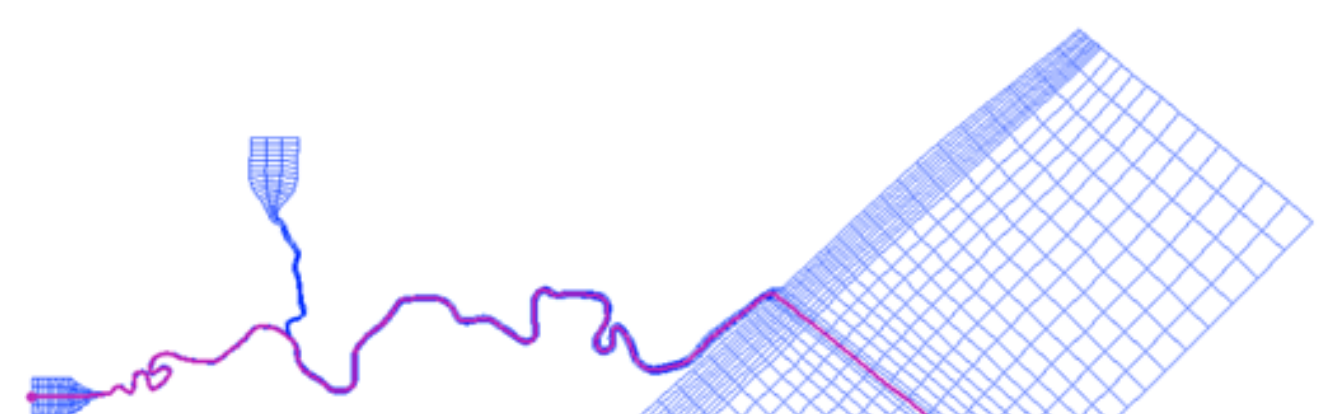

A

(B)

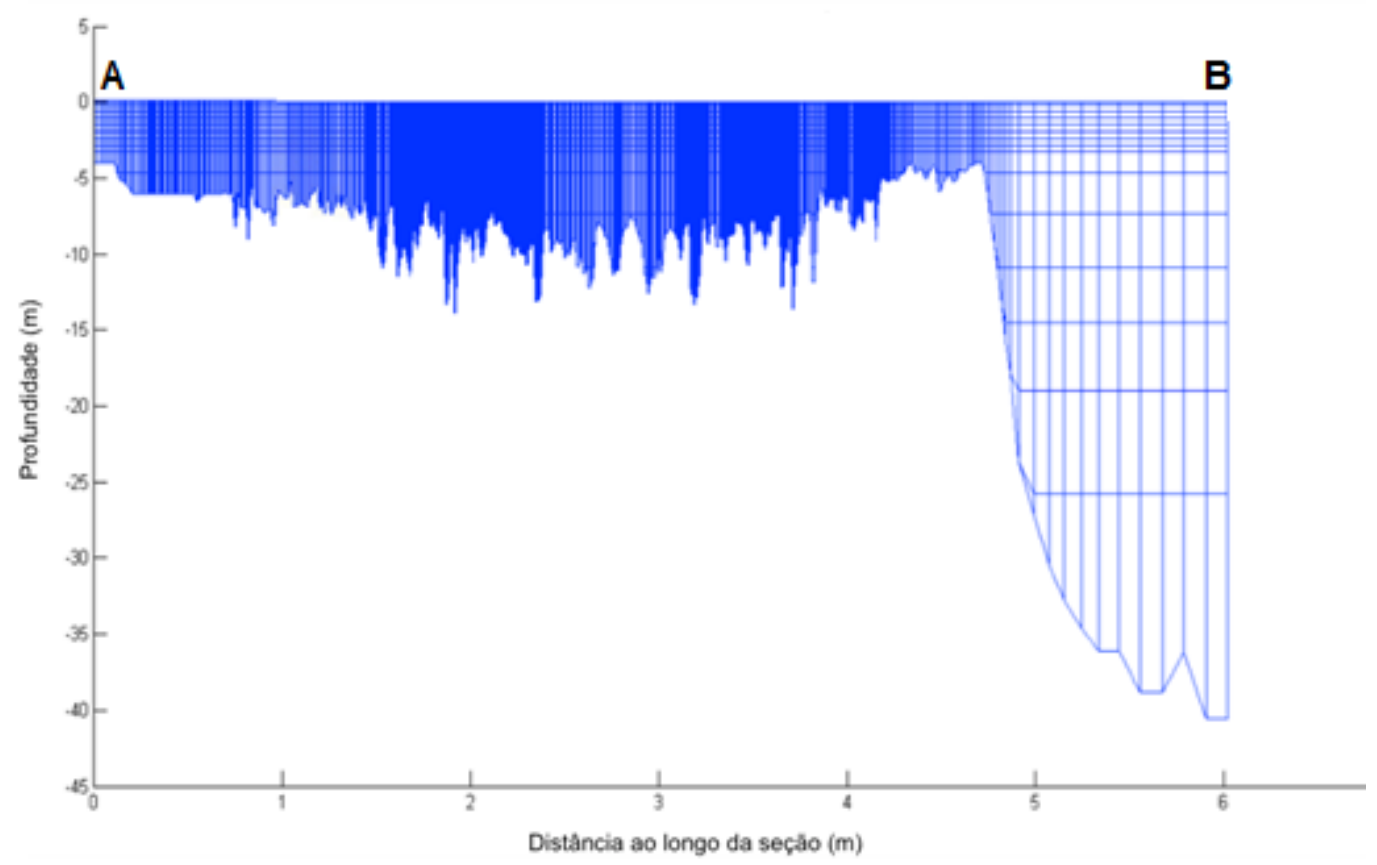

Figura 3.12. (A) Representação do trecho selecionado (em roxo) do domínio. (B) Representação do subdomínio. 
Em cada ponto da grade do subdomínio foram extraídos dados de velocidade das correntes, componentes U (x) e V (y), valores de salinidade, profundidade e distância. Esses foram os principais dados utilizados nos cálculos do deslocamento das partículas. As correntes, em cada ponto das células do domínio, foram transformadas para determinar sua orientação em termos de correntes de vazante e de enchente. Como em estuário relativamente estreitos o fluxo é orientado pela sua geometria, na maior parte dos casos, a velocidade pode ser transformada em um sistema unidimensional, onde valores positivos e negativos indicam correntes de enchente ou vazante. Neste trabalho, as correntes de vazante são indicadas por valores positivos $(+)$ e de enchente por valores negativos (-).

Quando se pretende determinar a orientação das correntes em poucos pontos, um método é achar em que direção das correntes se encontra a maior energia, indicada através da variância, como foi feito no processo de calibração (Seção 3.1.3). Uma vez determinada essa direção, os dados são rotacionados e decompostos em componentes longitudinal e transversal. Como no modelo numérico as velocidades são calculadas em centenas de pontos, no caso da seção selecionada em 644 pontos, e o canal é bastante sinuoso, com algumas curvas bem fechadas, a transformação das velocidades foi realizada de forma diferente.

Primeiramente, foi calculada a velocidade resultante, pra cada ponto, com os valores das componentes U e V pela relação de Pitágoras:

$V_{a}=\left(U^{2}+V^{2}\right)^{1 / 2}$

E a direção da corrente foi obtida pelo quadrante do vetor velocidade e pelo arco tangente entre U e V. De cada seção transversal do canal foram extraídos os ângulos entre a orientação principal do canal em relação ao norte, conforme exemplificado pelo esquema representado na Figura (3.13). Os valores de direção das correntes foram rotacionados para o norte pela subtração entre o ângulo da corrente e o ângulo da seção transversal. Com a direção corrigida e a velocidade absoluta calculada pela Equação (3.17), as componentes cartesianas da velocidade $\mathrm{U}$ e $\mathrm{V}$ foram calculadas de acordo com as Equações 3.18 e 3.19. Sendo que U passa a ser a componente leste-oeste 
(transversal) e V a componente norte-sul (principal). Para o modelo de trajetória das partículas, apenas a componente principal (longitudinal) da velocidade foi considerada.

$U=V_{a} * \operatorname{sen}(D * p i / 180)$

$V=V_{a} * \cos (D * p i / 180)$

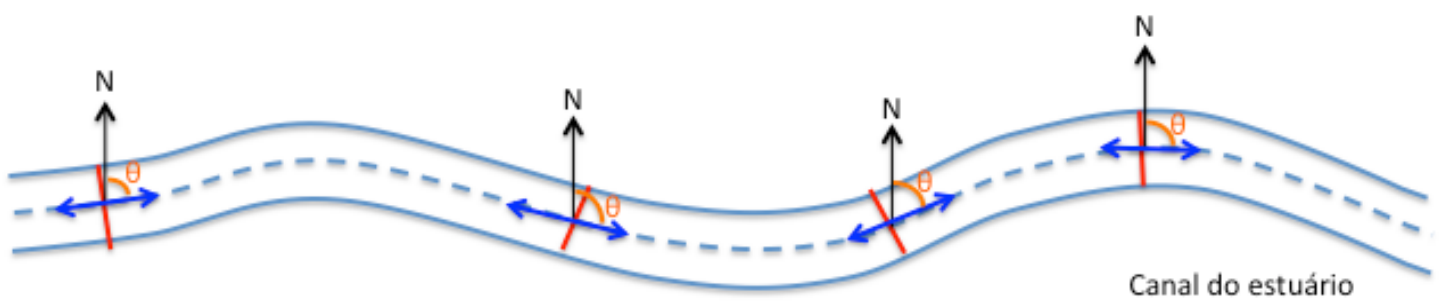

Figura 3.13. Representação do angulo $(\theta)$ entre a orientação principal do canal e o norte.

\subsubsection{Velocidade de decantação das partículas}

As velocidades de decantação das partículas foram estimadas com base em parte dos resultados de experimentos realizados no tanque anular. Um conjunto de experimentos foi realizado para estudar o processo de floculação do material particulado em suspensão do estuário do rio Araranguá. Experimentos dinâmicos, com variação da velocidade do fluxo, foram realizados no tanque e experimentos estáticos em uma coluna de decantação. O trabalho completo dos experimentos com o tanque está descrito em Couceiro \& Schettini (2010). Este trabalho foi realizado com o objetivo de avaliar os efeitos do $\mathrm{pH}$ e da salinidade no processo de floculação do material particulado em suspensão do estuário do rio Araranguá. No qual, os autores concluíram que o baixo pH das águas do rio Mãe Luzia intensifica o processo de floculação no estuário. 
De forma resumida, os experimentos consistiram na mistura das águas dos rios Itoupava (carga em suspensão) e Mãe Luzia ( $\mathrm{pH}$ baixo, 3), principais formadores do rio Araranguá, em diferentes proporções, com ou sem a adição de água salgada. Em um tanque anular (Fig. 3.14) foram testadas a mistura das águas dos dois rios, conforme a Tabela 3.3. Uma concentração inicial de sedimento (35 mg. $\left.\mathrm{l}^{-1}\right)$ coletado no estuário do rio Araranguá, foi adicionado ao tanque no início de cada experimento. A velocidade da água no tanque variou da mesma forma em todos os experimentos, com uma sequência de desaceleração, repouso e aceleração da velocidade. De forma que a velocidade inicial de $45 \mathrm{~cm} . \mathrm{s}^{-1}$ foi reduzida (desaceleração) em cinco etapas, a cada 20 minutos, até zero. Então, o tanque permaneceu com velocidade nula por 180 minutos até o início da etapa de aceleração, onde a cada 20 minutos a velocidade aumentou até $45 \mathrm{~cm} . \mathrm{s}^{-1}$. A variação da velocidade ao longo do tempo das três etapas está representada na Figura 3.15. 


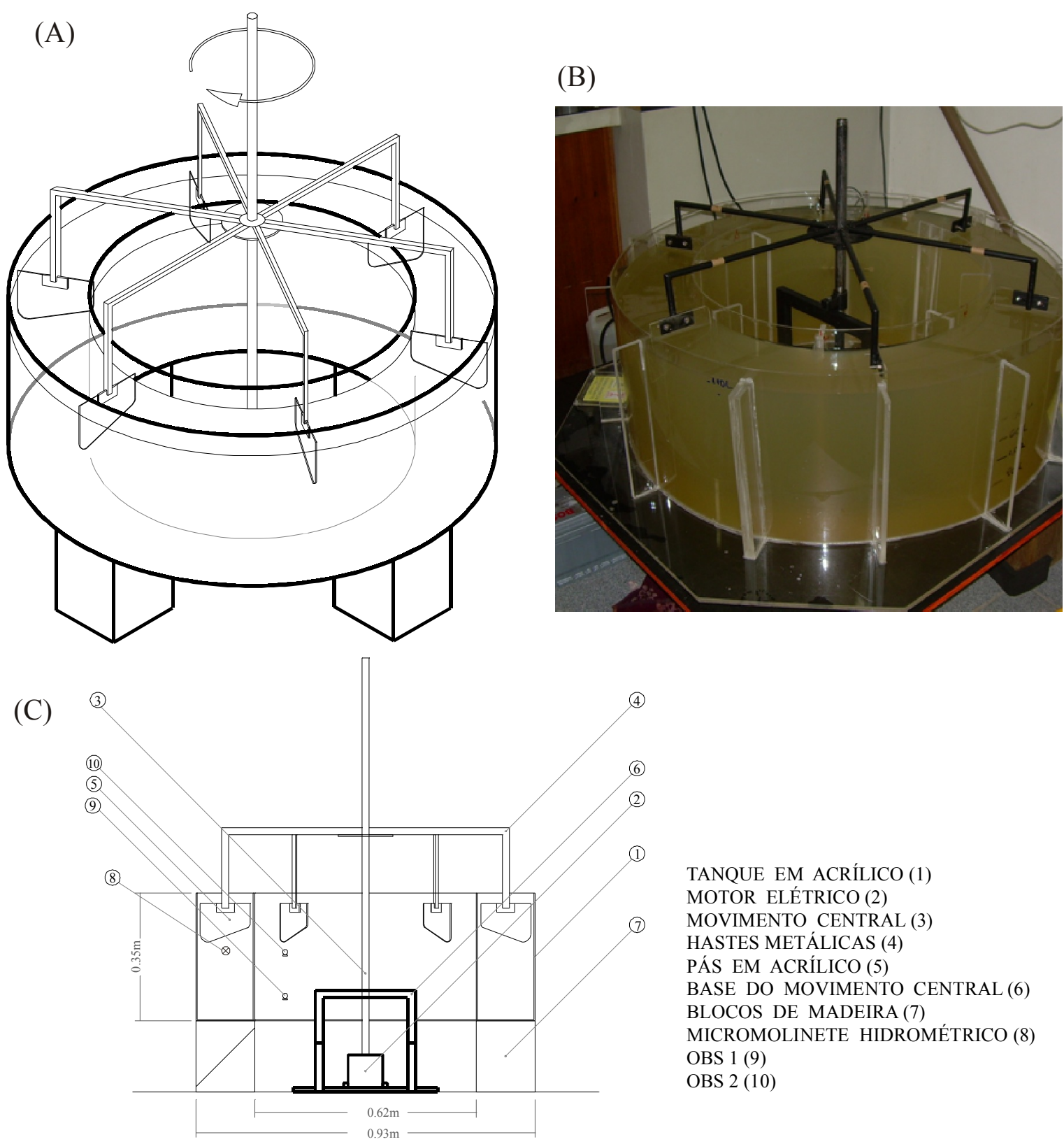

Figura 3.14. (A) Perspectiva isométrica do tanque anular e sua instrumentação; (B) fotografia do tanque durante um experimento; e (C) seção transversal do tanque.

Duas séries de experimentos foram realizadas, sendo que a primeira correspondeu à mistura entre as águas dos rios (série A) e a segunda consistiu na mistura entre as água dos rios e do mar (série B). Ambas as séries experimentais variaram do mesmo modo, no que se reportaram às proporções das águas dos rios e às condições físicas (Tabela 3.3). Os experimentos da série A consistem apenas na mistura 
das águas dos rios formadores do estuário, com suas propriedades naturais, sem adição de sal. Já nos experimentos da série B, além das propriedades naturais, o sal foi introduzido na mistura para avaliar o comportamento do sedimento em suspensão, quando há salinidade. E em ambas as séries, experimentos de aquecimento e com $100 \%$ do rio Itoupava foram realizados.

Tabela 3.3. Resumo das séries experimentais. Em destaque (azul), os experimentos cujo os resultados foram utilizados para estimar a velocidade de decantação das partículas. Adaptado de Couceiro \& Schettini (2010).

\begin{tabular}{lccc}
\hline Experimentos & $\begin{array}{c}\text { Volume do } \\
\text { Itoupava }\end{array}$ & Volume do Mãe Luzia & Salinidade \\
\hline série $\boldsymbol{A}$ & & & 0 \\
\hline Aquecimento A & $100 \%$ & $0 \%$ & 0 \\
SA1 & $100 \%$ & $1 \%$ & 0 \\
SA2 & $99 \%$ & $10 \%$ & 0 \\
SA3 & $90 \%$ & & 0 \\
\hline série B & & $0 \%$ & 1 \\
\hline Aquecimento B & $100 \%$ & $0 \%$ & 1 \\
SB1 & $100 \%$ & $1 \%$ & 1 \\
SB2 & $99 \%$ & $10 \%$ & \\
SB3 & $90 \%$ & & \\
\hline
\end{tabular}

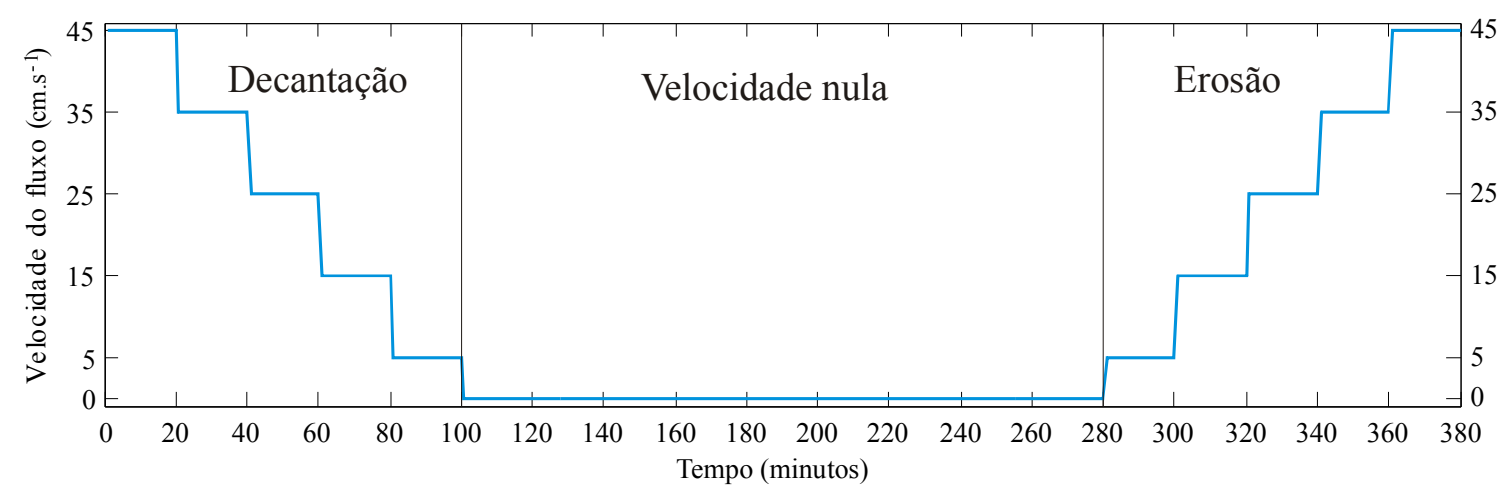

Figura 3.15. Representação da variação da velocidade do fluxo ao longo do tempo. Adaptado de Couceiro \& Schettini (2010). 
Das duas séries (A e B) de experimentos, foram utilizados os resultados dos experimentos SA1, SA3, SB1 e SB3. Em SA1 e SB1, apenas a água do rio Itoupava foi testada com e sem a adição de salinidade. E em SB1 e SB3, foram testadas as misturas entre as águas dos rios Itoupava, com 90 \% do volume e do Mãe Luzia, com 10\% do volume, com e sem adição de salinidade. Esses experimentos foram escolhidos pois representam, de forma mais apropriada, as condições naturais de mistura das águas dos rios formadores do rio Araranguá (SA3), e uma condição hipotética, sem a influência do baixo $\mathrm{pH}$ (SA1), considerando apenas as características do rio Itoupava, e para ambas as condições os experimentos com adição de salinidade (SB1 e SB3).

\section{Velocidade de decantação estimada}

Para calcular as velocidade de decantação das partículas foram utilizados os resultados da etapa de desaceleração e velocidade nula, que representam a etapa de decantação dos experimentos dinâmicos do tanque. Durante todos os experimentos, a concentração de material em suspensão foi registrada em duas profundidades, a 7 e 20 $\mathrm{cm}$ acima do fundo do tanque. A variação do material particulado em suspensão para os experimentos selecionados estão representados na Figura 3.16.

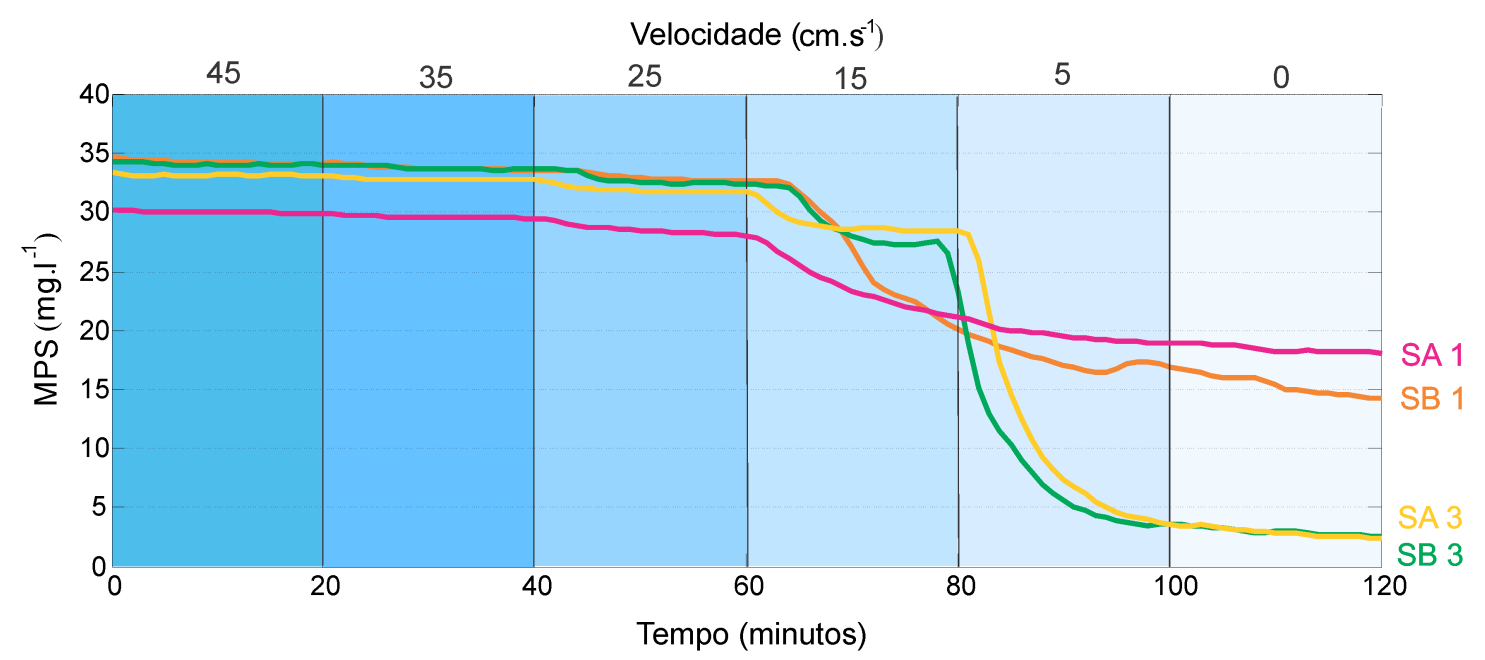

Figura 3.16. Séries temporais da variação da concentração de MPS para os experimentos SA1 (linha rosa), SA3 (linha amarela), SB1 (linha laranja) e SB3 (linha verde). Adaptado de Couceiro \& Schettini (2010). 
A velocidade de decantação das partículas foi calculada com base na evolução temporal da concentração de material particulado em suspensão, em diferentes condições de velocidade de fluxo do tanque. Para cada intervalo de tempo com velocidade constante, da etapa de decantação, foi calculada a variação da concentração de sedimento em suspensão e estimada a velocidade de decantação pela equação da conservação de massa:

$\frac{\partial C}{\partial t}+\frac{\partial\left(V_{d} C\right)}{\partial z}=0$

onde $C$ é a concentração de sedimento em suspensão, $t$ o tempo, $V_{d}$ a velocidade de decantação e $z$ a coordenada vertical. Uma solução aproximada por diferenças finitas é:

$V_{d}^{n}=-\left(\frac{C^{n+1}-C^{n}}{\Delta t^{n}}\right) \frac{H^{n}}{C^{n}}$

onde $V_{d}^{n}$ é a velocidade média de decantação no tempo $n, C^{n+1}$ e $C^{n}$ são as concentrações médias de material em suspenção na coluna de água nos tempos $n+1$ e $n$, $H^{n}$ a altura da coluna de água $(28 \mathrm{~cm})$ e $\Delta t^{n}$ o intervalo de tempo entre $n+1$ e $n$ (e.g. Portela et al., 2013). A velocidade de decantação foi estimada desta forma para manter uma certa integridade do processo de floculação e defloculação nas simulações da trajetória da partícula. Desta forma, um valor de velocidade de decantação foi relacionado para uma determinada condição de fluxo (velocidade da corrente) e característica físico-químicas da água (com baixo $\mathrm{pH}$ e $\mathrm{pH}$ normal).

Os resultados dos cálculos da estimativa da velocidade de decantação das partículas estão representados na Tabela 3.4. Em cada condição de velocidade do tanque um valor de velocidade de decantação foi calculado, para todos os quatro experimentos considerados. Esses valores de velocidade de decantação foram utilizados no modelo da trajetória da partícula. 
Tabela 3.4. Valores estimados da velocidade de decantação $\left(\mathrm{cm}^{-1}{ }^{-1}\right)$ calculados pela Equação (3.21) em diferentes condições de velocidade de fluxo para os experimentos dinâmicos com o tanque anular.

\begin{tabular}{ccccc}
\hline & \multicolumn{4}{c}{ Velocidade de decantação $\left(\mathbf{c m}^{-1} \mathbf{s}^{-1}\right.$} \\
\hline $\begin{array}{c}\text { Velocidade do } \\
\text { tanque }\left(\mathrm{cm}^{-1}\right)^{-1}\end{array}$ & $\begin{array}{c}\text { Itoupava 100\% } \\
\text { (SA1) }\end{array}$ & $\begin{array}{c}\text { Itoupava 100\% } \\
\text { Salinidade 1 } \\
\text { (SB1) }\end{array}$ & $\begin{array}{c}\text { Itoupava 90\% } \\
\text { Mãe Luzia 10\% } \\
\text { (SA3) }\end{array}$ & $\begin{array}{c}\text { Itoupava 90\% } \\
\text { Mãe Luzia 10\% } \\
\text { salinidade 1 } \\
\text { (SB3) }\end{array}$ \\
\hline 45 & 0,000207 & 0,000257 & 0,000087 & 0,000109 \\
35 & 0,000385 & 0,000235 & 0,000108 & 0,000183 \\
25 & 0,000895 & 0,000322 & 0,000799 & 0,000822 \\
15 & 0,005831 & 0,013046 & 0.001139 & 0,003721 \\
5 & 0,002015 & 0,006756 & 0.020588 & 0,021701 \\
0 & 0,000255 & 0,001018 & 0.000750 & 0,000937 \\
\hline \hline
\end{tabular}

\subsubsection{Programando no Matlab}

O MTP consiste em um algoritmo desenvolvido em ambiente Matlab® (MathWorks, Inc.). O modelo carrega os dados de saída do modelo hidrodinâmico, previamente tratados em relação aos dados de velocidade, conforme a seção 3.3.1, e as velocidades de decantação da partícula, estimadas na seção 3.3.2. E calcula o deslocamento das partículas ao longo do tempo e do espaço, em uma grade numérica computacional formada pelo subdomínio, representado pela seção longitudinal central do canal.

O subdomínio é representado por uma grade computacional formada por $15 \times 644$, onde 15 é o número de linhas no plano vertical e 644 o número de colunas no plano horizontal. A resolução da grade, tanto na vertical quanto na horizontal é exatamente a mesma das simulações hidrodinâmicas. Ou seja, o espaçamento entre as células da grade na horizontal é mesmo, e na vertical também, mudando apenas a espessura da primeira célula, que varia ao longo do tempo devido as variações da superfície livre. No modelo hidrodinâmico a grade computacional é curvilínea. No MTP a grade funciona como uma grade Cartesiana, com as linhas retas, formada por células 
de formato quadrado. A grade é irregular, o tamanho de cada célula varia ao longo da grade tanto na horizontal quanto na vertical.

Os resultados do modelo hidrodinâmico são salvos em arquivos, os quais contêm todas as informações. Cada informação pode ser extraída do arquivo através de rotinas processadas no Matlab® (MathWorks, Inc.) ou através da exportação dos dados pelo programa de visualização de dados do Delft3d (QUICKPLOT). Quando separados os dados são organizados em matrizes. Essas matrizes de dados do modelo hidrodinâmico são carregadas pelo MTP e permanecem separadas, uma para cada variável: velocidade longitudinal, salinidade, níveis de profundidade e distâncias na horizontal. Cada matriz possui 15 linhas por 644 colunas. Portanto, para cada propriedade existe uma matriz, e esses valores são renovados com intervalo de uma hora. Se fosse considerada como uma matriz única de dados, cada ponto da grade teria um valor para: velocidade longitudinal, salinidade, profundidade (em relação à superfície) e distância (em relação a primeira célula da grade). A matriz que representa a distancia entre as células na horizontal não é renovada ao longo do tempo, pois a resolução das células não mudam no eixo $\mathrm{x}$, somente no eixo $\mathrm{z}$.

O núcleo do MTP é composto por três ciclos: o primeiro carrega as matrizes que representam os subdomínios, o segundo faz as 150 interações e o terceiro calcula o deslocamento de cada partícula para cada interação. $\mathrm{O}$ primeiro e o segundo são os responsáveis por renovar as propriedades do subdomínio em sub-passos de tempo. Ou seja, em um intervalo de uma hora, neste caso, o modelo calcula o deslocamento da partícula 150 vezes, até que os subdomínios sejam renovados e o ciclo continue. No terceiro ciclo são realizados os cálculo do deslocamento da partícula, o qual representa a estrutura geral do algoritmo da trajetória da partícula.

De forma geral, o terceiro ciclo realiza os seguintes passos: identifica a posição inicial da partícula, determina a velocidade em sua posição (interpolação), calcula a nova posição (integração) e encontra a nova posição. Considerando apenas uma partícula, o terceiro ciclo do MTP funciona da seguinte forma: (A) as coordenas da partícula em x (i) e em y (j) são identificadas; (B) sua coordenada é testada para determinar se a partícula alcançou os limites de contorno do domínio (partícula inativa) ou se continua no domínio (partícula ativa); (C) a velocidade e a salinidade são 
calculadas por interpolação linear; (D) a velocidade e a salinidade são testada para determinar a velocidade de decantação da partícula de acordo com a Tabela 3.4; (E) calcula o deslocamento da partícula; (F) renova a posição da partícula; (G) testa se com o deslocamento a partícula avançou ou regrediu em relação ao eixo longitudinal (x); $(\mathrm{H})$ testa se a partícula ganhou profundidade com o deslocamento na vertical (y); (I) atualiza suas coordenadas em x e y; (J) armazena todas as informações da partícula. Um fluxograma com a sequência lógica do terceiro ciclo está representado na Figura (3.17)

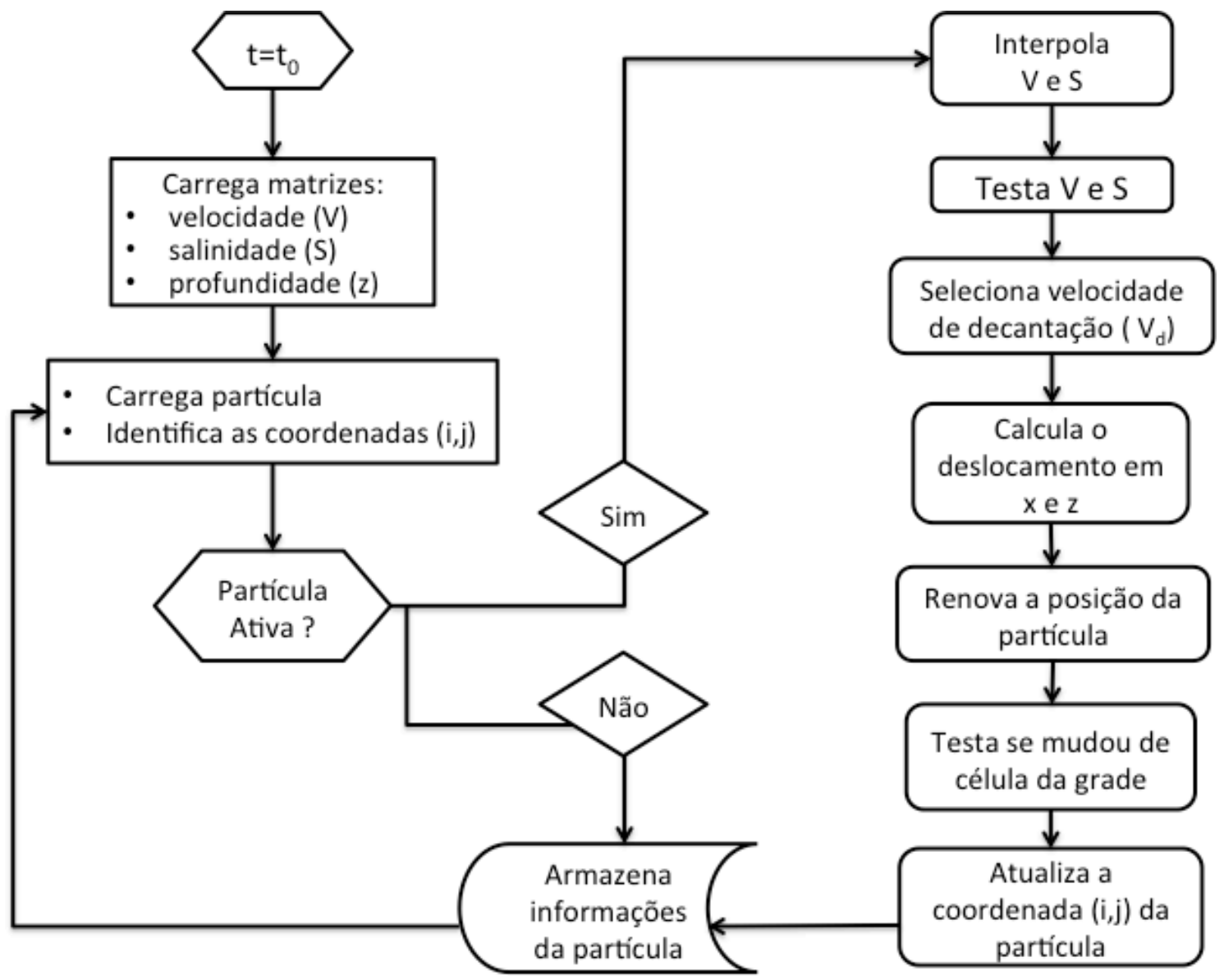

Figura 3.17. Fluxograma da sequência lógica dos passos realizados pelo terceiro ciclo do MTP. Para o cálculo da trajetória da partícula. 
Primeiramente a posição da partícula é identificada, definindo a célula da grade na qual a partícula se encontra. Para determinar a velocidade nesse ponto, as velocidade das extremidades da célula são interpoladas. Dentro da área de cada célula da grade (Fig. 3.18), a velocidade e a salinidade são calculadas por interpolação linear, segundo as Equações 3.22 e 3.23. Em um determinado instante (t), a velocidade e a salinidade será a mesma em qualquer ponto dentro dos limites da célula da grade computacional. Esse método foi escolhido por ser um método simples, que envolve apenas os valores de velocidade dos vértices das células.

$$
\begin{aligned}
& V_{c}=\frac{V_{(i, j)}+V_{(i, j+1)}+V_{(i+1, j)}+V_{(i+1, j+1)}}{4} \\
& S_{c}=\frac{S_{(i, j)}+S_{(i, j+1)}+S_{(i+1, j)}+S_{(i+1, j+1)}}{4}
\end{aligned}
$$

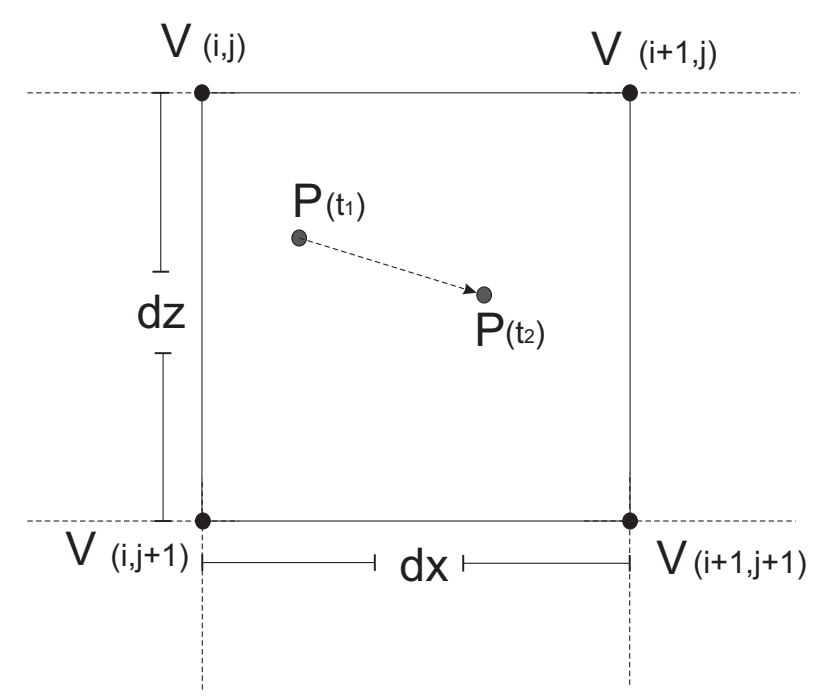

Figura 3.18. Representação de uma célula da grade para os cálculos do MTP. P representa a partícula e $\mathrm{V}$ a velocidade em cada vértice da célula.

O passo seguinte é calcular a próxima posição da partícula. A nova posição pode ser calculada a partir de vários métodos de integração, desde um simples esquema de primeira ordem, como o esquema de Euler, até o esquema de quarta ordem de Runge- 
Kutta. O deslocamento da partícula nas direções x e $\mathrm{z}$ foi calculado através do esquema de Euler de acordo com as seguintes equações, respectivamente:

$$
\begin{aligned}
& D_{x}^{n+1}=D_{x}^{n}+V_{c} d t \\
& D_{z}^{n+1}=D_{z}^{n}+W_{s} d t
\end{aligned}
$$

onde $D_{x}^{n+1}$ e $D_{z}^{n+1}$ são os deslocamentos da partícula no instante $n+1$ na direção x e z, respectivamente. $D_{x}^{n}$ e $D_{z}^{n}$ as posições das partículas no instante $n$ na direção x e z, respectivamente. $V_{c}$ a velocidade interpolada na direção $\mathrm{x}$ e $W_{s}$ a velocidade de decantação da partícula. O esquema de Euler exige um passo de tempo (dt) pequeno para manter a precisão do deslocamento das partículas. No caso, foi utilizado um dt constante para todas as interações de $24 \mathrm{~s}$. Quando a complexidade do fluxo aumenta, e o passo de tempo se torna maior, é necessário aplicar um esquema com maior precisão, como o de Runge-Kutta. Nas equações de integração (3.24 e 3.25) não foram adicionados nenhum esquema de trajetória aleatória das partícula.

A velocidade de decantação da partícula foi calcula de acordo com a velocidade do fluxo no tanque e a variação da concentração do material particulado em suspensão, para os experimentos do tanque. No MTP, a velocidade de decantação é definida de acordo com a velocidade calculada pela Equação 3.21 e pela presença ou não de salinidade, seguindo a Tabela 3.4. Portanto, a velocidade de decantação de cada partícula não é constante, os valores variam no espaço e no tempo de acordo com as condições de fluxo, representados pela velocidade longitudinal e a presença ou não de salinidade. Por exemplo, se a velocidade calculada pela Equação 3.22 for de $30 \mathrm{~cm} . \mathrm{s}^{-1} \mathrm{e}$ a salinidade calculada pela Equação 3.23 for 10 , a velocidade de decantação da partícula, no caso de um cenário sem a influência do baixo $\mathrm{pH}$, será de $0,000322 \mathrm{~cm} \cdot \mathrm{s}^{-1}$.

A nova posição da partícula é novamente testada para saber se a partícula permanece na mesma célula ou se foi deslocada para outra célula vizinha. No caso, a partícula pode se deslocar para células a direita ou a esquerda, na direção x, e para baixo, tanto para direita quanto para esquerda, na direção y. Não existem movimentos 
ascendentes da partícula entre as células da grade, apenas para os lados e para baixo. $\mathrm{O}$ deslocamento resultante da partícula é na diagonal.

Para cada partícula, o ciclo de A a J se repete enquanto a partícula for considerada ativa e suas informações são renovadas ao longo do tempo. A partícula é considerada inativa quando suas coordenadas correspondem aos limites de contorno, tanto em x quanto em y. Quando a partícula alcança a célula mais profunda do domínio, não retorna mais para a coluna de água e é considerada depositada. Em cada uma das 150 interações realizadas por hora, o ciclo de A a J é calculado para todas as partículas que estão no domínio. Desta forma, o campo advectivo calculado no modelo hidrodinâmico foi usado para forçar o MTP a produzir o deslocamento das partículas a cada passo de tempo.

\section{Observações sobre o MTP}

De forma direta, o MTP calcula o transporte das partículas em suspensão e considera o processo de deposição, sem considerar a velocidade crítica de deposição. $\mathrm{O}$ MTP não calcula o transporte das partículas junto ao fundo, não considera os processos de erosão, ressuspensão e floculação, e não simula a formação de lama fluída.

No MTP as partículas não interagem entre si, não alteram a profundidade da coluna de água e nem a forma do relevo do fundo, não retornam para o domínio do estuário quando são depositadas ou exportadas, e sua quantidade não altera as características do fluido. O modelo não reproduz condições de difusão turbulenta, gerada por correntes mais fortes, o que poderiam transportar as partículas para cima, impedindo que elas depositem.

Os processos de floculação e defloculação são considerados, mas de forma indireta, através dos dados da velocidade de decantação das partículas calculadas pelos experimentos dinâmicos com o tanque. A velocidade de deposição das partículas não é constante, varia de acordo com as condições de fluxo e pH da água. 


\section{Número de partículas}

Definir a quantidade de partículas que serão lançadas no modelo não é uma decisão fácil, pois a quantidade deve ser representativa estatisticamente (Brickman \& Smith, 2001). Partículas a mais ou de menos podem gerar problemas no modelo, seja em seus resultados, quando a quantidade não é representativa, ou na eficiência da execução do modelo, quando o número de partículas é muito grande e o processamento se torna muito demorado. Além de sobrecarregar o modelo, uma quantidade muito grande pode não ser representativa. Existem relativamente poucos estudos de trajetória da partícula em estuários que estabelece uma ideia da quantidade de partículas que deve ser usada nos modelos.

A quantidade de partículas lançadas no modelo de trajetória, a cada intervalo de tempo, pode ser definida da seguinte forma: as partículas são lançadas em suspensão na região da confluência dos rios, na camada mais superficial do domínio vertical, e medidas em um momento posterior em uma determinada célula da grade, localizada na porção intermediária da extensão do estuário, a jusante do ponto de lançamento. Essa quantidade representa a concentração das partículas de modo que:

$$
\text { Concentração }=\frac{\text { número de partículas na célula }}{\text { número total lançado }}
$$

A tendência é que a concentração, em função do número de partículas, pare de flutuar quando um número suficiente de partículas for utilizada. Nessa condição é possível determinar o número de partículas suficientes nas células do domínio estatisticamente representativas.

A forma como as partículas são lançadas, seja somente na superfície, no fundo ou em toda a coluna deve ser pensada de acordo com o objetivo do estudo. No estuário do rio Araranguá, não existe muita informação sobre a distribuição dos sedimentos na coluna da água. $\mathrm{Na}$ campanha de 2008, foram realizados quatro perfis verticais da concentração de material em suspensão, dois perfis no dia 02 de agosto e dois no dia 30 de setembro (Fig. 3.19). Amostras de água a cada metro foram coletadas em dois pontos do estuário, uma mais a montante na região da Estação \#2 e outro mais a jusante na 
Estação \#1 (Fig. 3.2). Essas amostras foram filtradas e a concentração foi obtida pela razão do peso do material retido no filtro pelo volume de água filtrada.

A

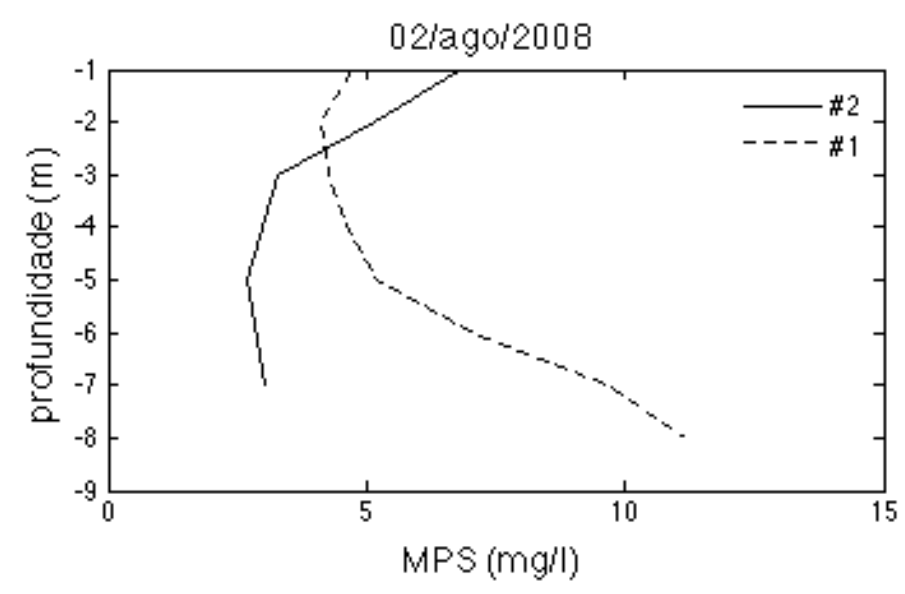

B

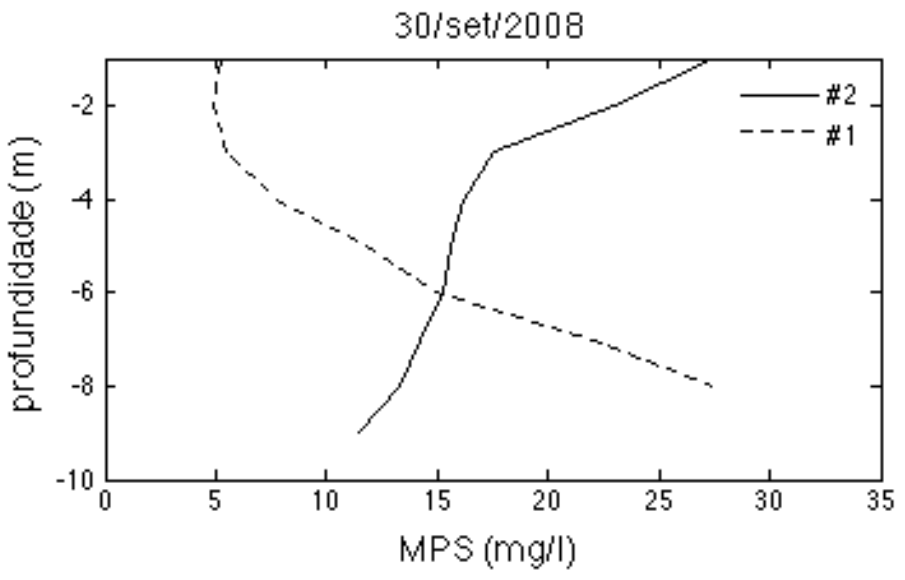

Figura 3.19. Perfis verticais de material particulado em suspensão (MPS) nas estações $\# 1 \mathrm{e} \# 2$, nos dias 02 de agosto (A), com descarga fluvial $\sim 25 \mathrm{~m}^{3} \cdot \mathrm{s}^{-1} \mathrm{e} 30$ de setembro de 2008, após um evento de alta descarga $\left(\sim 400 \mathrm{~m}^{3} \cdot \mathrm{s}^{-1}\right)$.

A configuração do número de partículas em um perfil vertical, como partículas sendo lançadas em suspensão, desde a superfície até o fundo, foi baseada no perfil do dia 02 de agosto. Observado em um ponto mais próximo da confluência em condições de baixa descarga fluvial $\left(\sim 25 \mathrm{~m}^{3} \cdot \mathrm{s}^{-1}\right)$. Para ter um valor aproximado, o número de partículas lançadas em cada profundidade, segue, em proporção, a variação do perfil observado. Assim, as 1.000 partículas em suspensão são divididas nas camadas verticais do domínio de acordo com essa proporção. Mais partículas são lançadas nas profundidades onde foram registradas as maiores concentrações. 


\subsubsection{Cenários e lançamento das partículas}

Quatro cenários foram simulados com o modelo da trajetória da partícula para avaliar os efeitos do baixo pH da água na dinâmica das partículas no estuário (Tab. 3.5). Foram realizadas simulações considerando o efeito do $\mathrm{pH}$ baixo, utilizando as velocidades de decantação estimadas pelos experimentos SA3 e SB3 (Tab. 3.4), e simulações considerando apenas as condições físico-química da água do rio Itoupava ( $\mathrm{pH}$ normal), utilizando as velocidades de decantação estimadas pelos experimentos SA1 e SB1.

Entre as simulações realizadas com o modelo hidrodinâmico, foram escolhidas duas situações de evento de descarga fluvial: com o pico de $400 \mathrm{~m}^{3} \cdot \mathrm{s}^{-1}$ (Q400) e pico de $1000 \mathrm{~m}^{3} \cdot \mathrm{s}^{-1}$ (Q1000). Q1000 representa, entre as simulações, o evento extremo de descarga, e o evento que promoveu o transporte da cunha salina estuário afora. E Q400, representa um evento intermediário, entre os modelados, que causou certa perturbação da circulação e da distribuição da salinidade. Ambas as simulações correspondem ao evento de pico ocorrendo em condições de maré de sizígia.

Foram lançadas em suspensão 1.000 (mil) partículas na coluna da água, a cada hora e durante apenas o período de duração do pico de descarga fluvial, na região da confluência dos rios Itoupava e Mãe Luzia. Após a descida do evento de descarga fluvial, quando a descarga voltou a ser $30 \mathrm{~m}^{3} \cdot \mathrm{s}^{-1}$, o lançamento das partículas foi interrompido. As partículas lançadas e que permaneceram no domínio do estuário, foram monitoradas até o final do experimento, quando todas as partículas depositaram.

Como as partículas lançadas em suspensão no modelo da trajetória são indicadoras do comportamento do material floculado (ou não) do estuário do rio Araranguá, o local de lançamento foi à região do domínio que corresponde a confluência. A distribuição na coluna da água durante o lançamento seguiu conforme está descrito da seção anterior (3.3.3. Programando no Matlab).

Neste estudo, as partículas não representam uma determinada concentração de material particulado em suspensão. Elas são apenas indicadoras do comportamento do material particulado em suspensão. E a relação entre número de partículas e 
concentração do material particulado em suspensão no estuário foi apenas com a intenção de criar um perfil de lançamento representativo, e não de reproduzir uma condição pré-determinada.

Tabela 3.5. Esquema dos cenários configurados para as simulações com o MTP.

\begin{tabular}{lcc}
\hline Cenários & $\begin{array}{c}\text { Picos de descarga } \\
\text { fluvial }\left(\mathrm{m}^{3} \cdot \mathrm{s}^{-1}\right)\end{array}$ & $\mathrm{pH}$ \\
\hline Caso 1 & 400 & Baixo \\
Caso 2 & 400 & Normal \\
Caso 3 & 1000 & Baixo \\
Caso 4 & 1000 & Normal \\
\hline
\end{tabular}




\section{Capítulo 4}

\section{Resultados}

\subsection{Calibração e validação}

\subsubsection{Calibração}

A calibração do modelo hidrodinâmico tridimensional foi realizada utilizando os dados do nível da água, das correntes, da salinidade do fundo e da distribuição longitudinal da salinidade. Análises comparativas foram realizadas entre os dados do modelo e os dados observados, para o período de 10 de junho a 10 de julho de 2008, em duas estações localizadas no estuário do rio Araranguá, \#1 e \#2 (Fig. 3.2). Os valores médios diários da descarga fluvial, utilizados com forçante do modelo durante o período de calibração estão apresentados na Figura 4.1. No início da simulação de calibração a descarga fluvial permaneceu baixa e no dia 28 de junho ocorreu um pico descarga fluvial de aproximadamente $125 \mathrm{~m}^{3} \cdot \mathrm{s}^{-1}$. Após o pico, a descarga permaneceu baixa até o final do período analisado. Os valores dos parâmetros estatísticos para cada variável são apresentados na Tabela 4.1 .

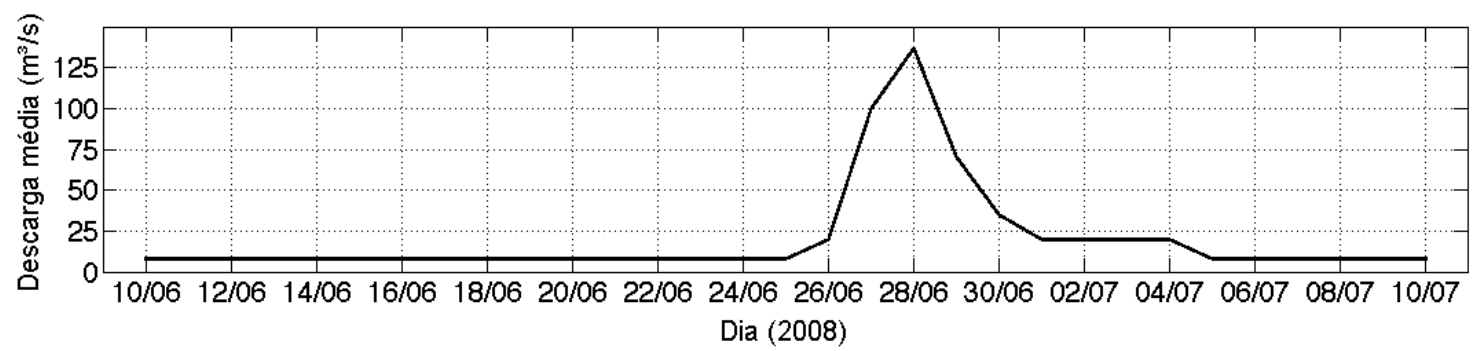

Figura 4.1. Descarga fluvial média diária utilizada no processo de calibração. 
A comparação entre as séries temporais modeladas e observadas para a variação do nível e velocidade das correntes estão apresentadas nas Figuras 4.2 e 4.3. Na estação \#1, a comparação entre a variação do nível observado e modelado (Fig. 4.2-A) mostra uma excelente concordância entre os valores, com valor de Skill de 0,99. Na estação \#2 (Fig. 4.2-B), o nível modelado e observado também apresenta uma excelente concordância, com algumas pequenas diferenças na amplitude, com valor de Skill de 0,96. A diferença média entre o nível modelado e observado foi de 0,0087 e 0,0486 m para as estações \#1 e \#2, respectivamente.

(A)

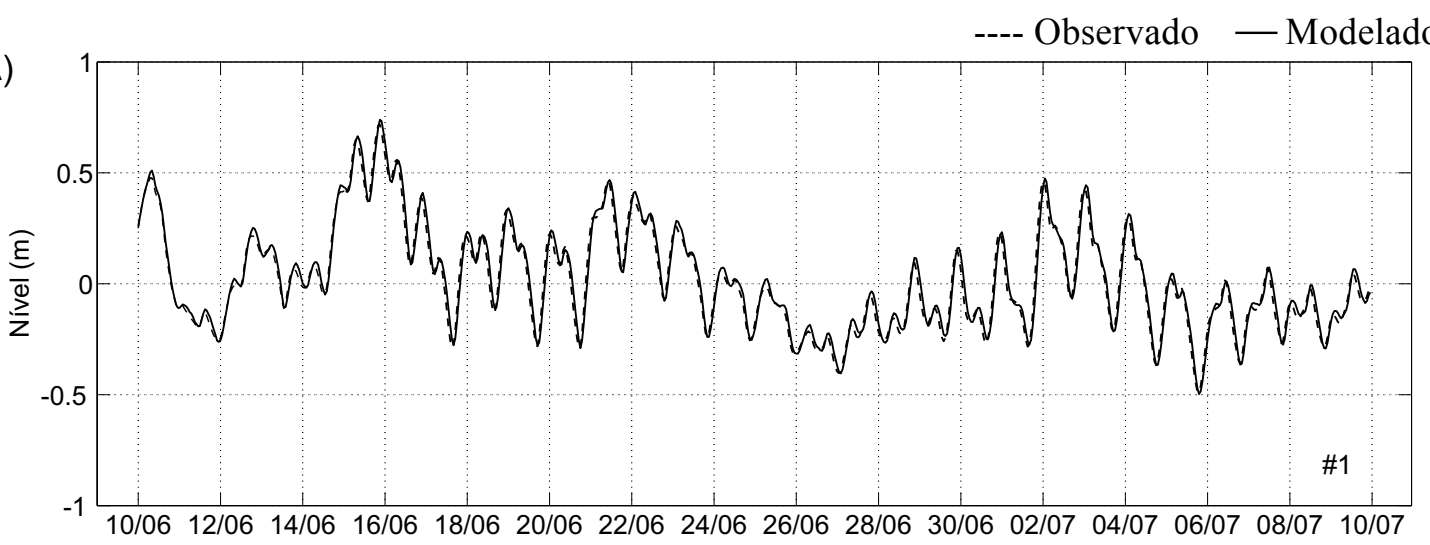

(B)

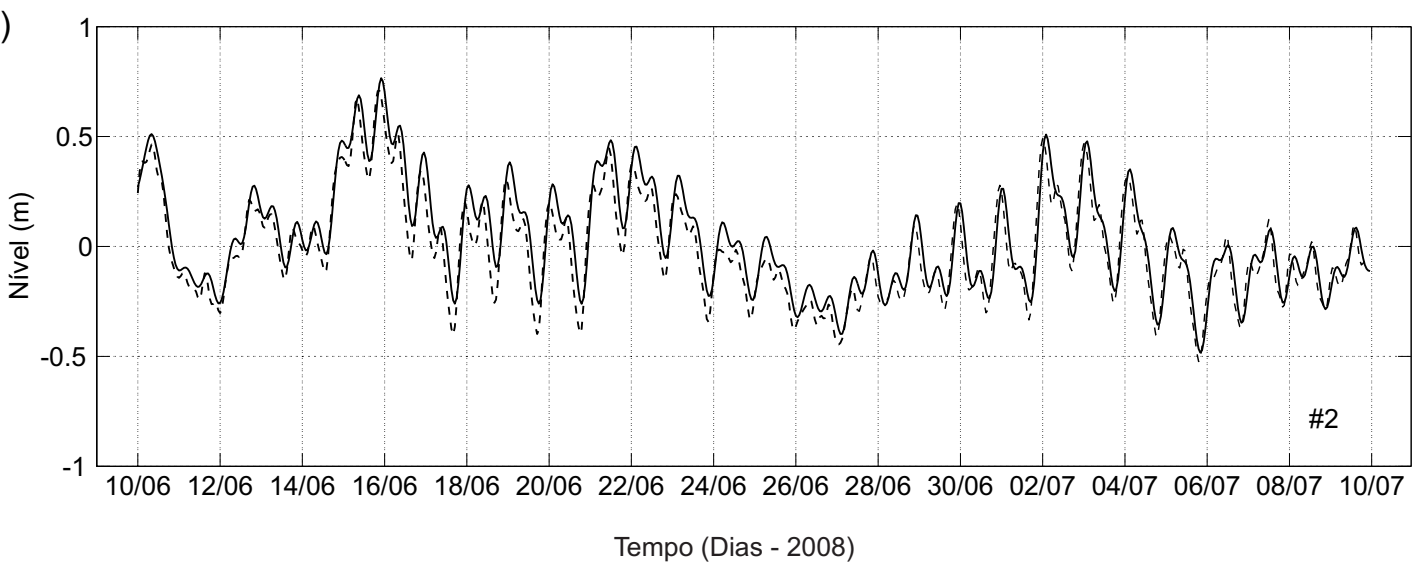

Figura 4.2. Comparação da série temporal do nível da água observada (----) e modelada (-) nas estações \#1 (A) e \#2 (B) para o período de calibração (10/06 - 09/07). 
Para o campo das velocidades, somente as correntes médias na coluna de água foram comparadas. As correntes modeladas e observadas nas duas estações (Fig. 4.3, A e B) exibem as variações das marés de sizígia e quadratura. Embora existam diferenças entre as correntes modeladas e observadas, tanto na magnitude quanto na fase, a concordância foi excelente nas duas estações, com valores de Skill de 0,90. A diferença média entre a corrente modelada e observada foi de 0,0075 e $0,0022 \mathrm{~m} . \mathrm{s}^{-1}$ para as estações \#1 e \#2, respectivamente. A magnitude da corrente alcançou valor máximo de vazante de $0,22 \mathrm{~m} . \mathrm{s}^{-1}$ (observado) na estação \#2, durante o período de pico de descarga de $100 \mathrm{~m}^{3} \cdot \mathrm{s}^{-1}$. Esse aumento da velocidade da corrente com o aumento da descarga fluvial não foi reproduzido pelo modelo. Provavelmente, devido ao fato de que os valores de descarga fluvial que que forçaram o modelo, durante os experimentos de calibração, correspondem aos valores médios diários fornecidos pela ANA (Agência Nacional de Águas).
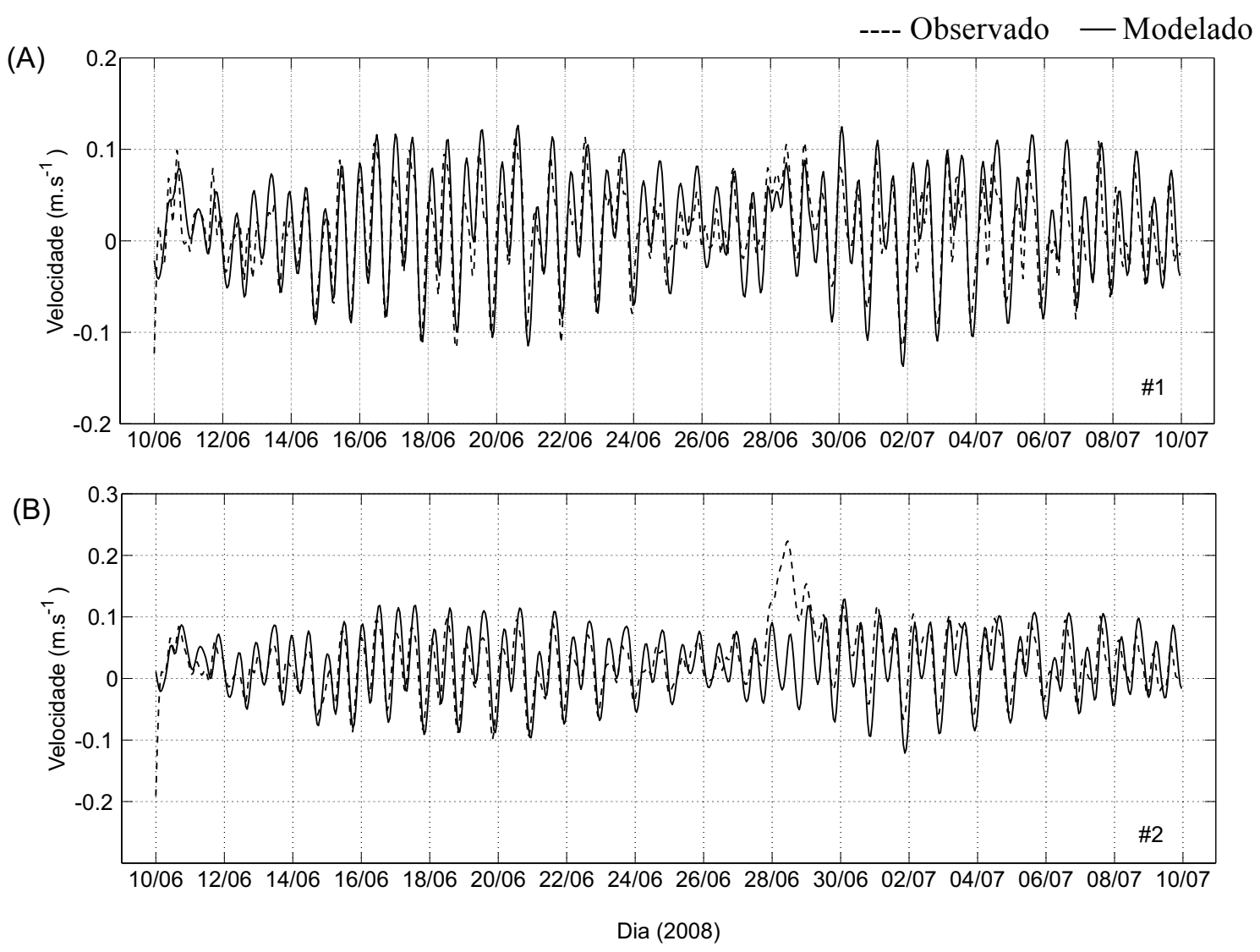

Figura 4.3. Comparação da série temporal da velocidade das correntes observada (----) e modelada (-) nas estações \#1 (A) e \#2 (B) para o período de calibração (10/06 09/07). 
Os resultados do modelo para a salinidade de fundo, na estação \#1 (Fig. 4.4), mostram que o modelo reproduziu a tendência geral da variação da salinidade ao longo do tempo. Pequenas flutuações da salinidade podem ser observadas durante o ciclo de marés nos dados observados. Os dados de salinidade do modelo oscilaram menos nos período de quadratura e mais nos períodos de sizígia. A diferença média entre os dados observados e medidos foi de 0,26 , e a máxima diferença de 2,56 observada na sizígia. $\mathrm{O}$ valor do parâmetro de Skill para comparação entre a salinidade de fundo observada e modelada mostrou uma boa correlação, com valor de 0,31 . O erro médio absoluto foi de 0,61 e o erro médio quadrático foi de 0,82 .

---- Observado — Modelado

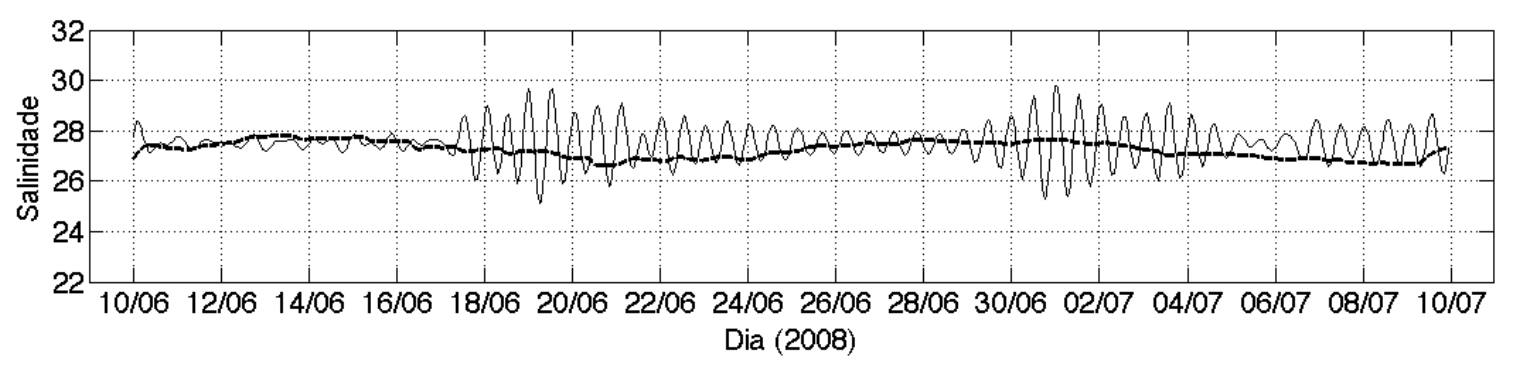

Figura 4.4. Comparação entre a salinidade do fundo observada (----) e modelada (-) na estação \#1, para o período de calibração.

Para calibrar a distribuição da salinidade, foram utilizados dados de dois perfis longitudinais de salinidade realizados no estuário. Os perfis foram observados nos dias 01 de agosto e 30 de setembro de 2008. O perfil de agosto foi realizado em condições de baixa descarga fluvial, em torno de $10 \mathrm{~m}^{3} . \mathrm{s}^{-1}$. Em setembro, os dias que antecederam o perfil apresentaram uma sequência de dois picos de descarga fluvial, em torno de $1000 \mathrm{~m}^{3} \cdot \mathrm{s}^{-1}$, para o primeiro, e de aproximadamente $400 \mathrm{~m}^{3} \cdot \mathrm{s}^{-1}$ para o segundo. 
Os perfis longitudinais de salinidade modelados, correspondentes ao perfis observados, foram retirados de uma simulação contínua. Essa simulação foi realizada para ajustar o campo de distribuição da salinidade. O período de simulação correspondeu ao período completo da campanha de 2008, descrita do Capítulo 4 (Metodologia), entre o dia 10 de junho e 30 de setembro. O modelo foi forçado pela variação do nível observada na estação \#1 e pela vazão média diária.

Comparando os perfis longitudinais da salinidade, modelado e observado, para agosto (Fig. 4.5), é possível observar que o modelo reproduziu bem a estrutura estratificada da salinidade ao longo do estuário. Para o perfil de setembro (Fig. 4.6), o modelo reproduziu estrutura estratificada ao longo do estuário, com algumas diferenças, principalmente em relação ao gradiente horizontal da salinidade do fundo. A salinidade do fundo variou entre 30 na desembocadura e 5 na região mais a montante para os dados do modelo. Enquanto que para os dados observados, a salinidade nas camadas mais profundas permaneceu estável em 25 ao longo do estuário. O modelo reproduziu o aumento da espessura e a estratificação na região da desembocadura.

Para demostrar de forma numérica a proximidade entre os dois resultados, modelado e observado, foram calculados os parâmetros de estratificação ao longo de todo o estuário. O parâmetro médio de estratificação para os dados modelado e observado foi de 1,2 e 0,8 , respectivamente, para o perfil de agosto. Para setembro os valores foram de 2,8 e 2,2 para o modelado e observado, respectivamente. No geral, o modelo foi capaz de reproduzir a natureza altamente estratificada do estuário. 
(A) Observado

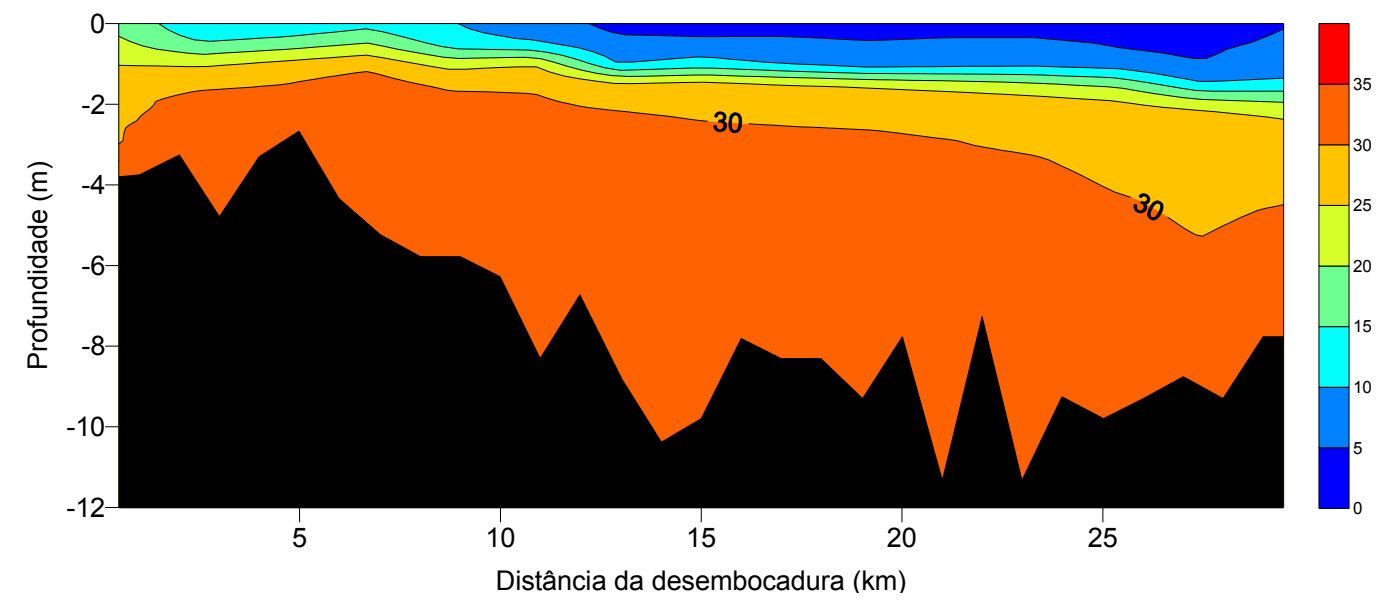

(B) Modelado

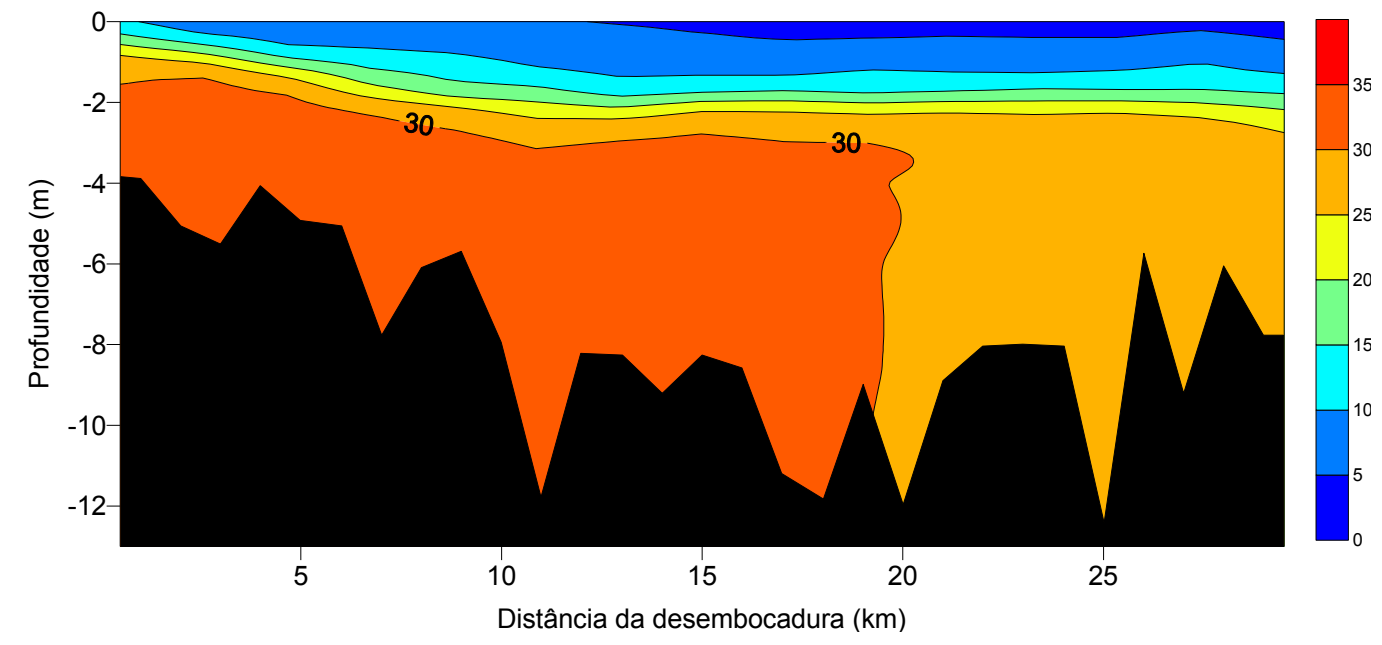

Figura 4.5. Comparação da distribuição longitudinal da salinidade em relação ao perfil realizado em 01 de agosto de 2008 para (A) observado e (B) modelado. 
(A) Observado

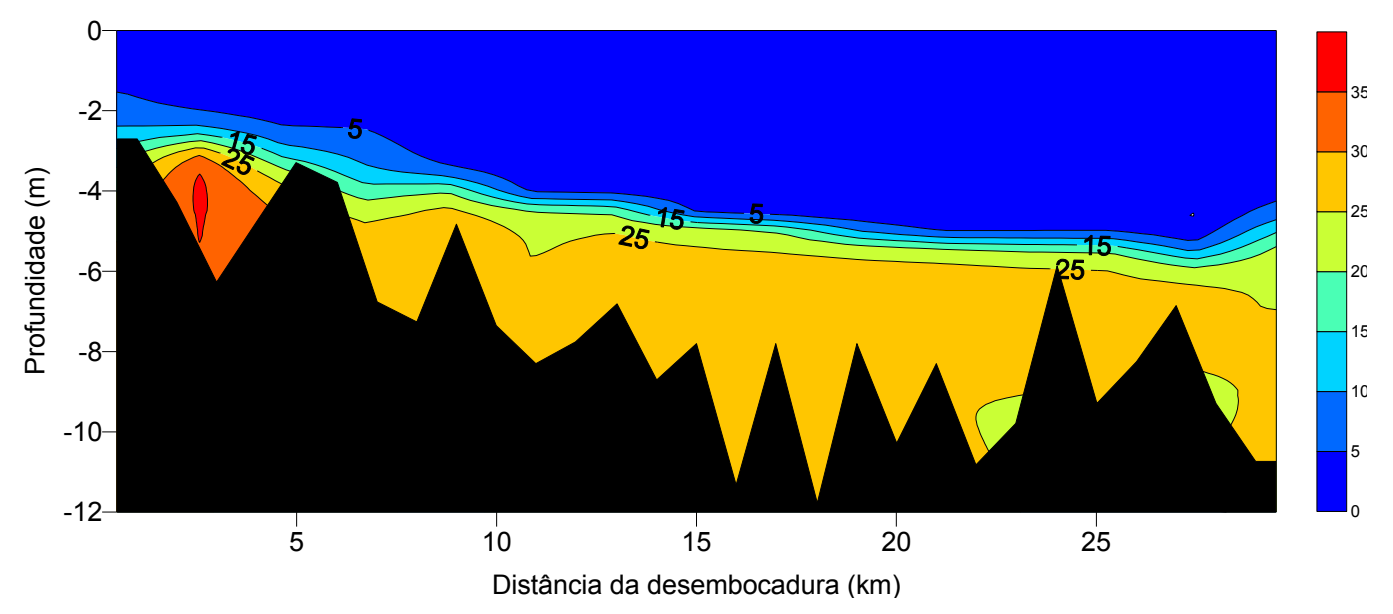

(B) Modelado

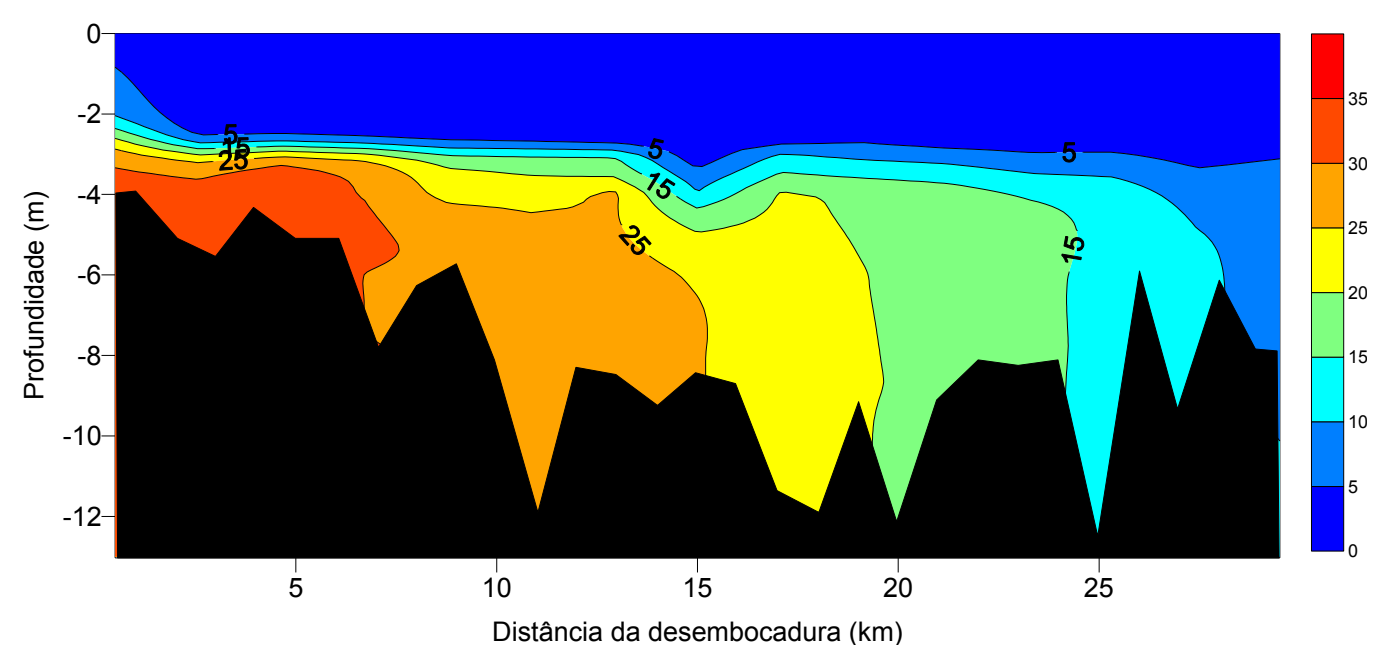

Figura 4.6. Comparação da distribuição longitudinal da salinidade em relação ao perfil realizado em 30 de setembro de 2008 para (A) observado e (B) modelado.

Tabela 4.1. Comparação estatística entre os dados do modelo e os dados observados para variação do nível da água $(\mathrm{m})$, velocidade de corrente $\left(\mathrm{m} . \mathrm{s}^{-1}\right)$ e salinidade do fundo, para o período da calibração.

\begin{tabular}{lcccc}
\hline \multicolumn{1}{c}{ Variáveis } & Localização & $E A M$ & REQM & SKILL \\
\hline Nível & $\# 1$ & 0,0297 & 0,0364 & 0,99 \\
& $\# 2$ & 0,0715 & 0,0870 & 0,96 \\
Velocidade & $\# 1$ & 0,0260 & 0,0315 & 0,90 \\
& $\# 2$ & 0,0274 & 0,0333 & 0,90 \\
Salinidade do fundo & $\# 1$ & 0,6158 & 0,8248 & 0,31 \\
\hline
\end{tabular}




\subsubsection{Validação}

O modelo foi adicionalmente verificado pela comparação entre os resultados do modelo com as séries temporais de nível da água, correntes e salinidade do fundo para o período entre o dia 01 e 31 de agosto de 2008. Os valores médios diários da descarga fluvial utilizados com forçante do modelo durante o período de validação estão representados na Figura 4.7. Os valores do parâmetro estatísticos para cada variável são apresentados na Tabela 4.2 .

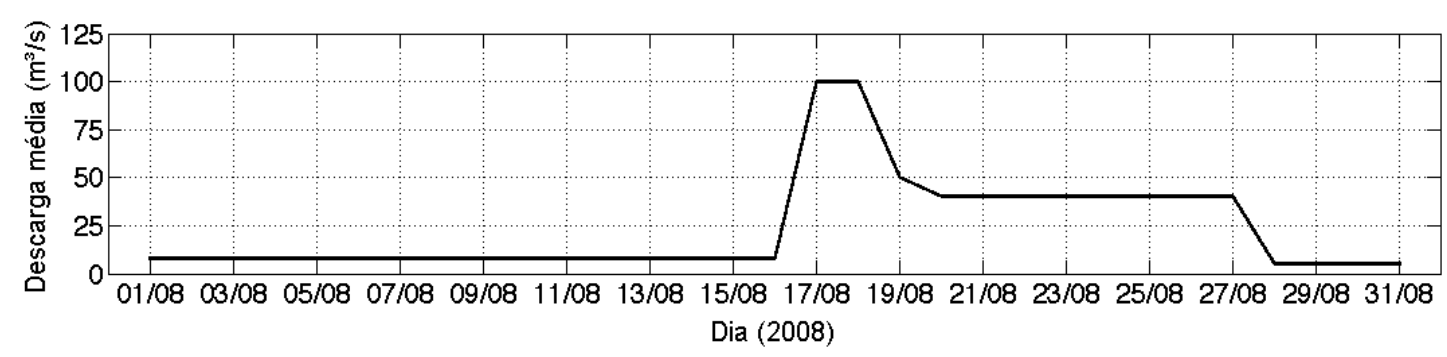

Figura 4.7. Descarga fluvial média diária utilizada no processo de validação.

A Figura 4.8 (A e B) mostra as comparações entre os dados modelados e observados para a variação do nível da água e velocidade nas duas estações (\#1 e \#2). O nível da água simulado pelo modelo mostra uma excelente concordância com os dados observados nas duas estações. O parâmetro de Skill entre o modelado e o observado foi de 0,99 e 0,95 nas estações \#1 e \#2, respectivamente. $O$ erro médio absoluto foi de 0,035 m na estação \#1 e de 0,077 m na estação \#2.

A velocidade modelada apresentou uma boa concordância em relação aos dados observados (Fig. 4.8 -C e D). Algumas diferenças podem ser notadas na magnitude entre os valores para alguns períodos da simulação. Em alguns momentos o modelo sobrestima o valor da velocidade e em outros subestima. O valor de Skill foi de 0,90 para a comparação nas duas estações. $O$ erro médio absoluto foi de 0,029 m na estação \#1 e de 0,026 m na estação \#2. 
(A)

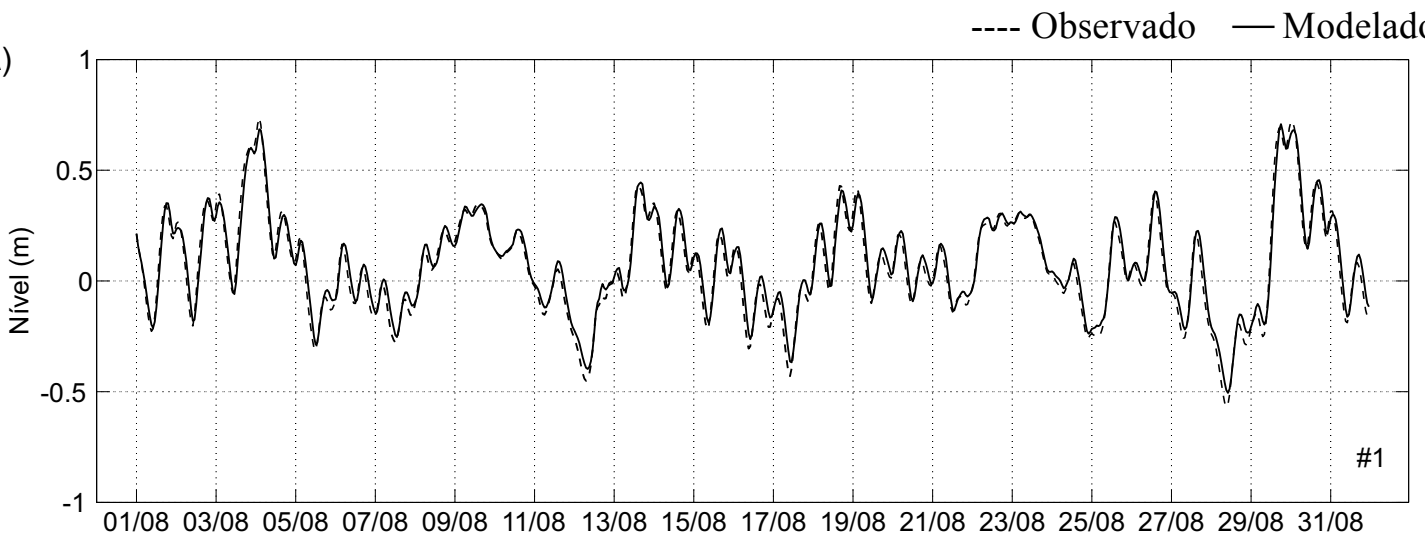

(B)

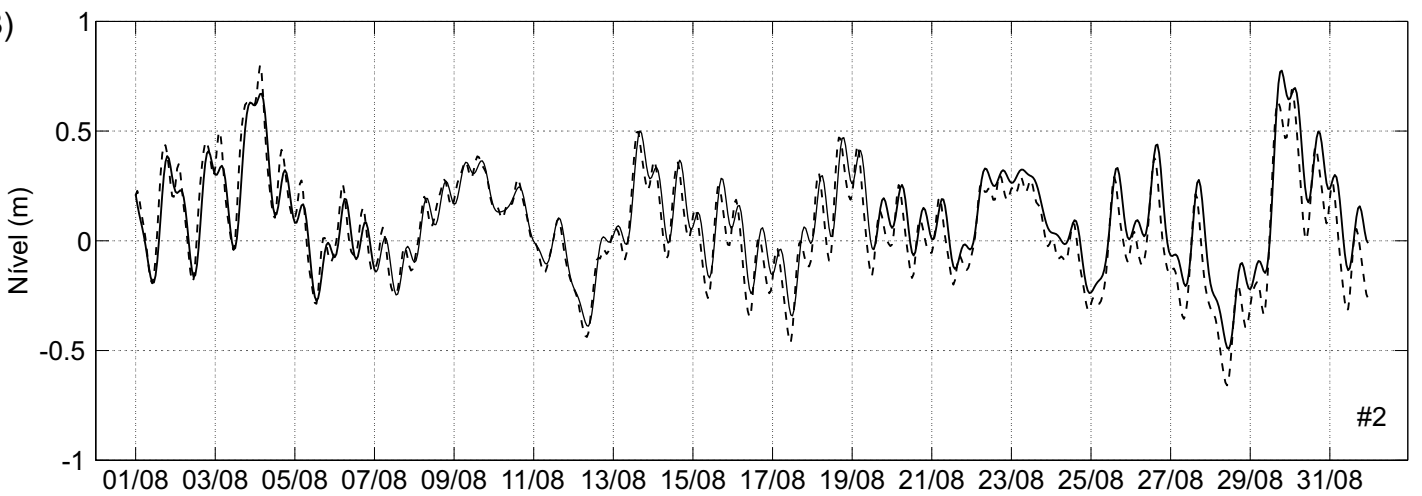

(C)

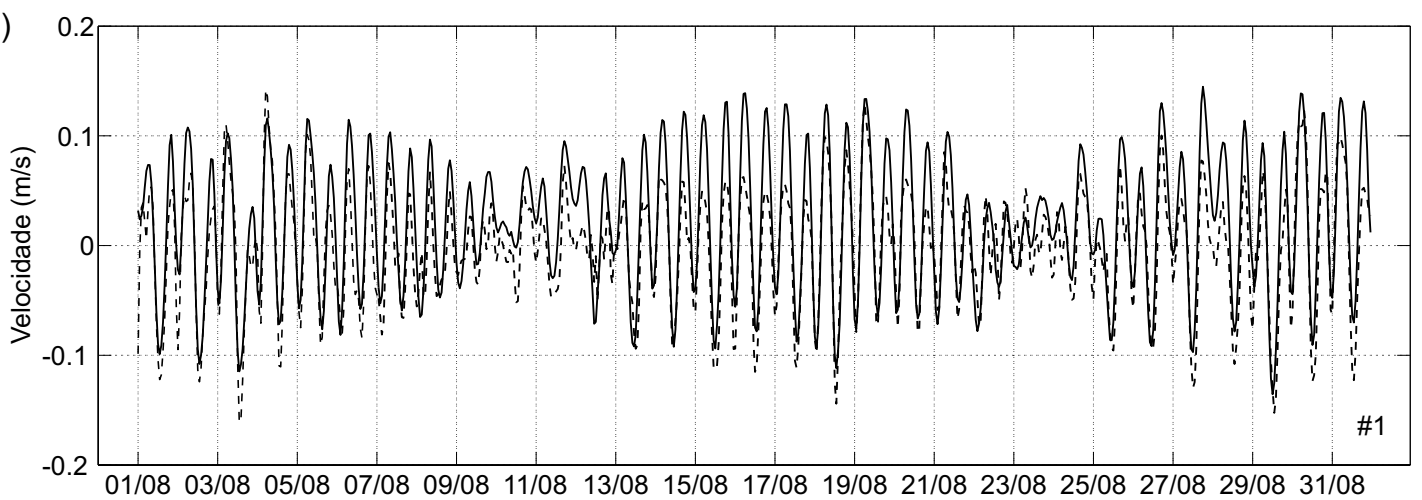

(D)

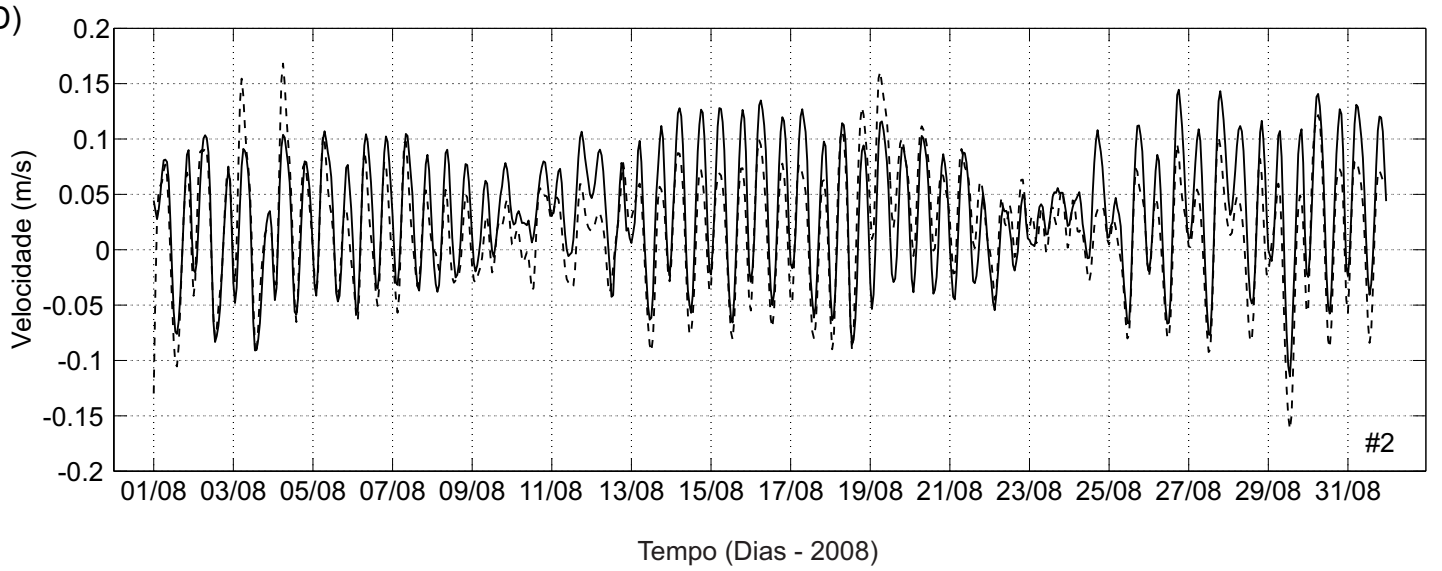

Figura 4.8. Comparação da série temporal observada (----) e modelada (-) do nível da água (A-\#1 e B-\#2) e corrente longitudinal média (C-\#1 e D-\#2) para o período de validação $(01 / 08-31 / 08)$. 
A comparação entre a salinidade de fundo modelada e observada para a validação do modelo (Fig. 4.9), mostra que os dados não estão em concordância durante todo o período de simulação. Os valores de salinidade são mais próximos no período de quadratura e mais distantes no período de sizígia. A salinidade, tanto modelada quando observada, oscila conforme a variação da maré. Na sizígia a salinidade modelada oscila mais em relação ao período de quadratura. A máxima diferença entre salinidade modelada e observada foi de 4,58. O valor do parâmetro de Skill para comparação entre a salinidade de fundo observada e modelada mostrou uma boa correlação, com valore de 0,39. O erro médio absoluto foi de 0,93 e o erro médio quadrático foi de 1,23.

---- Observado — Modelado

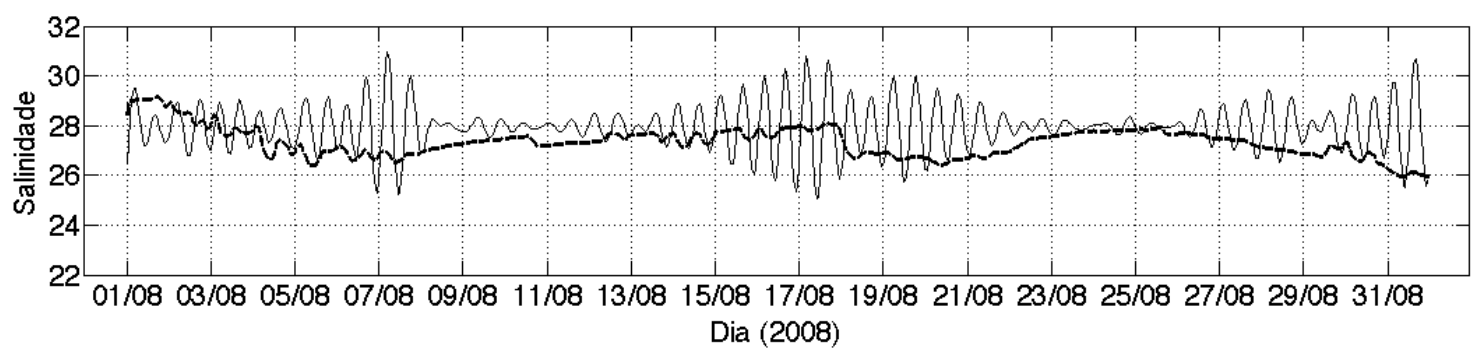

Figura 4.9. Comparação entre a salinidade do fundo modelada (-) e observada (----) na estação \#1, para o período de validação.

Tabela 4.2. Comparação estatística entre os dados do modelo e os dados observados para variação do nível da água $(\mathrm{m})$ e velocidade de corrente $\left(\mathrm{m} . \mathrm{s}^{-1}\right)$ para a validação.

\begin{tabular}{lcccc}
\hline \multicolumn{1}{c}{ Variáveis } & Localização & EAM & REQM & SKILL \\
\hline Nível & $\# 1$ & 0,0355 & 0,0437 & 0,99 \\
& $\# 2$ & 0,0773 & 0,0979 & 0,95 \\
Velocidade & $\# 1$ & 0,0296 & 0,0367 & 0,90 \\
& $\# 2$ & 0,0261 & 0,0324 & 0,90 \\
Salinidade do fundo & $\# 1$ & 0,9321 & 1,2347 & 0,39 \\
\hline
\end{tabular}


As figuras comparativas entre o resultado do modelo e os dados observados, tanto para no processo de calibração quanto na validação, mostram que o modelo reproduz bem as variações do nível da água e das velocidades das correntes. E como foram comparados em dois pontos distantes, um mais à montante e outro mais à jusante, é possível ter uma certeza de que na maior parte da área de interesse do estudo, que corresponde ao rio Araranguá, os resultados do modelo são confiáveis. A distribuição longitudinal e vertical da salinidade também foi reproduzida pelo modelo. Algumas diferenças foram observadas mas de um modo geral, a estrutura estratificada foi bem reproduzida pelo modelo. Essa estrutura foi monitorada durante a calibração e a validação para ter certeza da estabilidade da estratificação da salinidade sobre condições constantes de descarga fluvial e variação da maré. Considerando os bons resultados da calibração e validação do modelo, o modelo foi considerado apto para executar os experimentos hidrodinâmicos planejados. 


\subsection{Simulações de pico}

As simulações de pico de descarga fluvial foram realizadas com o objetivo de investigar as mudanças na hidrodinâmica, na distribuição da salinidade e no transporte advectivo de sal no estuário do rio Araranguá, sob o efeito de diferentes eventos de descarga fluvial. Todas as simulações começaram com descarga fluvial de $30 \mathrm{~m}^{3} \cdot \mathrm{s}^{-1}$, seguida por um pico de descarga, e retornando nos dias seguintes a descarga de $30 \mathrm{~m}^{3} . \mathrm{s}^{-}$ 1. Os picos simulados foram os de 100, $400700 \mathrm{e} 1000 \mathrm{~m}^{3} \cdot \mathrm{s}^{-1}$, nomeadas de Q100, Q400, Q700 e Q100, respectivamente. A duração de cada evento de elevação da descarga foi de dois dias, entre o aumento da descarga e sua diminuição. Uma simulação com descarga constante de $30 \mathrm{~m}^{3} \cdot \mathrm{s}^{-1}$ (Q30) também foi simulada, para servir de base de comparação e para ter uma ideia das características hidrodinâmicas do estuário em condições de baixa descarga fluvial. Todas as simulações foram forçadas pela elevação do nível da água nos contornos externos do modelo, na região da costeira adjacente. Dois conjuntos de simulações foram realizados, sendo que a diferença entre eles está no período de ocorrência dos picos. Uma série de simulações para o pico ocorrendo em condições de maré de quadratura e outro em maré de sizígia.

\subsubsection{Simulações quadratura}

As variações temporais do nível da água, da velocidade das correntes e da salinidade na estação \#1, localizada no estuário do rio Araranguá (Fig. 4.2), para todas as simulações estão apresentadas na Figura 4.10. A Figura 4.10 (A) é uma representação da evolução da descarga fluvial durante as simulações, no eixo x estão representados os dias simulados. O pico é representado pelo aumento da descarga fluvial no primeiro dia (3) e a descida do pico ocorre no segundo dia (4).

Durante a passagem do evento de pico de descarga de 700 e $1000 \mathrm{~m}^{3} \cdot \mathrm{s}^{-1}$, o nível da água apresentou uma elevação (Fig. 4.10-B), em relação às demais simulações. Sendo que os níveis máximos modelados foram de 0,24 m para Q30, Q100 e Q400, de 0,36 m para Q700 e de 0,6 m em Q1000. 
Com o aumento da descarga fluvial as velocidades das correntes em toda coluna da água aumentou, e o movimento passou a ser unidirecional, estuário abaixo. Esse movimento foi observado em todas as simulações durante o dia do pico (Fig. 4.10-C), exceto na simulação Q30. Para Q400 o movimento estuário baixo permaneceu até o dia seguinte, e para Q700 e Q1000 o movimento permaneceu até o final do segundo dia após o evento. As velocidades máximas modeladas, para todo o período, foram de 0,4 ,

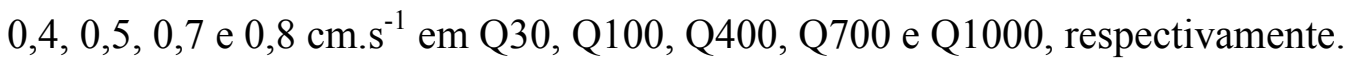

Durante o período do pico de descarga, nas simulações Q100 e Q400, a estrutura vertical da salinidade não variou de forma significativa, quando comparadas com Q30 (Fig. 4.10-D). Com a passagem do evento de 700 e $1000 \mathrm{~m}^{3} \cdot \mathrm{s}^{-1}$ a salinidade foi transportada estuário afora. Em Q700 a descarga fluvial transporta a salinidade para plataforma, mas logo, a cunha salina retorna para dentro do estuário. Já em Q1000, a cunha salina é transportada para plataforma e retorna somente $48 \mathrm{~h}$ depois do evento. No dia 6, dois dias após o evento, a estratificação aumentou consideravelmente, principalmente em Q400, Q700 e Q1000, quando comparadas com Q30. Em Q100, a estrutura vertical da salinidade, após o evento, apresentou maior estratificação, quando comparada com Q30. Observando apenas a variação da salinidade em Q30 e Q100 é possível identificar uma diferença da estratificação nos períodos de quadratura e sizígia. Em condições de sizígia, a coluna de água é menos estratificada em relação ao período de quadratura.

O restabelecimento das variações do nível e das velocidades das correntes, após o evento de aumento da descarga fluvial, é mais rápido comparado com o restabelecimento da circulação gravitacional. A partir do dia 6, os níveis de todas as simulações voltam a oscilar igualmente (amplitude e fase) e a partir do dia 7 as velocidades voltam a apresentar variações iguais (amplitude e fase). Os valores de variação da salinidade na coluna da água (Fig. 4.10-D), diferença entre a salinidade do fundo pela superfície, convergem para o mesmo valor, observando Q30 como referência, após cerca de 13 dias para Q100, 19 dias para Q400 e 23 dias para Q700 e Q1000. Essas diferenças de tempo do restabelecimento das condições do estuário sobre mesma condição de descarga fluvial $\left(30 \mathrm{~m}^{3} \cdot \mathrm{s}^{-1}\right)$ e variação da maré ocorrem devido as diferenças da magnitude de cada evento, tanto durante a elevação do pico quanto durante a descida dele. 
(A)

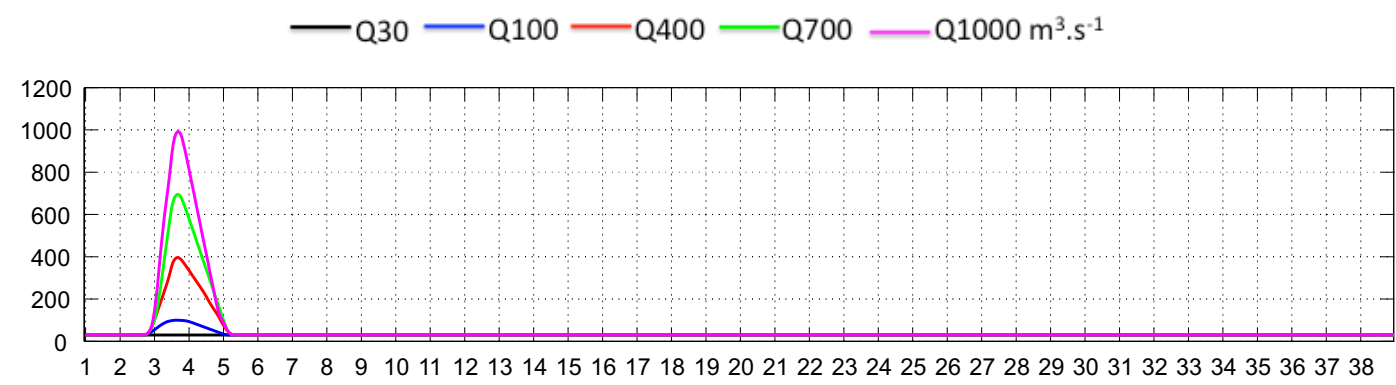

(B)

estação \#1

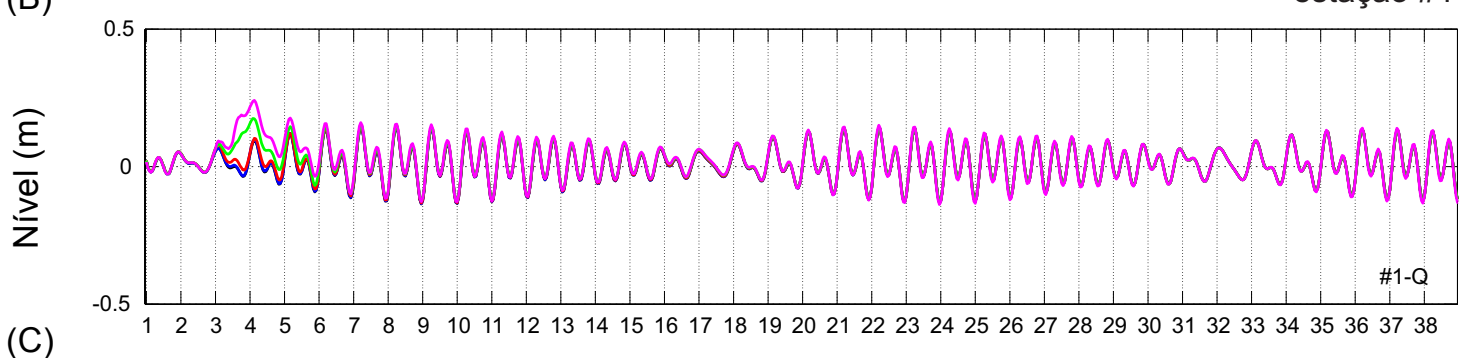

(C)

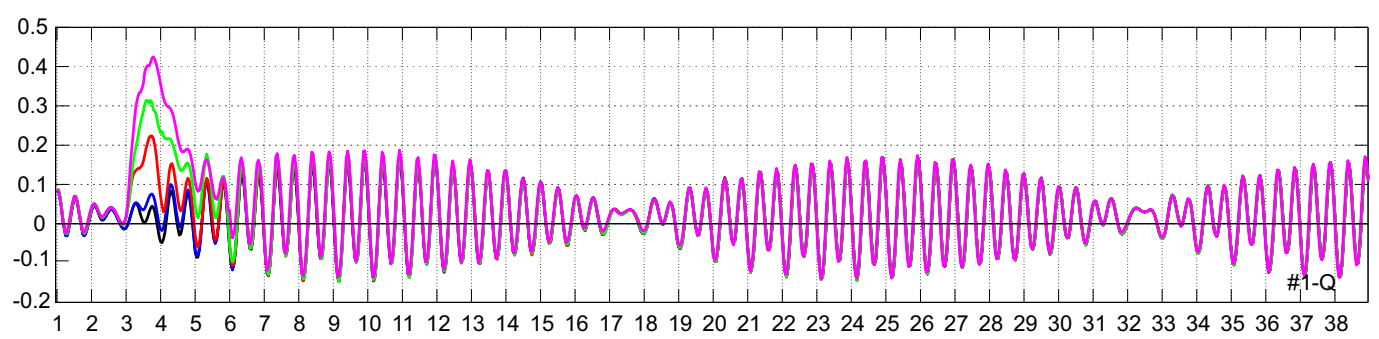

(D)

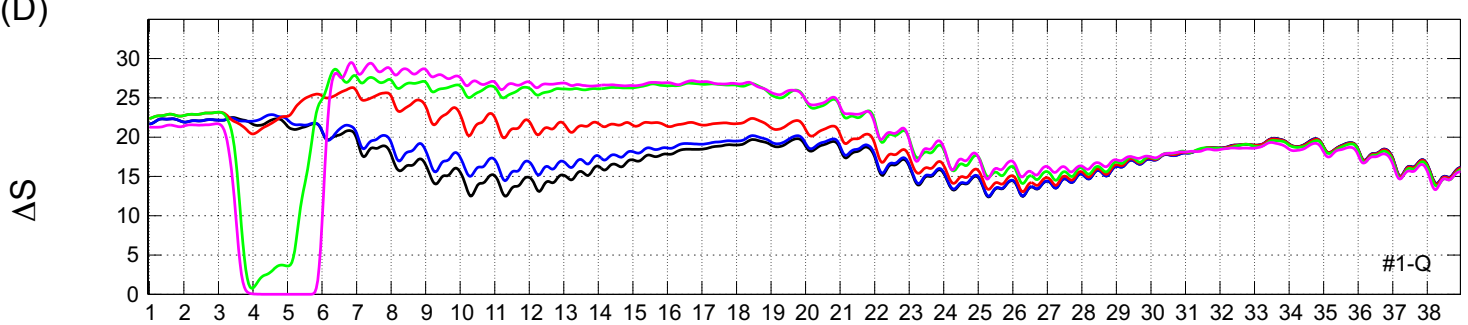

Tempo (dia)

Figura 4.10. Resultados do modelo. Séries temporais da variação do nível da água (B), da velocidade das correntes $(C)$ e da salinidade (diferença entre a salinidade do fundo e da superfície) (D), das simulações de descarga fluvial, Q30 (linha preta), Q100 (linha azul), Q400 (linha vermelha), Q700 (linha verde) e Q1000 (linha magenta) em condição de maré de quadratura para a Estação \#1. As velocidades positivas indicam as correntes de vazante e as negativas as correntes de enchente.

O transporte advectivo de sal foi calculado com os dados de velocidade da corrente, salinidade e temperatura obtidos pelo modelo em um ponto localizado a aproximadamente 7 km de distância da desembocadura (\#1, Fig. 3.2). Para ter uma ideia de como os termos do transporte advectivo variam durante o evento de elevação da descarga fluvial, os cálculos foram realizados em janelas de 25 horas. As janelas correspondem ao deslocamento em uma hora ao longo de todo o tempo. Por exemplo, o 
primeiro cálculo utiliza os dados da primeira até a vigésima quinta hora (1-25), o segundo cálculo abrange a segunda até a vigésima sexta hora (2-26) e assim por diante.

A variação temporal dos termos de descarga fluvial e circulação gravitacional durante todas as simulações estão apresentadas na Figura 4.11. O termo da circulação gravitacional está representado em módulo para melhor visualização. Com o aumento da descarga fluvial, o transporte de sal estuário abaixo aumentou. $\mathrm{O}$ termo dispersivo da circulação gravitacional, responsável pelo transporte de sal estuário acima, diminui consideravelmente durante a passagem do pico nas simulações Q700 e Q1000. Já nas simulações Q100 e Q400, o termo da circulação gravitacional aumentou durante os eventos. Nos instantes seguintes a passagem do pico, nas simulações Q400, Q700 e Q1000, o termo da circulação gravitacional aumentou consideravelmente. Indicando o início do restabelecimento das condições do estuário, com a estabilização da descarga fluvial.

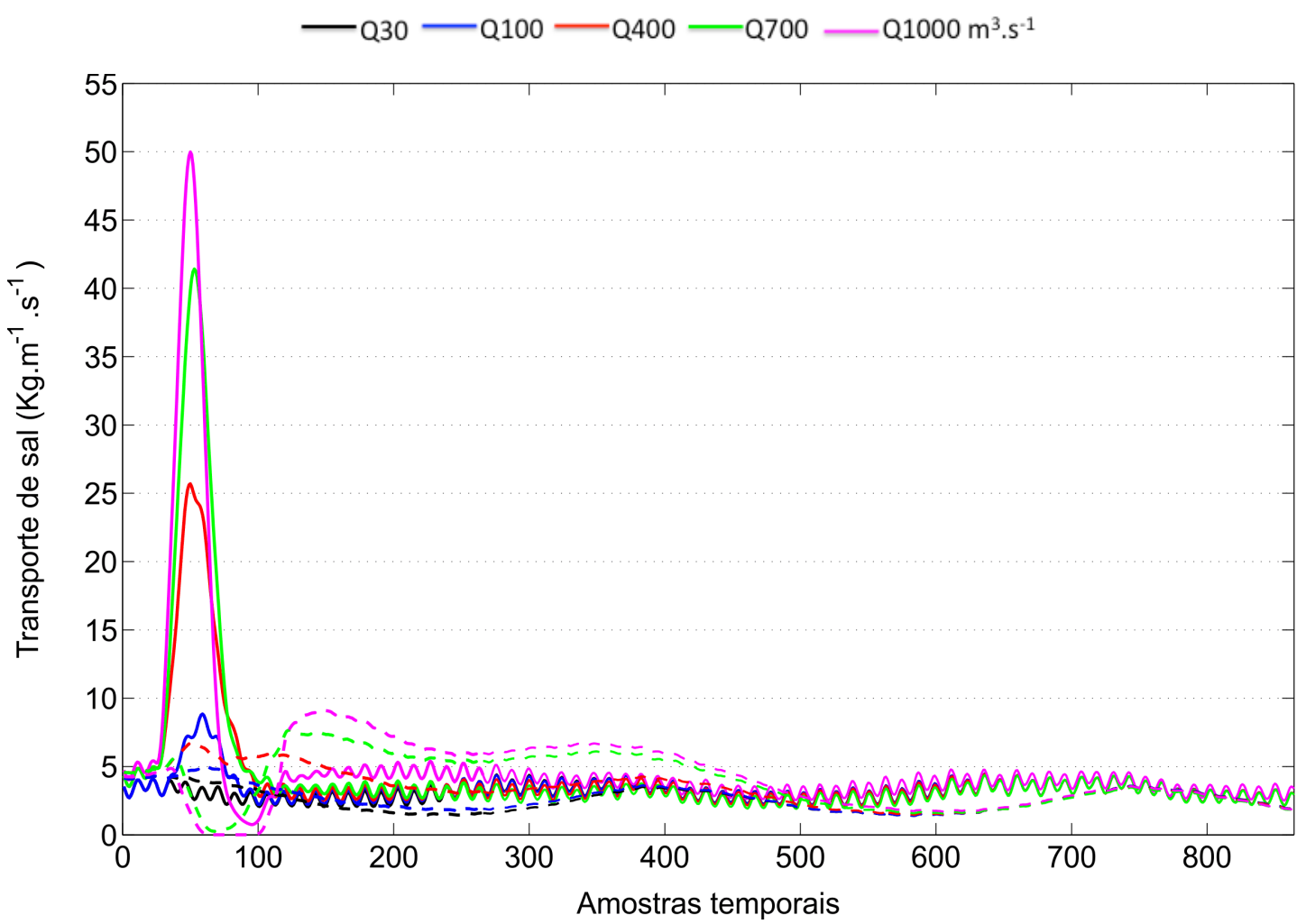

Figura 4.11. Resultados do modelo. Variação temporal dos termos de descarga fluvial (linhas sólidas) e circulação gravitacional (linhas descontinuas) da equação do transporte advectivo de sal, em $\mathrm{kg} \cdot \mathrm{m}^{-1} \cdot \mathrm{s}^{-1}$. Os valores estão em módulo. Para todas as simulações realizadas na quadratura na posição que corresponde a estação \#1. 
Os termos do transporte advectivo de sal calculados durante período de aumento da descarga fluvial, que corresponde às 25 horas do dia do evento, estão apresentadas na Tabela 4.3. Na simulação Q30, com descarga fluvial constante, o termo dominante do transporte de sal foi a circulação gravitacional, seguido pelo termo da descarga fluvial, com transporte total de $-1,4 \mathrm{~kg} \cdot \mathrm{m}^{-1} \cdot \mathrm{s}^{-1}$, estuário acima. Em Q400 e Q700 os termos dominantes foram a descarga fluvial e a circulação gravitacional, com transporte total de 2,58 e 18,27 kg.m $\mathrm{m}^{-1} \cdot \mathrm{s}^{-1}$ estuário abaixo, respectivamente. Na simulação Q700 o termo dominante foi a descarga fluvial seguido pela circulação gravitacional, com transporte total de $38 \mathrm{~kg} \cdot \mathrm{m}^{-1} \cdot \mathrm{s}^{-1}$, estuário abaixo. Nesta simulação, os termo da correlação da maré e do bombeamento da maré contribuíram com $-0,15$ e $-0,96 \mathrm{~kg} \cdot \mathrm{m}^{-1} \cdot \mathrm{s}^{-1}$ no processo dispersivo de sal estuário acima, respectivamente. Em Q1000 a descarga fluvial foi o termo dominante do transporte de sal estuário abaixo e correlação da maré foi o termo dominante do transporte de sal estuário acima, com o transporte total de $45,35 \mathrm{~kg} . \mathrm{m}^{-1} . \mathrm{s}^{-}$ 1 , estuário abaixo.

Comparando todas as simulações, é possível observar o aumento do transporte de sal estuário abaixo com o aumento da descarga fluvial. Intensificando o termo de natureza advectivo da descarga fluvial. A circulação gravitacional perde sua importância como processo dispersivo em Q1000 e ganha importância como termo dispersivo em Q30. O termo da correlação da maré contribui no processo dispersivo de sal estuário acima nas simulações Q700 e Q1000 e no processo advectivo de transporte de sal estuário abaixo em Q400. 
Tabela 4.3: Termos do transporte advectivo de sal, calculados como os resultados do modelo, para o período de passagem do pico de descarga (25 horas), em todas as simulações (Q30, Q100, Q400, Q700 e Q1000), realizadas em condições de maré de quadratura. Valores em $\mathrm{kg} \cdot \mathrm{m}^{-1} \cdot \mathrm{s}^{-1}$.

\begin{tabular}{lccccc}
\hline \hline \multicolumn{1}{c}{$\begin{array}{c}\text { Termos do transporte } \\
\text { advectivo }\end{array}$} & $Q 30$ & $Q 100$ & $Q 400$ & $Q 700$ & $Q 1000$ \\
\hline \hline 1-Descarga fluvial & $\mathbf{2 , 5 8}$ & $\mathbf{7 , 2 6}$ & $\mathbf{2 4 , 8 1}$ & $\mathbf{4 1 , 4 1}$ & $\mathbf{4 9 , 9 8}$ \\
2-Transporte de Stokes & $-0,01$ & $-0,08$ & $-0,03$ & 0,00 & 0,06 \\
3-Correlação da maré & 0,02 & 0,06 & $\mathbf{0 , 1 9}$ & $\mathbf{- 0 , 1 5}$ & $\mathbf{- 2 , 1 2}$ \\
4-Circulação gravitacional & $\mathbf{- 3 , 9 9}$ & $\mathbf{- 4 , 7 3}$ & $\mathbf{- 6 , 6 4}$ & $\mathbf{- 2 , 2 4}$ & $\mathbf{- 1 , 6 2}$ \\
5-Bombeamento da maré & $-0,00$ & 0,01 & $-0,05$ & $\mathbf{- 0 , 9 6}$ & $\mathbf{- 0 , 8 6}$ \\
6-Cisalhamento da maré & 0,00 & 0,00 & 0,00 & 0,00 & 0,00 \\
7-Flutuação do vento & $-0,00$ & 0,00 & $-0,00$ & $-0,00$ & $-0,00$ \\
\hline \multicolumn{1}{c}{ Transporte total } & $-1,4$ & 2,58 & 18,27 & 38,03 & 45,35 \\
\hline \hline
\end{tabular}

As Figuras de 4.13 a 4.17 apresentam a distribuição da salinidade ao longo do estuário do rio Araranguá. Cada figura contém uma sequência de gráficos da distribuição da salinidade modelada, em diferentes instantes das simulações realizadas. Os instantes foram escolhidos para visualizar a distribuição da salinidade ao longo do tempo para cada simulação (Fig. 4.12). E desta forma, acompanhar as mudanças na estrutura vertical e horizontal da salinidade durante a passagem do evento de descarga fluvial. A extensão do domínio onde está apresentada a distribuição da salinidade corresponde desde o limite do domínio estuário acima, no rio Itoupava, até a desembocadura do rio Araranguá.

No instante t1 é possível observar a estrutura da salinidade antes da passagem do pico em condições de baixa descarga. $\mathrm{O}$ instante $\mathrm{t} 2$ coincide com o máximo de descarga fluvial. Em t3 é possível observar o que acontece ao final do dia do pico, $\sim 12$ horas após o evento. Em t4, t5 e t6 é possível observar o que acontece após 84, 132 e 252 horas, respectivamente. A escolha desses instantes não foi baseada em um período característico, e sim em observações do movimento da cunha salina (recuo e avanço) nas simulações, através do programa de visualização dos resultados do modelo Delft3D (Quickplot). Assim, com esse conjunto de resultados é possível observar as principais 
mudanças da distribuição da salinidade conforme a variação da descarga fluvial. Os instantes são os mesmo para todas as simulações.

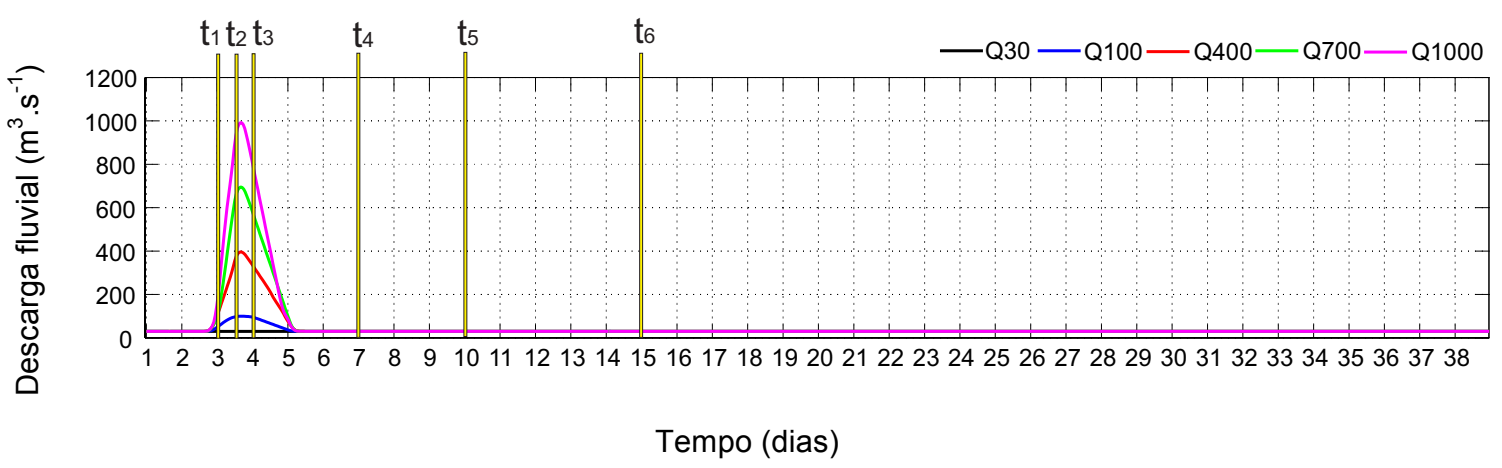

Figura 4.12. Representação dos instantes, $\mathrm{t} 1$, $\mathrm{t} 2$, $\mathrm{t} 3$, $\mathrm{t} 4, \mathrm{t} 5$ e $\mathrm{t} 6$, escolhidos para representar graficamente a distribuição da salinidade.

As Figuras 4.13 e 4.14 mostram que durante todo o período representado (entre t1 e t6), a salinidade permaneceu estratificada em toda a extensão do estuário nas simulações Q30 e Q100. O evento de elevação da descarga fluvial de 30 para $100 \mathrm{~m}^{3} . \mathrm{s}^{-1}$ não causou nenhum efeito na estrutura da distribuição de sal no estuário. A espessura da camada superficial da coluna da água com baixa salinidade não ultrapassou o primeiro metro, devido ao grande volume de água salgada no estuário. O gradiente horizontal da salinidade nas maiores profundidades se torna mais evidente no instante t6. Neste instante, a salinidade varia, aproximadamente, de 35 na desembocadura a 20 na região mais a montante, em Q30 e Q100.

No caso da simulação Q400 (Fig. 4.15), com a passagem do pico, um volume maior de água doce chegou ao estuário promovendo a desestabilização da estratificação ao longo do estuário, principalmente na porção superior, e o aumento da espessura de água doce nas camadas superiores da coluna de água. Após o evento, a cunha salina avançou estuário acima e a espessura de água doce nas camadas superiores diminuiu, com a diminuição da descarga fluvial. 
Com a passagem dos picos de 700 (Fig. 4.16) e $1000 \mathrm{~m}^{3} \cdot \mathrm{s}^{-1}$ (Fig. 4.17) a estrutura estratificada da coluna de água foi completamente desestabilizada e o sal foi transportado estuário abaixo. No instante t3 da simulação Q1000 é possível observar que o sal foi transportado para plataforma e a água doce ocupou todo o volume do estuário. Neste mesmo instante em Q700 é possível observar o aprisionamento de sal nas regiões mais profundas do estuário entre a desembocadura e o quilômetro 11 . No instante t4 é possível observar o avanço da cunha salina estuário acima em Q700 e Q1000, e em t6 a estrutura estratificada alcança a estabilização novamente. 

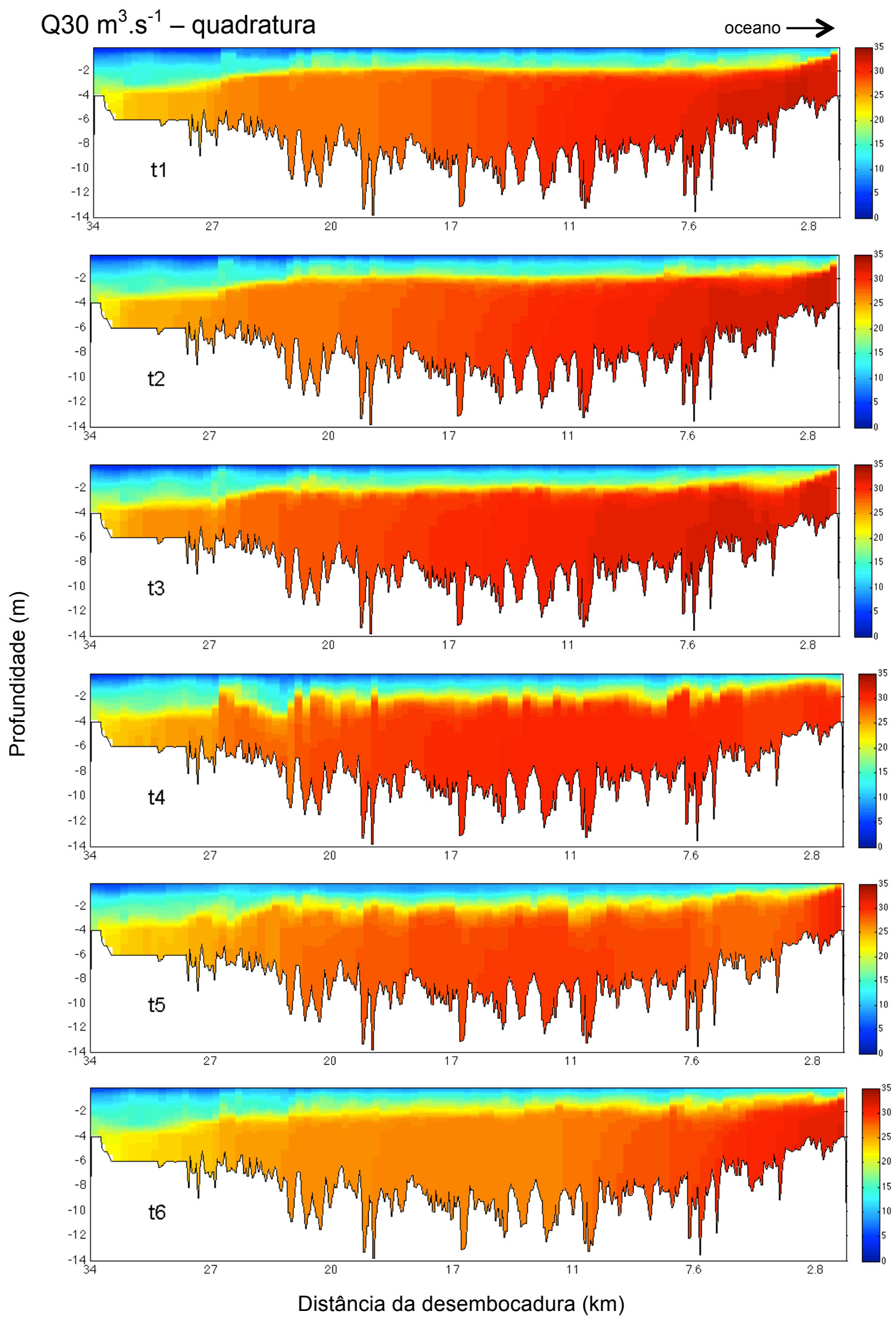

Figura 4.13. Resultados do modelo. Distribuição vertical da salinidade ao longo do perfil longitudinal e ao longo do tempo (t1, t2, t3, $t 4, \mathrm{t} 5$ e $\mathrm{t} 6)$, no estuário do rio Araranguá, em condições de descarga fluvial de $30 \mathrm{~m}^{3} \cdot \mathrm{s}^{-1}(\mathrm{Q} 30)$, com início na quadratura. 

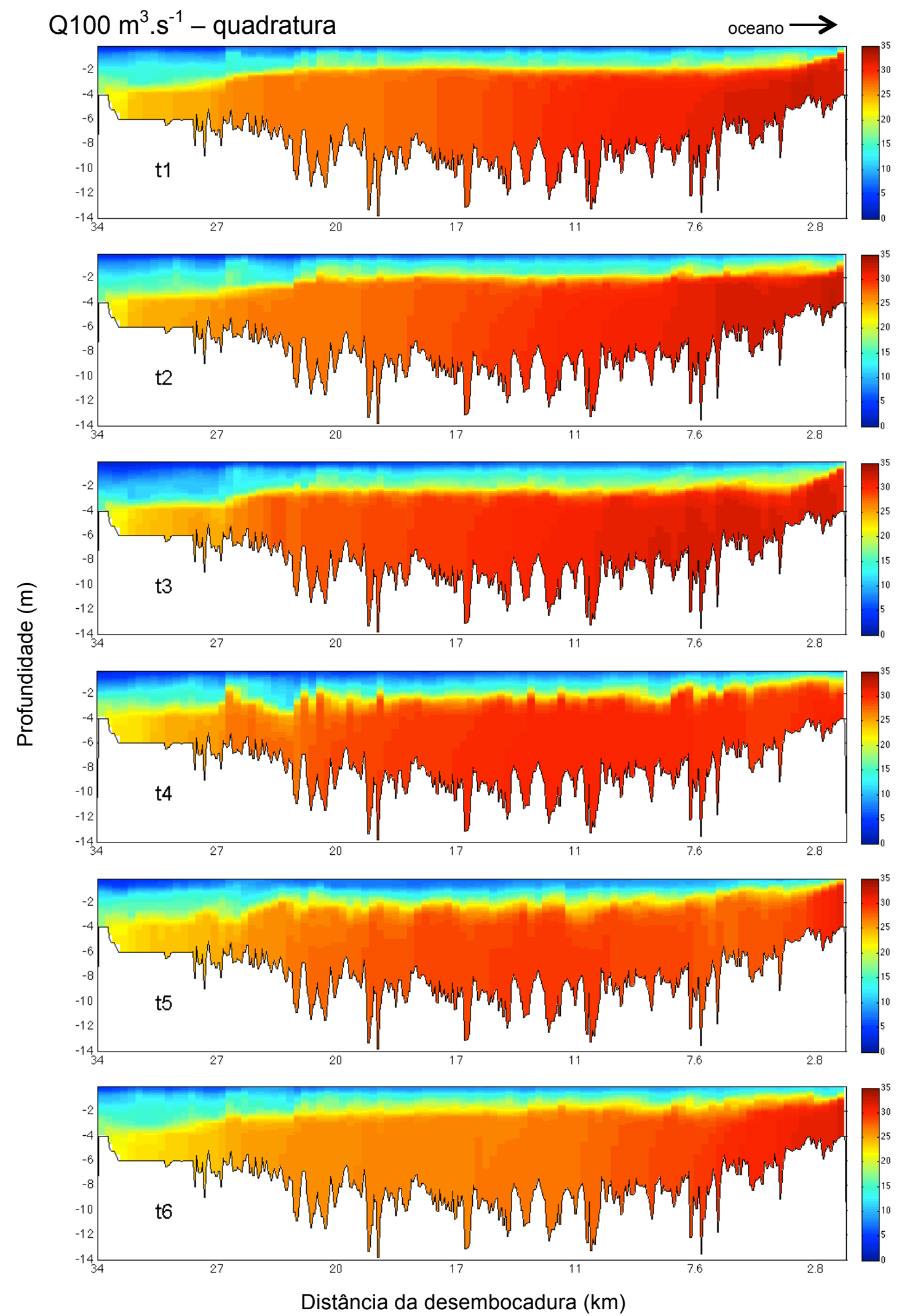

Figura 4.14. Resultados do modelo. Distribuição vertical da salinidade ao longo do perfil longitudinal e ao longo do tempo ( $t 1, \mathrm{t} 2, \mathrm{t} 3, \mathrm{t} 4, \mathrm{t} 5 \mathrm{e} \mathrm{t} 6)$, no estuário do rio Araranguá, para a simulação Q100, com pico na quadratura. 

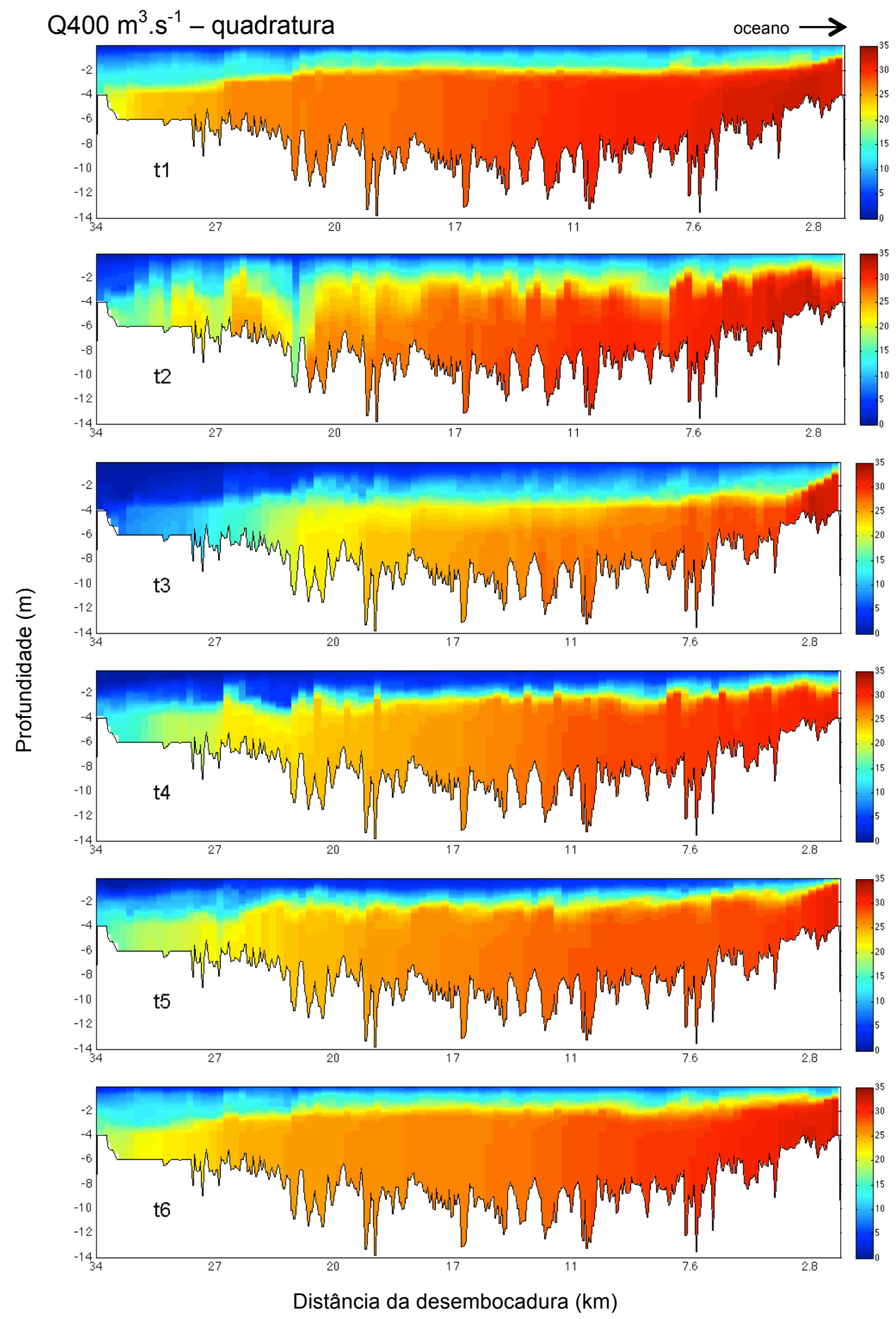

Figura 4.15. Resultados do modelo. Distribuição vertical da salinidade ao longo do perfil longitudinal e ao longo do tempo ( $\mathrm{t} 1, \mathrm{t} 2, \mathrm{t} 3, \mathrm{t} 4, \mathrm{t} 5 \mathrm{e} \mathrm{t} 6)$, no estuário do rio Araranguá para a simulação Q400, com pico na quadratura. 

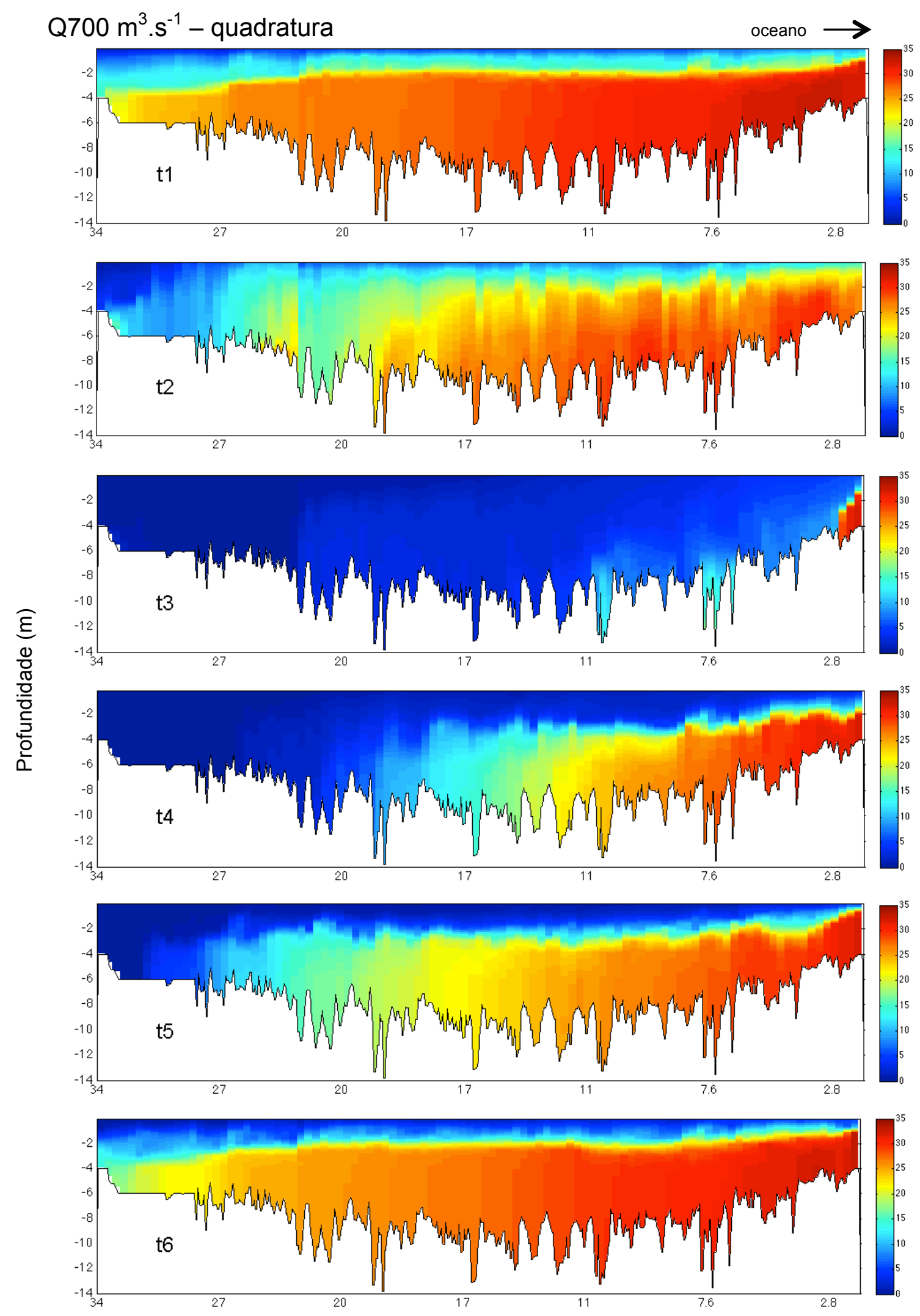

Distância da desembocadura $(\mathrm{km})$

Figura 4.16. Resultados do modelo. Distribuição vertical da salinidade ao longo do perfil longitudinal e ao longo do tempo ( $\mathrm{t} 1, \mathrm{t} 2, \mathrm{t} 3, \mathrm{t} 4, \mathrm{t} 5 \mathrm{e} \mathrm{t} 6)$, no estuário do rio Araranguá para a simulação Q700, com pico na quadratura. 

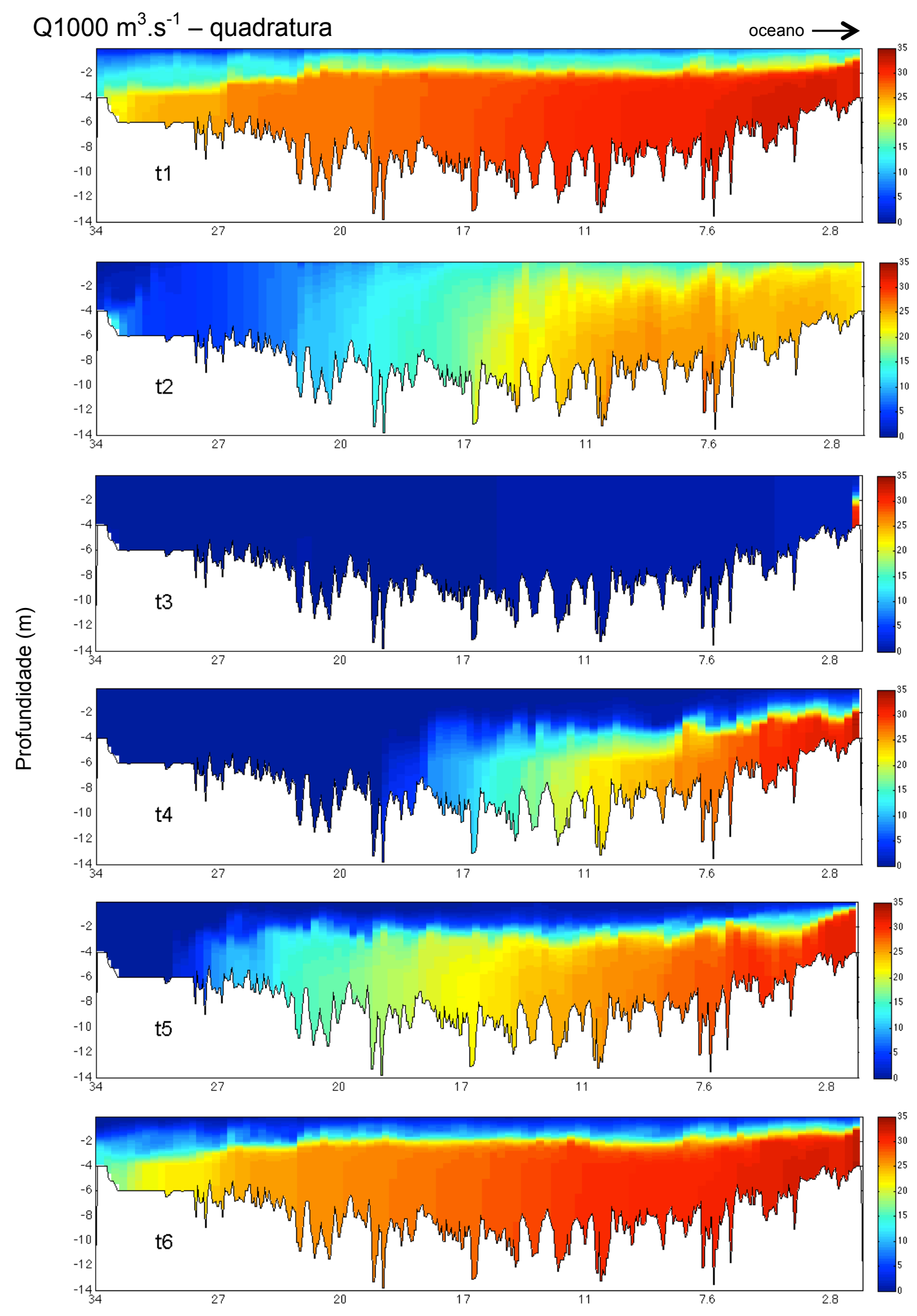

Distância da desembocadura $(\mathrm{km})$

Figura 4.17. Resultados do modelo. Distribuição vertical da salinidade ao longo do perfil longitudinal e ao longo do tempo ( $\mathrm{t} 1, \mathrm{t} 2, \mathrm{t} 3, \mathrm{t} 4, \mathrm{t} 5 \mathrm{e} \mathrm{t} 6)$, no estuário do rio Araranguá para a simulação Q1000, com pico na quadratura. 
Os perfis verticais de salinidade e velocidade, no período entre t1 e t6, que corresponde a 288 horas (12 dias), foram utilizadas para representar a salinidade e a velocidade residual para cada simulação. Os perfis médios foram calculados com os dados do modelo para o ponto que representa a localização da estação \#1, a mesma utilizada no processo de calibração e nos cálculos do transporte advectivo de sal.

Os perfis médios da velocidade para todas as simulações estão apresentados na Figura (4.18-A). Os perfis mostram que as maiores velocidades, para todas as simulações, se encontram nas camadas superficiais, nos dois primeiros metros de profundidade, com velocidade resultante estuário abaixo. As velocidades máximas modeladas, para o período analisado, foram de $0,14,0,15,0,17,0,19$ e $0,2 \mathrm{~m} \cdot \mathrm{s}^{-1}$, para Q30, Q100, Q400, Q700 e Q1000, respectivamente. Nas camadas mais profundas, abaixo dos $2 \mathrm{~m}$, as velocidades são mais baixas e a resultante é estuário acima para todas as simulações, exceto em Q1000. Nesta, a velocidade resultante foi estuário abaixo em praticamente toda a coluna da água, sendo que no primeiro metro acima do fundo a velocidade é aproximadamente zero.

Os perfis médios de salinidade (Fig. 4.18-B) apresentaram um gradiente vertical bastante pronunciado em todas as simulações. A salinidade na superfície foi de 11, 10, 6, 3 e 2, para Q30, Q100, Q400, Q700 e Q1000, respectivamente, e no fundo de 29, para Q30, Q100, Q400, Q700 e 27 para Q1000. 
(A)

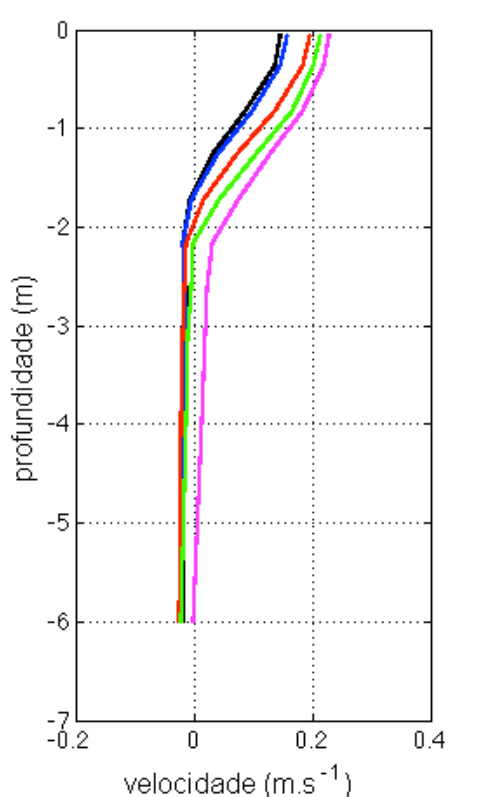

(B)

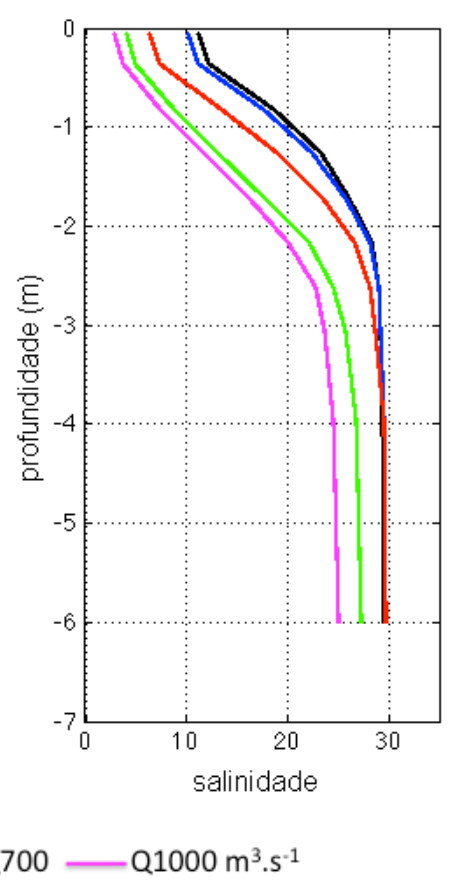

Figura 4.18. Resultados do modelo. Perfis médios de velocidade (A) e salinidade (B) para o período entre t1 e t6. Para todas as simulações com pico na quadratura, Q30 (linha preta), Q100 (linha azul), Q400 (linha vermelha), Q700 (linha verde) e Q1000 (linha magenta), na estação \#1 ( 7 km da desembocadura)

A salinidade do fundo modelada, entre a desembocadura e a região da confluência, para todas as simulações está apresentada na Figura 4.19. Em Q30 e Q100 a descarga fluvial não influenciou na distribuição da salinidade ao longo do estuário (Fig. $4.19 \mathrm{~A}$ e B). O evento de $100 \mathrm{~m}^{3} \cdot \mathrm{s}^{-1}$ não promoveu a desestabilização da estratificação. Nessas duas simulações é possível observar que o gradiente de distribuição da salinidade oscila entre os períodos de maré de quadratura e sizígia. Durante a quadratura o gradiente de salinidade avança estuário acima e durante a sizígia o avanço não é tão significativo. O pico de $400 \mathrm{~m}^{3} . \mathrm{s}^{-1}$ (Fig. 4.19-C) promoveu uma desestabilização da estratificação ao longo do estuário, principalmente no trecho acima do quilômetro 21. A salinidade foi transportada estuário abaixo nas simulações com pico de 700 e $1000 \mathrm{~m}^{3} \cdot \mathrm{s}^{-1}$ (Fig. $4.19 \mathrm{D}$ e E). O avanço da cunha salina pode ser observado ao longos dos dias após os eventos em Q700 e Q1000. 
(A)

Q30

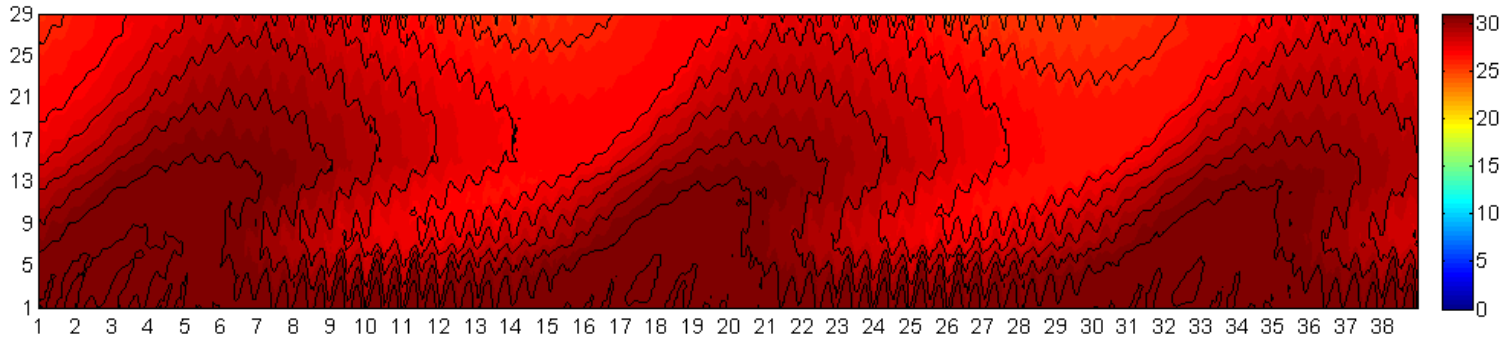

(B)

Q100

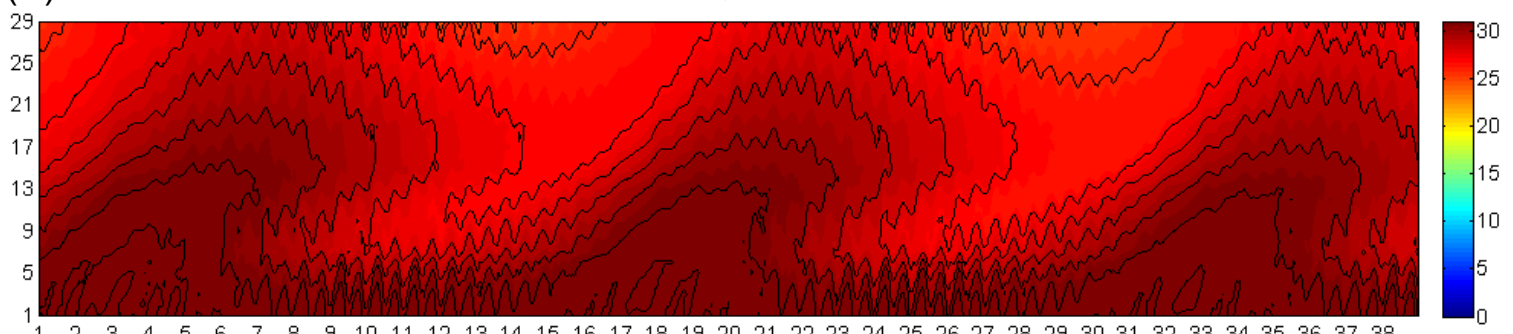

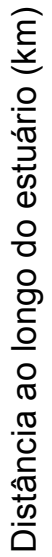

(C)

Q400

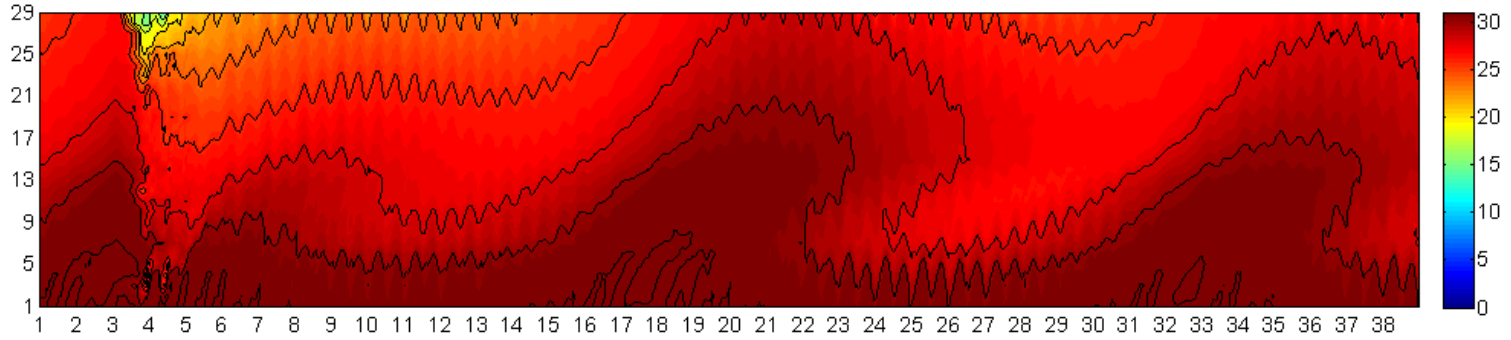

(D)

Q700

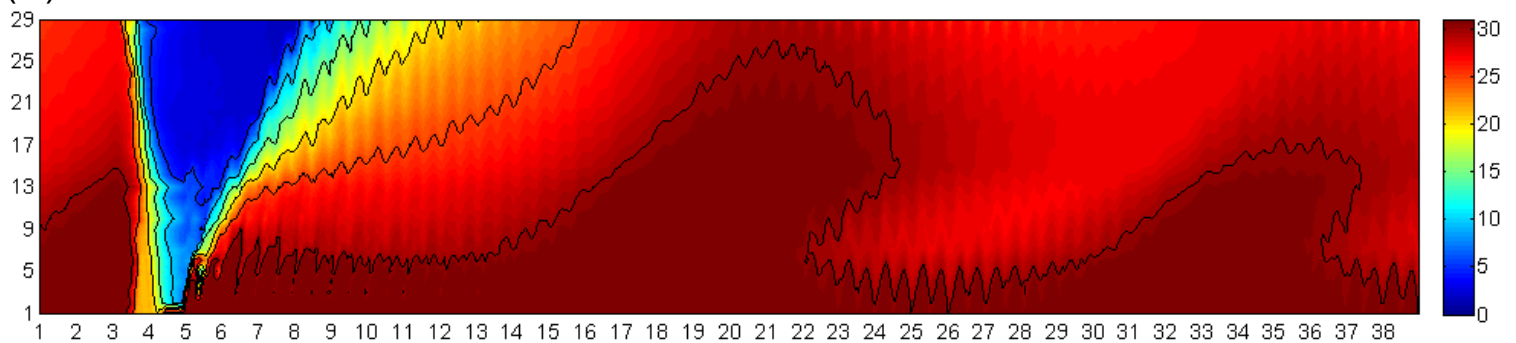

(E)

Q1000

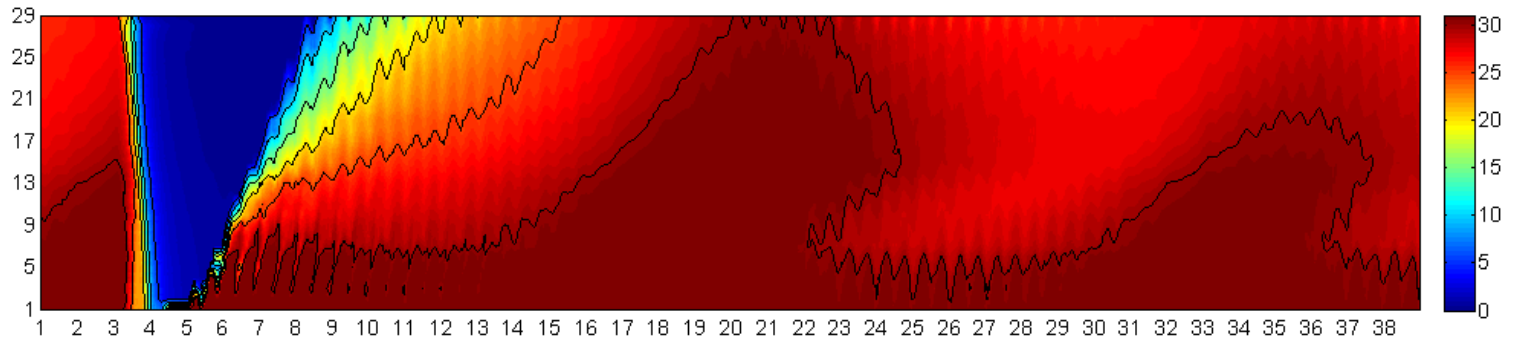

Tempo (dia)

Figura 4.19. Resultado do modelo. Salinidade do fundo nos primeiros $29 \mathrm{~km}$ do estuário do rio Araranguá ao longo do tempo para as simulações Q30 (A), Q100 (B), Q400 (C), Q700 (D) e Q1000 (F), com inicio em condições de quadratura. 


\subsubsection{Simulações sizígia}

Os resultados apresentados para as simulações com o pico na maré de sizígia, seguem a mesma ordem dos resultados apresentados nas simulações de quadratura. As variações temporais do nível da água, da velocidade das correntes e da salinidade na estação \#1, localizada no estuário do rio Araranguá (Fig. 4.2), para todas as simulações estão apresentadas na Figura 4.20. Durante a passagem do evento de pico de descarga de 700 e $1000 \mathrm{~m}^{3} \cdot \mathrm{s}^{-1}$, o nível da água apresentou uma elevação (Fig. 4.20-B), em relação as demais simulações. Os níveis máximos modelados foram de 0,24, 0,25, 0,31, 0,41 e 1 m para Q30, Q100, Q400, Q700 e Q1000, respectivamente.

Com o aumento da descarga fluvial o movimento da água passou a ser unidirecional, estuário abaixo. Esse movimento foi observado em todas as simulações durante o dia do pico (Fig. 4.20-C), exceto nas simulações Q30 e Q100. Para Q400 o movimento unidirecional das correntes estuário baixo ocorreu apenas durante as $24 \mathrm{~h}$ do aumento da descarga fluvial. Já na Q700 o movimento estuário abaixo das correntes permaneceu até o final do dia seguinte e na Q1000 até o final do segundo dia consecutivo após o evento. As velocidades máximas modeladas, para todo o período, foi de $0,4,0,48,0,64,0,78$ e $0,8 \mathrm{~cm} \cdot \mathrm{s}^{-1}$ em Q30, Q100, Q400, Q700 e Q1000, respectivamente.

Durante o período do pico de descarga, na simulações Q100 e Q400, a estrutura vertical da salinidade não variou de forma significativa, quando comparadas com Q30 (Fig. 4.20-D). Com a passagem do evento de 700 e $1000 \mathrm{~m}^{3} \cdot \mathrm{s}^{-1}$ a salinidade foi transportada para fora do estuário. Em Q1000, a cunha salina é transportada para plataforma e retorna somente $48 \mathrm{~h}$ depois do evento. No dia 6 , dois dias após o evento, a estratificação aumentou consideravelmente, principalmente em Q400, Q700 e Q1000, quando comparadas com Q30. É possível identificar uma diferença da estratificação nos períodos de quadratura e sizígia, na simulação Q30 e Q100. Em condições de sizígia, a coluna de água é menos estratificada em relação ao período de quadratura. 
(A)

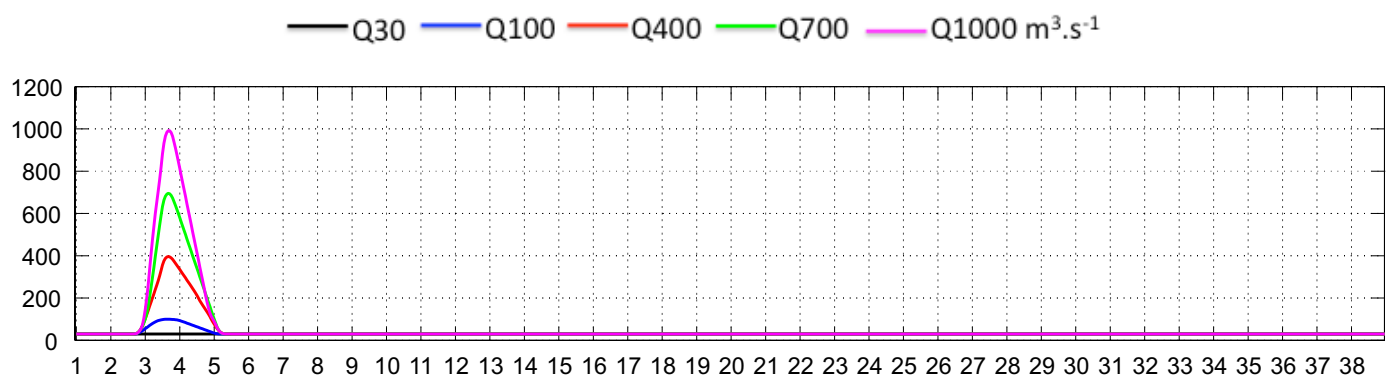

(B)
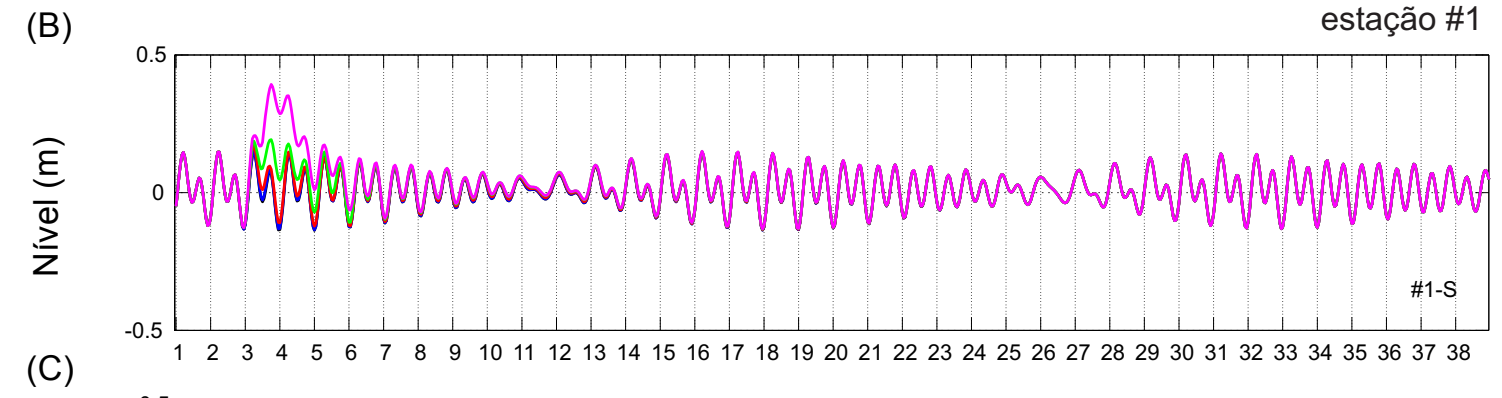

(C)

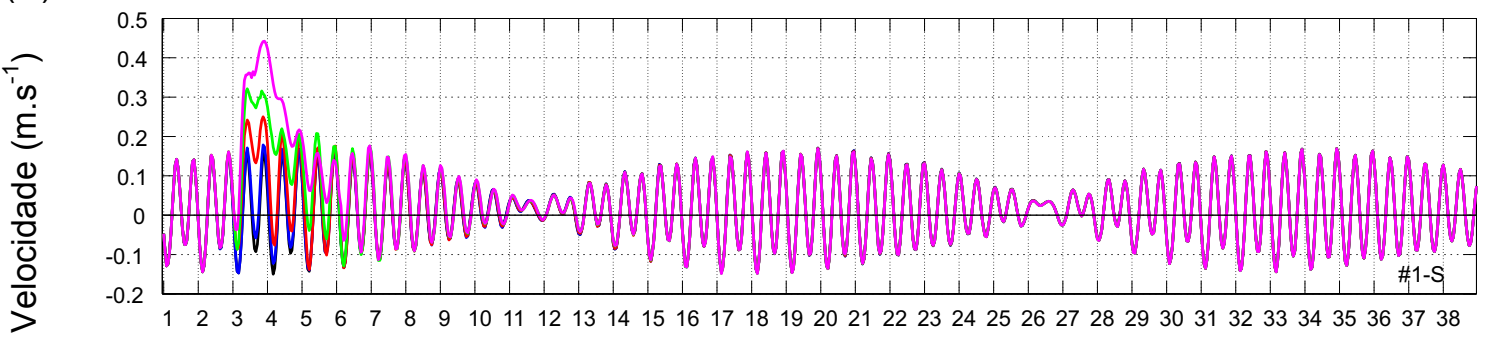

(D)

里

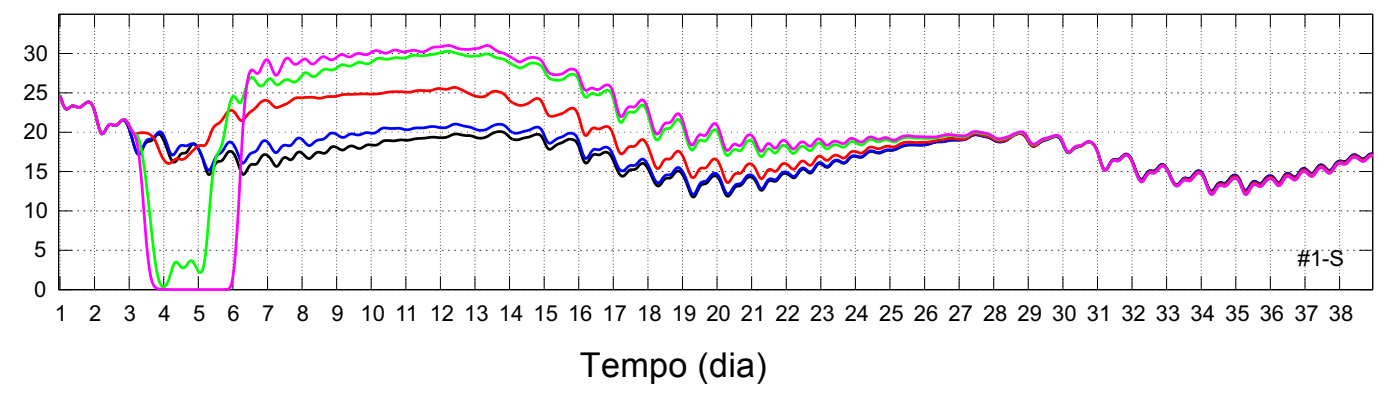

Figura 4.20. Resultados do modelo. Séries temporais da variação do nível da água (B), da velocidade das correntes $(C)$ e da salinidade (diferença entre a salinidade do fundo e da superfície) (D), das simulações de descarga fluvial, Q30 (linha preta), Q100 (linha azul), Q400 (linha vermelha), Q700 (linha verde) e Q1000 (linha magenta), em condição de maré de sizígia para a estação \#1.

O restabelecimento das variações do nível e das velocidades das correntes, após o evento de aumento da descarga fluvial, é mais rápido comparado com o restabelecimento da circulação gravitacional. A partir do dia 6, os níveis de todas as simulações voltam a oscilar igualmente e a partir do dia 7 as velocidades voltam a apresentar variações iguais. Os valores de variação da salinidade na coluna da água, diferença entre a salinidade do fundo pela superfície, convergem para o mesmo valor 
após cerca de 12 dias para Q100, 20 dias para Q400 e 21 dias para Q700 e Q1000. A diferença entre o tempo de duração do movimento unidirecional das velocidades na coluna da água, tanto nas simulações da quadratura quanto nas simulações da sizígia, pode ser explicado pela diferença entre os valores da descarga nos instantes de descida do pico.

A variação temporal dos termos de descarga fluvial e circulação gravitacional durante todas as simulações estão apresentadas na Figura 4.21. Com o aumento da descarga fluvial, o transporte de sal estuário abaixo aumentou. $\mathrm{O}$ termo dispersivo da circulação gravitacional, responsável pelo transporte de sal estuário acima, diminui consideravelmente durante a passagem do pico nas simulações Q700 e Q1000. Já nas simulações Q100 e Q400, o termo da circulação gravitacional aumentou. Nos instantes seguintes a passagem do pico, nas simulações Q400, Q700 e Q1000, o termo da circulação gravitacional aumentou, indicando o inicio do restabelecimento das condições do estuário, com a estabilização da descarga fluvial. 


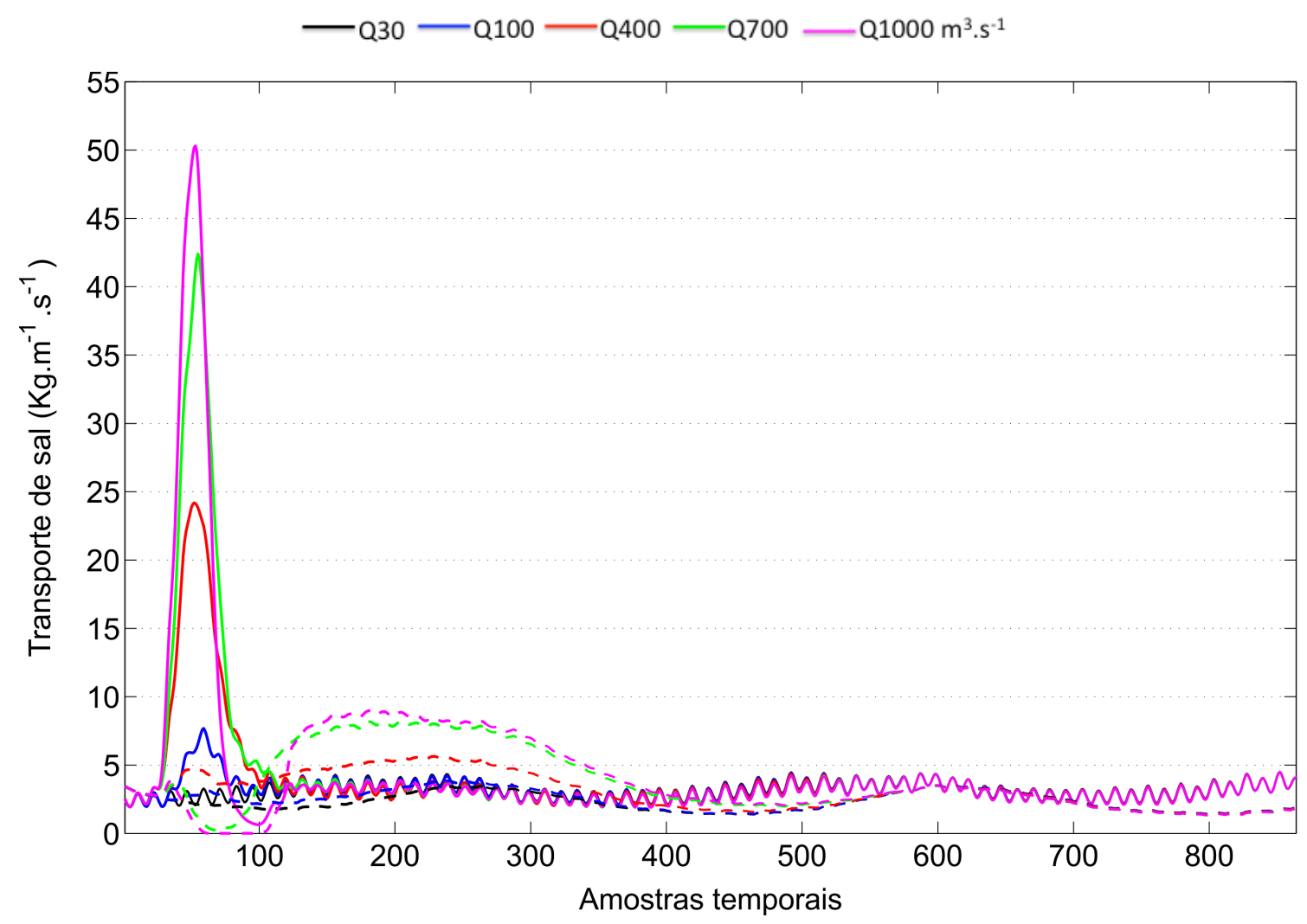

Figura 4.21. Resultados do modelo. Variação temporal dos termos de descarga fluvial (linhas sólidas) e circulação gravitacional (linhas descontinuas) da equação do transporte advectivo de sal, em $\mathrm{kg} \cdot \mathrm{m}^{-1} \cdot \mathrm{s}^{-1}$. Os valores estão em módulo. Para todas as simulações realizadas na quadratura na posição que corresponde a estação \#1.

Os termos do transporte advectivo de sal calculados durante período de aumento da descarga fluvial, que corresponde às 25 horas do dia do evento, estão apresentadas na Tabela 4.4. Na simulação Q30, com descarga fluvial constante, o termo dominante do transporte de sal foi a circulação gravitacional, seguido pelo termo da descarga fluvial, com transporte total de $-0,36 \mathrm{~kg} \cdot \mathrm{m}^{-1} . \mathrm{s}^{-1}$, estuário acima. Em Q400 e Q700 os termos dominantes foram a descarga fluvial e a circulação gravitacional, com transporte total de 3,22 e 19,18 $\mathrm{kg} \cdot \mathrm{m}^{-1} \cdot \mathrm{s}^{-1}$ estuário abaixo, respectivamente. Na simulação Q700 o termo dominante foi a descarga fluvial seguido pela circulação gravitacional, com transporte total de $41,21 \mathrm{~kg} \cdot \mathrm{m}^{-1} \cdot \mathrm{s}^{-1}$, estuário abaixo. Nesta simulação, os termo da correlação da maré e do bombeamento da maré contribuíram com 0,67 e $-0,64 \mathrm{~kg} \cdot \mathrm{m}^{-1} \cdot \mathrm{s}^{-1}$ no processo dispersivo de sal estuário abaixo e acima, respectivamente. Em Q1000 a descarga fluvial foi o termo dominante do transporte de sal estuário abaixo e correlação da maré foi o termo dominante do transporte de sal estuário acima, com o transporte total de $46,71 \mathrm{~kg} \cdot \mathrm{m}^{-1} \cdot \mathrm{s}^{-1}$, estuário abaixo. 
Comparando todas as simulações, é possível observar o aumento do transporte de sal estuário abaixo com o aumento da descarga fluvial. Intensificando o termo de natureza advectivo da descarga fluvial. A circulação gravitacional perde sua importância como processo dispersivo em Q1000 e ganha importância como termo dispersivo em Q30. O termo da correlação da maré contribui no processo dispersivo de sal estuário acima nas simulações Q700 e Q1000.

Tabela 4.4: Termos do transporte advectivo de sal, calculados com os resultados do modelo, para o período de passagem do pico de descarga (25 horas), em todas as simulações (Q30, Q100, Q400, Q700 e Q1000), realizadas em condições de maré de sizígia. Valores em $\mathrm{kg} \cdot \mathrm{m}^{-1} \cdot \mathrm{s}^{-1}$.

\begin{tabular}{lccccc}
\hline \hline \multicolumn{1}{c}{$\begin{array}{c}\text { Termos do transporte } \\
\text { advectivo }\end{array}$} & $Q 30$ & $Q 100$ & $Q 400$ & $Q 700$ & $Q 1000$ \\
\hline \hline 1-Descarga fluvial & $\mathbf{2 , 0 5}$ & $\mathbf{6 , 2 9}$ & $\mathbf{2 4 , 1 3}$ & $\mathbf{4 2 , 3 8}$ & $\mathbf{5 0 , 3 1}$ \\
2-Transporte de Stokes & $-0,10$ & $-0,11$ & $-0,07$ & $-0,02$ & 0,08 \\
3-Correlação da maré & $-0,10$ & $-0,03$ & $-0,10$ & $\mathbf{0 , 6 7}$ & $\mathbf{- 2 , 2 8}$ \\
4-Circulação gravitacional & $\mathbf{- 2 , 1 4}$ & $\mathbf{- 2 , 7 9}$ & $\mathbf{- 4 , 6 4}$ & $\mathbf{- 1 , 1 8}$ & $\mathbf{- 0 , 6 7}$ \\
5-Bombeamento da maré & $-0,07$ & $-0,13$ & $-0,13$ & $\mathbf{- 0 , 6 4}$ & $\mathbf{- 0 , 6 5}$ \\
6-Cisalhamento da maré & 0,00 & 0,00 & $-0,00$ & 0,00 & 0,00 \\
7-Flutuação do vento & 0,00 & 0,00 & $-0,00$ & $-0,00$ & $-0,08$ \\
\hline \multicolumn{1}{c}{ Transporte total } & -0.36 & 3,22 & 19,18 & 41,21 & 46,71 \\
\hline \hline
\end{tabular}

As figuras de 4.22 a 4.26 apresentam a distribuição da salinidade ao longo do estuário do rio Araranguá. Cada figura contém uma sequência de gráficos da distribuição da salinidade modelada em diferentes instantes (t1 a t6) das simulações realizadas. Os instantes selecionados ao longo das simulações estão apresentado na Figura 4.12.

As Figuras 4.22 e 4.23 mostram que durante todo o período representado (entre t1 e t6), a salinidade permaneceu estratificada em toda a extensão do estuário nas simulações Q30 e Q100. A estrutura da distribuição de sal no estuário não foi perturbada pela passagem do evento de descarga fluvial de $100 \mathrm{~m}^{3} \cdot \mathrm{s}^{-1}$. A espessura da 
camada superficial da coluna da água com baixa salinidade não ultrapassou o primeiro metro, devido ao grande volume de água salgada no estuário. A estratificação da salinidade nos instante t4 e t5, nas simulações Q30 e Q100 é menos estável. Na simulação Q400 (Fig. 4.24), com a passagem do pico, um volume maior de água doce chegou ao estuário promovendo a desestabilização da estratificação ao longo de todo o estuário, principalmente na porção superior, e o aumento da espessura de água doce nas camadas superiores da coluna de água. Após o evento, a cunha salina avançou estuário acima e a espessura de água doce nas camadas superiores diminuiu, com a diminuição da descarga fluvial.

Com a passagem dos picos de 700 (Fig. 4.25) e $1000 \mathrm{~m}^{3} \cdot \mathrm{s}^{-1}$ (Fig. 4.26) a estrutura estratificada da coluna de água foi completamente desestabilizada e o sal foi transportado estuário abaixo. No instante t3, em Q700 e Q1000, é possível observar que o estuário foi preenchido pela água doce advinda da alta descarga fluvial. Nesses dois casos a cunha salina foi transportada para plataforma. Em Q700 é possível observar o aprisionamento de sal nas regiões mais profundas do estuário entre a desembocadura e o quilômetro 11 no instante t3. No instante t4 é possível observar o avanço da cunha salina estuário acima em Q700 e Q1000. Em t6 a distribuição da salinidade de forma estratificada foi estabilizada. 

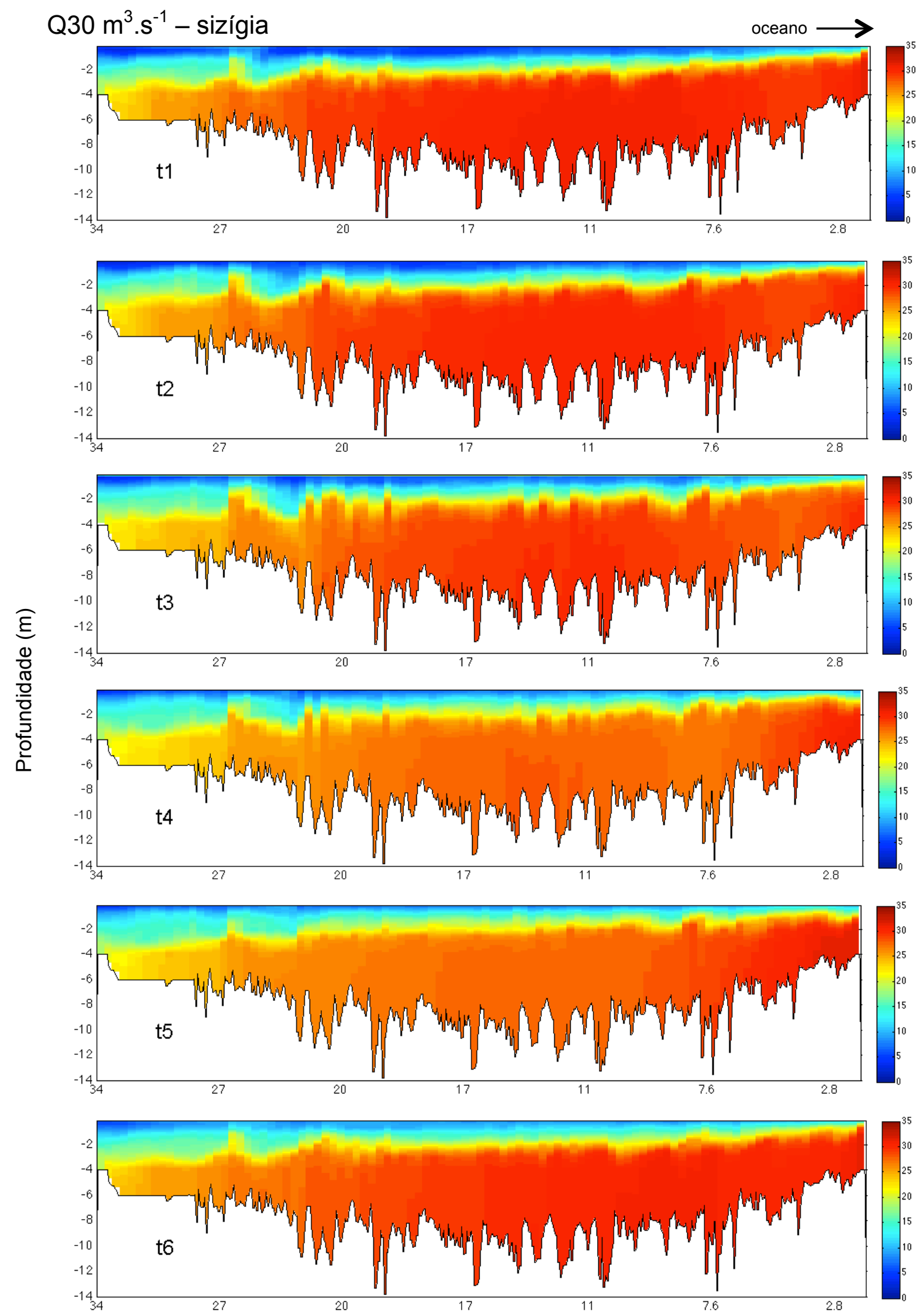

Distância da desembocadura $(\mathrm{km})$

Figura 4.22. Resultados do modelo. Distribuição vertical da salinidade ao longo do perfil longitudinal e ao longo do tempo ( $\mathrm{t} 1, \mathrm{t} 2, \mathrm{t} 3, \mathrm{t} 4, \mathrm{t} 5 \mathrm{e} \mathrm{t6}$ ), no estuário do rio Araranguá, em condições de descarga fluvial de $30 \mathrm{~m}^{3} \cdot \mathrm{s}^{-1}(\mathrm{Q} 30)$, com início na sizígia. 

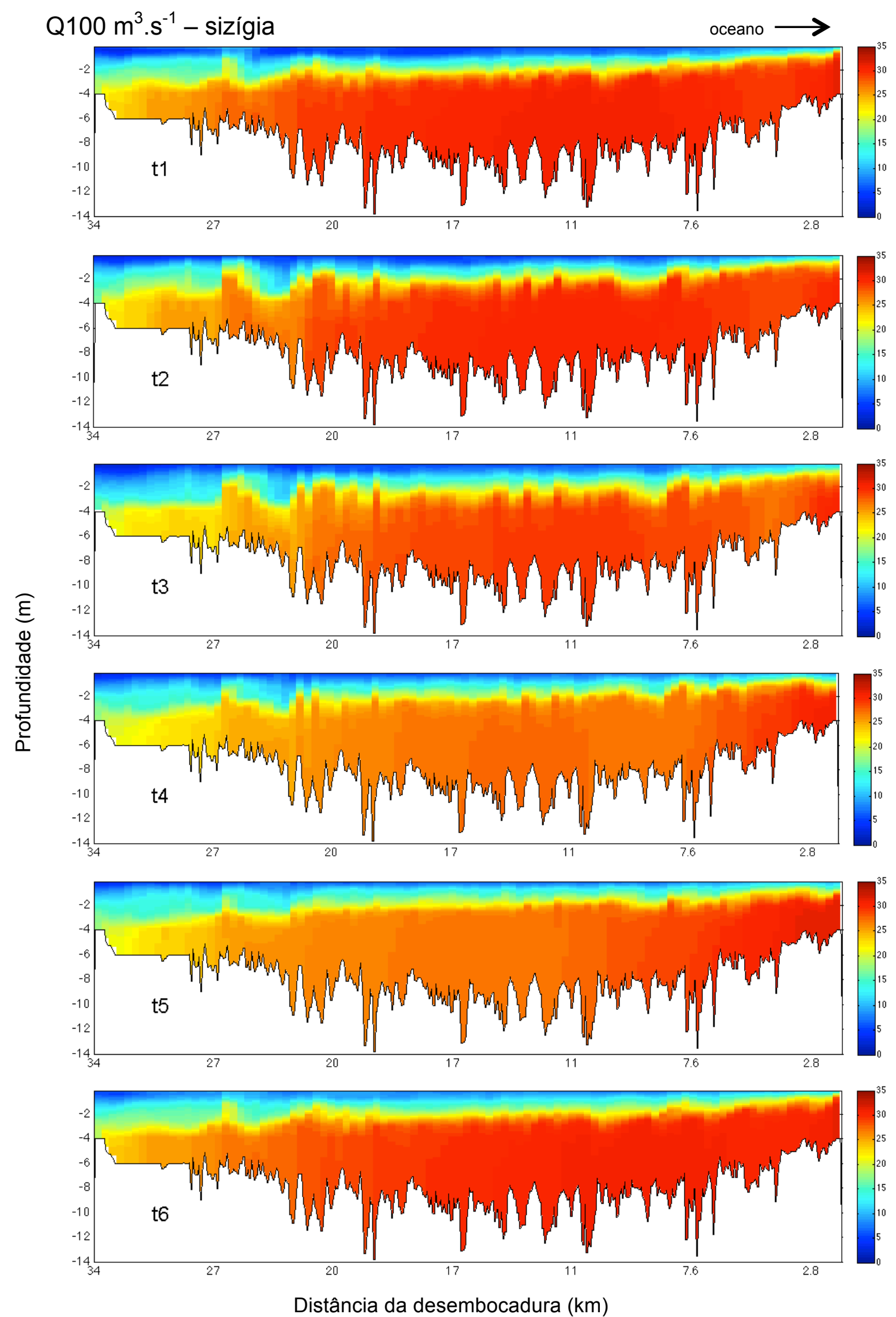

Figura 4.23. Resultados do modelo. Distribuição vertical da salinidade ao longo do perfil longitudinal e ao longo do tempo $(\mathrm{t} 1, \mathrm{t} 2, \mathrm{t} 3, \mathrm{t} 4, \mathrm{t} 5 \mathrm{e} \mathrm{t} 6)$, no estuário do rio Araranguá, da simulação Q100, com pico na sizígia. 

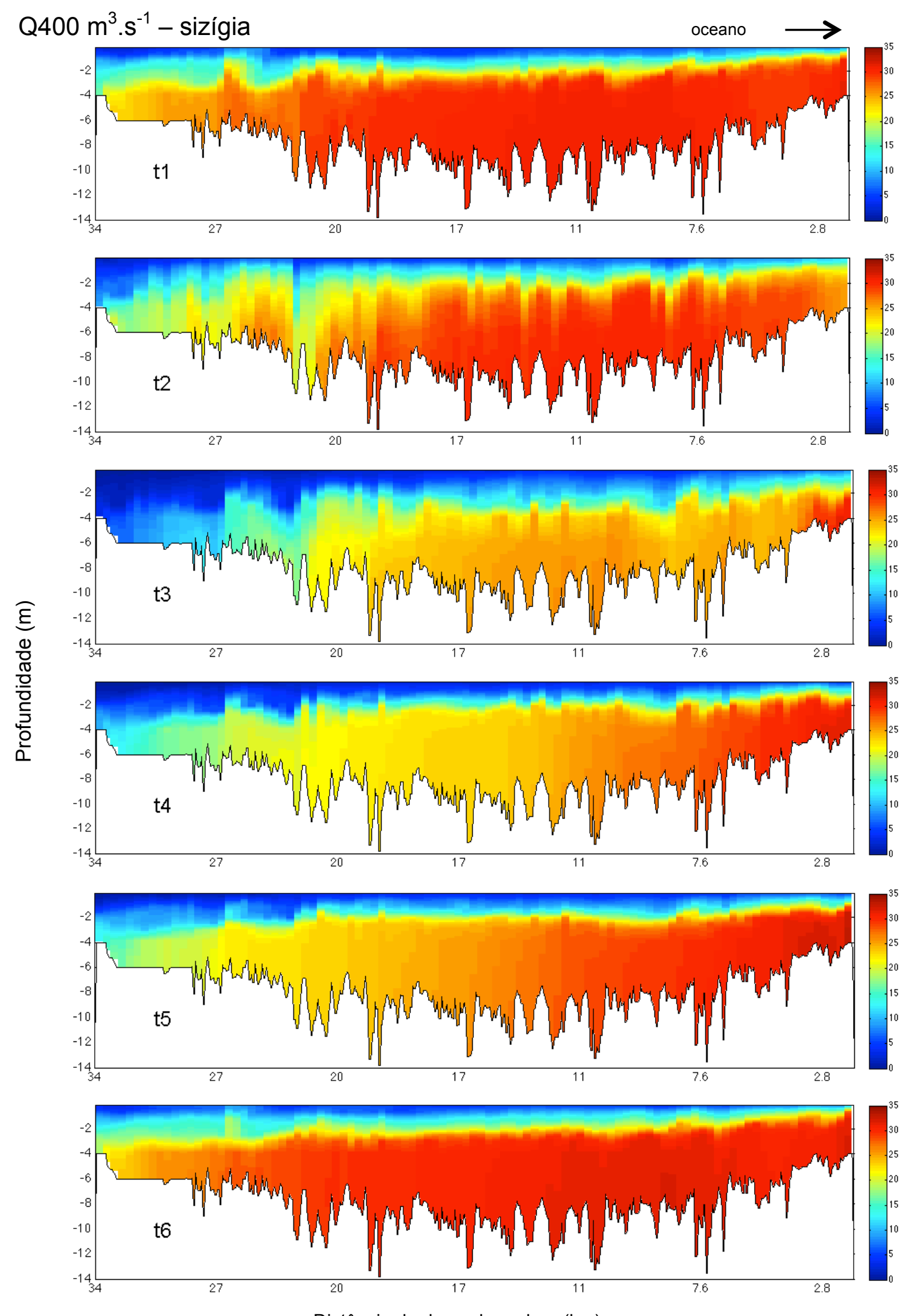

Distância da desembocadura (km)

Figura 4.24. Resultados do modelo. Distribuição vertical da salinidade ao longo do perfil longitudinal e ao longo do tempo ( $\mathrm{t} 1, \mathrm{t} 2, \mathrm{t} 3, \mathrm{t} 4, \mathrm{t} 5$ e $\mathrm{t} 6)$, no estuário do rio Araranguá, da simulação Q400, com pico na sizígia. 

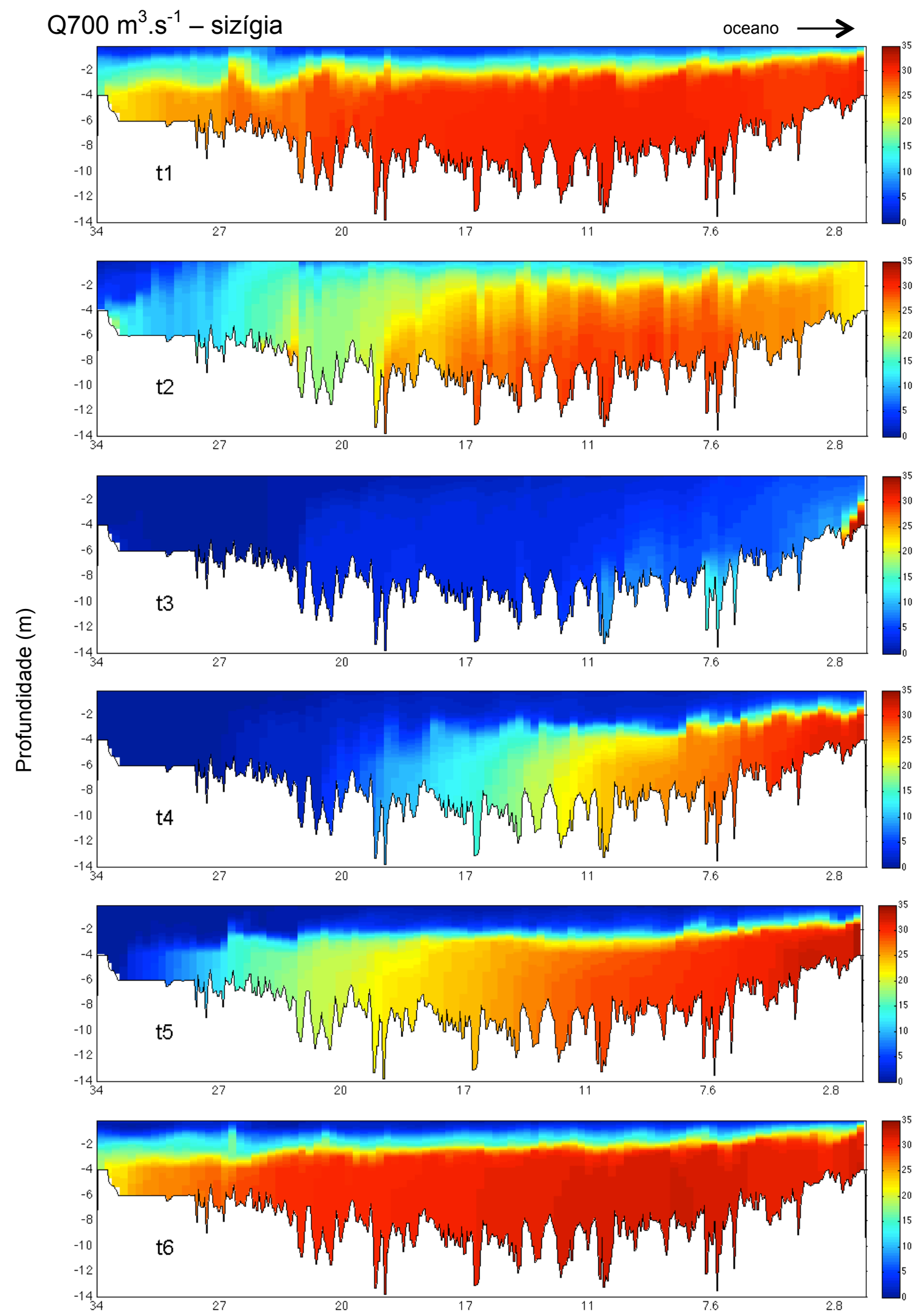

Distância da desembocadura $(\mathrm{km})$

Figura 4.25. Resultados do modelo. Distribuição vertical da salinidade ao longo do perfil longitudinal e ao longo do tempo $(\mathrm{t} 1, \mathrm{t} 2, \mathrm{t} 3, \mathrm{t} 4, \mathrm{t} 5 \mathrm{e} \mathrm{t} 6)$, no estuário do rio Araranguá, da simulação Q700, com pico na sizígia. 

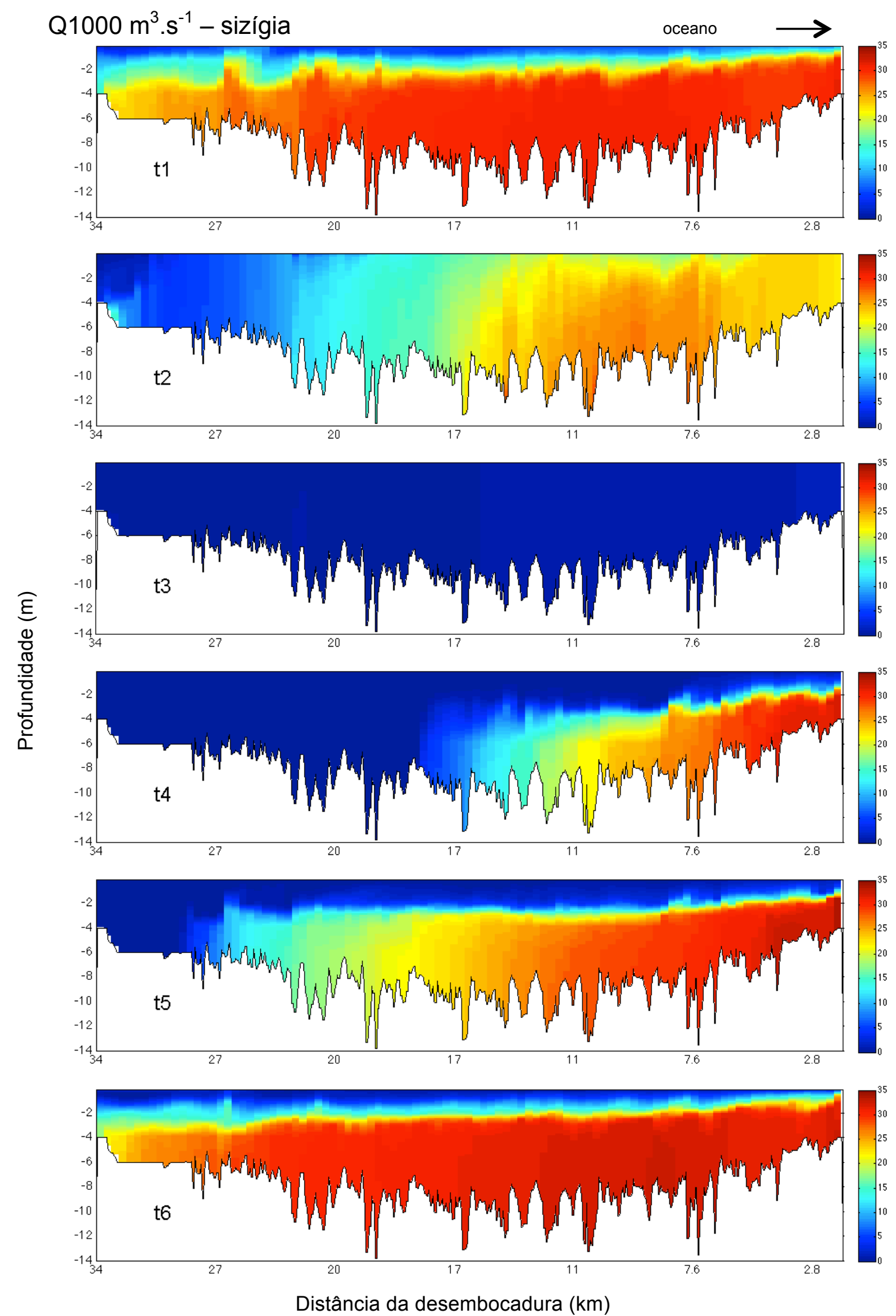

Figura 4.26. Resultados do modelo. Distribuição vertical da salinidade ao longo do perfil longitudinal e ao longo do tempo $(\mathrm{t} 1, \mathrm{t} 2, \mathrm{t} 3, \mathrm{t} 4, \mathrm{t} 5 \mathrm{e} \mathrm{t} 6)$, no estuário do rio Araranguá, da simulação Q1000, com pico na sizígia. 
Os perfis médios da velocidade calculados para todas as simulações na estação \#1 entre os instantes t1 e t6, estão apresentados na Figura (4.27-A). Os perfís mostram que as maiores velocidades, para todas as simulações, se encontram nas camadas superficiais, nos dois primeiros metros de profundidade, com velocidade resultante estuário abaixo. As velocidades máximas modeladas, para o período analisado, foram de 0,15, 0,16, 0,2, 0,21 e 0,22 $\mathrm{m}_{\mathrm{s}}{ }^{-1}$, para Q30, Q100, Q400, Q700 e Q1000, respectivamente. Nas camadas mais profundas, abaixo dos $2 \mathrm{~m}$, as velocidades são mais baixas e a resultante é estuário acima para todas as simulações, exceto em Q1000. Nesta, a velocidade resultante foi estuário abaixo em praticamente toda a coluna da água.

Os perfis médios de salinidade (Fig. 4.27-B) apresentaram um gradiente vertical bastante pronunciado em todas as simulações. A salinidade na superfície foi de 11, 10, 6, 4 e 2,5, para Q30, Q100, Q400, Q700 e Q1000, respectivamente, e no fundo de 30, para Q30, Q100 e Q400, de 28 para Q700 e 25 para Q1000.

(A)

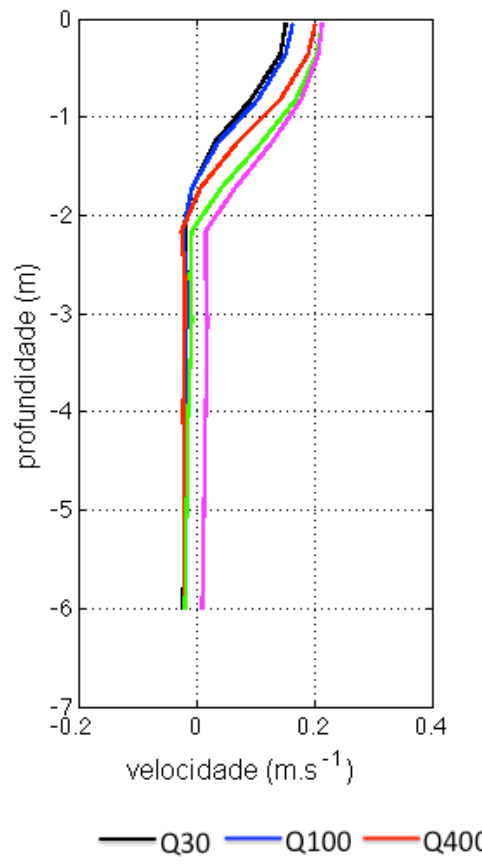

(B)

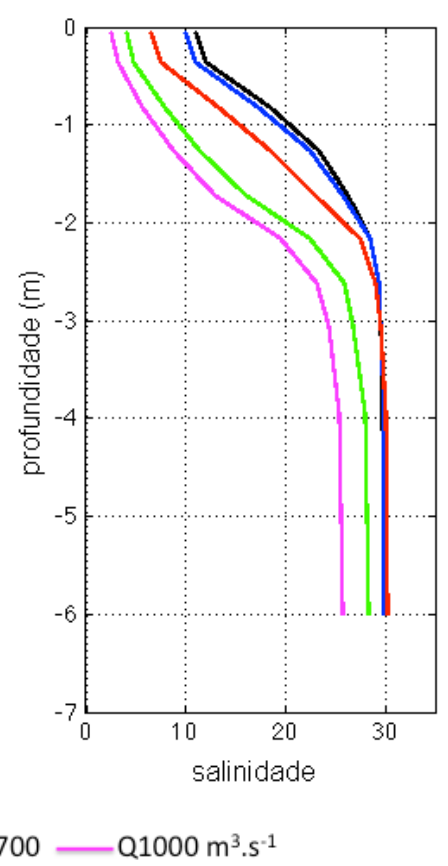

Figura 4.27. Resultados do modelo. Perfis médios de velocidade (A) e salinidade (B) para o período entre t1 e t6. Para todas as simulações com pico na sizígia, Q30 (linha preta), Q100 (linha azul), Q400 (linha vermelha), Q700 (linha verde) e Q1000 (linha magenta), na estação \#1 ( $7 \mathrm{~km}$ da desembocadura). 
A salinidade do fundo modelada em todas as simulações está apresentada na Figura 4.28. Em Q30 (Fig. 4.28-A) e Q100 (Fig. 4.28-B) a descarga fluvial não influenciou na distribuição da salinidade ao longo do estuário. O evento de $100 \mathrm{~m}^{3} \cdot \mathrm{s}^{-1}$ não promoveu a desestabilização da estratificação. Nessas duas simulações é possível observar que o gradiente de distribuição da salinidade oscila entre os períodos de maré de quadratura e sizígia. Durante a quadratura o gradiente de salinidade avança estuário acima e durante a sizígia o avanço não é tão significativo. O pico de $400 \mathrm{~m}^{3} . \mathrm{s}^{-1}$ (Fig. 4.28-C) promoveu uma desestabilização da estratificação na longo do estuário, e ao longo dos próximos dias, principalmente no trecho acima do quilômetro 13. A cunha salina foi transportada estuário abaixo nas simulações com pico de 700 (Fig. 4.28-D) e $1000 \mathrm{~m}^{3} \cdot \mathrm{s}^{-1}$ (Fig. 4.28-E). O avanço da cunha salina pode ser observado ao longos dias após o evento. 
(A)

Q30

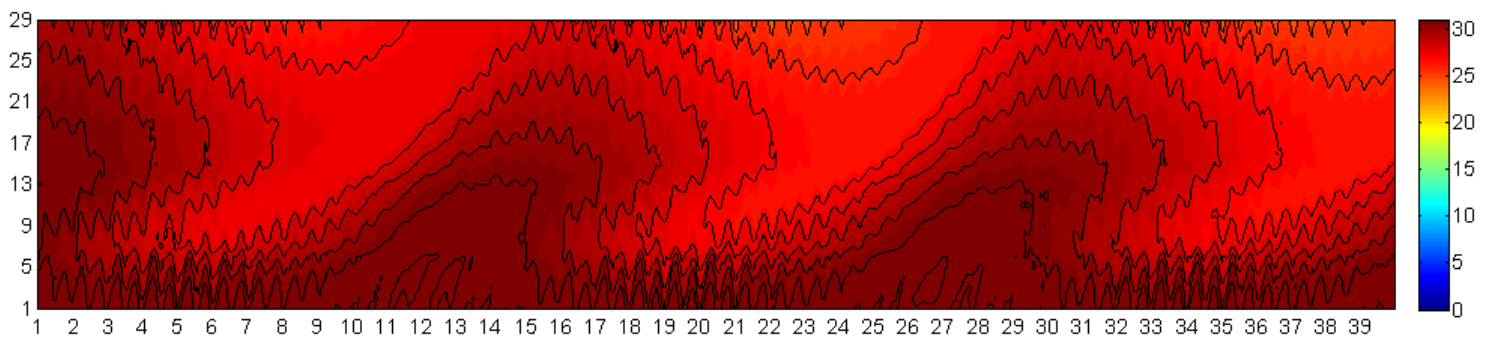

(B)

Q100

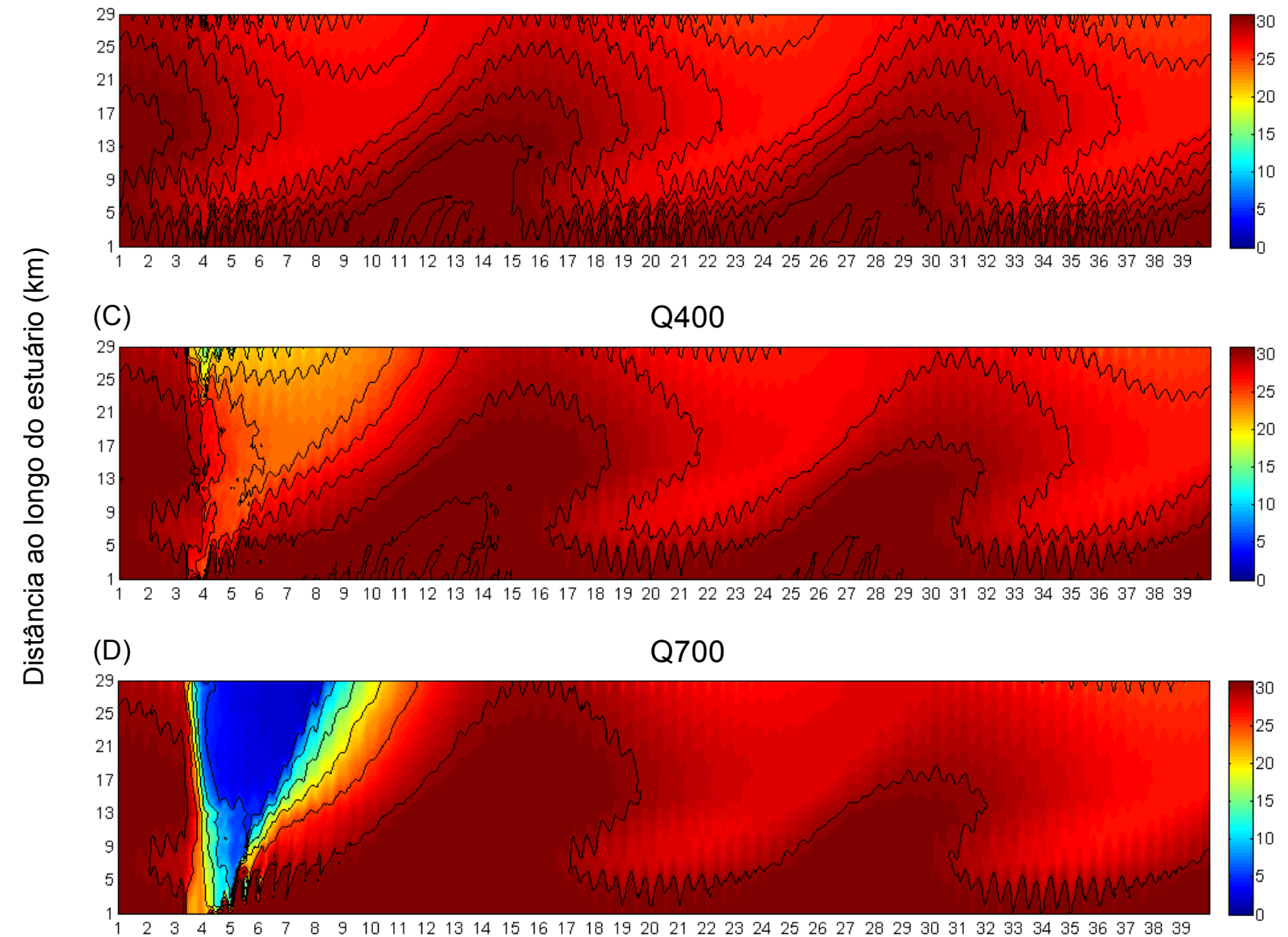

$(\mathrm{E})$

Q1000

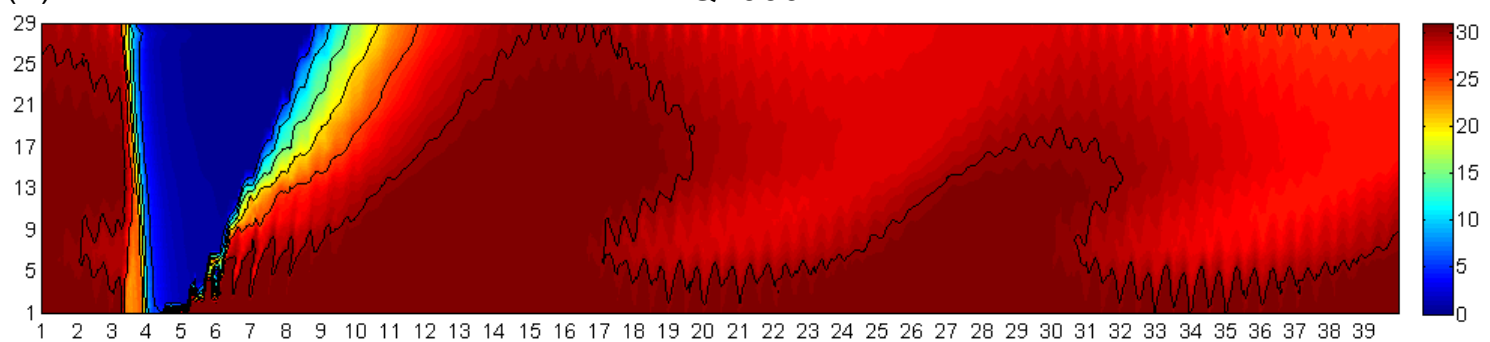

Tempo (dia)

Figura 4.28. Resultado do modelo. Salinidade do fundo nos primeiros $29 \mathrm{~km}$ do estuário do rio Araranguá ao longo do tempo para as simulações Q30 (A), Q100 (B), Q400 (C), Q700 (D) e Q1000 (F), com inicio em condições de sizígia. 


\subsection{Trajetória das partículas}

O domínio do modelo da trajetória das partículas é representado por uma seção longitudinal do canal que compreende toda a extensão do estuário do rio Araranguá, entre a desembocadura e a região da confluência, e os primeiros $12 \mathrm{~km}$ de extensão do rio Itoupava, entre a confluência e o final do domínio, definido no modelo hidrodinâmico (Fig. 4.29, A e B).

(A)

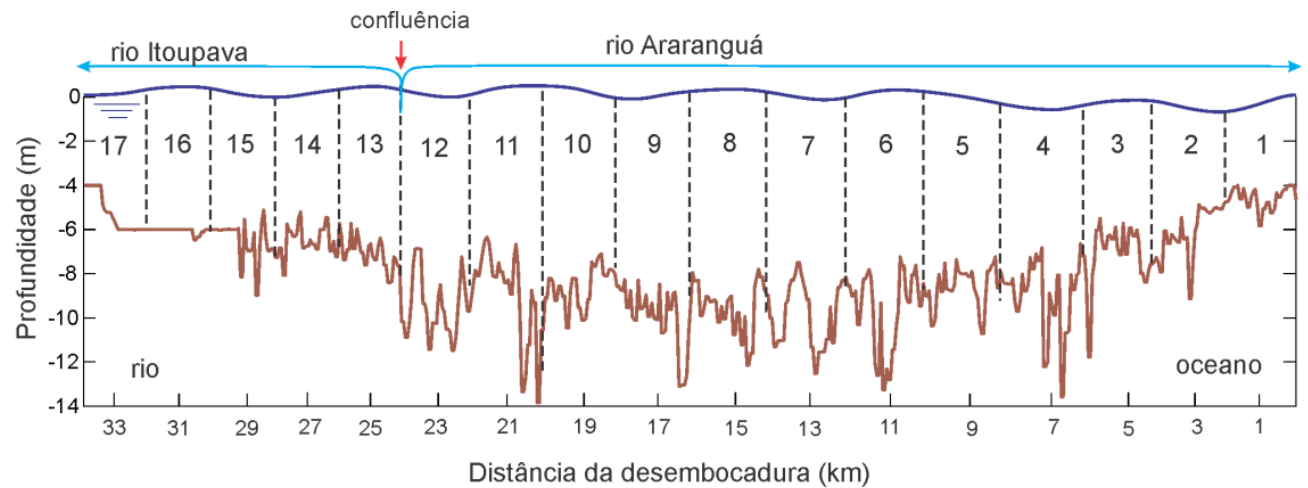

(B)

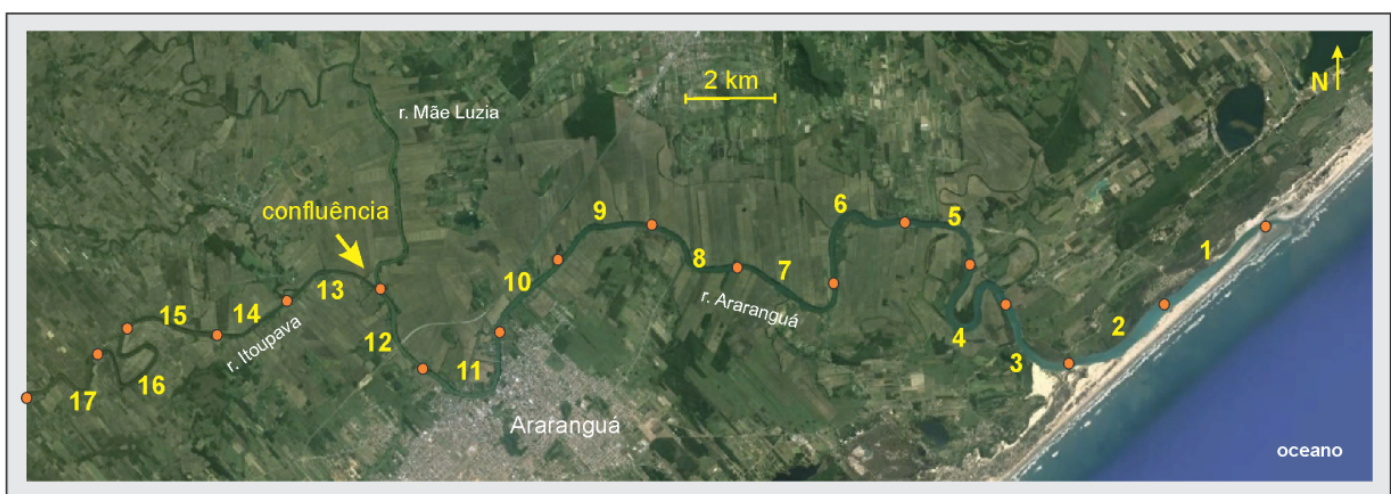

Figura 4.29. (A) Representação do domínio longitudinal do modelo do transporte das partículas. O esquema mostra os limites à montante (rio Itoupava) e à jusante (desembocadura do rio Araranguá), e a divisão do domínio em setores, utilizada para as representações dos locais de deposição das partículas. (B) Localização dos setores de deposição em uma imagem do Google. Os limites dos setores estão definidos pelo pontos laranja. No total são 17 setores. 
As partículas foram lançadas em suspensão no domínio do modelo na região da confluência entre os rios Itoupava e Mãe Luzia (Fig. 4.29-A). Um total de 1.000 (mil) partículas foram lançadas a cada hora durante o evento de descarga fluvial. O lançamento começou duas horas antes do início do aumento da descarga fluvial e terminou ao final do evento, totalizando $59 \mathrm{~h}$. Assim, ao final das primeiras $59 \mathrm{~h}$, o total de partículas lançadas no domínio foi de 59.000. Após o evento de pico não foram lançadas novas partículas. As trajetórias das partículas foram monitoradas desde o momento em que foram lançadas em suspensão no domínio, até o momento que depositaram no estuário ou que foram exportadas para plataforma.

Em relação as condições hidrodinâmicas dos cenários, o modelo da trajetória das partícula começou a partir do início da elevação do pico de descarga, que durou um pouco mais que dois dias, e foi até o último dia simulado. Observando os resultados das simulações de pico (Fig. 4.20), as simulações com as partículas foram realizadas a partir do dia 3 até o final da simulação, dia 38.

Para avaliar a diferença da dinâmica das partículas em diferentes condições de pH (baixo e normal) e sobre condições de regimes transientes, quando há um pulso de descarga fluvial, foram realizados quatro cenários. A configuração de cada cenário está descrita na Tabela 3.5. O Caso 1 simulou a dinâmica das partículas em condições de pH baixo e o lançamento das partículas ocorreu durante o pico de descarga de $400 \mathrm{~m}^{3} \cdot \mathrm{s}^{-1}$. O Caso 2 simulou em condições de $\mathrm{pH}$ normal e o lançamento das partículas ocorreu durante o pico de $400 \mathrm{~m}^{3} \cdot \mathrm{s}^{-1}$. O Caso 3 e o Caso 4, são reproduções dos Caso 1 e 2, respectivamente, com a diferença que as partículas foram lançadas durante o pico de descarga de $1000 \mathrm{~m}^{3} \cdot \mathrm{s}^{-1}$.

Nos Casos 1 e 2, o pico de descarga fluvial de $400 \mathrm{~m}^{3} \cdot \mathrm{s}^{-1}$ ocorreu no início da simulação (Fig. 4.30-A), e permaneceu constante em $30 \mathrm{~m}^{3} . \mathrm{s}^{-1}$ nos dias seguintes. As séries temporais do nível da água, da velocidade das correntes e da salinidade apresentadas na Figura 1, foram extraídas do modelo hidrodinâmico em um ponto localizado na região da confluência. As condições hidrodinâmicas foram as mesmas nos dois experimentos, Caso 1 e 2. 
A

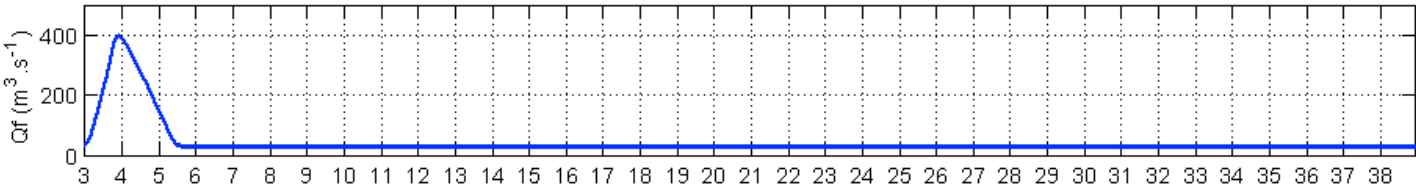

B

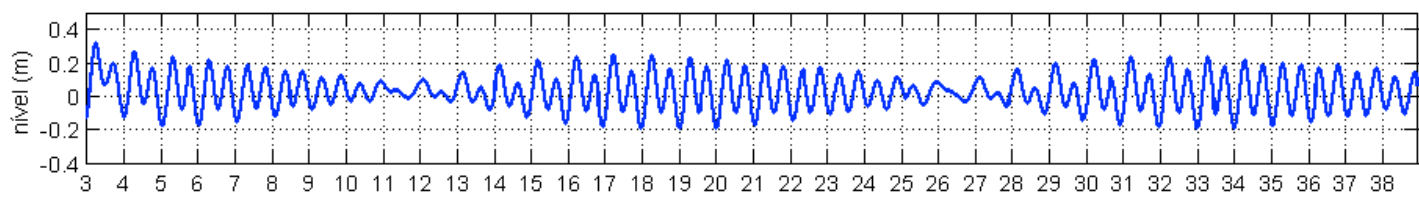

$\mathrm{C}$

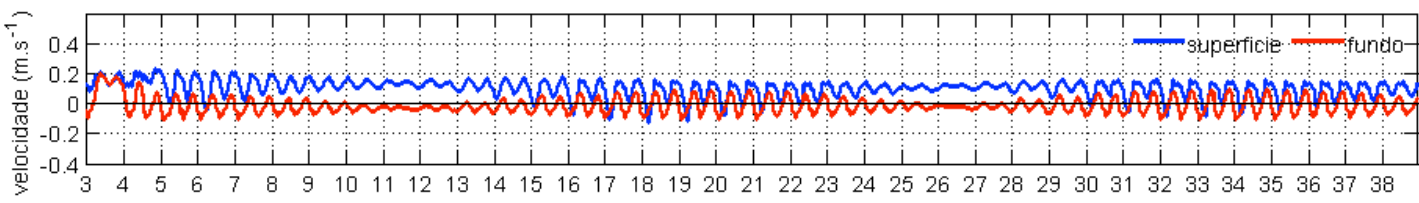

$\mathrm{D}$

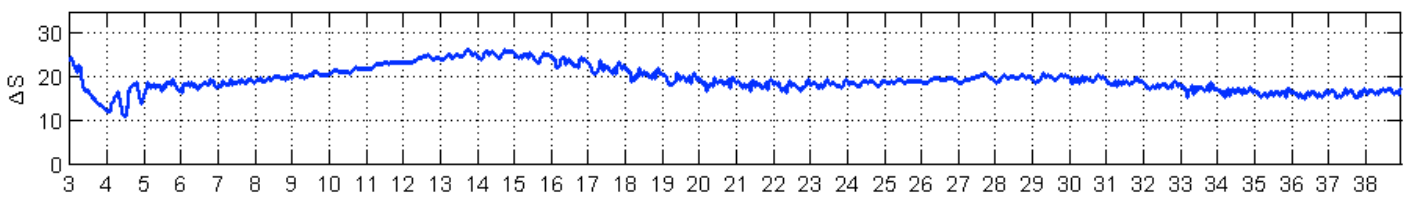

E

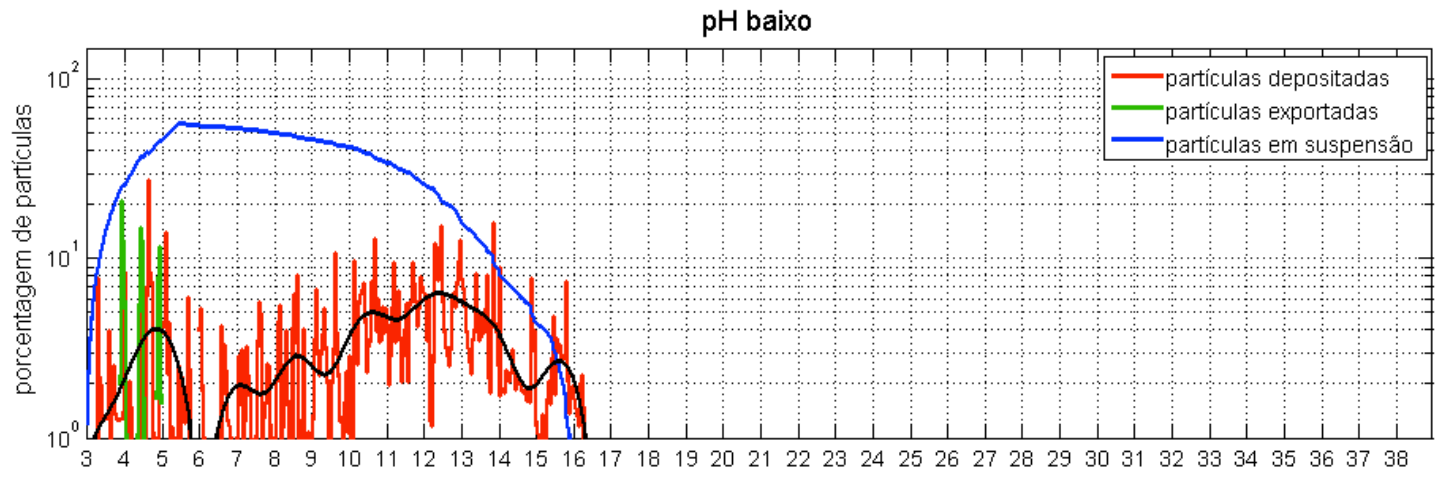

F

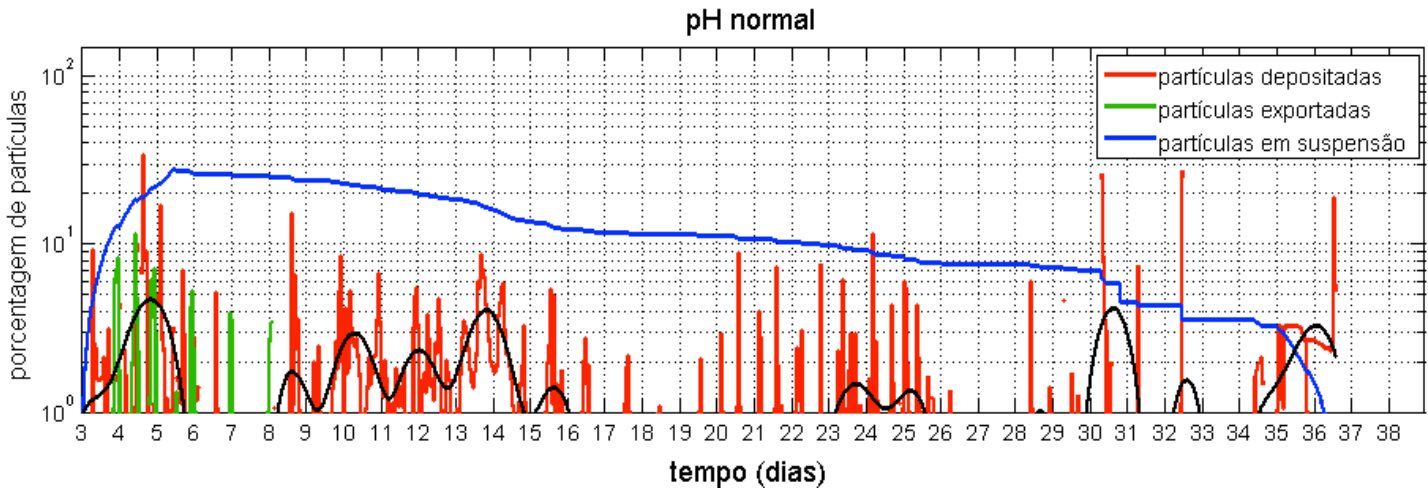

Figura 4.30. Série temporal (A) da descarga fluvial, (B) do nível da água, (C) da velocidade da corrente na superficie (linha azul) e no fundo (linha vermelha), (D) da variação da salinidade (diferença entre a salinidade do fundo pela superfície), (E) das partículas em suspensão (linha azul), exportadas (linha verde) e depositadas (linha vermelha) durante o experimento com $\mathrm{pH}$ baixo (Caso 1), (F) das partículas em suspensão (linha azul), exportadas (linha verde) e depositadas (linha vermelha) durante o experimento com $\mathrm{pH}$ normal (Caso 2). A linha preta em E e F representa a variação de baixa frequência dos valores das partículas depositadas. Os resultados em E e F correspondem ao lançamento das partículas durante o pico de descarga de $400 \mathrm{~m}^{3} . \mathrm{s}^{-1}$. Os resultados do modelo hidrodiâmico em B, C e D são de um ponto localizado na 
confluência entre os rio Itoupava e Mãe Luzia. Em C, as velocidade positivas indicam as corentes de vazante e as negativas as correntes de enchente.

O nível da água não apresentou aumento com a passagem do pico (Fig. 4.30-B). A velocidade da corrente na coluna da água permaneceu unidirecional, estuário abaixo, durante os instantes da passagem do pico (Fig. 4.30-C). Após o evento, as correntes na superfície continuaram orientadas em direção à desembocadura e as correntes no fundo passaram a apresentar o padrão de reversão de correntes, controlado pela variação da maré de enchente e vazante. Durante os períodos de maré de sizígia, ocorreu a reversão das correntes da superfície para o fundo e durante a quadratura, ocorreu a inversão das correntes, com as correntes se deslocam para jusante na superfície e para montante no fundo. A diferença entre a salinidade do fundo pela superfície mostra que durante a passagem do pico a estrutura vertical salinidade ficou menos estratificada (Fig. 4.30-D).

Para o Caso 1, a variação da quantidade de partículas, em porcentagem, que estavam em suspensão, que depositaram e que foram exportadas durante as simulações está apresentada na Figura 4.30-E. A porcentagem de partículas em suspensão aumentou no começo da simulação, devido ao lançamento contínuo de partículas durante o pico de descarga. Durante o evento de pico, algumas partículas foram exportadas e outras depositam. A exportação ocorreu em três instantes diferentes do dia 4, o primeiro ocorreu no mesmo instante em que a descarga é máxima (começo do dia), o segundo algumas horas depois (meio do dia), e o terceiro no final do dia. Nesses instantes, a velocidade da corrente foi máxima na superfície cerca de $0,2 \mathrm{~m} \cdot \mathrm{s}^{-1}$, estuário abaixo. A deposição das partículas ocorreu durante toda a simulação, apresentado um pico de deposição após a passagem do pico, entre o dia 4 e 5, e outro entre os dias 12 e 13, durante o período de quadratura. E conforme as partículas alcançaram o fundo, o número de partículas em suspenção diminuiu, até o momento em que todas as partículas depositam no dia 16.

No Caso 2, no começo da simulação, a porcentagem de partículas em suspensão aumentou, devido ao lançamento contínuo no começo, algumas partículas foram exportadas para plataforma, com o aumento das velocidade das correntes, e algumas partículas depositam (Fig. 4.30-F). As partículas em suspensão permaneceram em 
suspensão por um período prolongado de tempo durante a simulação. Algumas partículas foram exportadas durante a passagem do pico, em três instantes diferentes, como no Caso 1, e em outros três instantes, no início dos dias 6, 7 e 8 . A deposição não foi de forma contínua durante o período simulado, um pico de deposição ocorreu depois do evento de descarga, entre os dias 4 e 5 . No resto do tempo é possível observar uma relação entre o aumento da quantidade das partículas depositadas durante os períodos de maré de quadratura. E ao final do experimento, alguns picos de deposição podem ser observados, até que todas as partículas em suspensão alcançaram o fundo no dia 36.

No total, $6 \%$ e $18 \%$ das partículas lançadas no começo das simulações foram exportadas para plataforma no Caso 1 e 2, respectivamente (Tab. 4.5). Esses valores indicam que em condições normais de $\mathrm{pH}$ e durante um evento de descarga de $400 \mathrm{~m}^{3} . \mathrm{s}^{-}$ 1, o sistema exportou três vezes mais partículas quando comparado com o estuário em condições de pH baixo. Comparando as simulações Caso 1 e 2, em relação ao tempo de permanência das partículas em suspensão, é possível observar que em condições de pH baixo, as partículas permaneceram por menos tempo em suspensão no estuário (Fig. 4.30 E e F), e no Caso 2, com condição de pH normal, as partículas permaneceram por mais tempo em suspensão. Foram necessários 20 dias a mais para que as partículas lançadas no Caso 2 chegassem ao fundo do estuário, em relação ao Caso 1.

Para cada partícula lançada no domínio, foi calculado o tempo entre o instante do lançamento e o instante em que a partícula deixou a coluna da água. O instante final significa que a partícula depositou ou foi exportada. O tempo médio de residência das partículas no estuário foi de 170 h e 304 h no Caso 1 e 2, respectivamente (Tab. 4.6). 
(2)

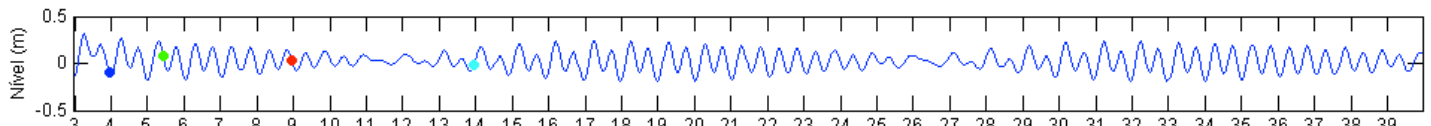
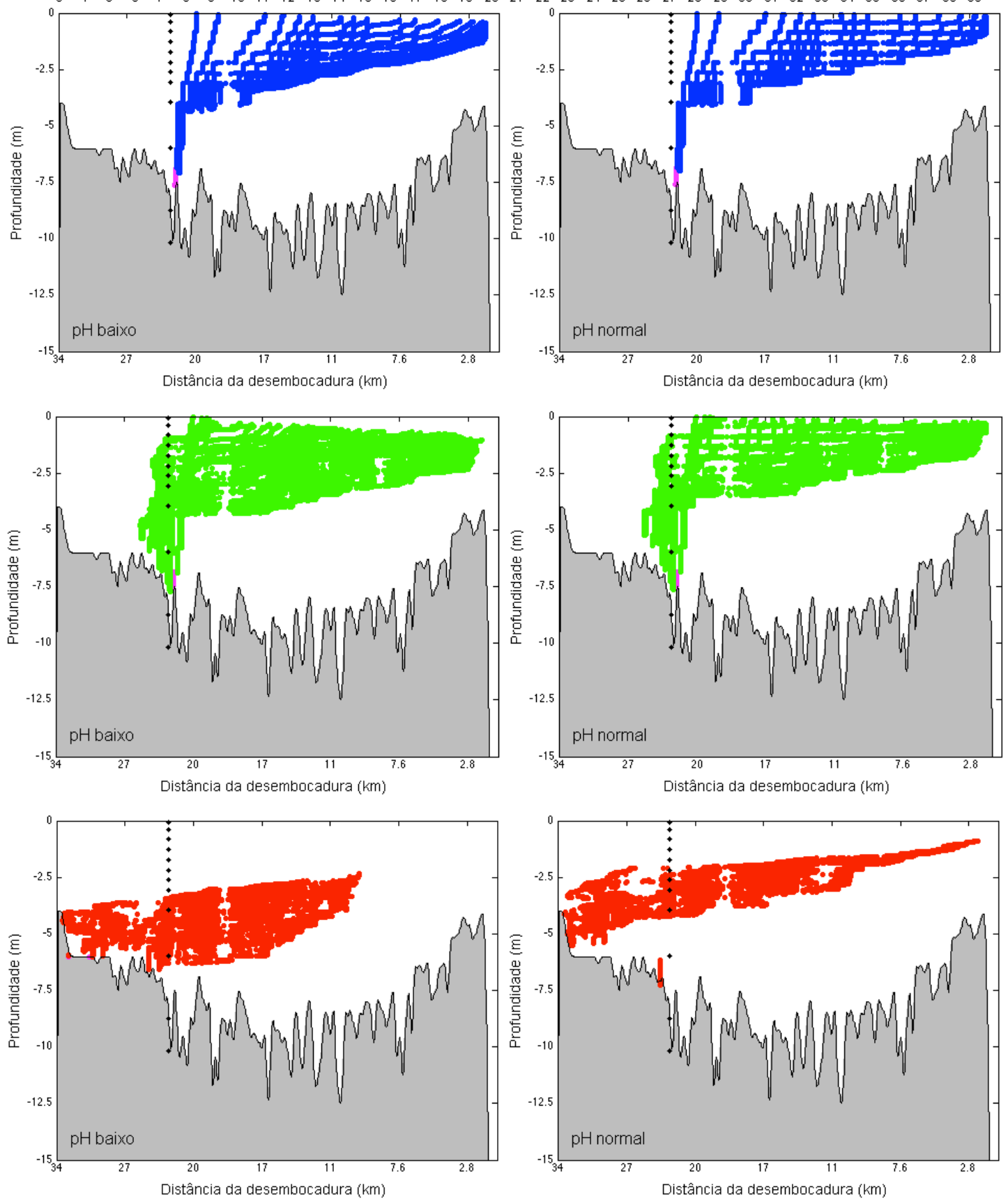

Figura 4.31. (continua na próxima página) 

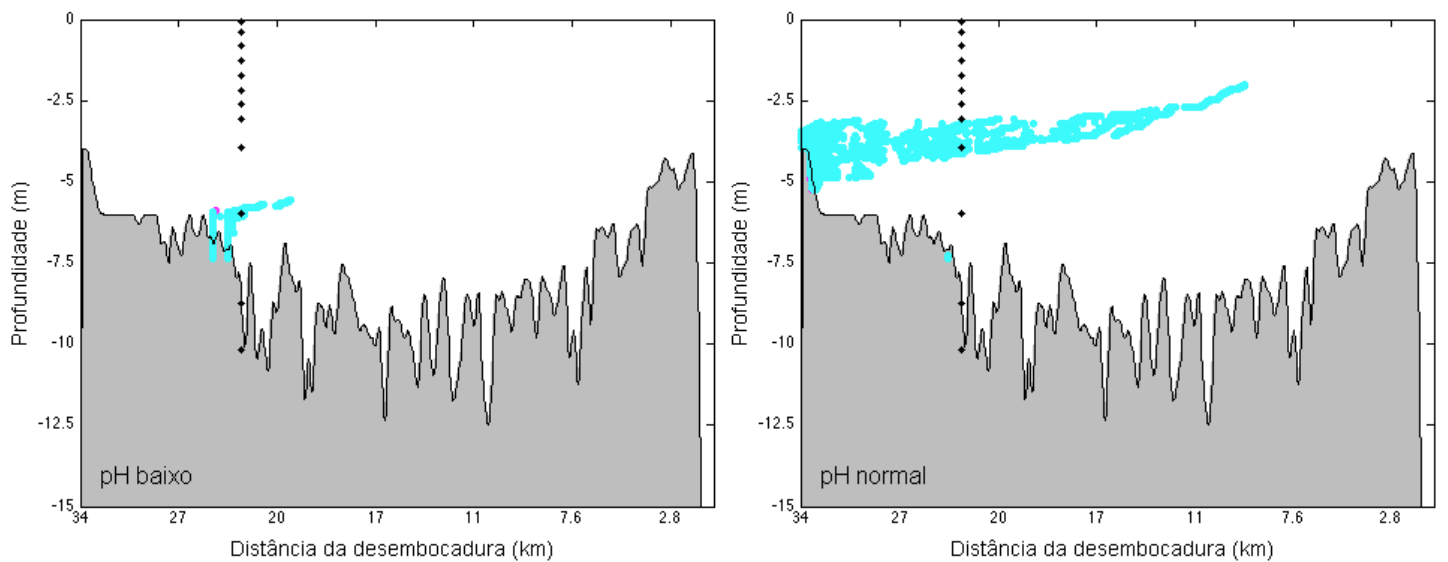

Figura 4.31. Gráficos indicando a posição das partículas no domínio do modelo da trajetória das partículas para alguns instantes da simulação com descarga de $400 \mathrm{~m}^{3} . \mathrm{s}^{-}$ 1. O gráfico superior mostra a variação a descarga fluvial $\left(\mathrm{m}^{3} \cdot \mathrm{s}^{-1}\right)$ e a variação do nível da água $(\mathrm{m})$, abaixo estão os gráficos da partícula para o experimento com $\mathrm{pH}$ baixo (gráficos da esquerda) e para o experimento com $\mathrm{pH}$ normal (gráficos da direita). A cor das partículas representa os instantes que estão destacados (círculo preenchido) nos gráficos de descarga e nível na parte superior. A cor desses círculos corresponde a cor das partículas. Os pontos em preto nos gráficos representam a região de lançamento das partículas (confluência).

A trajetória das partículas durante cada experimento com pico de descarga de $400 \mathrm{~m}^{3} . \mathrm{s}^{-1}$ pode ser observada na Figura 4.31. O primeiro instante representado é o momento de pico da descarga (dia 4). Nesses instantes, as partículas estão se deslocando estuário abaixo, nas camadas superficiais devido ao aumento das correntes, nos Caso 1 (gráfico esquerda) e Caso 2 (gráfico direita). O instante seguinte representa a posição das partículas ao final da descida do pico de descarga, o qual indica o final do lançamento das partículas. Portanto, nesse instante, todas as partículas já estão no domínio, com exceção das que foram exportadas para plataforma nos instantes anteriores. No final do pico, a grande maioria das partículas está em suspensão nas camadas superiores e em toda a extensão do estuário do rio Araranguá. No dia 9, as partículas ganharam profundidade e estão sendo transportadas para montante, depositando nos setores à montante da confluência. Nesse instante é possível notar algumas diferenças entre os experimentos do Caso 1 e 2. No experimento com $\mathrm{pH}$ baixo, as partículas em suspensão estão localizadas em profundidades maiores quando comparadas com o conjunto de partículas transportadas em suspensão do experimento com pH normal. No dia 14, poucas partículas permanecem em suspensão na região da 
confluência com pH baixo e uma quantidade maior continua em suspensão com pH normal.

No geral, o deslocamento das partículas no experimento com $\mathrm{pH}$ baixo mostra que as partículas, após o evento de descarga de $400 \mathrm{~m}^{3} \cdot \mathrm{s}^{-1}$, são transportadas em profundidades maiores em relação as partículas com $\mathrm{pH}$ normal. A posição das partículas com $\mathrm{pH}$ normal consegue representar o formato da cunha salina e seu deslocamento para montante, uma vez que ficam mais tempo em suspensão. A forma como as partículas se deslocam para montante e a profundidade onde estão sendo transportadas indicam se as partículas depositam mais à montante ( $\mathrm{pH}$ normal) ou mais à jusante ( $\mathrm{pH}$ baixo). Observado as partículas com $\mathrm{pH}$ normal, no último instante representado, é possível prever que, provavelmente, essas partículas continuariam se deslocando para regiões mais à montante, além do limite do domínio do modelo.

O local de deposição das partículas, ao longo do domínio do estuário e ao longo do tempo, foi monitorado em todas as simulações. A extensão total do domínio foi dividida em setores a cada $2 \mathrm{~km}$ de distância, desde a desembocadura e o limite superior do rio Itoupava (34 km) (Fig. 4.29). A deposição nos setores foi observada no centro de cada um deles. O primeiro setor começa na desembocadura e vai até o final dois 2 primeiros quilômetros. Nesse setor, a quantidade de partículas depositadas no tempo são contabilizadas no centro, que corresponde ao quilômetro 1. E assim segue nos outros setores, totalizando 17 setores de deposição. A quantidade de partículas em cada setor representa o número de partículas acumuladas ao longo do tempo.

A anomalia de deposição entre as simulações com pH baixo (Caso 1) e pH normal (Caso 2) indica a região do estuário que as partículas decantaram durante as simulações (Fig. 4.32). Em condições de $\mathrm{pH}$ baixo, as partículas depositam entre os quilômetros 19 e 29. E em condições de $\mathrm{pH}$ normal as partículas depositaram acima do quilômetro 31, no rio Itoupava. Espacialmente, observa-se que o centro de deposição das partículas no Caso 2 é relativamente estático e que foi deslocado para jusante com a diminuição do $\mathrm{pH}$ (Caso 1). Com $\mathrm{pH}$ normal, as partículas permaneceram por mais tempo em suspensão, sendo carreadas para montante com a circulação gravitacional. Em condições de $\mathrm{pH}$ normal, com o evento de descarga de $400 \mathrm{~m}^{3} \cdot \mathrm{s}^{-1}$, as partículas que estavam em suspensão e foram carreadas para jusante pelas correntes, mas não foram 
exportadas, retornaram para o interior do estuário com a circulação gravitacional e depositaram mais à montante no rio Itoupava, e em condições de $\mathrm{pH}$ baixo, as partículas depositaram na região da confluência.

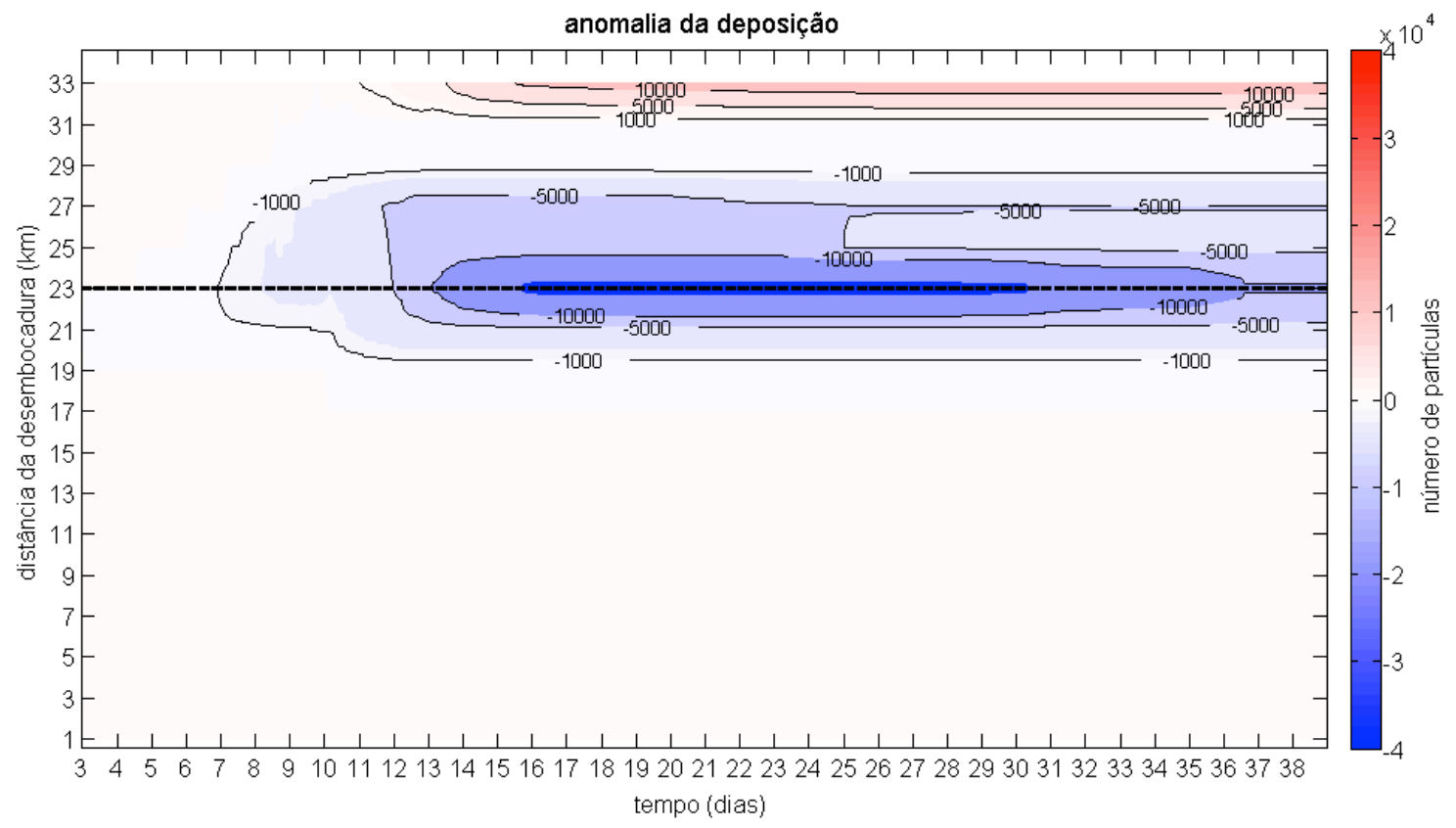

Figura 4.32. Gráfico da anomalia temporal da deposição das partículas ao longo do domínio. Lançamento das partículas no pico de descarga de $400 \mathrm{~m}^{3} . \mathrm{s}^{-1}$. Os valores negativos, em azul, indicam os setores de decantação das partículas do experimento com pH baixo (Caso 1) e os valores positivos, indicam os setores de decantação das partículas do experimento com $\mathrm{pH}$ normal (Caso 2). A linha tracejada indica a região da confluência. Acima da linha é o rio Itoupava e abaixo o rio Araranguá. O número de partículas, representa ao longo do tempo, a quantidade de partículas acumuladas em cada trecho do estuário.

Nos Casos 3 e 4, o pico de descarga fluvial de $1000 \mathrm{~m}^{3} \cdot \mathrm{s}^{-1}$ ocorreu no início da simulação (Fig. 4.33-A), e permaneceu constante em $30 \mathrm{~m}^{3} . \mathrm{s}^{-1}$ nos dias seguintes. As séries temporais do nível da água, da velocidade das correntes e da salinidade apresentadas na Figura 4.33, foram extraídas do modelo hidrodinâmico em um ponto localizado na região da confluência.

O nível da água aumentou consideravelmente na região da confluência com o aumento na descarga fluvial, com elevação máxima de $1 \mathrm{~m}$ (Fig. 4.33-B). O aumento da descarga intensificou as velocidades das correntes, estuário abaixo, em toda a coluna da 
água, com velocidade máxima 0,6 e $0,4 \mathrm{~m} \cdot \mathrm{s}^{-1}$ na superfície e no fundo, respectivamente (Fig. 4.33-C). As correntes permaneceram orientadas em direção à desembocadura durante a passagem do pico, até o final do dia 6. Entre o dia 6 e o dia 9, as velocidades diminuíram e toda a coluna da água e passou a apresentar um padrão de reversão do sentido das correntes de acordo com a maré de enchente e vazante. No dia 9, as correntes passaram a apresentar inversão da direção, com as correntes das camadas superficiais estuário abaixo e correntes do fundo estuário acima. Com o aumento da descarga a salinidade da região foi transportada estuário abaixo e o volume foi ocupado pela água doce (Fig. 4.33-D). O aumento da salinidade e o padrão de inversão das correntes na coluna da água no dia 9 indicam o início do restabelecimento baroclínico, quando a água mais densa se desloca estuário acima nas camadas mais profundas e a água menos densa se desloca estuário abaixo nas camadas da superfície.

A variação do número de partículas em suspensão, que depositaram e que foram exportadas durante o Caso 3 está apresentada na Figura 4.33-E. A quantidade de partículas aumentou no começo da simulação, devido ao lançamento contínuo de partículas durante o pico de descarga. Entre os dias 3 e 5, parte das partículas em suspensão foram exportadas para plataforma. Um pico de deposição das partículas pode ser observado no dia 5, após o evento de descarga, com diminuição significativa da quantidade de partículas em suspensão, cerca de 70\%. A quantidade de partículas em suspenção permaneceu estável entre os dias 7 e 10. Nos instantes finais, no dia 14, ocorreu um pico de deposição, indicando que todas as partículas que estavam em suspensão depositaram.

No Caso 4, no começo da simulação, o número de partículas em suspensão aumentou, devido ao lançamento contínuo no começo (Fig. 4.33-F). Entre os dias 3 e 5 parte das partículas em suspensão foi exportada para plataforma. A quantidade de partículas em suspensão passou a diminuir de forma mais significativa a partir do dia 11. No começo da simulação teve um pico de deposição, não tão significativo quanto o pico de deposição observado após o pico de descarga no experimento com pH baixo. Outros picos de deposição ocorreram ao longo da simulação e o número de partículas em suspensão passa a diminuir até não existir mais nenhuma partícula em suspensão no dia 24. 
A

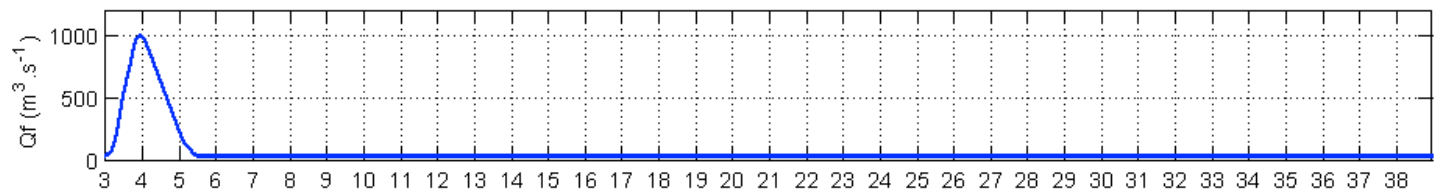

B

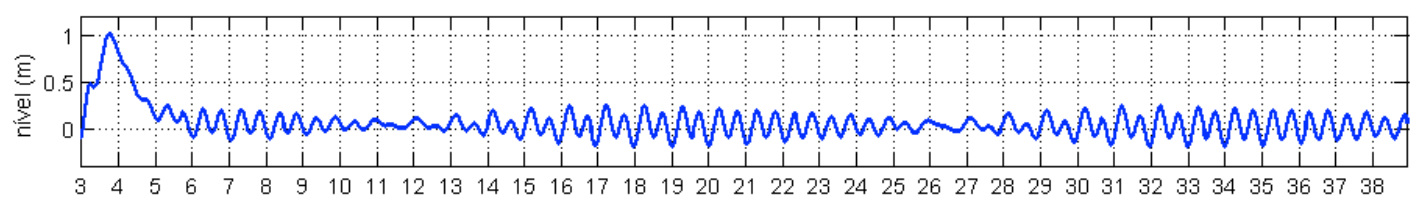

$\mathrm{C}$

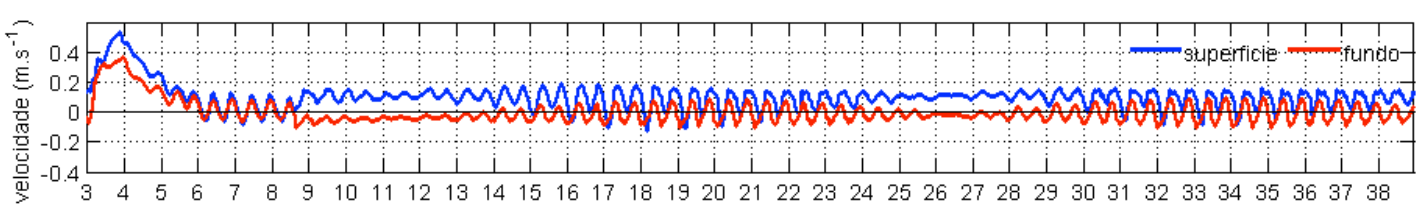

$\mathrm{D}$

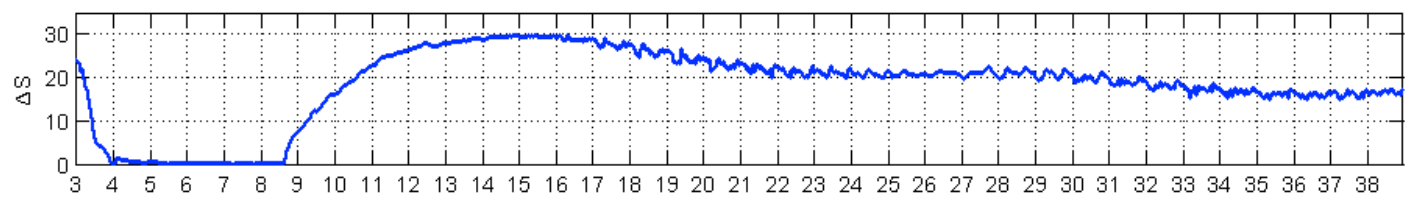

$\mathrm{E}$

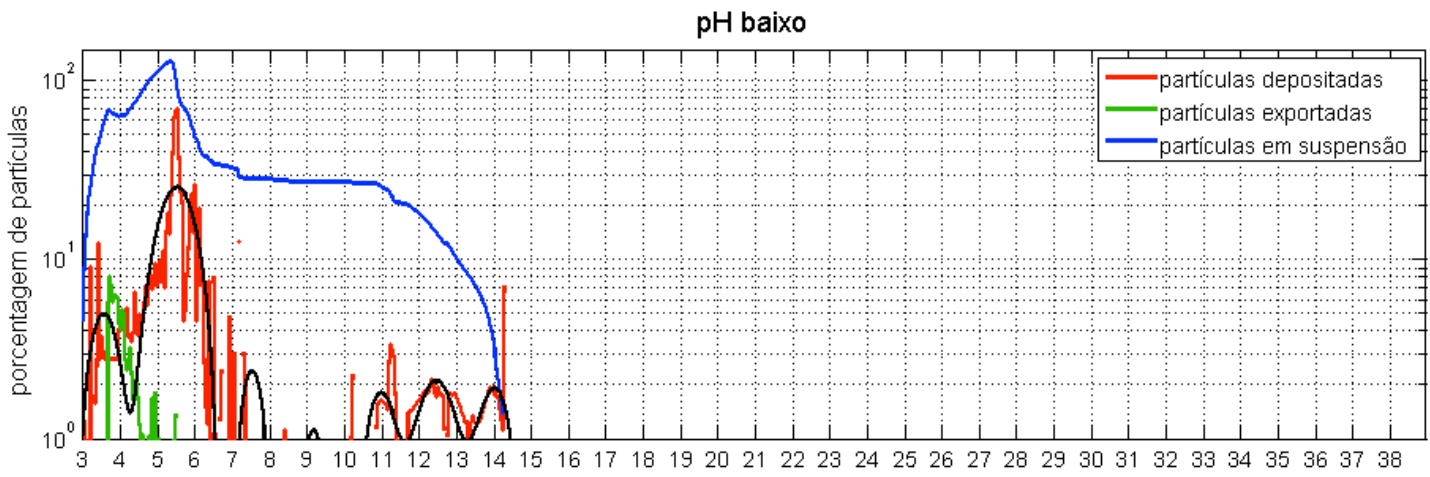

F

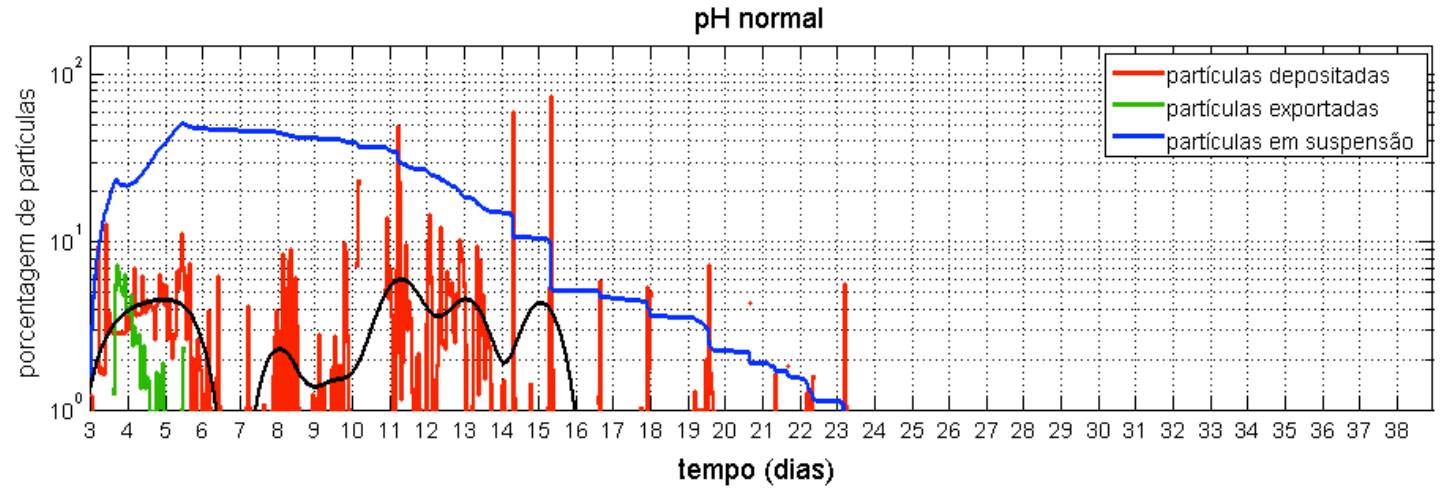

Figura 4.33. Série temporal (A) da descarga fluvial, (B) do nível da água, (C) da velocidade da corrente na superficie (linha azul) e no fundo (linha vermelha), (D) da variação da salinidade (diferença entre a salinidade do fundo pela superfície), (E) das partículas em suspensão (linha azul), exportadas (linha verde) e depositadas (linha vermelha) durante o experimento com $\mathrm{pH}$ baixo (Caso 3), (F) das partículas em suspensão (linha azul), exportadas (linha verde) e depositadas (linha vermelha) durante o experimento com $\mathrm{pH}$ normal (Caso 4). A linha preta em E e F representa a variação de baixa frequência dos valores das partículas depositadas. Os resultados em E e F correspondem ao lançamento das partículas durante o pico de descarga de $1000 \mathrm{~m}^{3} \cdot \mathrm{s}^{-1}$. Os resultados do modelo hidrodiâmico em B, C e D são de um ponto localizado na 
confluência entre os rio Itoupava e Mãe Luzia. Em C, as velocidade positivas indicam as corentes de vazante e as negativas as correntes de enchente.

Em relação ao total de partículas lançadas no domínio durante as simulações, $27 \%$ e $30 \%$ das partículas foram exportadas para plataforma no Caso 3 e 4, respectivamente (Tab. 4.5). A fração complementar indica que $73 \%$ e $70 \%$ das partículas lançadas depositaram no estuário ao final das simulações. Comparando as simulações Caso 3 e 4, em relação ao tempo de permanência das partículas em suspensão, é possível observar que em condições de $\mathrm{pH}$ baixo, as partículas permaneceram por menos tempo em suspensão no estuário (Fig. 4.33 E e F). No Caso 4, com condição de pH normal, as partículas permaneceram por mais tempo em suspensão. Foram necessários 8 dias a mais para que as partículas lançadas no Caso 4 chegassem ao fundo do estuário, quando comparado com o Caso 3. O tempo médio de residência das partículas no estuário foi de 66 e 136 horas no Caso 3 e 4, respectivamente (Tab. 4.6). As partículas, em média, permanecem o dobro do tempo em suspensão no estuário em condições de $\mathrm{pH}$ normal. 


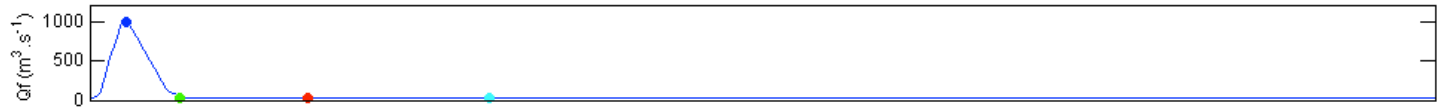
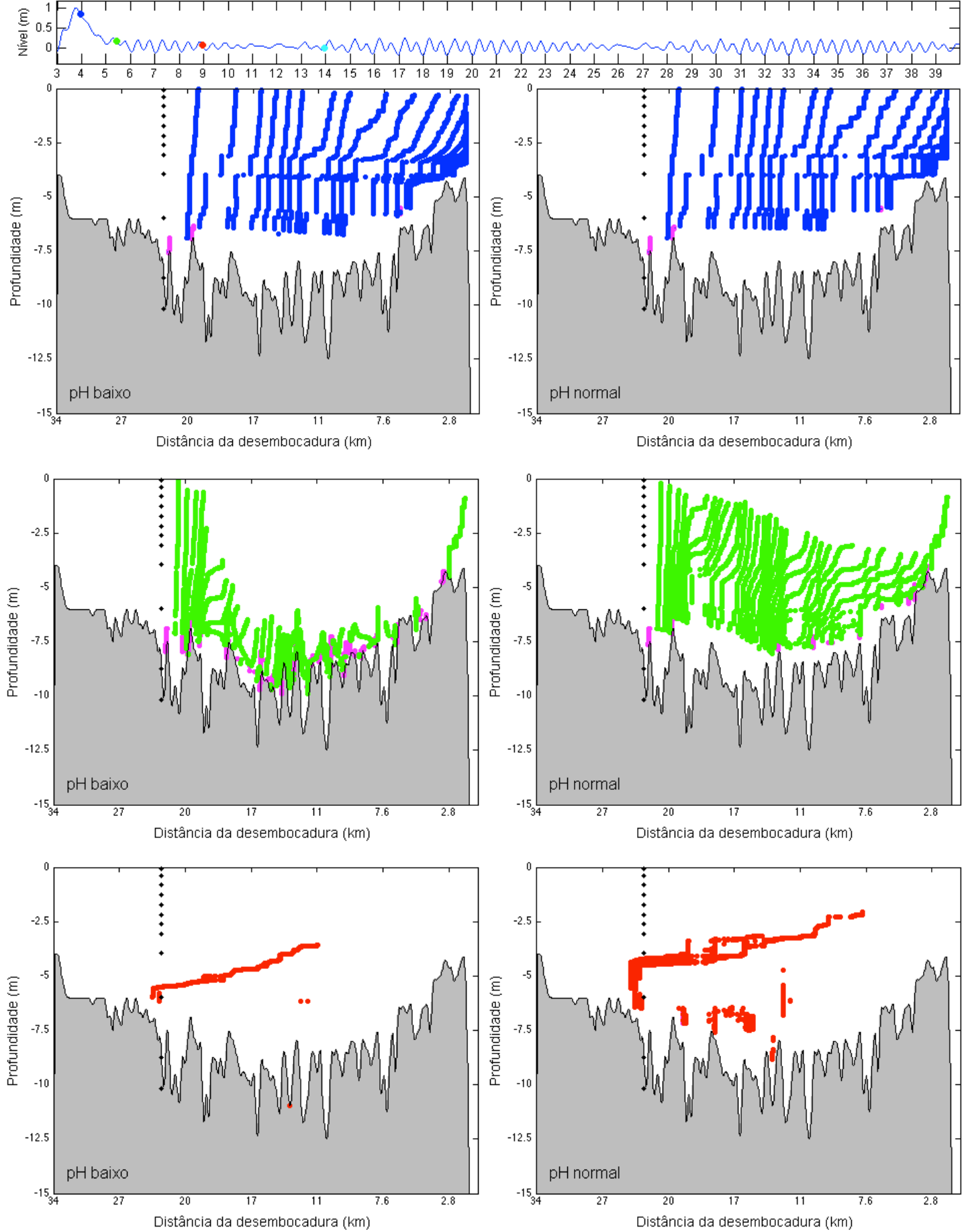

Figura 4.34. (continua na próxima página) 

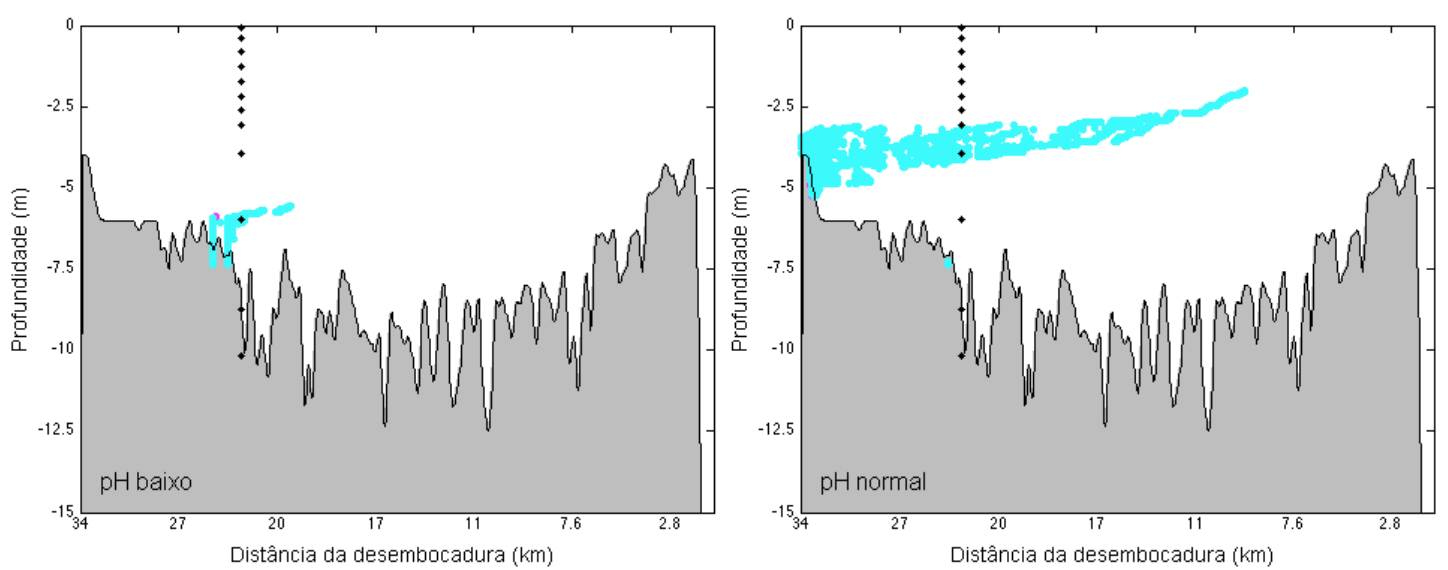

Figura 4.34. Gráficos indicando a posição das partículas no domínio do modelo da trajetória das partículas para alguns instantes da simulação com descarga de 1000 $\mathrm{m}^{3} \cdot \mathrm{s}^{-1}$. O gráfico superior mostra a variação a descarga fluvial $\left(\mathrm{m}^{3} \cdot \mathrm{s}^{-1}\right)$ e a variação do nível da água $(\mathrm{m})$, abaixo estão os gráficos da partícula para o experimento com $\mathrm{pH}$ baixo (gráficos da esquerda) e para o experimento com $\mathrm{pH}$ normal (gráficos da direita). A cor das partículas representa os instantes que estão destacados (círculo preenchido) nos gráficos de descarga e nível na parte superior. A cor desses círculos corresponde a cor das partículas. Os pontos em preto nos gráficos representam a região de lançamento das partículas (confluência).

A trajetória das partículas durante cada experimento com pico de descarga de $1000 \mathrm{~m}^{3} \cdot \mathrm{s}^{-1}$ pode ser observada na Figura 4.34. O primeiro instante representado é o momento de pico da descarga (dia 4). Nesses instante, as partículas estão se deslocando estuário abaixo, ao longo de toda a coluna da água, devido ao aumento das correntes, nos Caso 1 (gráfico esquerda) e Caso 2 (gráfico direita). Nestes casos, as partículas de deslocam com maior espaçamento entre si devido as maiores velocidade das correntes, quando comparadas com os experimentos, correspondentes, em condição de descarga menor. Ao final da descida do pico, é possível observar que a grande maioria das partículas que estavam em suspensão no experimento com $\mathrm{pH}$ baixo depositaram no estuário médio. Nesse mesmo instante, a maior parte das partículas permaneciam em suspensão no experimento com pH normal. No dia 9, uma pequena parte das partículas que foram lançadas permanecia em suspensão com $\mathrm{pH}$ baixo. Nesse mesmo instante, no experimento com $\mathrm{pH}$ normal, é possível observar que boa parte das partículas depositaram no médio estuário nos instantes anteriores, visto que sobram poucas partículas em suspensão. No dia 14, poucas partículas permanecem em suspensão na região da confluência com $\mathrm{pH}$ baixo e uma quantidade um pouco maior continua em suspensão com pH normal, se deslocando para montante. 
A anomalia de deposição entre as simulações com pH baixo (Caso 3) e pH normal (Caso 4), em condições de evento extremo de descarga fluvial $\left(1000 \mathrm{~m}^{3} \cdot \mathrm{s}^{-1}\right)$, indica que em condições de $\mathrm{pH}$ baixo, as partículas depositaram ao longo de toda a extensão do estuário do rio Araranguá (Fig. 4.35). Em condições de pH normal, as partículas depositaram, preferencialmente, acima do quilômetro 31 e um pouco mais abaixo, entre os quilômetros 25 e 28 , no rio Itoupava.

Ao longo do tempo observa-se que em condições de $\mathrm{pH}$ baixo, as partículas depositaram na extensão do rio Araranguá após o evento de pico de descarga. E que parte das partículas que permaneceram em suspensão e foram carregadas estuário abaixo, retornaram para montante, trazidas pela circulação gravitacional, entre os dias 11 e 15, e depositaram na região da confluência (quilômetro 23). Em condições de pH normal, a anomalia indica que as partículas em suspensão que foram carreadas estuário abaixo, retornaram para montante, trazidas pela circulação gravitacional e depositaram acima do quilômetro 31 .

Tabela 4.5. Porcentagem das partícula que foram exportadas e que depositaram, contabilizadas no final de cada experimento, com lançamento das partículas durante os eventos de descarga fluvial (400 e $1000 \mathrm{~m}^{3} \cdot \mathrm{s}^{-1}$ )

\begin{tabular}{ccccc}
\hline \hline & \multicolumn{2}{c}{ Exportação (\%) } & \multicolumn{2}{c}{ Deposição (\%) } \\
\hline $\begin{array}{c}\text { Pico de descarga } \\
\left(\mathrm{m}^{3} \cdot \mathrm{s}^{-1}\right)\end{array}$ & $\mathrm{pH}$ baixo & $\mathrm{pH}$ normal & $\mathrm{pH}$ baixo & $\mathrm{pH}$ normal \\
\hline 400 & 6 & 18 & & \\
1000 & 27 & 30 & 73 & 70 \\
\hline \hline
\end{tabular}

Tabela 4.6. Tempo médio de residências das partículas em suspensão no estuário durante todo os experimentos com $\mathrm{pH}$ baixo (Caso 1 e 3) e pH normal (Caso 2 e 4).

\begin{tabular}{ccc}
\hline \hline & \multicolumn{2}{c}{ Tempo médio de residência (horas) } \\
\hline $\begin{array}{c}\text { Pico de descarga } \\
\left(\mathrm{m}^{3} \cdot \mathrm{s}^{-1}\right)\end{array}$ & $\mathrm{pH}$ baixo & $\mathrm{pH}$ normal \\
\hline 400 & & 304 \\
1000 & 66 & 136 \\
\hline \hline
\end{tabular}




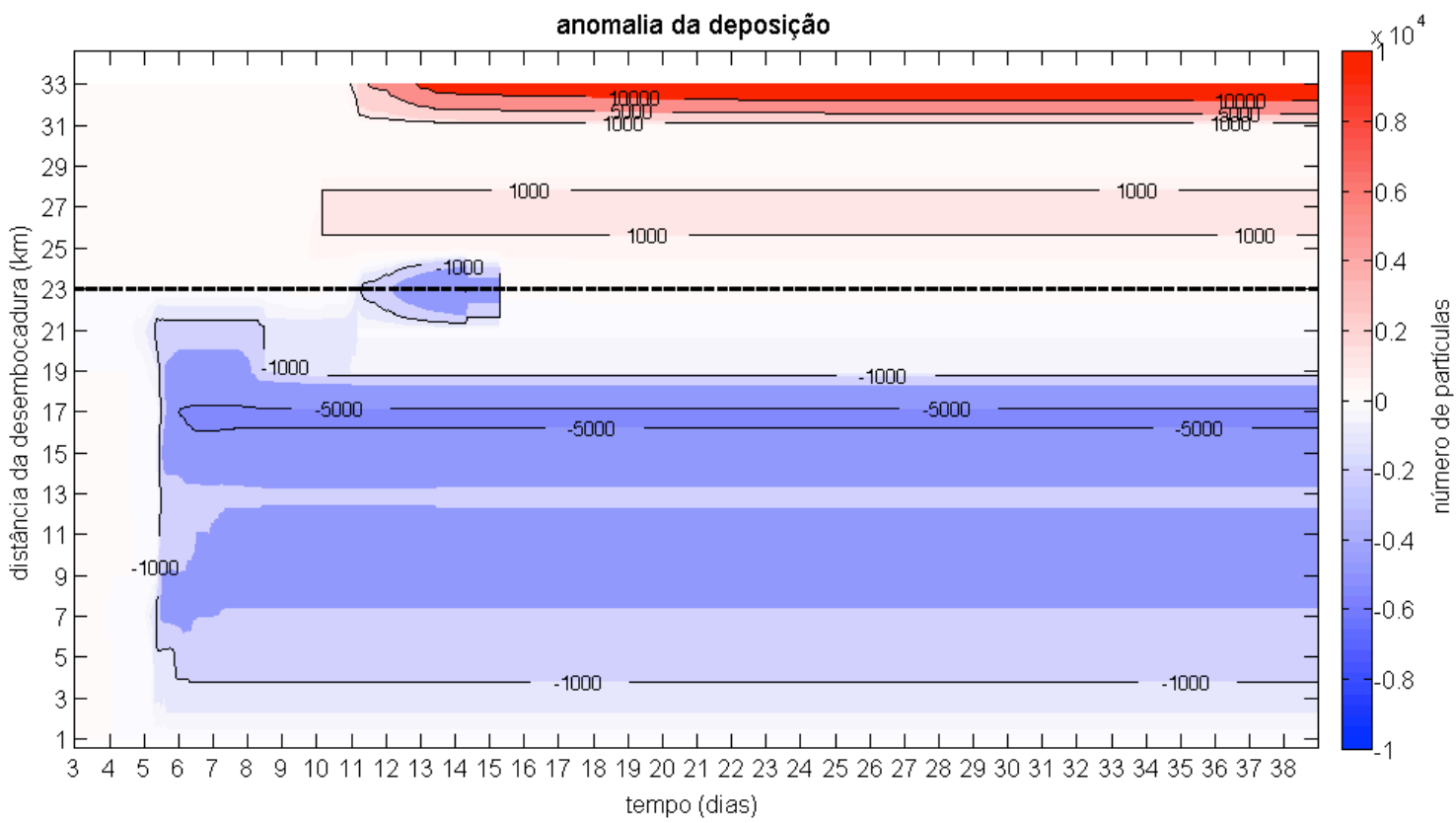

Figura 4.35. Gráfico da anomalia temporal da deposição das partículas ao longo do domínio. Lançamento das partículas no pico de descarga de $1000 \mathrm{~m}^{3} \cdot \mathrm{s}^{-1}$. Os valores negativos, em azul, indicam os setores de decantação das partículas do experimento com pH baixo (Caso 3) e os valores positivos, indicam os setores de decantação das partículas do experimento com $\mathrm{pH}$ normal (Caso 4). A linha tracejada indica a região da confluência. Acima da linha é o rio Itoupava e abaixo o rio Araranguá. O número de partículas, representa ao longo do tempo, a quantidade de partículas acumuladas em cada trecho do estuário. 


\section{Capítulo 5}

\section{Discussão}

Um modelo hidrodinâmico tridimensional e um modelo Lagrangeano de transporte de partículas foram aplicados para o estuário do rio Araranguá para compreender a dinâmica dos sedimentos coesivos em suspensão, sobre condições transientes de descarga fluvial e em duas condições físico-químicas da água: com pH baixo e pH normal. Os resultados sugerem que em condições de $\mathrm{pH}$ baixo, o tempo de permanência das partículas em suspensão é menor quando comparado com o experimento com $\mathrm{pH}$ normal. Isso porque as partículas depositam mais rápido em condições de pH baixo. Em termos de exportação das partículas, em condições de pH normal, o estuário exporta mais partículas. As velocidades das correntes mais baixas, a presença da circulação gravitacional e o baixo $\mathrm{pH}$, indicador do processo de floculação, fornecem as condições ideais para a retenção das partículas no estuário do rio Araranguá.

A calibração e a validação do modelo hidrodinâmico tridimensional mostraram que o modelo reproduziu bem as variações do nível da água e das velocidades das correntes, apresentando excelentes correlações com os dados observados. Os valores altos de Skill indicaram essa boa correlação nos processos de calibração e validação (Tab. 4.1 e 4.2). Provavelmente, a melhor concordância na estação \#1, em relação a estação \#2, pode ser explicada pelo fato de que o modelo é forçado com esses valores no contorno costeiro.

A calibração e validação da distribuição da salinidade foram realizadas em algumas etapas, devido a complexidade de implementação de um modelo numérico para um estuário altamente estratificado. Para que o modelo reproduzisse de forma aceitável as principais características do estuário, em termos de circulação e estratificação da salinidade, essas etapas foram necessárias para a construção do domínio do modelo e sua configuração. 
A dificuldade em modelar ambientes estratificados é manter a estabilidade da estrutura vertical na coluna da água, no caso a salinidade, para evitar mistura artificial. O Delft3D trabalha com dois tipos de coordenadas vertical de camadas, sigma e $\mathrm{Z}$. Entre essas duas, a recomendada é o $\mathrm{Z}$, pois suas camadas horizontais possibilitam a formação da haloclina. O inconveniente de se utilizar a coordena $Z$, com o modelo Delft3D, é que os módulos relacionados ao transporte de sedimento se tornam impossibilitados de serem utilizados.

Algumas tentativas de reproduzir a estrutura vertical da salinidade utilizando o modelo de camadas sigma foram realizadas, mas os resultados mostraram uma instabilidade da coluna da água, com mistura das propriedades entre as camadas. Isso acontece independentemente do número de camadas utilizadas e dos ajustes realizados nos parâmetros do modelo de viscosidade e difusividade vertical. Uma explicação pode estar relacionada com o fato de a topografia do fundo do estuário do rio Araranguá possuir variações abruptas e, embora o modelo sigma seja ajustado ao fundo nem sempre terá uma resolução adequada na picnoclina (Deltares, 2011).

Com o modelo de camadas- $Z$ foi possível viabilizar a formação da estrutura estratificada da salinidade e obter uma boa reprodução nas simulações. Os principais ajustes foram em relação ao número de camadas e a resolução entre elas. O domínio como um todo foi dividido em 20 camadas verticais. Dentro do estuário, o domínio ficou divido em 9 camadas. Os primeiros $4 \mathrm{~m}$, do domínio inteiro, foram divididos em 8 camadas com espaçamento de 0,5 m. Com base nos resultados observados ao longo de vários testes com o modelo, é possível constatar que com uma resolução maior nos primeiro metros, utilizando a coordenada-Z, o modelo reproduz bem a estratificação da salinidade no estuário.

Os resultados da aplicação do modelo hidrodinâmico mostraram diferenças entre as simulações com diferentes picos de descarga fluvial na circulação, distribuição da salinidade e no transporte advectivo de sal. Entre os resultados das simulações com o pico ocorrendo na quadratura e na sizígia, não foi possível observar diferenças significativas entre os resultados dos dois conjuntos de simulações. Observado os perfis médios de velocidade e salinidade calculados entre o dia 3 e o dia 15 (t1 a t6), para um mesmo ponto (estação \#1), e para as duas simulações de quadratura (Fig. 4.18) e sizígia 
(Fig. 4.27), nota-se que os perfis médios são semelhantes. Por esse motivo foram escolhidas apenas as simulações realizadas na sizígia, uma vez que os resultados mostram que não existem diferenças significativas.

Durante a elevação da descarga fluvial, o aumento do nível da água foi mais significativo em Q700 e Q1000, devido ao maior volume de água doce que entrou no estuário. As velocidades médias da corrente na coluna da água aumentaram com o aumento da descarga fluvial. E durante a passagem do pico, as velocidades médias da coluna da água foram positivas, indicando que durante esse período, o componente barotrópico da força de gradiente de pressão passou a predominar sobre o baroclínico em Q400, Q700 e Q1000.

A estratificação da salinidade diminuiu em Q400 e foi desestabilizada em Q700 e Q1000. Nestas simulações, a cunha salina foi transportada para plataforma e o volume do estuário foi preenchido por água doce. Esses resultados mostram que a resposta ao evento de elevação da descarga fluvial foi bastante rápida (Figs. 4.10 e 4.20). Em seus estudos, MacCready (1998) observou, utilizando um modelo numérico e um analítico, que um estuário fortemente estratificado e outro bem misturado, respondem rápido a mudanças da descarga fluvial e da maré.

No instante $\mathrm{t} 3$, poucas horas depois do pico de descarga, nota-se que a salinidade foi transportada estuário afora em condições de descarga de 700 e $1000 \mathrm{~m}^{3} . \mathrm{s}^{-1}$ (Figs. $4.16,4.17,4.25$ e 4.26). No que seria uma remoção total da salinidade, o pico de 1000 $\mathrm{m}^{3} \cdot \mathrm{s}^{-1}$ foi o mais efetivo, e aparentemente, em condições de sizígia. Em períodos de alta descarga fluvial a penetração da cunha salina é limitada, ou até mesmo transportada estuário afora, diminuindo a eficiência de filtração (Schubel \& Carter, 1984). Ainda no instante t3, observa-se que em Q400 a estratificação da salinidade diminuiu e a cunha salina recuou, para jusante, tanto na quadratura (Fig. 4.15) quanto na sizígia (Fig. 4.24). Durante as simulações com descarga de $100 \mathrm{~m}^{3} \cdot \mathrm{s}^{-1}$, a distribuição da salinidade não foi alterada devido ao aumento da descarga. Esses resultados sugerem que durante os eventos de elevação da descarga, a intrusão salina é controlada pela descarga fluvial. A intensidade do evento pode promover uma mistura significativa, como ocorreu em Q400, ou a completa remoção da cunha salina como em Q1000. 
A variação da salinidade do fundo ao longo do tempo e ao longo do estuário (Fig. 4.19 e 4.28), mostra o recuo da cunha salina com a passagem dos picos de 400, 700 e $1000 \mathrm{~m}^{3} \cdot \mathrm{s}^{-1}$, e depois o avanço da cunha com a diminuição da descarga. É possível observar também, o avanço de águas mais salinas, da ordem de 30, durante a maré de quadratura, nas simulações Q30 e Q100. Na sizígia esse avanço fica restrito aos primeiros $5 \mathrm{~km}$. Esses resultados sugerem que a transição entre a quadratura e a sizígia não acontece de forma uniforme, levando em consideração que o gradiente de densidade ao longo do estuário não é constante (e.g. Geyer \& MacCready, 2014), e em condições de maré de sizígia a intrusão de sal diminui. Depois de um evento de alta descarga, como os simulados em Q400, Q700 e Q1000, o avanço dessas águas mais salinas alcança maiores distâncias, na maré de quadratura seguinte ao evento. $\mathrm{O}$ avanço é maior após o pico de maior magnitude, no caso, $1000 \mathrm{~m}^{3} \cdot \mathrm{s}^{-1}$.

O transporte advectivo de sal é dominado pela descarga fluvial, durante a passagem do pico de descarga, em todas as simulações (quadratura e sizígia), exceto em Q30 (Tab. 5.4 e 5.5). A participação desse termo aumentou conforme a magnitude do evento. O termo dispersivo da circulação gravitacional foi o segundo em importância no transporte de sal para todas as simulações, exceto em Q30 e Q1000. Neste, o termo dispersivo da correlação da maré foi o segundo mais importante, o que, em geral, pode ser explicado por assimetria das correntes, seguido pela circulação gravitacional e pelo bombeamento da maré. Em Q700, o terceiro termo dispersivo mais importante foi o bombeamento pela maré.

A contribuição do termo dispersivo da circulação gravitacional aumentou consideravelmente, em relação ao período anterior ao pico, depois que o termo advectivo da descarga fluvial perdeu sua importância, nas simulações Q400, Q700 e Q1000 (Fig. 5.11 e 5.21). Após o evento, com a diminuição da descarga, ocorreu o ajuste baroclínico e a estratificação passou a aumentar, permitindo o movimento da intrusão salina estuário acima. A intensificação da circulação gravitacional também foi observada após um evento de descarga $137 \mathrm{~m}^{3} \cdot \mathrm{s}^{-1}$ no estuário do rio Araranguá (Barreto \& Schettini, 2014). 
As simulações mostram que em condições de baixa descarga fluvial $\left(30 \mathrm{~m}^{3} \cdot \mathrm{s}^{-1}\right) \mathrm{o}$ transporte de sal é dominado pelo termo dispersivo da circulação gravitacional, seguido pela descarga fluvial. Nessas condições, de baixa descarga fluvial, as correntes no estuário são controladas pelas variações da maré, com maiores velocidade na sizígia e menores na quadratura. Esse padrão também foi observado no estuário do rio Itajaí-Açu, aproximadamente a $300 \mathrm{~km}$ ao norte, do rio Araranguá, durante períodos de baixa descarga (Schettini, 2002).

A maioria das parametrizações da velocidade de decantação dos flocos produz um valor médio de queda no tempo e no espaço (Manning et al, 2011). Valores constantes de velocidade de sedimentação de $0,5-1 \mathrm{~mm} \cdot \mathrm{s}^{-1}$ tem sido considerados para representar a sedimentação de coesivos, embora subestimem significativamente as taxas de queda dos macroflocos (Manning et al., 2011). No modelo da trajetória da partícula, as velocidades de decantação, foram estimadas utilizado os dados da variação da concentração do material em suspensão (Portela et al., 2013) de experimentos dinâmicos realizados em um tanque anular (Couceiro \& Schettini, 2010). Desta forma, para cada condição do fluxo (velocidade) a partícula recebe uma velocidade de decantação.

Neste trabalho, as partículas simuladas no modelo Lagrangeano da trajetória das partículas são consideradas apenas indicadoras do comportamento do material particulado em suspensão no estuário do rio Araranguá. O modelo não avalia o comportamento das partículas como sedimento, considerando todas as suas propriedades, seus mecanismos de transporte e suas interações com o fluido. Avalia somente o comportamento das partículas em função da velocidade de decantação e dos componentes barotrópico e baroclínico da força do gradiente de pressão. A quantidade das partículas não está relacionada com a concentração desse material na coluna da água.

As características físico-químicas da água, como o $\mathrm{pH}$ e a salinidade, influenciam no processo de floculação em ambientes estuarinos. No caso do estuário do rio Araranguá, os experimentos com tanque anular mostram que o $\mathrm{pH}$ baixo do rio Mãe Luzia intensifica o processo de floculação do material particulado em suspensão (Couceiro \& Schettini, 2010). Considerando as velocidades de decantação estimadas a 
partir dos resultados do tanque anular, foi possível simular a dinâmica das partículas em condições de $\mathrm{pH}$ baixo e normal. Com as simulações em condições de $\mathrm{pH}$ baixo foi possível compreender algumas das características do comportamento das partículas no estuário dentro do cenário atual. O objetivo de simular em condições normais é o de comparar os resultados para ter uma percepção do que mudou no estuário com e sem o efeito da drenagem ácida.

O estuário do rio Araranguá é classificado como altamente estratificado e dominado pela descarga fluvial (D'Aquino et al., 2010). O regime transiente de descarga fluvial, quando um evento de alta descarga fluvial ocorre em um curto período de tempo. Esses eventos ocorrem esporadicamente nesse estuário, assim como em outros da região, em função da precipitação na bacia hidrográfica. Esse evento de alta descarga causa uma perturbação no ambiente, provocando o desequilíbrio dos padrões de circulação e estratificação do estuário.

Para reproduzir essa condição de regime transiente foram escolhidos dois picos de descarga fluvial da simulação hidrodinâmica (Delft3d), um pico de 400 e outro de $1000 \mathrm{~m}^{3} \cdot \mathrm{s}^{-1}$. A descarga mais baixa $\left(400 \mathrm{~m}^{3} \cdot \mathrm{s}^{-1}\right)$, que pode ser considerada alta, em relação aos picos reproduzido pelo modelo e em relação aos outros estuários, reproduz estratificação e circulação gravitacional. E na condição mais alta $\left(1000 \mathrm{~m}^{3} \cdot \mathrm{s}^{-1}\right), \mathrm{o}$ sistema é totalmente dominado pela advecção fluvial suficiente para transportar a cunha salina estuário afora. Cada condição de descarga foi simulada para os dois experimentos com $\mathrm{pH}$ baixo e normal, somando ao todo quatro experimentos. $\mathrm{O}$ evento ocorreu no início da simulação e após sua passagem, a descarga fluvial permaneceu constante em $30 \mathrm{~m}^{3} \cdot \mathrm{s}^{-1}$ até o final da simulação. Somente durante o período de elevação e descida do pico de descarga é que as partículas foram lançadas em suspensão no domínio do modelo. O número de partículas foi o mesmo nos quatro experimentos, independente da magnitude do evento e da condição físico-química da água. Uma vez que as partículas são indicadoras do comportamento, sua quantidade não representa a concentração de sedimento.

Os quatro experimentos realizados, Caso 1, Caso 2, Caso 3 e Caso 4, foram configurados para responder algumas perguntas a respeito da dinâmica do material em suspensão no estuário do rio Araranguá, sobre condições transientes de descarga fluvial 
e em diferentes condições de $\mathrm{pH}$, baixo e normal. A pergunta principal está relacionada com a mudança da dinâmica dos sedimentos em diferentes condições de $\mathrm{pH}$ e de descarga fluvial.

A velocidade de deposição das partículas em condições de baixa velocidade das correntes e salinidade nula, são maiores em condições de $\mathrm{pH}$ baixo, como mostra a Tabela 4.4. Um pico de deposição como esse, com grande quantidade de partículas depositando, não foi observado durante o experimento com pico de descarga de 400 $\mathrm{m}^{3} \mathrm{~s}^{-1}$ e pH baixo (Caso 1). Neste, as partículas permaneceram em suspensão, devido a presença da cunha salina nas camadas inferiores, a qual serviu de barreira para o transporte das partículas entre as camadas. Barreira não no sentido intransponível, mas sim devido às velocidades das correntes.

Durante os experimentos com pico de descarga de $400 \mathrm{~m}^{3} \cdot \mathrm{s}^{-1}$ uma quantidade maior de partículas (três vezes maior) foram exportadas no experimento com $\mathrm{pH}$ normal (18\%) em relação ao experimento com pH baixo (6\%) (Tab. 4.5). Com o pico de 1000 $\mathrm{m}^{3} \cdot \mathrm{s}^{-1}$ a porcentagem de partículas exportadas, entre os experimentos, foi muito próxima, com valores de $27 \%, \mathrm{pH}$ baixo e $30 \%$, $\mathrm{pH}$ normal. Esses resultados mostram que com o aumento da intensidade do pico, mais partículas deixam o estuário. E essa razão pode aumentar com o aumento da intensidade ou com o aumento da duração do evento, pois, conforme a cunha salina é transportada estuário abaixo, as partículas também são (Dyer, 1986). Entretanto, a duração de eventos de alta descarga fluvial e a fisiografia do estuário devem ser consideradas na eficiência do transporte do material particulado em suspensão.

O tempo de permanência das partículas em suspensão é menor nos experimentos com pH baixo. O que reflete o efeito da floculação, que em geral, é diminuir o tempo no qual elevada concentração persiste em suspensão (Kranck, 1984). Entre os experimentos com descarga fluvial de 400 e $1000 \mathrm{~m}^{3} \cdot \mathrm{s}^{-1}$, as partículas ficam em suspensão por menos tempo nos experimentos com pico de $1000 \mathrm{~m}^{3} \cdot \mathrm{s}^{-1}$. Em números, o tempo médio de residência das partículas em suspensão no estuário foi de 170 h e 340 h, com pH baixo e normal, respectivamente, com pico de $400 \mathrm{~m}^{3} \cdot \mathrm{s}^{-1}$. E, de $66 \mathrm{~h}$ e $136 \mathrm{~h}$, com pH baixo e normal, respectivamente, com pico de $1000 \mathrm{~m}^{3} . \mathrm{s}^{-1}$. Em proporção, as partículas ficam o dobro do tempo em suspenção em condições de pH normal. Esses valores indicam que, 
em média, as partículas ficam menos tempo em suspensão no estuário em condições de $\mathrm{pH}$ baixo, e que durante o evento extremo de descarga fluvial, as partículas deixam a coluna da água mais rápido. Neste caso, as partículas deixam a coluna da água porque depositaram no estuário, e não por terem sido exportadas para plataforma, já que os valores de deposição, em porcentagem, são maiores que os valores de exportação, tanto no experimento com $\mathrm{pH}$ baixo quanto no experimento com $\mathrm{pH}$ normal (Tab. 4.5).

Observando as figuras 4.31 e 4.34, é possível contar a história geral da trajetória das partículas para todas as simulações. As partículas são lançadas em suspensão no domínio, uma pequena parte delas deposita no início e a outra parte permanece em suspensão. Quando parte das partículas alcançam a região do baixo estuário, devido ao processo advectivo gerado pela descarga fluvial, parte delas são exportadas para plataforma e parte permanece em suspensão. Em suspensão, também ficam algumas partículas no interior do estuário (médio estuário). Essas partículas que não foram exportadas para plataforma, ganham profundidade e retornam para o interior do estuário, nas camadas intermediárias, transportadas pela circulação gravitacional. E depositam no estuário em regiões mais a montante.

A região de deposição dessas partículas, transportadas para o interior do estuário pela circulação gravitacional, pode ser observada através dos gráficos da anomalia da deposição, que representam a diferença entre os dados comparados. Esses valores são representados pelo o número de partículas acumuladas ao longo do tempo. Nos experimentos com evento de descarga de $400 \mathrm{~m}^{3} \cdot \mathrm{s}^{-1}$, a anomalia da deposição indica que com $\mathrm{pH}$ baixo, as partículas depositaram, preferencialmente, na região da confluência (quilômetro 23), e com o pH normal, na região mais à montante do domínio (quilômetro 33) (Fig. 4.31).

O mesmo comportamento pode ser observado nos experimentos com pico de $1000 \mathrm{~m}^{3} \cdot \mathrm{s}^{-1}$ em termos do local de deposição (Fig. 4.34). A diferença está na quantidade de partículas depositadas. No Caso 3 ( $\mathrm{pH}$ baixo), como grande parte das partícula depositaram no médio estuário, durante a passagem do pico, restaram poucas partículas em suspensão. No Caso 4 (pH normal), parte das partículas foram depositadas no médio estuário após o pico de descarga, mas uma quantidade maior, em ralação ao Caso 3, depositou à montante da confluência. Essa quantidade maior de partículas depositadas 
final do experimento no Caso 4, pode ser explicada pelo fato de que mais partículas permaneceram em suspensão em relação ao Caso 3, após o evento de descarga.

Observando os resultados da anomalia da deposição é possível demostrar que com a diminuição do $\mathrm{pH}$, o que seria o centro de deposição, em condições de pH normal, migrou para jusante. Como as velocidades de decantação das partículas são em média menores em condições de $\mathrm{pH}$ normal, as partículas permaneceram por mais tempo em suspensão e foram transportadas para montante pela circulação gravitacional. Em condições de pH baixo, a velocidade média de decantação das partículas é maior, o que pode explicar a sua deposição mais à jusante.

$\mathrm{O}$ perfil longitudinal das profundidades do estuário mostra que à jusante $\mathrm{o}$ estuário passa a ser mais raso a partir do setor 3 e à montante a partir do setor 13 (Fig. 4.29-A). Entre esses dois setores, o estuário apresenta profundidades relativamente altas em relação a sua dimensão. As duas regiões mais rasas funcionaram como uma barreira para as partículas, dependendo das condições de transporte: estuário abaixo, devido à advecção fluvial e estuário acima, devido à circulação gravitacional. Durante o transporte das partículas no evento de alta descarga de $1000 \mathrm{~m}^{3} \cdot \mathrm{s}^{-1}$ (Caso 3 e 4), as partículas são interceptadas na região mais rasa à jusante (Fig. 4.34) . E durante o transporte das partículas estuário acima, pela circulação gravitacional, em condições de pH baixo, as partículas foram interceptadas na região mais rasa à montante (Fig. 5.34). A interceptação das partículas em condições de $\mathrm{pH}$ normal pelo transporte e pela circulação gravitacional, ocorreu no setor 17, representado pelo limite superior do domínio do estuário.

O regime transiente simulado para a trajetória das partículas e para as simulações hidrodinâmicas, não representam condições totalmente dominadas pela maré, uma vez que foi utilizada uma descarga de $400 \mathrm{~m}^{2} \cdot \mathrm{s}^{-1}$, e nem totalmente dominada pela descarga fluvial $\left(1000 \mathrm{~m}^{3} \cdot \mathrm{s}^{-1}\right)$, pois o período de duração foi curto (dois dias). Nessas condições, as simulações hidrodinâmicas podem responder o tempo de recuperação do sistema após esses eventos quando comparados com a simulação com descarga baixa. Em todos os experimentos, o restabelecimento do nível e da velocidade é mais rápido comparado com o restabelecimento da circulação gravitacional. 
Observando apenas as simulações com pico de $400 \mathrm{~m}^{3} \cdot \mathrm{s}^{-1}$ e $1000 \mathrm{~m}^{3} \cdot \mathrm{s}^{-1}$ na sizígia, que foram os utilizados no modelo das partículas, o restabelecimento da circulação gravitacional ocorreu 20 e 21 dias depois dos eventos de menor $\left(400 \mathrm{~m}^{3} \cdot \mathrm{s}^{-1}\right)$ e maior magnitude $\left(1000 \mathrm{~m}^{3} \cdot \mathrm{s}^{-1}\right)$, respectivamente.

A complexidade da difusão turbulenta que ocorre durante regimes transientes em estuários estratificados, devido ao aumento das velocidades das correntes, não foi reproduzida pelo modelo da trajetória das partículas, impossibilitando descrever os movimentos verticais da partícula com o aumento das velocidades das correntes. Os movimentos ascendentes provavelmente manteriam as partículas em suspensão por mais tempo evitando que elas depositem. Embora o modelo da trajetória da partícula tenha reduzido a complexidade do ambiente, sua simplicidade permitiu identificar os principais movimentos, gerando informações relevantes sobre a dinâmica das partículas.

Os resultados obtidos pelos experimentos com o modelo da trajetória da partícula sugerem que o estuário do rio Araranguá se comporta de forma diferente no que se refere ao transporte de sedimento em suspensão, em relação ao estuário do rio Itajaí-Açu. Este possui dois modos principais de transporte, um fluvial, responsável por exportar grandes quantidades de material particulado em suspensão, durante eventos de alta descarga fluvial, e o modo marinho, responsável por importar sedimento da plataforma adjacente (Schettini \& Toldo Jr., 2006). No estuário do rio Araranguá, os experimentos com $\mathrm{pH}$ baixo indicam que durante a passagem de um pico de descarga fluvial, da mesma proporção $\left(1000 \mathrm{~m}^{3} \cdot \mathrm{s}^{-1}\right)$ do observado por Schettini \& Toldo Jr (2006), apenas uma pequena fração das partículas (27\%), que estavam em suspensão no estuário, foi exportada para plataforma. Por essa comparação, o estuário do rio Araranguá não pode ser considerado um exportador de sedimentos em suspensão. $\mathrm{O}$ modo marinho não pode ser comparado, uma vez que o modelo não considerou a importação de partículas da plataforma, mas considerando que na região mais ao sul de Santa Catarina as alturas da maré são inferiores e o baixo estuário do rio Araranguá é raso, com profundidade máxima de $4 \mathrm{~m}$, possivelmente, o modo marinho terá um papel menor. 
No baixo curso do estuário, no trecho final onde o canal de desloca para nordeste e segue paralelo à linha de costa os sedimentos do fundo são arenosos, e possivelmente, de origem marinha (D’Aquino et al., 2010). A desembocadura do estuário é livre, sem a presença de molhes de orientação do fluxo, com profundidade $4 \mathrm{~m}$ e a deriva litorânea na região transporta o sedimento de sudoeste para nordeste (Siegle \& Asp, 2007). Provavelmente, esse material arenoso pode ter sido transportado para dentro do estuário através do avanço da cunha salina, durante o restabelecimento baroclínico, após um evento de curta duração de elevada descarga fluvial.

Em termos de exportação o que mudou em relação aos experimentos, com pH baixo e pH normal, foi a quantidade. Em condições de descarga média, três vezes mais partículas foram exportadas para plataforma interna. Nessas condições as partículas foram transportadas estuário afora nas camadas superficiais. Em condições de descarga extrema, a diferença não foi significativa. Em termos de deposição, os centros de deposição são divergentes. Com $\mathrm{pH}$ normal, as partículas depositam à montante da região da confluência e com pH baixo as partículas depositam mais à jusante, na região da confluência.

As mudanças que ocorrem na hidrodinâmica e na distribuição da salinidade durante os eventos de descarga, foram refletidas no transporte das partículas ao longo dos experimentos. $\mathrm{O}$ transporte foi mais efetivo durante dois momentos da passagem do pico, quando as velocidades das correntes foram máximas, e as partículas chegaram no baixo estuário, e quando a advecção fluvial perdeu energia e a circulação gravitacional passou a ganhar força, intensificando o transporte das partículas estuário acima. Isso mostra que o restabelecimento hidrodinâmico que ocorre no estuário, após um pico de descarga, é refletido também no transporte das partículas.

O cenário atual do estuário considera as informações obtidas pelos experimentos com pH baixo. Nesse contexto, é possível descrever algumas das características do material particulado em suspensão. O material particulado em suspensão é transportado estuário abaixo em condições de descarga elevadas. Quando o evento de descarga não é suficiente para promover o recuo da cunha salina (à jusante), as partículas são transportadas nas camadas superficiais. $\mathrm{O}$ alcance será determinado pela intensidade das correntes, assim com a quantidade exportada. Quando o evento é suficiente para 
transportar a cunha salina para jusante, as partículas são transportadas em toda coluna da água, aumentando a probabilidade de depositarem no médio estuário, entre as duas regiões mais rasas do estuário, onde também são encontradas as maiores profundidades. Muito provavelmente, durante um evento de descarga suficiente para aumentar as velocidades na camada do fundo, a ressuspensão das partículas depositadas na região mais rasa à montante seja promovida. Nessas condições, de ressuspensão do material depositado, as partículas terão o mesmo comportamento das partículas em suspensão. Em condições de baixa descarga, as partículas depositam na região mais rasa à montante, entre os quilômetros 19 e 29.

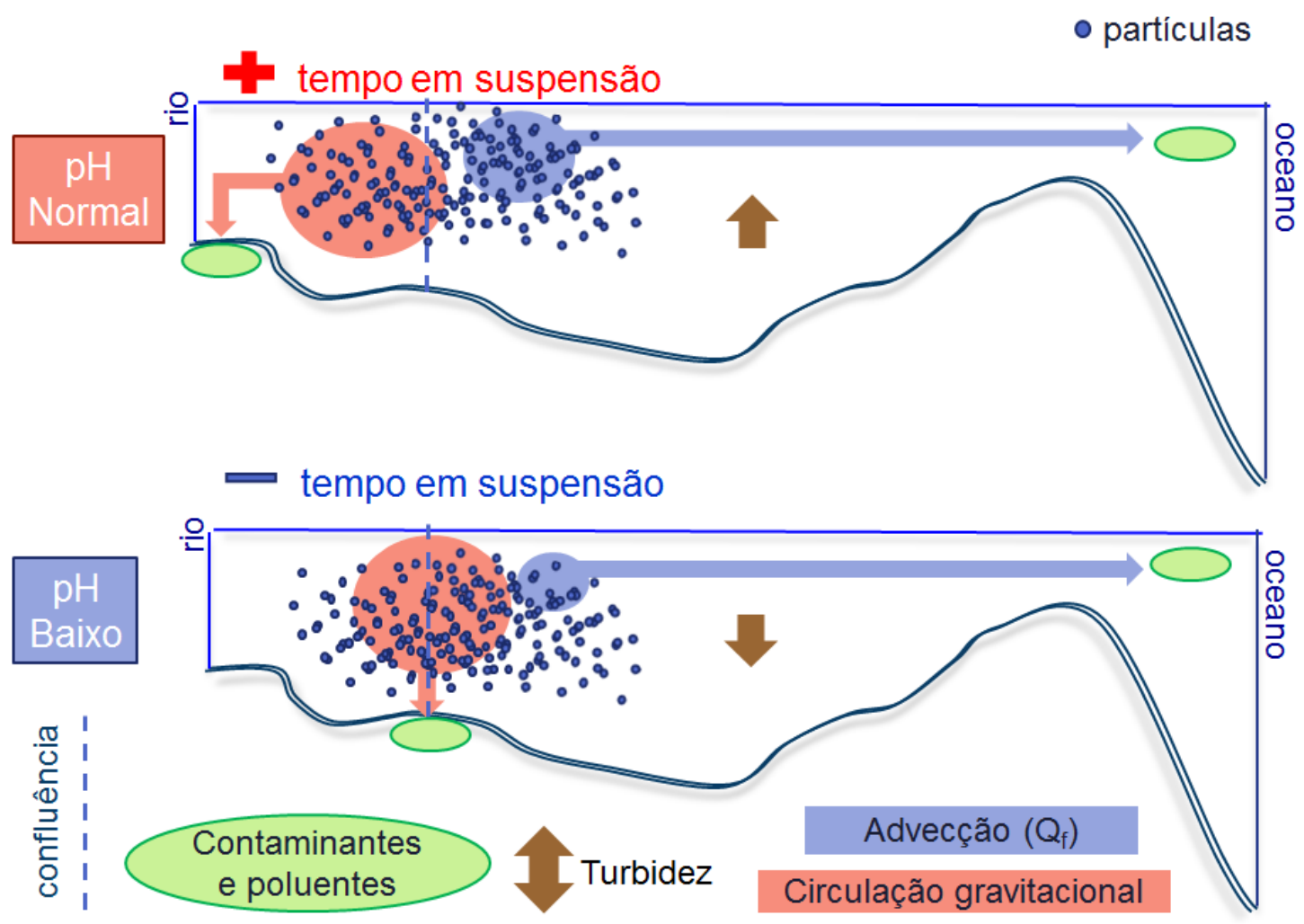

Figura 5.1. Representação do modelo conceitual do transporte das partículas no estuário do rio Araranguá em condições de $\mathrm{pH}$ normal e pH baixo.

O mapa conceitual (Fig. 5.1) permite visualizar um esquema das possibilidades do transporte no material particulado em suspensão no estuário do rio Araranguá, em duas condições, considerando: o efeito da atividade carvoeira ( $\mathrm{pH}$ baixo) e sem o efeito da atividade carvoeira ( $\mathrm{pH}$ normal), na bacia de drenagem do rio Araranguá. 
Em uma situação sem os efeitos da atividade carvoeira, as partículas permaneceriam por mais tempo em suspensão na coluna da água. O que aumentaria a probabilidade de serem transportadas pela circulação gravitacional para montante no estuário, tanto pelo rio Itoupava, quanto pelo rio Mãe Luzia, ou serem exportadas para plataforma adjacente durante eventos de elevada descarga fluvial. Os centros deposicionais, nesse caso, se encontrariam à montante nesses rios. Pelo fato das partículas permanecerem por mais tempo em suspensão, aumentaria a turbidez da água ao longo de sua extensão, o que poderia, por exemplo, ser um limitante na produtividade primária do sistema.

No cenário atual, com os efeitos da atividade carvoeira ( $\mathrm{pH}$ baixo), as partículas permanecem menos tempo em suspensão na coluna da água, o que aumenta a probabilidade de retenção do material em suspensão no estuário, principalmente em condições de baixa velocidade das correntes. Como consequência, ocorre a diminuição da turbidez de suas águas. Comparando com as águas do rio Itajaí-Açu, por exemplo, as águas do rio Araranguá são mais transparentes, muito provavelmente, por causa favorecimento do processo de floculação, devido ao $\mathrm{pH}$ baixo de suas águas. Os centros deposicionais no estuário do rio Araranguá, estão localizados à jusante da região da confluência entre os rios Itoupava e Mãe Luzia.

O destino final do material particulado em suspensão indica também, o destino final do transporte de poluentes e contaminantes nos estuário, uma vez que estão adsorvidos aos sedimentos coesivos, e estes fazem parte do material particulado em suspensão. Deste modo, os centros deposicionais desse material, identificados pelas simulações, podem informar quais são as regiões do estuário suscetíveis a sofrerem impactos ambientais. Esses centros podem indicar também os possíveis pontos de assoreamento, devido à deposição do material floculado. Além disso, os resultados das simulações hidrodinâmicas, realizadas aqui, podem ser utilizadas na gestão dos recursos hídricos na bacia do rio Araranguá, e os resultados no modelo das partículas, podem auxiliar nas ações de manejo do material floculado no estuário, por exemplo. 


\section{Capítulo 6}

\section{Conclusões}

Compreender a dinâmica de sedimentos coesivos é um tarefa difícil, levando em consideração todas as propriedades físicas dos sedimentos coesivos e sua natureza complexa no ambiente. O modelo simplificado utilizado para trajetória das partículas demostrou ser uma boa ferramenta, uma vez que permite observar a dinâmica do material floculado, em termos de transporte em suspensão, exportação e deposição. As características do material em suspensão, floculado ou não, foram representadas por suas velocidades de decantação. A hidrodinâmica foi representada pelas duas principais forçantes do estuário do rio Araranguá: o termo advectivo, pela descarga fluvial e a circulação gravitacional. As conclusões a seguir sumarizam os principais resultados obtidos com a modelagem numérica e a modelagem do transporte das partículas indicadoras do material em suspensão no estuário do rio Araranguá:

1. O modelo hidrodinâmico Delft3D apresenta uma reprodução do ambiente com comparações excelentes (nível e velocidade) e boas (salinidade) entre os resultados do modelo e os dados observados. No entanto, o modelo numérico não foi adequado para simular sedimentos coesivos no estuário do rio Araranguá devido a limitações nas suas configurações.

2. Apesar da relativa simplicidade do modelo Lagrangeano de trajetória das partículas, no que concerne aos processos simulados e sua representatividade em termos de domínio, os resultados possibilitam ter uma ideia do que acontece no estuário em termos de transporte em suspensão, deposição e exportação das partículas. Considerado uma ferramenta bastante eficiente para o estudo proposto aqui.

3. O gradiente barotrópico é dominante sobre o baroclínico quando o aumento da intensidade da descarga fluvial é suficiente para manter as correntes da coluna da água orientadas estuário abaixo. E conforme aumenta a intensidade da 
descarga, aumenta também o transporte advectivo de sal dominado pela descarga fluvial.

4. A magnitude da descarga fluvial é o fator dominante que afeta a distribuição da salinidade no estuário do rio Araranguá. Em condições de descarga fluvial extrema $\left(>1000 \mathrm{~m}^{3} \cdot \mathrm{s}^{-1}\right)$ a cunha salina é transportada para fora do estuário e o transporte de sal é dominado pela descarga fluvial. Em condições de baixa descarga $\left(\sim 30 \mathrm{~m}^{3} \cdot \mathrm{s}^{-1}\right)$ a água salina entra no estuário e o transporte de sal é dominado pela circulação gravitacional.

5. As partículas indicam que quando o evento de descarga fluvial não é suficiente para transportar a cunha salina estuário afora, ou seja, existe a estratificação, sua trajetória é estuário abaixo nas camadas superficiais, e quando a intensidade da corrente diminui, as partículas ganham profundidade e a sua trajetória passa a ser controlada pela circulação gravitacional, estuário acima. Como a estratificação, força estabilizadora, reduz a turbulência, essas partículas, provavelmente, ficam retidas na margem da intrusão salina (zona de convergência). Quando o evento de descarga é suficiente para transportar a cunha salina para plataforma interna, as partículas indicam o transporte em toda a coluna da água. Nessas condições, a deposição das partículas no médio estuário é favorecida.

6. Em termos de exportação, com o pH normal, mais partículas são exportadas quando comparadas com condições de $\mathrm{pH}$ baixo. Indicando maior retenção das partículas em condições de $\mathrm{pH}$ baixo. A exportação de grande quantidade de material particulado em suspensão provavelmente ocorre durante eventos de elevada descarga por tempo prolongado, nas duas condições de $\mathrm{pH}$.

7. Em termos de deposição, os centros de deposição apontados pela anomalia da deposição indicam que com a atividade carvoeira ( $\mathrm{pH}$ baixo), esses centros migraram para jusante, quando comparados com condições sem a atividade carvoeira ( $\mathrm{pH}$ normal). Isso pode ocorre pelo fato de que a velocidade de decantação das partículas são em média maiores. Ou, esse ganho em velocidade de decantação, pode estar atrelado ao fato de que nessas condições de velocidade 
das correntes e salinidade, a floculação foi favorecida durante os experimentos com o tanque, e está sendo refletida no modelo da trajetória das partículas.

8. As condições hidrodinâmicas do estuário, com baixas velocidades e circulação gravitacional também favorecem a retenção das partículas no interior do estuário. A circulação gravitacional desempenhou um papel fundamental no transporte das partículas para o interior do estuário após os eventos de alta descarga. Canais com alta salinidade e baixa velocidade, como o estuário do rio Araranguá, resultam na floculação e deposição de sedimentos finos transportados pelo fluxo (Metha \& Partheniades, 1975).

9. O trabalho demonstra que apesar da alta estratificação do estuário, a acidez de suas águas, seu padrão de circulação, com baixas velocidades e a presença da cunha salina, possuem um papel fundamental no transporte das partículas, resultando em maior potencial de retenção do material em suspensão no estuário do rio Araranguá.

Embora este estudo tenha fornecido alguma informação sobre o transporte das partículas em suspensão no estuário, trabalhos futuros serão necessários para avançar nos estudos da dinâmica dos sedimentos coesivos. Avanços nos estudos do material floculado no estuário do rio Araranguá podem ser obtidos, por exemplo, com o aprimoramento e ampliação do modelo da trajetória das partículas. Os processos de intrusionamento e ressuspensão podem ser inseridos nos modelo, assim como a incorporação da difusão. A investigação dos processos de fluxo de materiais com a plataforma adjacente, importação e exportação de sedimentos, aumentaria a compreensão do transporte sedimentar no sistema estuarino . 


\section{Referências}

ANA. Agência Nacional de Águas - Sistema de Informações Hidrológicas. http://hidroweb.ana.gov.br/.

ALLEN, J. I.; SOMERFILD, P. J.; GILBERT, F. J. 2007. Quantifying uncertainty in high resolution coupled hydrodynamic-ecosystem models. Journal of Marina Systems, v. 64, n. $1-4$, p. $3-14$.

BARRETO, G.A.M.; SCHETTINI, C.A.F. 2014. Papel da maré e da descarga fluvial na circulação do estuário do Rio Araranguá. Revista Brasileira de Recursos Hídricos, v. 19, n.3, p. 7-17.

BIDONE, E. D.; CASTILHOS, Z. C.; GUERRA, T. 2000. Interação dos estudos através de uma abordagem (sócio) econômico-ambiental. In: Carvão e meio ambiente. Porto Alegre: (ed) da Universidade/UFRGS, p. 271-439.

BOWDEN, K. F. 1963. The mixing processes in a tidal estuary. Journal Air Water Pollution, v. 7, p. 343-356.

BRAUNGARDT, C.B.; ACHTERBERG, E.P.; ELBAZ- POULICHET, F.; MORLEY, N.M. 2003. Metal geochemistry in a mine-polluted estuarine system in Spain. Applied Geochemistry, v. 18, p. 1757-1771.

BRICKMAN, D.; SMITH, P. C. 2002. Lagrangian stochastic modeling in coastal oceanography. Journal of Atmospheric and Oceanic Technology, v. 19, n. 1, p. 83-99.

BROWN, J. M.; AMOUDRY, L. O.; SOUZA, A. J.; REES J. 2015. Fate and pathways of dredged estuarine sediment spoil in response to variable sediment size and baroclinic coastal circulation. Journal of Environmental Management, v. 149, p. 209-221.

CAMERON, W. M.; PRITCHARD, D. W. 1963. Estuaries. In: Hill, M. N. (ed.). The Sea. New York, Wiley Interscience. p.306-32. 
CEREJO, M.; DIAS, J. M. 2007. Tidal transport and dispersal of marine toxic microalgae in a shallow, temperate coastal lagoon. Marine Environmental Research, v. 63 , n. 4 , p. 313-340.

CHEN, XJ. 2004. Modeling hydrodynamics and salt transport in the Alafia River estuary, Florida during May 1999-December 2001. Estuarine Coastal and Shelf Science, v. 61, n. 3, p. 477-490.

CHENG, RT.; BURAU, J.R.; GARTNER, J.W. 1991. Interfacing data analysis and numerical modelling for tidal hydrodynamic phenomena. In: PARKER, B.B. (ed.), Tidal Hydrodynamics. John Wiley, New York, p. 201-219.

CHENG, R.T.; CASULLI, V.; GARTNER, J. 1993. Tidal, residual, intertidal mudflat (TRIM) model and its applications to San Francisco Bay, California. Estuarine, Coastal and Shelf Science, v. 36, p. 235-280

COUCEIRO, M. A. A. \& SCHETTINI, C. A. F. 2010. Estudo da dinâmica dos sedimentos em suspensão do estuário do rio Araranguá ( $\mathrm{SC}$ ): possíveis efeitos da drenagem ácida da atividade de mineração de carvão. Geociências, v. 29, n. 2, p. 251266, UNESP, São Paulo.

D’AQuino, C. A; SCHETTINI, C. A. F.; PEREIRA FILHO, J. 2010 Fluvial modulation and salt transport in a highly stratified estuary. Brazilian Journal of Oceanography, v. 58, n. 3, p. 165-175.

DELTARES, 2011. User manual Delft-3D FLOW, Deltares (www.deltares.nl), Delft, The Netherlands.

DIMOU, K. N.; ADAMS, E. E. 1993. A random-walk, particle tracking model for wellmixed estuaries and coastal waters. Estuarine, Coastal and Shelf Science, v. 37, n. 1, p. 99-110.

DÖBEREINER, C. 1982. Aggregation and deposition of fine particles in the Tay estuary. Tese de doutorado. Faculty of Science in the University of Dundee, Scotland, UK, 151 p. 
DYER, K. R. 1974. The salt balance in stratified estuaries. Estuarine and Coast Marine Science, v. 2, p. 273-281.

DYER, K. R. 1986. Coastal and estuarine sediment dynamics. New York, John Wiley and Sons, $342 \mathrm{p}$.

DYER, K. R. 1995. Sediment transport processes in estuaries. In: Geomorphology and sedimentology of estuaries. Developments in sedimentology. (ed). Perillo G.M.E. p.423-449.

DYER, K. R. 1997. Estuaries: a physical introduction. John Wiley \& Sons. 140 p.

EISMA, D. 1986. Flocculation and de-flocculation of suspended matter in estuaries. Netherlands Journal of Sea Research, v. 20, p. 183-199.

FISCHER, H. B. 1976. Mixing and dispersion in estuaries. Annual Review of Fluid Mechanics, v. 8, p.107-133.

FUNGARO, D. A.; IZIDORO, J. C. 2006. Remediação de drenagem ácida de mina usando zeólitas sintetizadas a partir de cinzas leves de carvão. Química Nova, v. 29, p. 735-740.

GESTEIRA, M. G.; MONTERO, P.; PREGO, R.; TABOADA, J. J.; LEITAO, P.; VILLARREAL, M. R.; VILLAR, V. P. 1999. A two-dimensional particle tracking model for pollution dispersion in A Coruña and Vigo Rias (NW Spain). Oceanologia Acta, 22(2), 167-177.

GOTHE, C. A. V. 1989. Diagnóstico Ambiental da região Carbonífera Catarinense. Florianópolis: ENESMA, v. 3, p. 62-96.

GEYER, W. R.; MACCREADY, P. 2014. The estuarine circulation. Annual. Review of Fluid Mechanics, v. 46, n. 1, p. 175, 2014. 
GEYER, W. R. 2010. Estuarine salinity structure and circulation. Contemporary issues in estuarine physics, transport and water quality. Cambridge University Press, New York, p. 12-26.

HASAN, G. M. J.; VAN MAREN, D. S.; FATT, C. H. 2013. Numerical study on mixing and stratification in the Ebb-Dominant Johor Estuary. Journal of Coastal Research, v. 29, n. 1, p. 201-215.

HAYES, M.O. 1975. Morphology of sand accumulation in estuaries: an introduction to the symposium. In: L.E. Cronin (ed.). Estuarine Research. Vol. II. New York: Academic Press, p. 3-22.

HUANG, W. 2007. Hydrodynamic modeling of flushing time in a small estuary of North Bay, Florida, USA. Estuarine, Coastal and Shelf Science, v. 74, n. 4, p. 722-731.

HUNKINS, K. 1981. Salt dispersion in the Hudson estuary. Journal of Physical Oceanography, v. 11, p. 729-738.

JI, ZG; GUANGDOU H.; SHEN J.; WAN, Y. 2007. Three-dimensional modeling of hydrodynamic processes in the St. Lucie Estuary. Estuarine, Coastal and Shelf Science, v. 73 , n. 1, p. $188-200$.

KJERFVE, B. 1986. Circulation and salt flux in a well mixed estuary. In: Van de Kjerfve, J. (ed). Physics of Shallow Estuaries and Bays. Berlin, Spring-Verlag,. p. 2229.

KRANK, K. 1984. The role of flocculation in the filtering of particle matter in estuaries. In: KENNEDY, V. S. (ed). The estuary as a filter. New York, Academic Press, p.159175.

KREBS, A. S. J. 2004. Contribuição ao conhecimento dos recursos hídricos subterrâneos da bacia hidrográfica do rio Araranguá, SC. Tese doutorado Centro de Filosofia e Ciências Humanas da UFSC, Universidade Federal de Santa Catarina, Florianópolis, 375 p. 
KRONE, R. B. Aggregation of suspended particle in estuaries. 1978. In: Kjerfve, B. (ed.) Estuarine transport processes. Columbia, USC-Press, p. 177-190.

LAU, Y. L.; DROPPO, I. G.; KRISHNAPPAN, B. G. 2001. Sequential erosion/deposition experiments - demonstrating the effects of depositional history on sediment erosion. Water Research, v, 35, n. 11, p. 2767-2773.

LERCZAK, J. A.; ROCKWELL G, W. 2004. Modeling the lateral circulation in straight, stratified estuaries. Journal of Physical Oceanography, v. 34, n. 6, p. 14101428 .

LIU, WC; CHEN, WB; CHENG, R. T.; HSU, MH; KUO, A.Y. 2007. Modeling the influence of river discharge on salt intrusion and residual circulation in Danshuei River estuary, Taiwan. Continental Shelf Research, v. 27, n. 7, p. 900-921.

LIU, WC.; CHEN, WB; HSU, MH. 2011. Influences of Discharge Reductions on Salt Water Intrusion and Residual Circulation in Danshuei River. Journal Marine Science and Technology, v. 19, n. 6, p. 596-606.

LUMBORG, U.; WINDELIN. 2002. Hydrography and cohesive sediment modelling: aplication to the Romo Dyb tidal area. Journal of Marine Systems, v. 38, p. 287-303.

MACCREADY, P. 1999. Estuarine adjustment to changes in river flow and tidal mixing. Journal of Physical Oceanography, v. 29, n. 4, p. 708-726.

MANIQUE, G. A.; D’AQUINO C. A.; SCHETTINI, C. A. F. 2011.Transporte de sedimentos em suspensão em um estuário altamente estratificado sob condições de descarga fluvial transiente. Pesquisa em Geociências., v. 38, n. 3, p. 225-234.

MANNING, A. J; DYER, K. R. 1999. A laboratory examination of floc characteristics with regard to turbulent shearing. Marine Geology, v. 160, n. 1/2, p. 147-170. 
MANNING, A. J.; SPEARMAN, J. R.; BAUGH, J. V.; WHITEHOUSE, R. J. S.; SOULBY, R. L. 2011. Cohesive sediment flocculation and the application to settling flux modelling. INTECH Open Access Publisher.

MARINONE, S. G.; ULLOA, M. J.; PARÉS-SIERRA, A.; LAVÍN, M. F.; CUDNEY B, R. 2008. Connectivity in the northern Gulf of California from particle tracking in a three-dimensional numerical model. Journal of Marine Systems, v.71 n.1, 149-158.

MEHTA, A. J.; PARTHENIADES, E. 1975. An investigation of the depositional properties of flocculated fine sediments. Journal of Hydraulic Engineering, v. 13, n. 4, p. 361-381.

MILLIGAN, T.G.; LORING, D. H. 1997. The effect of flocculation on the size distributions of bottom sediment in coastal inlets: implications for contaminant transport. Water Air Soil Pollution, v.99, p. 33-42.

MILLIGAN, T. G.; KINEKE, G. C.; BLAKE, A. C.; ALEXANDER, C. R.; HILL, P. S. 2001. Flocculation and sedimentation in the ACE Basin, South Carolina. Estuaries, v. 24, p. 734-744.

MIRANDA, L. B.; CASTRO, B. M.; KJERFVE, B. 2002. Princípios de oceanografia física de estuários. São Paulo, Edusp. 414 p.

MIRANDA, L. B.; CASTRO, B. M.; KJERFVE, B. 2012. Princípios de oceanografia física de estuários. $2^{\text {a }}$ edição. São Paulo, Editora da Universidade de São Paulo (EDUSP), v.1. 426 p.

NORTH, E. W.; SCHLAG, Z.; HOOD, R. R.; LI, M.; ZHONG, L.; GROSS, T.; KENNEDY, V. S. 2008. Vertical swimming behavior influences the dispersal of simulated oyster larvae in a coupled particle-tracking and hydrodynamic model of Chesapeake Bay. Marine Ecology Progress Series v. 359, p. 99.

PRITCHARD, D. W. 1955. Estuarine circulation patterns. Proceedings of the American Society of Civil Engineers. V. 81, n.717, p.1-11. 
POMPÊO, M. L. M.; MOSCHINI, C. V.; ALEXANDRE N. Z.; SANTO, E. 2008. Qualidade da água em região alterada pela mineração de carvão na microbacia do rio Fiorita (Siderópolis, Estado de Santa Catarina, Brasil)-DOI: 10.4025/actascibiolsci. v26i2. 1610. Acta Scientiarum Biological Sciences, v. 26, n. 2, p. 125-136.

PORTELA, L.I.; RAMOS, S.; TEIXEIRA, A. T. 2013. Effect of salinity on the settling velocity of fine sediments of a harbor basin. In: Conley, D.C., Masselink, G., Russell, P.E. and O'Hare, T.J. (eds.), Proceedings $12^{\text {th }}$ International Coastal Symposium (Plymouth, England), Journal of Coastal Research, Special Issue Nn. 65, p. 1188-1193, ISSN 0749-0208.

POSTMA, H. 1967. Sediment transport e sedimentation in the estuarine environment. In: Lauff, G. H. (ed). Estuaries. Washington, AAAS Publication No. 83, p. 158-179.

RALSTON, D. K.; GEYER, W. R.; LERCZAK, J. A. 2008. Subtidal salinity and velocity in the Hudson River estuary: Observations and modeling. Journal of Physical Oceanography, v. 38, n. 4, p. 753-770.

SANTA CATARINA. 1997. Secretaria de Estado do Desenvolvimento Rural e da Agricultura. Zoneamento da disponibilidade e da qualidade hídrica da bacia do rio Araranguá. Documento síntese. Florianópolis, v.1.

SANTA CATARINA. 2004. Secretaria de Estado do Desenvolvimento Social, Urbano e Meio Ambiente - SDS. Instituto Brasileiro do Meio Ambiente e dos Recursos Naturais Renováveis - IBAMA. Relatório Parcial.

SIEGLE, E; ASP, N. E. 2007. Wave refraction and longshore transport patterns along the southern Santa Catarina coast. Brazilian Journal of Oceanography, v. 55, n. 2, p. 109-120.

SENTCHEV, A.; KOROTENKO, K. 2005. Dispersion processes and transport pattern in the ROFI system of the eastern English Channel derived from a particle-tracking model. Continental Shelf Research, v. 25, n. 18, p. 2294-2308. 
SCHETTINI, C.A.F. 2002. Caracterização física do Estuário do Rio Itajaí-açu, SC. Revista Brasileira de Recursos Hídricos, v. 7 n. 1, p. 123-142.

SCHETTINI, C. A. F.; TOLDO JR, E. E. 2006. Fine sediment transport modes in the Itajaí-Açu estuary, Southern Brazil. Journal of Coastal Research, p. 515-519.

SCHUBEL, J. R.; CARTER, H. H. 1984. The estuary as a filter for fine-grained suspended sediment. In: Kennedy, V. S. (ed). The estuary as a filter. New York, Academic Press, p. 81-105.

VALE, L. M.; DIAS, J. M. 2011. Coupling of a Lagrangian particle tracking module to a numerical hydrodynamic model: Simulation of pollution events inside an estuarine port area. Journal of Coastal Research, SI64, p. 1609-1613.

VALLE-LEVINSON, A. 2010. Contemporary issues in estuarine physics. (ed.). Cambridge University Press, 327 p.

VAN RIJN, L. C. 1993. Principles of sediment transport in rivers, estuaries and coastal seas. Amsterdam: Aqua publications.

XU, H.; LIN, J.; WANG, D. 2008. Numerical study on salinity stratification in the Pamlico River Estuary. Estuarine and Coastal Shelf Science, v. 80, n. 1, p. 74-84.

WARNER, J. C.; GEYER, W. R; LERCZAK, J. A. 2005. Numerical modeling an estuary: A comprehensive skill assessment. Journal of Geophysical Research, v. 110, p. $1-13$.

WILMOTT, C. J. 1981. On the validation of models, Physical Geography., v. 2, p. 184194.

WINTER, C.; BECKER, M.; ERNSTSEN, V. B.; HEBBELN, D.; PORT, A.; BARRTHOLOMA, A.; LUNAU, M. 2007. In-situ observation of aggregate dynamics in a tidal channel using acoustics, laser diffraction, and optics. In: International Coastal 
Symposium, 9, 2007. Gold Coast, Australia, Proceedings... Journal of Coastal Research, Special Issue, $50 \mathrm{p}$.

WINTERWERP, J. C. 2002. On the flocculation and settling velocity of estuarine mud. Continental Shelf Research, v. 22, p. 1339-1360.

WINTERWERP, J. C; KESTEREN W. G. M. van. 2004. Introduction to the Physics of Cohesive Sediment in the Marine Environment. Amsterdam: Elsevier, 466 p. 
Anexo I - Descrição do modelo numérico 


\section{AI.1. O modelo Delft3D}

O modelo numérico utilizado nesse estudo é o Delft3D, desenvolvido pela Deltares, um instituto independente localizado em Delft, Holanda. Apenas o módulo hidrodinâmico (Delft3D-FLOW), com foco na modelagem hidrodinâmica, foi utilizado nas simulações. O modulo Delft3D-RGFGRID foi utilizado para gerar a grade numérica da área de estudo e o modulo Delft3D-QUICKIN para gera a malha batimétrica interpolada (dados de batimetria e grade). O pós processamento foi realizado em ambiente Matlab ${ }^{\circledR}$ (MathWorks, Inc.), através de rotinas geradas para extrair os dados de saída do modelo para gerar informações e gráficos. As informações fornecidas aqui é um apanhado do que está descrito nos manuais do Delft3D-FLOW (Deltares, 2011).

\section{AI.1.1. Módulo hidrodinâmico (Delft3D-FLOW)}

O módulo Delft3D-FLOW pode ser aplicado em mares rasos, áreas costeiras, estuários, lagoas, rios e lagos. O FLOW é o módulo que fornece a base hidrodinâmicas para outros módulos como o da qualidade da água (WAQ), ecológico (ECO), ondas (WAVE) e morfológico (MORF). As simulações podem ser realizadas nos modos bidimensional e tridimensional. Para fluidos verticalmente homogêneos o modo bidimensional (uma camada computacional) é o mais apropriado, com resultados médios na coluna da água. Alguns exemplos de sua aplicação são ondas de maré, maré de tempestade, tsunamis, seiches e transporte de poluentes em regimes verticalmente bem misturado. O modo tridimensional é recomendados para problemas que envolve maior variação vertical das propriedades do fluido. Pode ser utilizado em estudos de dispersão de resíduos, águas frias em lagos e áreas costeiras, ressurgência e subsidência de nutrientes, intrusão salina em estuários, descarga de água doce em baias e estratificação térmica em lagos e mares.

O sistema numérico do Delft3D-FLOW resolve as equações de águas rasas nas duas dimensões, bidimensional e tridimensional. O sistema de equações consiste nas equações do movimento, na equação da continuidade e nas equações do transporte para constituintes conservativos. As equações são formuladas em coordenadas curvilíneas 
horizontais ortogonais. Curvilínea significa que a grade pode ter curvas e ortogonais significa que o ângulo de intersecção entre as células da grade deve ser aproximado de $90^{\circ}$. A ortogonalidade entre as células garante a precisão durantes os cálculos. As coordenadas da grade podem ser implementadas no sistema Cartesiano ou esférico. $\mathrm{O}$ Cartesiano utiliza o plano horizontal como referencia e o esférico a curvatura da Terra (WGS84).

Em relação as células secas e inundadas, o modelo assume que um ponto de velocidade é seco, em relação ao nível da água, quando a atual profundidade está abaixo da metade do limite definido pelo usuário. Se o ponto está seco, então a velocidade nesse ponto é igual a zero. O ponto é considerado inundado novamente, quando a profundidade está acima do limite. O atraso entre a secagem e a inundação é introduzida para evitar esses processos em duas etapas consecutivas. O processo de secagem e inundação causa um movimento descontínuo das fronteiras fechadas em planícies de maré. Uma célula permanece seca quando os quatro pontos de velocidade localizados nas faces da célula da grade estão secos ou quando a profundidade da água no centro da célula é abaixo de zero (volume negativo).

$\mathrm{Na}$ direção vertical o Delft3D-FLOW oferece dois diferentes sistemas de coordenada vertical da grade: a coordenada sigma (modelo- $\sigma$ ) e a coordenada $Z$ (modelo-Z) (Fig. AI.1-A). No modelo- $\sigma$, as camadas verticais da grade são delimitadas por dois planos não horizontais, que seguem a topografia do fundo e a superfície livre da água. O número de camadas é constante em todo o domínio horizontal, sem considerar a profundidade local da coluna da água. Usualmente, a resolução entre as camadas não é uniforme, depende da profundidade local. O que permite maior resolução em regiões de interesse, como por exemplo próximo da superfície (trocas de calor com a atmosfera) e próximo do fundo (transporte de sedimento).

Em áreas costeiras, estuários e lagos, o fluxo estratificado ocorre em combinação com variações abruptas da topografa do fundo. E embora o modelo- $\sigma$ seja ajustado ao fundo, nem sempre terá uma resolução adequada na região da picnoclina. $\mathrm{O}$ modelo- $\mathrm{Z}$ possui as linhas da coordenada horizontal, aproximadamente, paralelas com as interfaces de mesma densidade (isopicnais), em regiões com variações abruptas do 
fundo. Reduzindo a mistura artificial das propriedades escalares como a temperatura e a salinidade. O fundo e a superfície não são, geralmente, representados por uma linha, e sim por uma linha escalonada. O número de células na vertical varia conforme a profundidade local.

O sistema vertical da grade do modelo- $Z$ é baseado em camadas horizontais constantes que cruzam a coluna coluna de água (Fig. AI.1-B). A espessura da camada superior $\Delta z_{k m a x}$ é definida pela distancia entre a superfície livre e a primeira superfície horizontal abaixo. A espessura da camada superior pode variar no tempo e espaço. A espessura da camada do fundo é a distância entre o fundo $(z=-d(x, y))$ e a primeira camada acima.

A
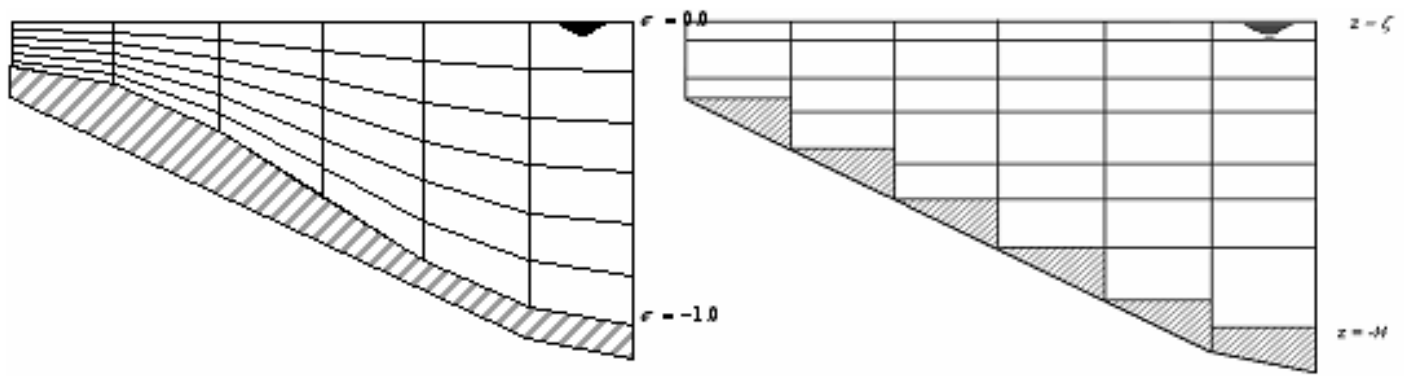

B
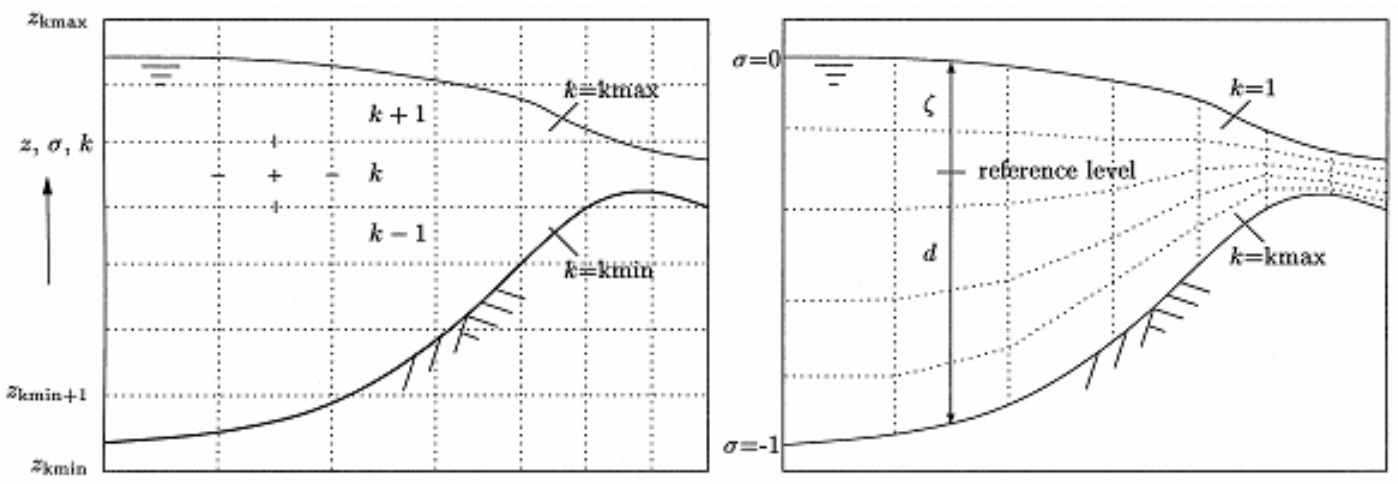
$\mathrm{C}$
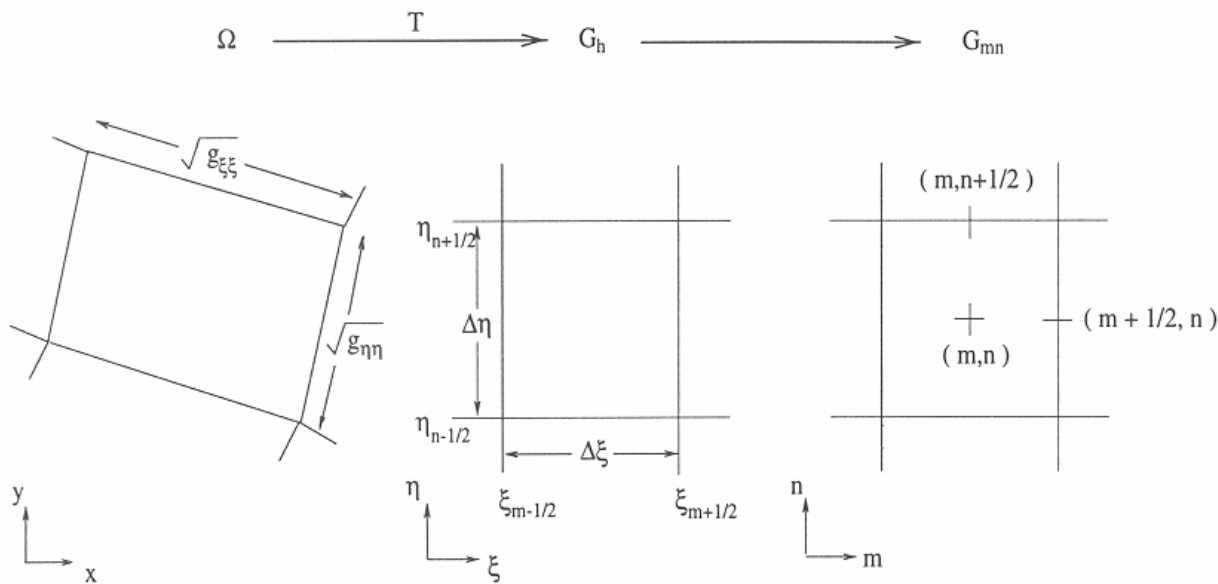

Figura AI.1. (A) Exemplo de uma grade vertical sigma (esquerda) e Z (direita). (B) Grade computacional vertical modelo- $Z$ (esquerda) e modelo- $\sigma$ (direita). (C) Mapa do espaço físico para o espaço computacional na direção $\mathrm{x}(\xi)$ e $\mathrm{y}(\eta)$. No caso de grade curvilínea, o $\Delta x=\sqrt{G_{\xi \xi}}$ e $\Delta y=\sqrt{G_{\eta \eta}}$.

Cada sistema de coordenadas possui vantagens e desvantagens, a escolha por um deles depende do fenômeno a ser estudado. O modelo- $\sigma$ é a opção padrão do Delft3DFLOW. Para aumentar a versatilidade foi adicionado o modelo-Z como opção. Inicialmente o modelo- $Z$ foi desenvolvido para simular fluxos em lagos controlados pelo vento, no qual a precisão dos processos do transporte vertical é o ponto chave. No Delft3D-FLOW, ambos os modelo são baseados em métodos numéricos praticamente iguais. As principais diferenças estão na discretização das equações.

\section{AI.1.1.1. Equações hidrodinâmicas}

O Delft3D-FLOW resolve as equações de Navier Stokes para um fluido incompressível. As equações são discretizadas em uma grade do tipo Arakawa C. O Delft3D-FLOW calcula as equações do momentum e da continuidade na direção horizontal. Para o modelo tridimensional, os cálculos da velocidade vertical são computados na equação da continuidade. Na equação do momentum na vertical não são consideradas as acelerações verticais, o que leva a equação da pressão hidrostática. Um conjunto de equações diferenciais parciais combinadas com condições iniciais e de contorno apropriadas é resolvida em uma grade de diferenças finitas. 


\section{Equação da continuidade}

$$
\frac{\partial \zeta}{\delta \mathrm{t}}+\frac{1}{\sqrt{G_{\zeta \xi}} \sqrt{G_{\eta \eta}}} \frac{\partial\left[(d+\zeta) U \sqrt{G_{\eta \eta}}\right]}{\partial \xi}+\frac{1}{\sqrt{G_{\xi \xi}} \sqrt{G_{\eta \eta}}} \frac{\partial\left[(d+\zeta) V \sqrt{G_{\eta \eta}}\right]}{\partial \eta}=\mathrm{Q}
$$

Q representa a contribuição por unidade de área devido a entrada ou saída da água, precipitação e evaporação:

$Q=H \int_{-1}^{0}\left(q_{\text {in }}-q_{\text {out }}\right) d \sigma+P-E$

onde:

$\zeta \quad=$ nível da água acima de um plano de referencia (datum)

$\xi, \eta \quad=$ coordenada horizontal da grade curvilínea

$t \quad=$ tempo

$\sqrt{G_{\xi \xi}} \begin{array}{ll}=\text { coeficiente usado para transformar coordenadas curvilíneas para } \\ \text { retangular }\end{array}$

$\begin{array}{ll}\sqrt{G_{\eta \eta}} & =\text { coeficiente usado para transformar coordenadas curvilíneas para } \\ \text { retangular }\end{array}$

$d \quad=$ profundidade abaixo de um plano de referência (datum) (m)

$U \quad=$ velocidade média na direção $\xi(\mathrm{x})$

$V \quad=$ velocidade média na direção $\eta(\mathrm{y})$ $(\mathrm{m} / \mathrm{s})$

$H \quad=$ profundidade total $(H=d+\zeta)$

$q_{\text {in }} \quad=$ fonte local por unidade de volume

$q_{\text {out }}=$ sorvedouro local por unidade de volume

$E \quad=$ evaporação

$P \quad=$ precipitação 
O sistema de coordenadas sigma ( $\sigma$ ) é definido por:

$\sigma=\frac{z-\zeta}{d-\zeta}=\frac{z-\zeta}{H}$

onde $z$ é a coordenada física no espaço.

\section{Equação do momentum na direção horizontal}

As equações do momentum nas direções $\xi$ e $\eta$ são dadas por:

$$
\begin{aligned}
\frac{\partial u}{\partial t}+\frac{u}{\sqrt{G_{\xi \xi}}} \frac{\partial u}{\partial \xi} & +\frac{v}{\sqrt{G_{\eta \eta}}} \frac{\partial u}{\partial \eta}+\frac{w}{d+\zeta} \frac{\partial u}{\partial \sigma}-\frac{v^{2}}{\sqrt{G_{\xi \xi}} \sqrt{G_{\eta \eta}}} \frac{\partial \sqrt{G_{\eta \eta}}}{\partial \xi} \\
& +\frac{u v}{\sqrt{G_{\xi \xi}} \sqrt{G_{\eta \eta}}} \frac{\partial \sqrt{G_{\xi \xi}}}{\partial \eta}-f v \\
& =-\frac{1}{\rho_{0} \sqrt{G_{\xi \xi}}} P_{\xi}+F_{\xi}+\frac{1}{(d+\zeta)^{2}} \frac{\partial}{\partial \sigma}\left(v_{V} \frac{\partial u}{\partial \sigma}\right)+M_{\xi}
\end{aligned}
$$

e

$$
\begin{aligned}
\frac{\partial v}{\partial t}+\frac{u}{\sqrt{G_{\xi \xi}}} \frac{\partial v}{\partial \xi} & +\frac{v}{\sqrt{G_{\eta \eta}}} \frac{\partial v}{\partial \eta}+\frac{w}{d+\zeta} \frac{\partial v}{\partial \sigma}-\frac{u v}{\sqrt{G_{\xi \xi}} \sqrt{G_{\eta \eta}}} \frac{\partial \sqrt{G_{\eta \eta}}}{\partial \xi} \\
& -\frac{u^{2}}{\sqrt{G_{\xi \xi}} \sqrt{G_{\eta \eta}}} \frac{\partial \sqrt{G_{\xi \xi}}}{\partial \eta}+f u \\
& =-\frac{1}{\rho_{0} \sqrt{G_{\eta \eta}}} P_{\eta}+F_{\eta}+\frac{1}{(d+\zeta)^{2}} \frac{\partial}{\partial \sigma}\left(v_{V} \frac{\partial v}{\partial \sigma}\right)+M_{\eta}
\end{aligned}
$$

onde:

$$
\begin{array}{ll}
\mathrm{u} & =\text { velocidade do fluxo na direção } \xi(\mathrm{x}) \\
\mathrm{v} & =\text { velocidade do fluxo na direção } \eta(\mathrm{y}) \\
\mathrm{W} & =\text { velocidade do fluxo na direção } \mathrm{z} \\
f & =\text { parâmetro de Coriolis }
\end{array}
$$


$\rho_{0} \quad=$ densidade da água (referência)

$\left(\mathrm{kg} / \mathrm{m}^{3}\right)$

$P_{\xi} \quad=$ gradiente de pressão hidrostática na direção $\xi(\mathrm{x})$

$\left(\mathrm{kg} / \mathrm{m}^{2} \mathrm{~s}^{2}\right)$

$P_{\eta} \quad=$ gradiente de pressão hidrostática na direção $\eta$ (y)

$\left(\mathrm{kg} / \mathrm{m}^{2} \mathrm{~s}^{2}\right)$

$M_{\xi} \quad=$ fonte ou sorvedouro do momentum na direção $\xi(\mathrm{x})$

$\left(\mathrm{m} / \mathrm{s}^{2}\right)$

$M_{\eta} \quad$ = fonte ou sorvedouro do momentum na direção $\eta(\mathrm{y})$

$\left(\mathrm{m} / \mathrm{s}^{2}\right)$

$F_{\xi} \quad=$ fluxo turbulento do momentum na direção $\xi(\mathrm{x})$

$\left(\mathrm{m} / \mathrm{s}^{2}\right)$

$F_{\eta} \quad=$ fluxo turbulento do momentum na direção $\eta(\mathrm{y})$

$\left(\mathrm{m} / \mathrm{s}^{2}\right)$

$v_{V} \quad=$ viscosidade vertical

$\left(\mathrm{m}^{2} / \mathrm{s}\right)$

O coeficiente vertical de viscosidade $v_{V}$ é definido por:

$v_{V}=v_{m o l}+\max \left(v_{3 D}, v_{V}^{b}\right)$

$v_{m o l}$ é a viscosidade cinemática da água $\left(\mathrm{m}^{2} \cdot \mathrm{s}^{-1}\right) \cdot M_{\xi}$ e $M_{\eta}$ representam a contribuição devido as fontes e sorvedouros do momentum devido as forças externas (estruturas hidráulicas, descargas, ondas, etc.). A viscosidade na vertical $v_{3 D}$ é calculado no modelo de fechamento de turbulência. Nas equações do momentum as forças $F_{\xi}$ e $F_{\eta}$ representam as tensões horizontais de Reynolds por:

$$
\begin{gathered}
F_{\xi}=\frac{1}{\sqrt{G_{\xi \xi}}} \frac{\partial \tau_{\xi \xi}}{\partial \xi}+\frac{1}{\sqrt{G_{\eta \eta}}} \frac{\partial \tau_{\xi \eta}}{\partial \eta} \\
F_{\eta}=\frac{1}{\sqrt{G_{\xi \xi}}} \frac{\partial \tau_{\eta \xi}}{\partial \xi}+\frac{1}{\sqrt{G_{\eta \eta}}} \frac{\partial \tau_{\eta \eta}}{\partial \eta}
\end{gathered}
$$




\section{Velocidades verticais}

A velocidade vertical $\omega$ em relação ao sistema de coordenada- $\sigma$ é computado pela equação da continuidade:

$$
\begin{gathered}
\frac{\partial \zeta}{\partial t}+\frac{1}{\sqrt{G_{\xi \xi}} \sqrt{G_{\eta \eta}}} \frac{\partial\left[(d+\zeta) u \sqrt{G_{\eta \eta}}\right]}{\partial \xi}+\frac{1}{\sqrt{G_{\xi \xi}} \sqrt{G_{\eta \eta}}} \frac{\partial\left[(d+\zeta) v \sqrt{G_{\xi \xi}}\right]}{\partial \eta} \\
+\frac{\partial \omega}{\partial \sigma}=H\left(q_{\text {in }}-q_{\text {out }}\right)
\end{gathered}
$$

$\mathrm{Na}$ superfície o efeito da precipitação e evaporação é levado em conta. A velocidade vertical é relativa ao movimento do plano $\sigma$. Pode ser interpretada como a velocidade associada com os movimentos de ressurgência e subsidência. A velocidade vertical "física" no sistema Cartesiano de coordenadas não é considerada no modelo de equações. Essas velocidades podem ser expressas na velocidade horizontal, na profundidade da coluna da água, na variação do nível e da velocidade vertical $\omega$ de acordo com:

$$
\begin{gathered}
w=\omega+\frac{1}{\sqrt{G_{\xi \xi}} \sqrt{G_{\eta \eta}}}\left[u \sqrt{G_{\eta \eta}}\left(\sigma \frac{\partial H}{\partial \xi}+\frac{\partial \zeta}{\partial \xi}\right)+v \sqrt{G_{\xi \xi}}\left(\sigma \frac{\partial H}{\partial \eta}+\frac{\partial \zeta}{\partial \eta}\right)\right] \\
+\left(\sigma \frac{\partial H}{\partial t}+\frac{\partial \zeta}{\partial t}\right)
\end{gathered}
$$

\section{Pressão hidrostática}

Sob a hipótese de águas rasas a equação do momentum na direção vertical é reduzida a equação da pressão hidrostática. Aceleração vertical devido os efeitos da flutuação da superfície livre e devido a variações bruscas da topografia do fundo não são consideradas. Então:

$\frac{\partial P}{\partial \sigma}=-g \rho H$ 
Após a integração, a pressão hidrostática é dada por:

$$
P=P_{a t m}+g H \int_{\sigma}^{0} \rho\left(\xi, \eta, \sigma^{\prime}, t\right) d \sigma^{\prime}
$$

onde:

$$
\begin{aligned}
& P \quad=\text { pressão hidrostática da água } \quad\left(\mathrm{kg} / \mathrm{ms}^{2}\right) \\
& g \quad=\text { aceleração gravitacional }\left(\mathrm{m} / \mathrm{s}^{2}\right) \\
& \rho=\text { densidade da água } \quad\left(\mathrm{kg} / \mathrm{m}^{3}\right)
\end{aligned}
$$

Primeiramente, consideram a água com densidade constante e depois com densidade não uniforme. Com densidade constante e considerando a pressão atmosférica, o gradiente de pressão é lido por:

$$
\begin{aligned}
& \frac{1}{\rho_{0} \sqrt{G_{\xi \xi}}} P_{\xi}=\frac{g}{\sqrt{G_{\xi \xi}}} \frac{\partial \zeta}{\partial \xi}+\frac{1}{\rho_{0} \sqrt{G_{\xi \xi}}} \frac{\partial P_{a t m}}{\partial \xi} \\
& \frac{1}{\rho_{0} \sqrt{G_{\eta \eta}}} P_{\eta}=\frac{g}{\sqrt{G_{\eta \eta}}} \frac{\partial \zeta}{\partial \eta}+\frac{1}{\rho_{0} \sqrt{G_{\eta \eta}}} \frac{\partial P_{a t m}}{\partial \eta}
\end{aligned}
$$

Os gradientes da superfície livre são chamados de gradientes de pressão barotrópico. No caso de densidade não uniforme, a densidade local é relacionada aos valores de temperatura e salinidade pela equação do estado. A regra de Leibnitz é usada para obter a seguinte expressão para o gradiente horizontal de pressão:

$$
\begin{aligned}
& \frac{1}{\rho_{0} \sqrt{G_{\xi \xi}}} P_{\xi}=\frac{g}{\sqrt{G_{\xi \xi}}} \frac{\partial \zeta}{\partial \xi}+g \frac{d+\zeta}{\rho_{0} \sqrt{G_{\xi \xi}}} \int_{\sigma}^{0}\left(\frac{\partial \rho}{\partial \xi}+\frac{\partial \rho}{\partial \sigma} \frac{\partial \sigma}{\partial \xi}\right) d \sigma^{\prime} \\
& \frac{1}{\rho_{0 \sqrt{G_{\eta \eta}}}} P_{\eta}=\frac{g}{\sqrt{G_{\eta \eta}}} \frac{\partial \zeta}{\partial \eta}+g \frac{d+\zeta}{\rho_{0} \sqrt{G_{\eta \eta}}} \int_{\sigma}^{0}\left(\frac{\partial \rho}{\partial \eta}+\frac{\partial \rho}{\partial \sigma} \frac{\partial \sigma}{\partial \eta}\right) d \sigma^{\prime}
\end{aligned}
$$


Os primeiros termos das Equações AI.15 e AI.16 representam o gradiente de pressão barotrópico sem os gradientes de pressão atmosférica, e o segundo termo, o gradiente de pressão baroclínico.

\section{Equação do transporte}

No Delft3D-FLOW, o transporte de matéria e calor é modelado por uma equação de difusão e advecção nas três direções (x, y e z). Fontes e sorvedouros são incluídos para simular descargas e escoamentos. A equação do transporte é formulada em uma forma conservativa em grade curvilínea na direção horizontal e em sigma na vertical por:

$$
\begin{aligned}
\frac{\partial(d+\zeta) c}{\partial t}+ & \frac{1}{\sqrt{G_{\xi \xi}} \sqrt{G_{\eta \eta}}}\left\{\frac{\partial\left[\sqrt{G_{\eta \eta}}(d+\zeta) u c\right]}{\partial \xi}+\frac{\partial\left[\sqrt{G_{\xi \xi}}(d+\zeta) v c\right]}{\partial \eta}\right\}+\frac{\partial \omega c}{\partial \sigma} \\
& =\frac{d+\zeta}{\sqrt{G_{\xi \xi}} \sqrt{G_{\eta \eta}}}\left\{\frac{\partial}{\partial \xi}\left(D_{H} \frac{\sqrt{G_{\eta \eta}}}{\sqrt{G_{\xi \xi}}} \frac{\partial c}{\partial \xi}\right)+\frac{\partial}{\partial \eta}\left(D_{H} \frac{\sqrt{G_{\xi \xi}}}{\sqrt{G_{\eta \eta}}} \frac{\partial c}{\partial \eta}\right)\right\} \\
& +\frac{1}{d+\zeta} \frac{\partial}{\partial \sigma}\left(D_{V} \frac{\partial c}{\partial \sigma}\right)-\lambda_{d}(d+\zeta) c+S
\end{aligned}
$$

onde:

$c=$ concentração de massa

$\left(\mathrm{Kg} / \mathrm{m}^{3}\right)$

$\lambda d \quad=$ coeficiente de decaimento de primeira ordem

O coeficiente de difusão horizontal $\left(\mathrm{m}^{2} / \mathrm{s}\right)$ total é definido por:

$D_{H}=D_{S G S}+D_{V}+D_{H}^{b a c k}$

O coeficiente de difusão vertical $\left(\mathrm{m}^{2} / \mathrm{s}\right)$ é definido por:

$$
D_{V}=\frac{v_{m o l}}{\sigma_{m o l}}+\max \left(D_{3 D}, D_{V}^{\text {back }}\right)
$$


$\mathrm{S}$ é os termos de fonte e sorvedouro por unidade de área devido a descarga $q_{\text {in }}$ ou escoamento $q_{\text {out }}$ de água ou troca de calor com a superfície livre $Q_{t o t}$ :

$S=(d+\zeta)\left(q_{\text {in }} c_{\text {in }}-q_{\text {out }} c\right)+Q_{\text {tot }}$

\section{Equação do estado}

A densidade da água do mar $(\rho)$ é uma função da salinidade $(s)$ e temperatura $(t)$. No Delft3D-FLOW o usuário pode escolher entre duas formulações para a equação do estado: Eckart ou UNESCO. A configuração padrão calcula com base na formulação da UNESCO (1981a):

Variando $0<t<40^{\circ} \mathrm{C}, 0,5<s<43 \mathrm{ppt}$

$\rho=\rho_{0}+A s+B s^{3 / 2}+C s^{2}$

onde

$$
\begin{gathered}
\rho_{0}=999,842594+6,793952 \cdot 10^{-2} t-9,095290 \cdot 10^{-3} t^{2} \\
+1,001685 \cdot 10^{-4} t^{3}-1,120083 \cdot 10^{-6} t^{4}+6,536332 \\
\cdot 10^{-9} t^{5} \\
A=8,24493 \cdot 10^{-1}-4,0899 \cdot 10^{-3} t+7,6438 \cdot 10^{-5} t^{2}+ \\
-8,2467 \cdot 10^{-7} t^{3}+5,3875 \cdot 10^{-9} t^{4} \\
B=-5,72466 \cdot 10^{-3}+1,0227 \cdot 10^{-4} t-1,6545 \cdot 10^{-6} t^{2} \\
C=4,8314 \cdot 10^{-4}
\end{gathered}
$$




\section{Modelo de fechamento de turbulência}

Normalmente, a grade horizontal ou vertical é pouco refinada e o passo de tempo muito grande para resolver o movimento em escala turbulenta, sendo necessário uma sub-grade para calcular esse movimento. O coeficiente de viscosidade horizontal de fundo $\left(v_{H}^{\text {back }}\right)$ e o coeficiente de difusividade $\left(D_{H}^{b a c k}\right)$ devem ser especificados pelo usuário. Assim como o coeficiente de viscosidade vertical $\left(v_{V}^{\text {back }}\right)$ e o coeficiente de difusividade $\left(D_{V}^{\text {back }}\right)$, quando o modelo é tridimensional. Esses coeficientes horizontais também são usados para absorver ruídos de pequena escala pelos termos advectivos. Os coeficientes horizontais são uma ordem de grandeza maior que os coeficientes verticais. No Delft3D-FLOW, quatro modelos de fechamento de turbulência podem ser implementados para determinar $v_{V}$ e $D_{V}$ :

1. Modelo de coeficiente constante, apenas os valores de fundo são aplicados.

2. Modelo Algébrico, os coeficientes são determinados por equações algébricas para a energia turbulenta e comprimento de mistura.

3. Modelo $\boldsymbol{k}$ - $\boldsymbol{L}$, os coeficientes são determinados pela equação do transporte para a energia cinética turbulenta e o comprimento de mistura.

4. Modelo $\boldsymbol{k}-\boldsymbol{\varepsilon}$, os coeficientes são determinados pela equação do transporte para a energia cinética turbulenta e dissipação da energia cinética turbulenta.

Os modelos diferem em sua prescrição da energia cinética turbulenta $\boldsymbol{k}$, da taxa de dissipação da energia cinética turbulenta $\boldsymbol{\varepsilon}$ e no comprimento de mistura $\boldsymbol{L}$. No modelo de fechamento $k-\varepsilon$ a equação do transporte deve resolver a energia cinética turbulenta $(k)$ e dissipação da energia $(\varepsilon)$. O comprimento de mistura $(L)$ é determinado por $k$ e $\varepsilon$ de acordo com:

$L=c_{D} \frac{k \sqrt{k}}{\varepsilon}$

Onde $\mathrm{c}_{\mathrm{D}}$ é uma constante relacionada com o comprimento de mistura, energia cinética turbulenta e dissipação de energia no modelo $k$ - $\varepsilon$. As equações do transporte para $k$ e $\varepsilon$ 
são não lineares acopladas pela média de seus termos de difusividade $D_{k}, D_{\varepsilon}$ e os termos de dissipação. As equações do transporte para $k$ e $\varepsilon$ são dadas por:

$$
\begin{aligned}
\frac{\partial k}{\partial t}+\frac{u}{\sqrt{G_{\xi \xi}}} \frac{\partial k}{\partial \xi} & +\frac{v}{\sqrt{G_{\eta \eta}}} \frac{\partial k}{\partial \eta}+\frac{\omega}{d+\zeta} \frac{\partial k}{\partial \sigma} \\
& =\frac{1}{(d+\zeta)} \frac{\partial}{\partial \sigma}\left(D_{k} \frac{\partial k}{\partial \sigma}\right)+P_{k}+P_{k w}+B_{k}-\varepsilon \\
\frac{\partial \varepsilon}{\partial t}+\frac{u}{\sqrt{G_{\xi \xi}}} \frac{\partial \varepsilon}{\partial \xi}+ & \frac{v}{\sqrt{G_{\eta \eta}}} \frac{\partial \varepsilon}{\partial \eta}+\frac{\omega}{d+\zeta} \frac{\partial \varepsilon}{\partial \sigma} \\
& =\frac{1}{(d+\zeta)} \frac{\partial}{\partial \sigma}\left(D_{\varepsilon} \frac{\partial \varepsilon}{\partial \sigma}\right)+P_{\varepsilon}+P_{\varepsilon w}+B_{\varepsilon}-c_{2 \varepsilon} \frac{\varepsilon^{2}}{k}
\end{aligned}
$$

onde:

$B_{k}=$ termo de oscilação na equação do transporte para a energia $\left(\mathrm{m}^{2} / \mathrm{s}^{3}\right)$ turbulenta cinética

$B_{\varepsilon}=$ termo de oscilação na equação do transporte para a dissipação de $\left(\mathrm{m}^{2} / \mathrm{s}^{3}\right)$ energia turbulenta cinética

$P_{k} \quad=$ termo de produção na equação do transporte para energia cinética $\left(\mathrm{m}^{2} / \mathrm{s}^{3}\right)$ turbulenta

$P_{\varepsilon} \quad=$ termo de produção na equação do transporte para a dissipação de $\left(\mathrm{m}^{2} / \mathrm{s}^{4}\right)$ energia cinética turbulenta

com

$$
D_{k}=\frac{v_{m o l}}{\sigma_{m o l}}+\frac{v_{3 D}}{\sigma_{k}} \quad e \quad D_{\varepsilon}=\frac{v_{3 D}}{\sigma_{\varepsilon}}
$$

onde:

$v_{m o l}=$ coeficiente de viscosidade cinemática (molecular)

$\sigma_{m o l}=$ Número de Prandtl-Schimidt para mistura molecular

O coeficiente vertical de viscosidade $v_{3 D}$ é determinado por: 
$v_{3 D}=c^{\prime} u L \sqrt{k}$,

$$
=c_{\mu} \frac{k^{2}}{\varepsilon}
$$

com constate de calibração $\left(\mathrm{c}_{\mu}\right)$ :

$c_{\mu}=c_{D} c^{\prime}{ }_{\mu}$

onde $c^{\prime}{ }_{\mu}$ é a constante de Kolmogorov-Prandtlna formulação de viscosidade. Para a equação do transporte da dissipação $\varepsilon$, a seguinte condição de contorno é usada no fundo:

$\varepsilon_{\sigma=-1}=\frac{u_{* b}^{3}}{k z_{0}}$

e na superfície a dissipação é descrita por:

$\varepsilon_{\sigma=0}=\frac{u_{* s}^{3}}{\frac{1}{2} k \Delta z_{s}}$

Apenas o modelo $k-\varepsilon$ foi descrito, pois é o mais recomendado para simulações de fluxos estratificado e foi o modelo utilizado nesse estudo.

\section{Força de Coriolis}

O parâmetro de Coriolis $f$ depende da latitude geográfica e da velocidade angular da rotação da Terra, $\Omega$ :

$f=2 \Omega \sin \phi$ 


\section{Força gerada pela maré}

Os modelo numéricos de movimentos da maré de região costeira não consideram influencia direta das forças geradoras da maré. A quantidade de massa de água é relativamente pequena nesses modelos e o efeito desses forças pode ser desprezado. Em áreas costeiras a determinação da força da maré ao longo do contorno aberto é suficiente para gerar o movimento da maré de forma apropriada.

O equilíbrio da maré é modelado com a inclusão do termo de geração potencial da maré nas equações do momentum. Os termos seguintes são adicionados no lado direito das equações do momentum, Equações AI.4 e AI.5, respectivamente:

$\frac{g}{\sqrt{G_{\xi \xi}}} \frac{\partial \varphi}{\partial \xi} \quad e \frac{g}{\sqrt{G_{\eta \eta}}} \frac{\partial \varphi}{\partial \eta}$

O potencial da maré $(\varphi)$ para o equilíbrio da maré é decomposto nas séries:

$\varphi=\sum_{\nu=0,1,2} \varphi_{\nu}(\lambda, \phi, t)$

$\lambda e \phi$ coordenadas geográficas. Em termos de componentes astronômico a variação maré no contorno aberto, pode ser descrita pela formula geral da maré astronômica como:

$H(t)=A_{0}+\sum_{i=1}^{k} A_{i} F_{i} \cos \left(\omega_{i} t+\left(V_{0}+u\right)-G_{i}\right)$

onde:

$H(t) \quad=$ nível da água no instante $t$

$\mathrm{A}_{0} \quad=$ média do nível da água em um cero período

$K=$ número de constituintes relevantes

$i \quad=$ índice da constituinte 
$A_{i} \quad=$ amplitude da constituinte da maré local

$F_{i} \quad=$ fator nodal da amplitude

$\omega_{i} \quad=$ velocidade angular

$\left(V_{0}+u\right)_{i}=$ argumento astronômico

$G_{i} \quad=$ número de kappa (defasagem da fase local)

$F_{i}$ e $\left(V_{0}+u\right)_{i}$ são fatores dependentes do tempo, que junto com a velocidade angular podem facilmente ser calculados e são geralmente tabulados em vários livros anuais de maré. $V_{0}$ é o fator de correção de fase que relaciona a hora loca das observações a um período de tempo celestial acordado internacionalmente. $F_{i}$ e $u_{i}$ mostram a correção da variação da amplitude e da fase, como também a frequência dependente. $\mathrm{O}$ usuário pode aplicar correções ao definir as componentes astronômicas. Essas correções podem ser aplicadas em uma sub-grade, em uma seção do contorno aberto ou em um subconjunto de componentes astronômicas. As correções são normalmente aplicadas durante a fase de calibração do modelo. Ambas a fase (aditiva) e a amplitude (multiplicativa) podem ser corrigidas.

\section{Coeficiente de rugosidade do fundo}

As superfície do fundo e a vegetação exercem uma tensão de cisalhamento no deslocamento do fluxo. A magnitude dessa tensão do fundo é geralmente caracterizada por meio de coeficientes de rugosidade do tipo Chézy, Manning ou White Colebrook. Para um fluxo médio na coluna da água, a tensão no fundo induzido por um fluxo turbulento é assumido pela lei da fricção quadrática:

$\vec{\tau}_{b}=\frac{\rho_{0} g \vec{U}|\vec{U}|}{C_{2 D}^{2}}$

onde $|\vec{U}|$ é a magnitude da velocidade média na coluna de água.

O coeficiente de Chézy $\left(C_{2 D}\right)$ pode ser determinado de acordo com uma das três formulações a seguir: 
- Formulação de Chézy:

$$
\mathrm{C}_{2 \mathrm{D}}=\text { coeficiente de Chézy }\left(\mathrm{m}^{1 / 2} \cdot \mathrm{s}^{-1}\right) \text {. }
$$

- Formulação de Manning:

$$
C_{2 D}=\frac{\sqrt[6]{H}}{n}
$$

onde

$\begin{array}{lll}H & =\text { profundidade total } & (\mathrm{m}) \\ n & =\text { coeficiente de Manning } & \left(\mathrm{m}^{-1 / 3} \mathrm{~s}\right)\end{array}$

- Formulação de White Colebrook:

$$
C_{2 D}=18{ }^{10} \log \left(\frac{12 H}{k_{S}}\right)
$$

onde

$k_{s} \quad=$ o comprimento de rugosidade Nikuradse 
Anexo II - Batimetria do modelo numérico 


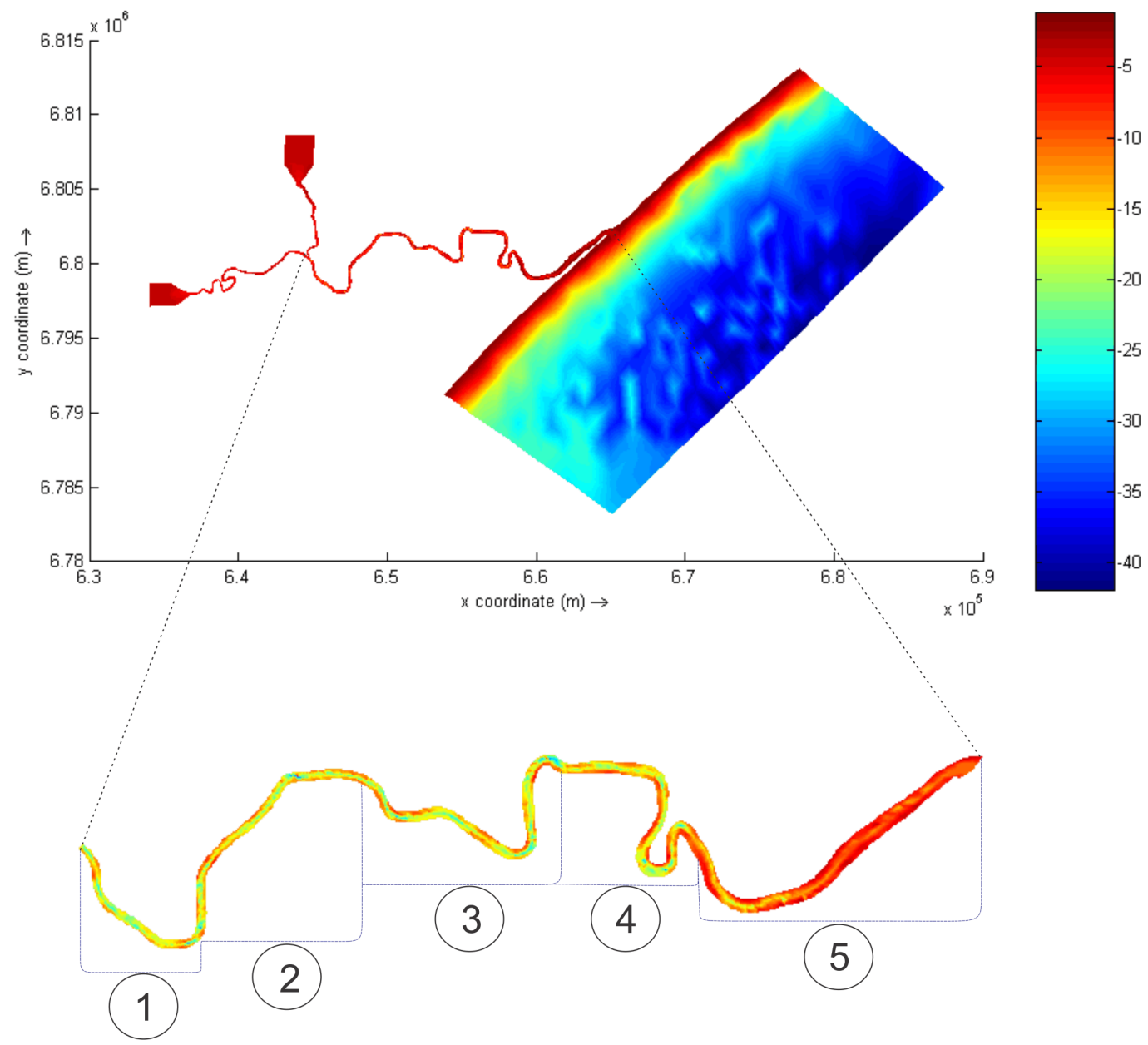

Figura AII.1. Representação da batimetria do domínio do modelo hidrodinâmico. Destacando o trecho do estuário do rio Araranguá, setorizado em 5 seções. Continuação na Figura AII.2. 

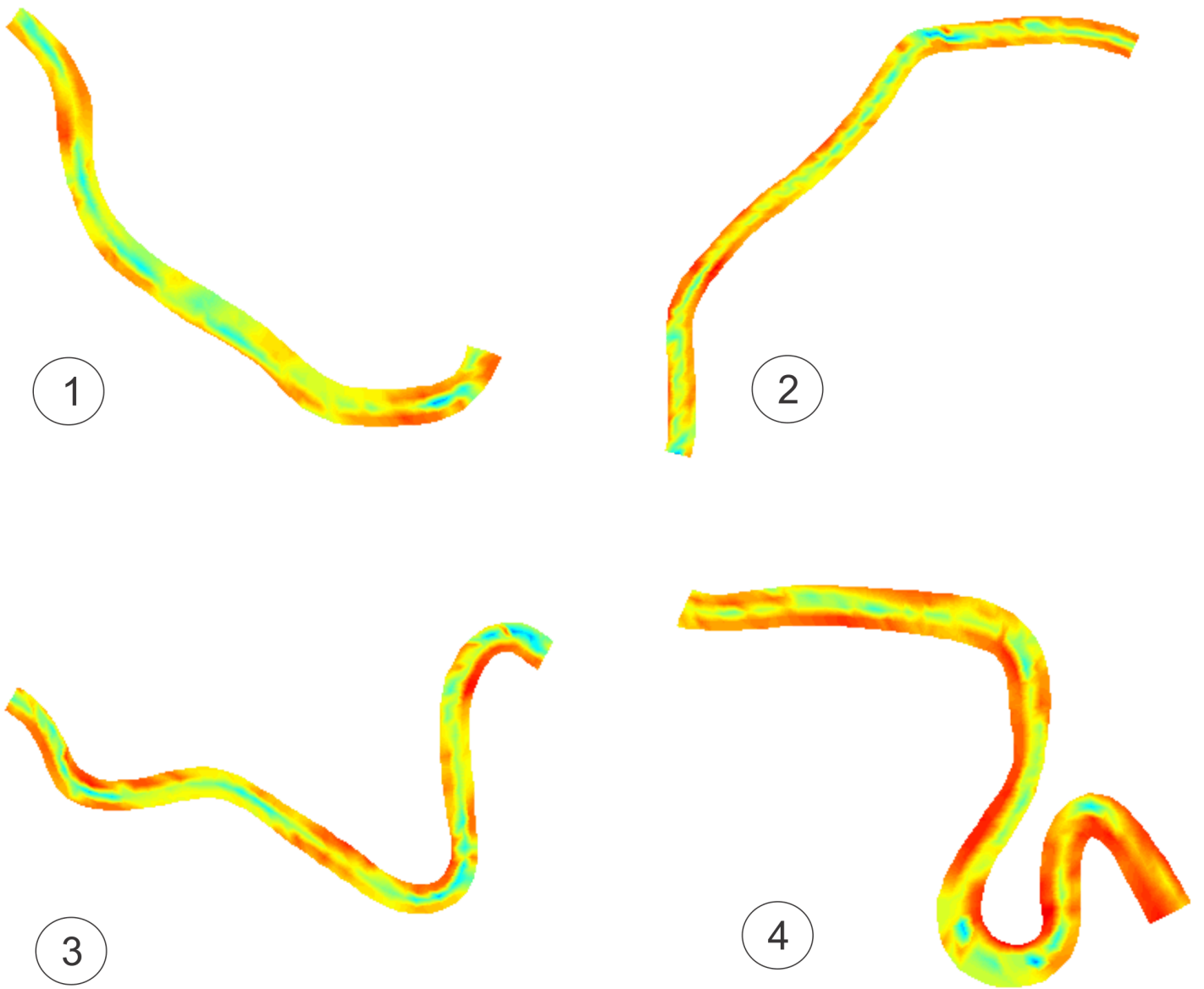

3
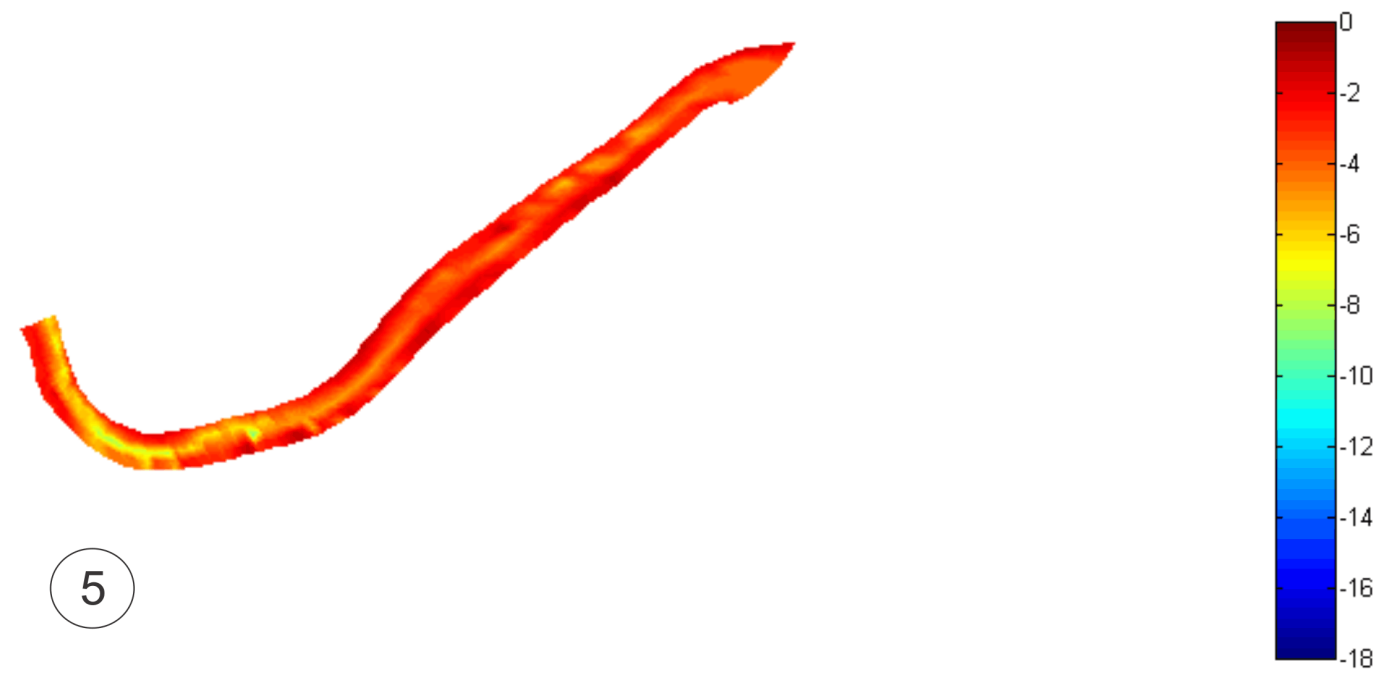

Figura AII.2. Continuação da Figura AII.1, batimetria dos trechos destacados do estuário do rio Araranguá. 